Cochrane Database of Systematic Reviews

\title{
Nutritional supplements for people being treated for active tuberculosis (Review)
}

Grobler L, Nagpal S, Sudarsanam TD, Sinclair D

Grobler L, Nagpal S, Sudarsanam TD, Sinclair D.

Nutritional supplements for people being treated for active tuberculosis.

Cochrane Database of Systematic Reviews 2016, Issue 6. Art. No.: CD006086.

DOI: 10.1002/14651858.CD006086.pub4.

www.cochranelibrary.com

Nutritional supplements for people being treated for active tuberculosis (Review) 
TABLE OF CONTENTS

PLAIN LANGUAGE SUMMARY

SUMMARY OF FINDINGS

BACKGROUND

OBJECTIVES

METHODS

RESULTS

Figure 1.

Figure 2.

DISCUSSION

AUTHORS' CONCLUSIONS

ACKNOWLEDGEMENTS

REFERENCES

\section{CHARACTERISTICS OF STUDIES}

DATA AND ANALYSES

Analysis 1.1. Comparison 1 Macronutrient supplementation, Outcome 1 Death (1 year of follow-up).

Analysis 1.2. Comparison 1 Macronutrient supplementation, Outcome 2 Cured (at 6 months).

Analysis 1.3. Comparison 1 Macronutrient supplementation, Outcome 3 Treatment completion.

Analysis 1.4. Comparison 1 Macronutrient supplementation, Outcome 4 Sputum negative at 8 weeks.

Analysis 1.5. Comparison 1 Macronutrient supplementation, Outcome 5 Mean weight gain.

Analysis 1.6. Comparison 1 Macronutrient supplementation, Outcome 6 Change in maximum grip strength (kg).

Analysis 1.7. Comparison 1 Macronutrient supplementation, Outcome 7 Change in quality of life score.

Analysis 2.1. Comparison 2 High cholesterol ( $850 \mathrm{mg} /$ day) versus low cholesterol ( $250 \mathrm{mg} /$ day) diet, Outcome 1 Sputum-culture positive.

Analysis 3.1. Comparison 3 Multivitamin and trace element tablets versus placebo, Outcome 1 Death during follow-up in adults and children.

Analysis 3.2. Comparison 3 Multivitamin and trace element tablets versus placebo, Outcome 2 Tuberculosis treatment completion.

Analysis 3.3. Comparison 3 Multivitamin and trace element tablets versus placebo, Outcome 3 Sputum-smear or sputumculture positive at 1 month.

Analysis 3.4. Comparison 3 Multivitamin and trace element tablets versus placebo, Outcome 4 Sputum-smear or sputumculture positive at 2 months.

Analysis 3.5. Comparison 3 Multivitamin and trace element tablets versus placebo, Outcome 5 Clearance of chest X-ray at 6 months.

Analysis 3.6. Comparison 3 Multivitamin and trace element tablets versus placebo, Outcome 6 Weight.

Analysis 3.7. Comparison 3 Multivitamin and trace element tablets versus placebo, Outcome 7 Anthropometrical changes at follow-up.

Analysis 3.8. Comparison 3 Multivitamin and trace element tablets versus placebo, Outcome 8 Mean change in handgrip strength $(\mathrm{kg})$.

Analysis 4.1. Comparison 4 Vitamin A versus placebo, Outcome 1 Children: mean serum retinol (normal range $>20 \mu \mathrm{g} / \mathrm{L}$ ). .....

Analysis 4.2. Comparison 4 Vitamin A versus placebo, Outcome 2 Adults: mean serum retinol (normal range $>70 \mu \mathrm{mol} / \mathrm{L}$ ). .....

Analysis 4.3. Comparison 4 Vitamin A versus placebo, Outcome 3 Death.

Analysis 4.4. Comparison 4 Vitamin A versus placebo, Outcome 4 Treatment completion.

Analysis 4.5. Comparison 4 Vitamin A versus placebo, Outcome 5 Symptomatic at 6 weeks.

Analysis 4.6. Comparison 4 Vitamin A versus placebo, Outcome 6 Sputum-smear and sputum-culture positive during followup.

Analysis 4.7. Comparison 4 Vitamin A versus placebo, Outcome $7 \mathrm{BMI}\left(\mathrm{kg} / \mathrm{m}^{2}\right)$.

Analysis 4.8. Comparison 4 Vitamin A versus placebo, Outcome 8 Body fat (\%).

Analysis 5.1. Comparison 5 Zinc versus placebo, Outcome 1 Serum zinc level (normal range $>10.7 \mu \mathrm{mol} / \mathrm{L}$ ).

Analysis 5.2. Comparison 5 Zinc versus placebo, Outcome 2 Death by 6 to 8 months. 
Analysis 5.5. Comparison 5 Zinc versus placebo, Outcome 5 Sputum-smear or sputum-culture positive during follow-up. ....... 107

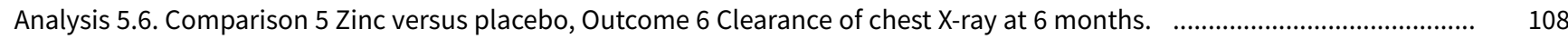

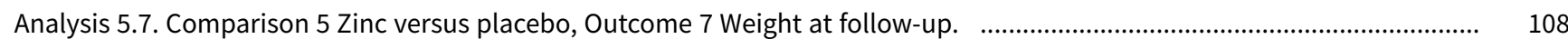

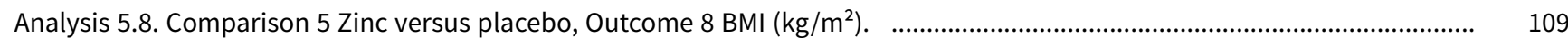

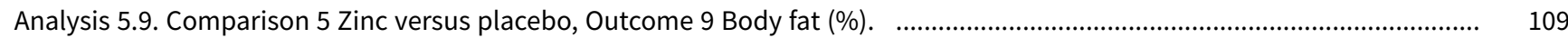

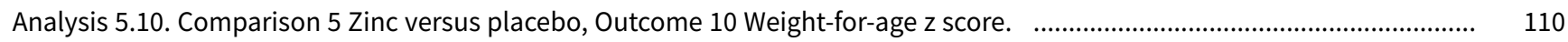

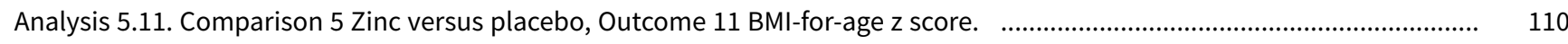
Analysis 5.12. Comparison 5 Zinc versus placebo, Outcome 12 Height-for-age $z$ score at follow-up. ............................................. 110

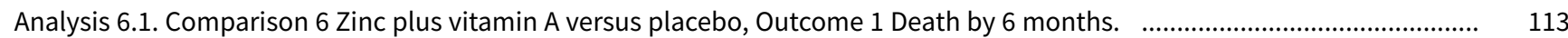
Analysis 6.2. Comparison 6 Zinc plus vitamin A versus placebo, Outcome 2 Treatment completion at 6 months. ..........................114 Analysis 6.3. Comparison 6 Zinc plus vitamin A versus placebo, Outcome 3 Sputum-smear and sputum-culture positive during 114 follow-up.

Analysis 6.4. Comparison 6 Zinc plus vitamin A versus placebo, Outcome 4 Body weight $(\mathrm{kg})$.

Analysis 6.5. Comparison 6 Zinc plus vitamin A versus placebo, Outcome $5 \mathrm{BMI}\left(\mathrm{kg} / \mathrm{m}^{2}\right)$.

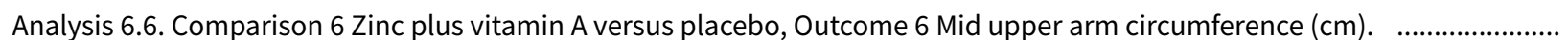
Analysis 6.7. Comparison 6 Zinc plus vitamin A versus placebo, Outcome 7 Biceps skinfold thickness (mm). Analysis 6.8. Comparison 6 Zinc plus vitamin A versus placebo, Outcome 8 Triceps skinfold thickness (mm). .......................... Analysis 6.9. Comparison 6 Zinc plus vitamin A versus placebo, Outcome 9 Subscapular skinfold thickness (mm). ................. Analysis 6.10. Comparison 6 Zinc plus vitamin A versus placebo, Outcome 10 Suprailiac skinfold thickness (mm). ................. Analysis 6.11. Comparison 6 Zinc plus vitamin A versus placebo, Outcome 11 Body fat (\%).

Analysis 6.12. Comparison 6 Zinc plus vitamin A versus placebo, Outcome 12 Fat mass (kg).

Analysis 6.13. Comparison 6 Zinc plus vitamin A versus placebo, Outcome 13 Karnofsky score.

Analysis 7.1. Comparison 7 Vitamin D versus placebo or no supplement, Outcome 1 Serum vitamin D levels $(\mathrm{nmol} / \mathrm{L})$. Analysis 7.2. Comparison 7 Vitamin D versus placebo or no supplement, Outcome 2 Death during follow-up ( 2 to 12 months). .. Analysis 7.3. Comparison 7 Vitamin D versus placebo or no supplement, Outcome 3 Death during follow-up ( 2 to 12 months). ... Analysis 7.4. Comparison 7 Vitamin D versus placebo or no supplement, Outcome 4 Cure at 6 months.

Analysis 7.6. Comparison 7 Vitamin D versus placebo or no supplement, Outcome 6 Sputum-smear or sputum-culture positive.

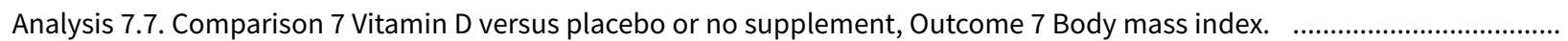
Analysis 7.8. Comparison 7 Vitamin D versus placebo or no supplement, Outcome 8 Body weight (kg). .................................. Analysis 7.9. Comparison 7 Vitamin D versus placebo or no supplement, Outcome 9 Karnofsky score at 8 weeks. ....................

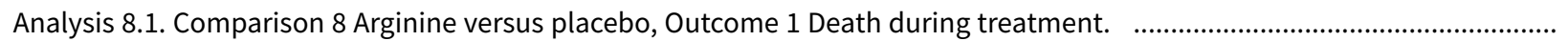
Analysis 8.2. Comparison 8 Arginine versus placebo, Outcome 2 Cured at $6 / 8$ months.

Analysis 8.3. Comparison 8 Arginine versus placebo, Outcome 3 Sputum-smear or sputum-culture positive.

Analysis 9.1. Comparison 9 Vitamin E plus selenium versus placebo, Outcome 1 Sputum-smear positive at follow-up. ADDITIONAL TABLES

\section{APPENDICES}

WHAT'S NEW 
[Intervention Review]

\section{Nutritional supplements for people being treated for active tuberculosis}

Liesl Grobler ${ }^{1}$, Sukrti Nagpal2 ${ }^{2}$ Thambu D Sudarsanam ${ }^{3}$, David Sinclair²

${ }^{1}$ Centre for Evidence-based Health Care, Faculty of Medicine and Health Sciences, Stellenbosch University, Cape Town, South Africa. 2Department of Clinical Sciences, Liverpool School of Tropical Medicine, Liverpool, UK. ${ }^{3}$ Medicine Unit 2 and Clinical Epidemiology Unit, Christian Medical College, Vellore, India

Contact: David Sinclair, Department of Clinical Sciences, Liverpool School of Tropical Medicine, Liverpool, UK. david.sinclair@lstmed.ac.uk.

Editorial group: Cochrane Infectious Diseases Group.

Publication status and date: Unchanged, published in Issue 6, 2016.

Citation: Grobler L, Nagpal S, Sudarsanam TD, Sinclair D. Nutritional supplements for people being treated for active tuberculosis. Cochrane Database of Systematic Reviews 2016, Issue 6. Art. No.: CD006086. DOI: 10.1002/14651858.CD006086.pub4.

Copyright (C) 2016 The Authors. Cochrane Database of Systematic Reviews published by John Wiley \& Sons, Ltd. on behalf of The Cochrane Collaboration. This is an open access article under the terms of the Creative Commons Attribution-Non-Commercial Licence, which permits use, distribution and reproduction in any medium, provided the original work is properly cited and is not used for commercial purposes.

\section{A B S T R A C T}

\section{Background}

Tuberculosis and malnutrition are linked in a complex relationship. Tuberculosis may cause undernutrition through increased metabolic demands and decreased intake, and nutritional deficiencies may worsen the disease, or delay recovery by depressing important immune functions. At present, there is no evidence-based nutritional guidance for adults and children being treated for tuberculosis.

\section{Objectives}

To assess the effects of oral nutritional supplements in people being treated with antituberculous drug therapy for active tuberculosis.

\section{Search methods}

We searched the Cochrane Infectious Disease Group Specialized Register, Cochrane Central Register of Controlled Trials (CENTRAL; Issue 1, 2016), MEDLINE (from 1946 to 4 February 2016), EMBASE (from 1980 to 4 February 2016), LILACS (from 1982 to 4 February 2016), the metaRegister of Controlled Trials ( $m R C T$ ), the World Health Organization (WHO) International Clinical Trials Registry Platform (ICTRP), and the Indian Journal of Tuberculosis up to 4 February 2016, and checked the reference lists of all included studies.

\section{Selection criteria}

Randomized controlled trials that compared any oral nutritional supplement given for at least four weeks with no nutritional intervention, placebo, or dietary advice only for people being treated for active tuberculosis. The primary outcomes of interest were all-cause death, and cure at six and 12 months.

\section{Data collection and analysis}

Two review authors independently selected trials for inclusion, and extracted data and assessed the risk of bias in the included trials. We presented the results as risk ratios (RR) for dichotomous variables, and mean differences (MD) for continuous variables, with 95\% confidence intervals $(\mathrm{Cls})$. Where appropriate, we pooled data from trials with similar interventions and outcomes. We assessed the quality of the evidence using the Grading of Recommendation Assessment, Development and Evaluation (GRADE) approach.

\section{Main results}

Thirty-five trials, including 8283 participants, met the inclusion criteria of this review. 


\section{Macronutrient supplementation}

Six trials assessed the provision of free food, or high-energy supplements. Only two trials measured total dietary intake, and in both trials the intervention increased calorie consumption compared to controls.

The available trials were too small to reliably prove or exclude clinically important benefits on mortality $(\mathrm{RR} 0.34,95 \% \mathrm{Cl} 0.10$ to 1.20 ; four trials, 567 participants, very low quality evidence), cure (RR $0.91,95 \% \mathrm{Cl} 0.59$ to 1.41 ; one trial, 102 participants, very low quality evidence), or treatment completion (data not pooled; two trials, 365 participants, very low quality evidence).

Supplementation probably produces a modest increase in weight gain during treatment for active tuberculosis, although this was not seen consistently across all trials (data not pooled; five trials, 883 participants, moderate quality evidence). Two small studies provide some evidence that quality of life may also be improved but the trials were too small to have much confidence in the result (data not pooled; two trials, 134 participants, low quality evidence).

\section{Micronutrient supplementation}

Six trials assessed multi-micronutrient supplementation in doses up to 10 times the dietary reference intake, and 18 trials assessed single or dual micronutrient supplementation.

Routine multi-micronutrient supplementation may have little or no effect on mortality in HIV-negative people with tuberculosis (RR 0.86, $95 \% \mathrm{Cl} 0.46$ to 1.6; four trials, 1219 participants, low quality evidence), or HIV-positive people who are not taking antiretroviral therapy (RR $0.92,95 \% \mathrm{Cl} 0.69$ to 1.23; three trials, 1429 participants, moderate quality evidence). There is insufficient evidence to know if supplementation improves cure (no trials), treatment completion (RR 0.99, 95\% Cl 0.95 to 1.04; one trial, 302 participants, very low quality evidence), or the proportion of people who remain sputum positive during the first eight weeks (RR $0.92,95 \% \mathrm{Cl} 0.63$ to 1.35 ; two trials, 1020 participants, very low quality evidence). However, supplementation may have little or no effect on weight gain during treatment (data not pooled; five trials, 2940 participants, low quality evidence), and no studies have assessed the effect on quality of life.

Plasma levels of vitamin A appear to increase following initiation of tuberculosis treatment regardless of supplementation. In contrast, supplementation probably does improve plasma levels of zinc, vitamin D, vitamin $E$, and selenium, but this has not been shown to have clinically important benefits. Of note, despite multiple studies of vitamin D supplementation in different doses, statistically significant benefits on sputum conversion have not been demonstrated.

\section{Authors' conclusions}

There is currently insufficient research to know whether routinely providing free food, or energy supplements improves tuberculosis treatment outcomes, but it probably improves weight gain in some settings.

Although blood levels of some vitamins may be low in people starting treatment for active tuberculosis, there is currently no reliable evidence that routinely supplementing above recommended daily amounts has clinical benefits.

\section{April 2019}

Update pending

Studies awaiting assessment

The CIDG is currently examining a new search conducted in April 2019 for potentially relevant studies. These studies have not yet been incorporated into this Cochrane Review.

\section{PLAIN LANGUAGE SUMMARY}

\section{Nutritional supplements for people being treated for active tuberculosis}

Cochrane researchers conducted a review of the effects of nutritional supplements for people being treated for tuberculosis. After searching for relevant studies up to 4 February 2016, they included 35 relevant studies with 8283 participants. Their findings are summarized below.

\section{What is active tuberculosis and how might nutritional supplements work?}

Tuberculosis is a bacterial infection which most commonly affects the lungs. Most people who get infected never develop symptoms as their immune system manages to control the bacteria. Active tuberculosis occurs when the infection is no longer contained by the immune system, and typical symptoms are cough, chest pain, fever, night sweats, weight loss, and sometimes coughing up blood. Treatment is with a combination of antibiotic drugs, which must be taken for at least six months.

People with tuberculosis are often malnourished, and malnourished people are at higher risk of developing tuberculosis as their immune system is weakened. Nutritional supplements could help people recover from the illness by strengthening their immune system, and 
by improving weight gain, and muscle strength, allowing them to return to an active life. Good nutrition requires a daily intake of macronutrients (carbohydrate, protein, and fat), and micronutrients (essential vitamins and minerals).

\section{What the research says}

\section{Effect of providing nutritional supplements to people being treated for tuberculosis}

We currently don't know if providing free food to tuberculosis patients, as hot meals or ration parcels, reduces death or improves cure (very low quality evidence). However, it probably does improve weight gain in some settings (moderate quality evidence), and may improve quality of life (low quality evidence).

Routinely providing multi-micronutrient supplements may have little or no effect on deaths in HIV-negative people with tuberculosis (low quality evidence), or HIV-positive people who are not taking anti-retroviral therapy (moderate quality evidence). We currently don't know if micronutrient supplements have any effect on tuberculosis treatment outcomes (very low quality evidence), but they may have no effect on weight gain (low quality evidence). No studies have assessed the effect on quality of life.

Plasma levels of vitamin A appear to increase after starting tuberculosis treatment regardless of supplementation. In contrast, supplementation probably does improve plasma levels of zinc, vitamin D, vitamin $E$, and selenium, but this has not been shown to have clinically important benefits. Despite multiple studies of vitamin D supplementation in different doses, statistically significant benefits on sputum conversion have not been demonstrated.

\section{Authors' conclusions}

Food or energy supplements may improve weight gain during recovery from tuberculosis in some settings, but there is currently no evidence that they improve tuberculosis treatment outcomes. There is also currently no reliable evidence that routinely supplementing above recommended daily amounts has clinical benefits. 


\section{SUMMARY OF FINDINGS}

Summary of findings for the main comparison. 'Summary of findings' table 1

Food provision compared with nutritional advice or no intervention for patients with active tuberculosis

Patient or population: adults and children with active tuberculosis

Settings: low- and middle-income countries

Intervention: calorie supplementation as food or energy dense supplements

Comparison: nutritional advice, micronutrient supplement, or no intervention

\begin{tabular}{|c|c|c|c|c|c|c|}
\hline \multirow[t]{3}{*}{ Outcomes } & \multicolumn{2}{|c|}{$\begin{array}{l}\text { Illustrative comparative risks* } \\
(95 \% \mathrm{Cl})\end{array}$} & \multirow[t]{3}{*}{$\begin{array}{l}\text { Relative effect } \\
(95 \% \mathrm{CI})\end{array}$} & \multirow{3}{*}{$\begin{array}{l}\text { Number of par- } \\
\text { ticipants } \\
\text { (trials) }\end{array}$} & \multirow{3}{*}{$\begin{array}{l}\text { Quality of the } \\
\text { evidence } \\
\text { (GRADE) }\end{array}$} & \multirow[t]{3}{*}{ Comments } \\
\hline & Assumed risk & $\begin{array}{l}\text { Corresponding } \\
\text { risk }\end{array}$ & & & & \\
\hline & Standard care & $\begin{array}{l}\text { Increased calo- } \\
\text { rie intake }\end{array}$ & & & & \\
\hline $\begin{array}{l}\text { Cured } \\
\text { (at } 6 \text { months) }\end{array}$ & 48 per 100 & $\begin{array}{l}\mathbf{4 4} \text { per } 100 \\
(28 \text { to } 68)\end{array}$ & $\begin{array}{l}\text { RR } 0.91 \\
(0.59 \text { to } 1.41)\end{array}$ & $\begin{array}{l}102 \\
\text { (1 trial) }\end{array}$ & $\begin{array}{l}\oplus \ominus \ominus \ominus \\
\text { very low } 2,3,4\end{array}$ & $\begin{array}{l}\text { We don't know if food supplementation increases cure } \\
\text { in tuberculosis patients }\end{array}$ \\
\hline $\begin{array}{l}\text { Treatment com- } \\
\text { pletion } \\
\text { (at } 6 \text { months) }\end{array}$ & 79 per 100 & $\begin{array}{l}85 \text { per } 100 \\
\text { (70 to } 100)\end{array}$ & Not pooled & $\begin{array}{l}365 \\
(2 \text { trials })\end{array}$ & $\begin{array}{l}\oplus \odot \odot \odot \\
\text { very low 3,5,6 }\end{array}$ & $\begin{array}{l}\text { We don't know if food supplementation increases } \\
\text { treatment completion in tuberculosis patients }\end{array}$ \\
\hline $\begin{array}{l}\text { Sputum nega- } \\
\text { tive } \\
\text { (at } 8 \text { weeks) }\end{array}$ & 76 per 100 & $\begin{array}{l}82 \text { per } 100 \\
(65 \text { to } 100)\end{array}$ & $\begin{array}{l}\text { RR } 1.08 \\
\text { (0.86 to } 1.37)\end{array}$ & $\begin{array}{l}222 \\
\text { (3 trials) }\end{array}$ & $\begin{array}{l}\oplus \ominus \ominus \ominus \\
\text { very low } 3,5,6\end{array}$ & $\begin{array}{l}\text { We don't know if food supplementation reduces the } \\
\text { duration of sputum positivity in tuberculosis patients }\end{array}$ \\
\hline $\begin{array}{l}\text { Mean weight } \\
\text { gain } \\
\text { (At } 8 \text { weeks) }\end{array}$ & - & - & Not pooled & $\begin{array}{l}883 \\
(5 \text { trials })\end{array}$ & $\begin{array}{l}\oplus \oplus \oplus \odot \\
\text { moderate } 7,8\end{array}$ & $\begin{array}{l}\text { Supplementation probably increases weight gain dur- } \\
\text { ing treatment }\end{array}$ \\
\hline
\end{tabular}




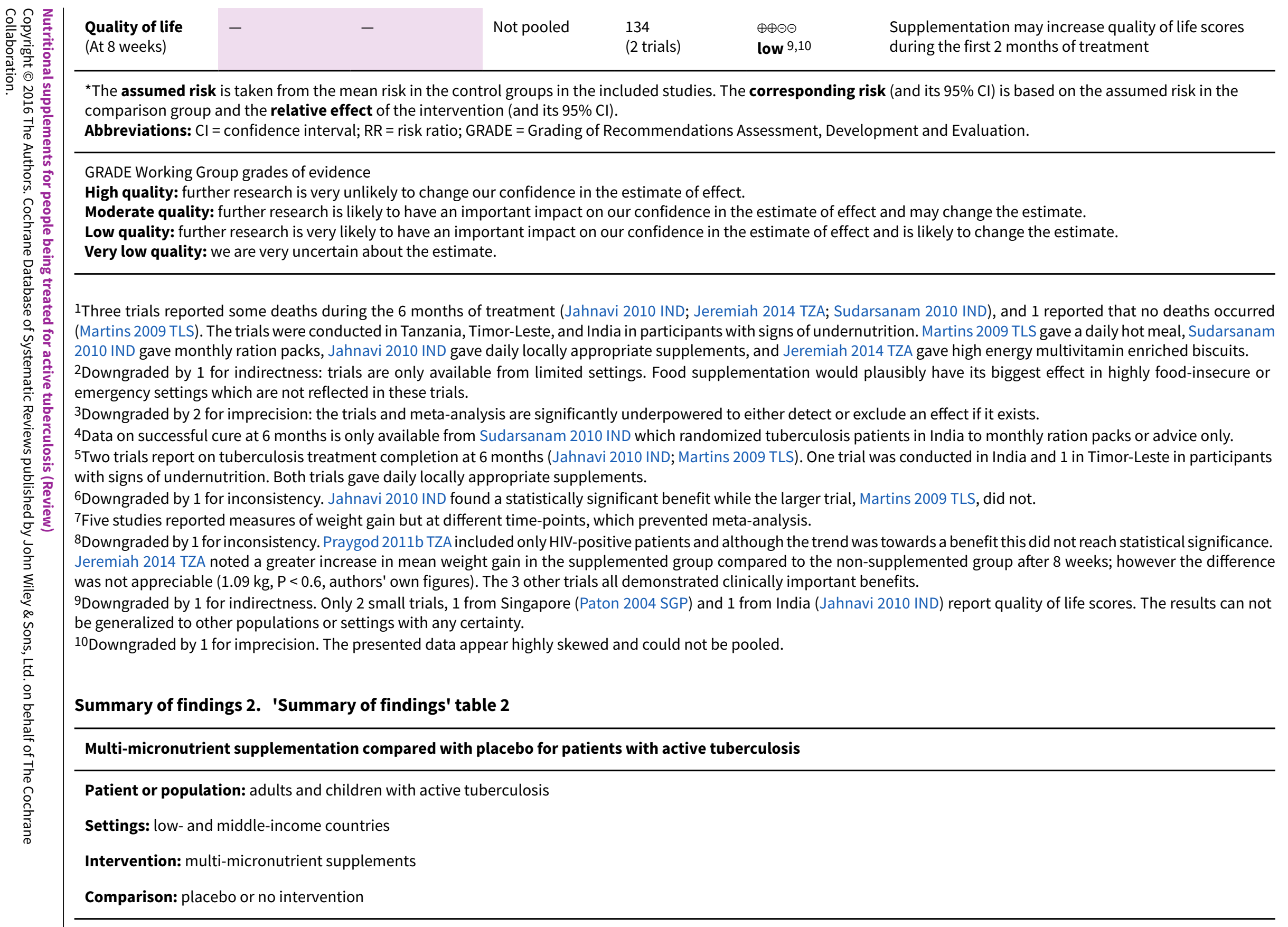




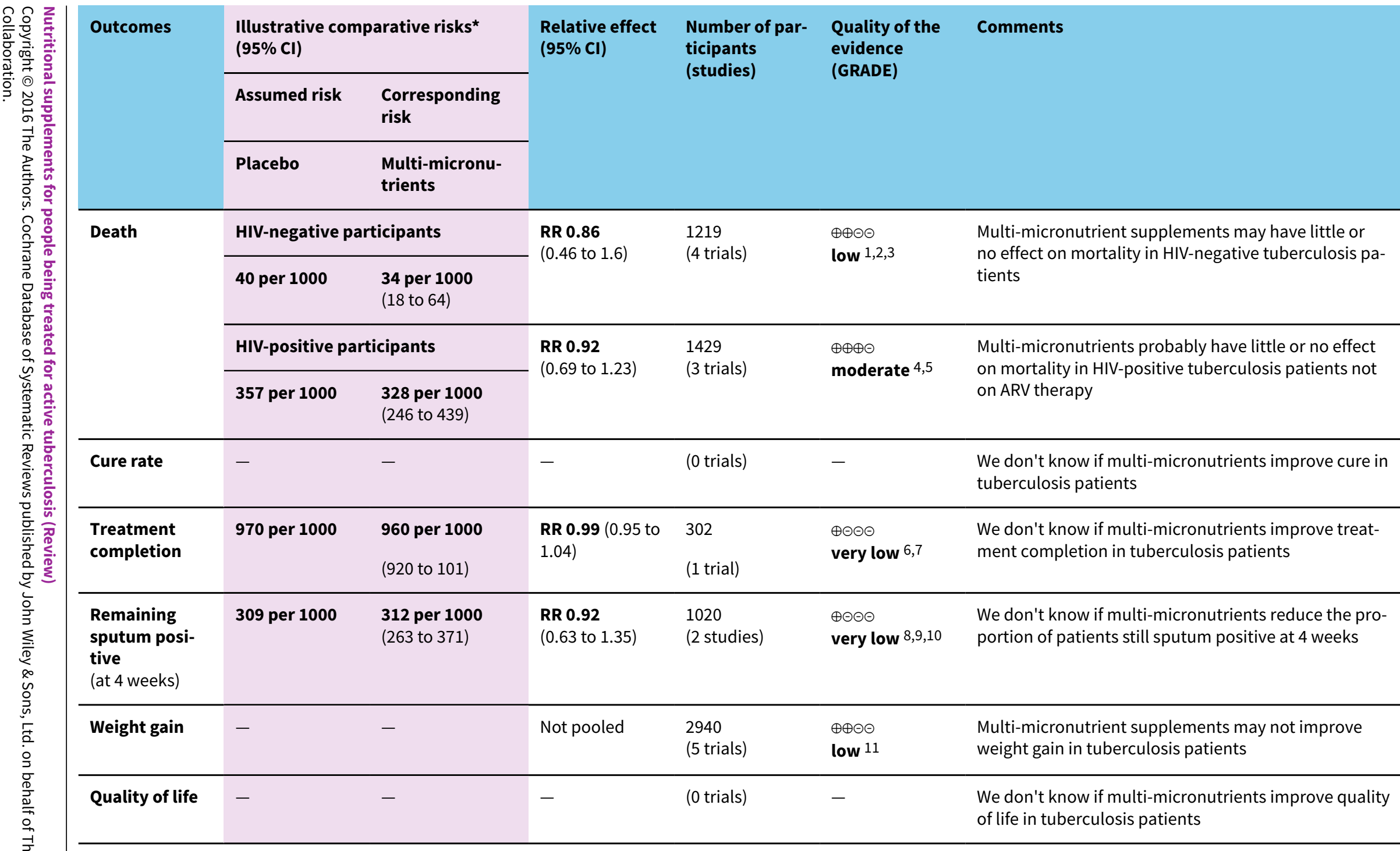

${ }^{\star}$ The assumed risk is taken from the risk in the control groups of the included studies. The corresponding risk (and its $95 \% \mathrm{Cl}$ ) is based on the assumed risk in the comparison group and the relative effect of the intervention (and its $95 \% \mathrm{Cl}$ ).

Abbreviations: $\mathrm{Cl}$ = confidence interval; $\mathrm{RR}$ = risk ratio; GRADE = Grading of Recommendations Assessment, Development and Evaluation.

GRADE Working Group grades of evidence

High quality: further research is very unlikely to change our confidence in the estimate of effect.

Moderate quality: further research is likely to have an important impact on our confidence in the estimate of effect and may change the estimate.

Low quality: further research is very likely to have an important impact on our confidence in the estimate of effect and is likely to change the estimate. 
1Five RCTs comparing multi-micronutrient supplementation with placebo in adults (Range 2005 TZA; Semba 2007 MWI; Villamor 2008 TZA) and children (Lodha 2014 IND; Mehta 2011 TZA), reported deaths during treatment. The exact composition of nutrients varied from 1 to 10 times the DRI. Three studies are from Tanzania, 1 from Malawi, and 1 from India. There is evidence of participants being significantly undernourished at baseline.

2No serious inconsistency: statistical heterogeneity was low. Although the estimate of effect is trending towards a benefit this is due to 1 trial (Villamor 2008 TZA), the remaining trials found non significant trends in the opposite direction. Not downgraded.

3Downgraded by 2 for imprecision: the $95 \% \mathrm{Cl}$ of the pooled effect crosses 1 and includes a $2 \%$ absolute reduction in death which might be considered beneficial given the low cost of the intervention. The optimal information size to reliably detect a clinically beneficial effect if there is 1 is greater than 2000 .

${ }^{4}$ Downgraded by 1 for indirectness: none of the participants in these trials were receiving antiretroviral therapy (Range 2005 TZA; Semba 2007 MWI; Villamor 2008 TZA). The exact composition of nutrients varied from 1 to 10 times the DRI. Two studies are from Tanzania and 1 in Malawi. There is evidence of participants being significantly undernourished at baseline.

5 No serious imprecision: the $95 \% \mathrm{Cl}$ of the pooled effect crosses 1 and does includes a $5 \%$ absolute reduction in death which might be considered beneficial given the low cost of the intervention. However, the effect estimate is of no difference between the treatments and the optimal information size to reliably detect a clinically beneficial effect is met. ${ }^{6}$ Downgraded by 2 for indirectness: current evidence is limited to 1 small trial (Lodha 2014 IND) conducted in moderately undernourished, HIV-negative children in India, where treatment completion was very high in both groups. The result is not easily generalized to other settings.

${ }^{7}$ Downgraded by 1 for imprecision: although this trial approaches adequate power to detect a result, the fact that treatment completion was so high in both arm renders the result irrelevant to settings where treatment completion is lower.

8Downgraded by 1 for inconsistency. Statistical heterogeneity is high; 1 study found a non-significant trend in favour of supplementation, and 1 study in favour of placebo.

${ }^{9}$ Downgraded by 1 for indirectness. Both studies were conducted in Tanzania. Different populations may differ in their micronutrient deficiency or requirement.

10Downgraded by 1 for imprecision. The $95 \% \mathrm{Cl}$ is wide and includes what may be clinically important effects.

11Downgraded by 2 for inconsistency: Statistical heterogeneity is very high. Four studies from Tanzania and India found no evidence of improved weight gain with supplements, while 1 study from Tanzania found large increases in weight with micronutrients at 8 months. 


\section{B A C K G R O U N D}

\section{Description of the condition}

Tuberculosis is an infection caused by the bacterium Mycobacterium tuberculosis, which is spread from person to person by inhalation of respiratory droplets (Harries 2006). In 2013, the World Health Organization (WHO) estimated that there were nine million new cases of active tuberculosis worldwide, and 1.5 million deaths (WHO 2014).

Most people who are infected with $M$. tuberculosis develop what is known as latent tuberculosis. People with latent tuberculosis are infected with the bacterium Mycobacterium tuberculosis, but the infection is contained by their immune system. These people remain well and do not exhibit any clinical signs or symptoms of illness (Barry 2009). The immune response to infection is complex, it initially involves the uptake of the bacterium into macrophage cells as part of the non-specific 'innate' immune response, and later recruitment of both B- and T-lymphocytes of the cellular immune response (Schluger 1998). These cells isolate the bacterium as a granuloma, typically in the lung (Saunders 2007).

Active tuberculosis occurs when the infection is no longer contained by the immune system, and can occur at any time following infection. The lifetime risk of conversion from latent to active tuberculosis is around $5 \%$ to $10 \%$ in an otherwise healthy population (Harries 2006), but this can rise to around $50 \%$ in people with severe impairment of their immune system, such as occurs with human immunodeficiency virus (HIV) infection (Zumla 2000; Aaron 2004).

Tuberculosis most commonly affects the lungs (pulmonary tuberculosis), but can also spread to affect the central nervous system, lymphatic system, circulatory system, genitourinary system, and bones and joints. The symptoms of active pulmonary tuberculosis include cough, chest pain, fever, night sweats, weight loss, and sometimes coughing up blood (Harries 2006).

Tuberculosis is treated with a combination of antibiotic drugs (antituberculous therapy), which must be taken for a period of at least six months to ensure success (WHO 2010). If left untreated, around half of those with active tuberculosis will die of the disease (Corbett 2003). With adequate treatment the mortality is around 5\% globally (WHO 2009), although this may be higher in HIV-positive people (Aaron 2004). The WHO target for successful cure in national tuberculosis control programmes is $85 \%$ (WHO 2009).

Throughout the world, poor nutritional status is more common in people with active tuberculosis than in people without tuberculosis (van Lettow 2003), and weight loss, including loss of lean body mass, is a well-recognized symptom of the disease. Cohort and cross-sectional studies have suggested that active tuberculosis is commonly associated with low serum levels of important micronutrients such as zinc (Taneja 1990), and vitamins A, C, D, and E (Davies 1985; Plit 1998; Nnoaham 2008). However, the measurement of serum vitamin levels during an acute infection, such as tuberculosis, is known to be unreliable, as transient abnormalities can occur (Louw 1992).

The daily nutritional requirements for healthy individuals of all age groups are well described (Meyers 2006), and it is unlikely that people with active tuberculosis would require less than these recommended amounts. The two important questions are therefore whether tuberculosis patients require more, and whether these increased requirements should be provided as part of routine health care.

The effects of supplementation in people with HIV (but without tuberculosis) is covered in two other Cochrane Reviews (Irlam 2010; Grobler 2013).

\section{Description of the intervention}

Nutritional requirements can be broadly divided into macronutrients (carbohydrate, protein, and fat) and micronutrients (essential vitamins and trace elements).

\section{Macronutrients}

Each day the average $70 \mathrm{~kg}$ male requires approximately 2500 kilocalories (kcal) of energy to maintain body weight and composition; ideally consumed as $55 \%$ carbohydrate, $15 \%$ protein, and 30\% fat (Meyers 2006).

If it was shown that patients with active tuberculosis required additional macronutrients; these could be purchased and consumed by the patient simply following nutritional advice. However, in many situations, especially in low- and middle-income countries, the patient may not be able to acquire this additional food due to economic hardship through illness and loss of work, or due to local food insecurity (Kamolratanakul 1999; Wyss 2001). In these situations healthcare services might provide increased nutrients through free provision of meals, take home rations, or specific high energy supplements. In many crisis or low-income settings this already happens and the World Food Programme (WFP) in particular is involved in many food support programmes for tuberculosis patients (WFP 2007).

\section{Micronutrients}

The daily micronutrient requirements for an adult male are given in Appendix 1. These are usually expressed as the 'dietary reference intake' (DRI), and this is different for each individual micronutrient (Meyers 2006).

These requirements can be gained from the consumption of a healthy, and varied diet, or through pharmaceutical supplementation as tablets, capsules, or powders. Any additional requirements could be gained through increased consumption following dietary advice, or through pharmaceutical provision via the health service or tuberculosis programme.

In trials of macronutrient and micronutrient interventions two important factors should be noted.

- The intervention is a supplement and does not represent the total daily intake of that nutrient.

- Any benefit derived from the intervention is likely to be dependant on the initial nutritional status of the patient.

In order to accurately interpret data it is therefore essential to consider both the baseline nutritional status, and the overall nutritional intake of the patients. 


\section{How the intervention might work}

Tuberculosis and undernutrition interact in a two-way process. Tuberculosis can lead to weight loss and micronutrient deficiencies by increasing nutritional requirements, by changing metabolic processes, or by decreasing appetite and causing a reduction in food intake (Macallan 1999). Alternatively, low body mass index (BMI; a measure of weight for height that is indicative of nutritional status) and some micronutrient deficiencies can depress cellmediated immunity, the key host defence against tuberculosis, increasing the susceptibility to active tuberculosis and delaying recovery (Chandra 1996; Zachariah 2002; Cegielski 2004).

The micronutrients which have received the most attention are the following.

- Vitamin A, which is involved in both T- and B-lymphocyte function, macrophage activity and the generation of antibody responses (Semba 1998; Stephensen 2001).

- Vitamin D, which is involved in the function of macrophages, a key component of the immune response to tuberculosis (Wintergerst 2007).

- Vitamin E, which has anti-oxidant properties and may protect against T-lympocyte failure due to oxidative stress (Wintergerst 2007).

- Zinc, which is necessary for adequate functioning of many aspects of human immunity (Shankar 1998).

- Selenium; which is essential for both cell-mediated and humoral immunity (Arthur 2003).

Nutritional interventions, in people with active tuberculosis, therefore have the potential to do the following.

- Improve tuberculosis treatment outcomes; through restoration of cell-mediated immunity, increasing the individuals' ability to fight the infection and hastening recovery from the illness.

- Promote nutritional recovery; with improved weight gain, restoration of muscle strength, function, and quality of life. Nutritional recovery is of great importance in tuberculosis treatment, allowing the patient to return to work, and recover economically as well as physically.

Food may also be given to people with tuberculosis for quite different reasons, such as; to promote adherence to treatment, or to mitigate the financial consequences of prolonged illness. Another Cochrane Review is addressing the use of food to promote adherence (Lutge 2009).

In addition, it is important to note that pathogens such as tuberculosis also require certain micronutrients for their own metabolism, and greater availability of these nutrients through supplementation could encourage their growth. There is some evidence for this in the case of iron (Lounis 2001), and so nutritional interventions cannot be considered entirely benign.

\section{Why it is important to do this review}

There is currently no evidence-based guidance on food provision or supplementation for adults or children being treated for tuberculosis, with or without concurrent HIV infection. This Cochrane Review seeks to assess the evidence for the effectiveness of different food and nutritional supplements in helping people to gain weight and recover from tuberculosis, and highlight where more research might be needed.

\section{O B JECTIVES}

To assess the effects of oral nutritional supplements in people being treated with antituberculous drug therapy for active tuberculosis.

\section{METHODS}

\section{Criteria for considering studies for this review}

\section{Types of studies}

Randomized controlled trials (RCTs).

\section{Types of participants}

Children or adults being treated for active tuberculosis with or without concurrent HIV infection, and with or without a diagnosis of being underweight, malnourished, or nutrient deficient.

\section{Types of interventions}

\section{Intervention}

Any oral macro or micronutrient supplement given for at least four weeks.

We excluded trials that assessed tube feeding or parenteral nutrition, and trials that assessed dietary advice alone without the actual provision of supplements.

\section{Control}

No nutritional intervention, placebo, or dietary advice alone.

\section{Types of outcome measures}

\section{Primary outcomes}

- All-cause death.

- Cure (completed treatment and sputum-smear or sputumculture negative) at six and 12 months.

\section{Secondary outcomes}

- Completion of treatment.

- Sputum positive at follow-up.

- Self-reported recovery from illness or resolution of symptoms.

- Change in weight, skinfold thickness, or other measure of lean or total mass.

- Any measure of growth in children.

- Any measures of physical functioning, quality of life, or ability to return to work.

- Total calorie intake.

- Micronutrient levels before and after supplementation.

We intended to include cure assessed at six and 12 months, as is customary. For other outcome measures, we accepted data presented at any time point.

\section{Search methods for identification of studies}

We attempted to identify all relevant trials regardless of language or publication status (published or unpublished, in press, or in progress). 


\section{Electronic searches}

We searched the following databases using the search terms and strategy described in Appendix 2.

- Cochrane Infectious Disease Group Specialized Register.

- Cochrane Central Register of Controlled Trials (CENTRAL; Issue 1, 2016).

- MEDLINE (from 1946 to 4 February 2016).

- EMBASE (from 1980 to 4 February 2016).

- LILACS (from 1982 to 4 February 2016).

We checked the metaRegister of Controlled Trials (mRCT) and the World Health Organization (WHO) International Clinical Trials Registry Platform (ICTRP) (www.who.int/ictrp/search/en) up to 4 February 2016, using 'tuberculosis' and 'supplementation' as search terms.

In addition we searched the Indian Journal of Tuberculosis using the keywords given in the search strategy (Appendix 2) on 4 February 2016.

\section{Searching other resources}

We also checked the reference lists of all studies identified by the above methods.

\section{Data collection and analysis}

\section{Selection of studies}

Two review authors (Liesl Grobler (LG) and Sukrti Nagpal (SN)/ Thambu Sudarsanam (TS)) independently screened all citations and abstracts identified in the search for potentially eligible studies. Full reports of potentially eligible studies were obtained and assessed for inclusion in the review by the same authors using a pre-designed eligibility form based on the inclusion criteria. Where it was unclear whether a study was eligible for the review, we attempted to contact the authors for clarification. We resolved differences in opinion by discussion and, where necessary, by discussion with a fourth author (David Sinclair). We screened all papers for multiple publications. We excluded studies that did not meet the criteria and documented the reasons for their exclusion.

\section{Data extraction and management}

Two review authors (LG and SN) independently extracted data using a tailored data extraction form. We extracted data on study design, participant characteristics, interventions, and outcomes.

For dichotomous data, we extracted the number of participants with the outcome and the total number analysed. For continuous data, we extracted the arithmetic mean and standard deviation (SD) for each group. If medians were used, we also extracted the ranges where possible. If there was skewed continuous data, we planned to extract geometric means where presented by the trial author(s). We resolved any discrepancies regarding extracted data by discussion between the review authors.

\section{Assessment of risk of bias in included studies}

Two review authors (LG and SN) independently assessed components of risk of bias of the included trials using the Cochrane 'Risk of bias' assessment tool (RevMan 2014), and discussed any differences of opinion. We followed the guidance to assess whether adequate steps were taken to reduce the risk of bias across six domains: sequence generation, allocation concealment, blinding (of participants, personnel, and outcome assessors), incomplete outcome data, selective outcome reporting, and other sources of bias. We categorized our judgements as either 'low', 'high', or 'unclear' risk of bias. Where our judgment was 'unclear', we attempted to contact the trial authors for clarification.

\section{Measures of treatment effect}

We compared interventions using risk ratios (RR) for dichotomous data, and mean difference (MD) values for continuous data. We presented all results with $95 \%$ confidence intervals (Cls).

\section{Unit of analysis issues}

We split trials that included more than two comparison groups and analysed them as individual pair-wise comparisons. When we conducted meta-analysis we ensured that we did not count participants and cases in the placebo group more than once, by dividing the placebo cases and participants evenly between the intervention groups.

\section{Dealing with missing data}

If data from the trial reports were insufficient, unclear, or missing, we attempted to contact the trial authors for additional information.

\section{Assessment of heterogeneity}

We assessed heterogeneity amongst trials by inspection of the forest plots (to detect overlapping Cls), the $\mathrm{I}^{2}$ statistic with a level of $50 \%$ to denote moderate levels of heterogeneity, and application of the $\mathrm{Chi}^{2}$ test with a $\mathrm{P}$ value of 0.10 to indicate appreciable heterogeneity.

\section{Assessment of reporting biases}

We planned to assess the likelihood of publication bias by examining the funnel plots for asymmetry. However, there were too few trials to make this assessment meaningful.

\section{Data synthesis}

We analysed the data using Review Manager (RevMan) (RevMan 2014). Using pair-wise meta-analyses we compared the treatments. We stratified meta-analyses by time-point or HIV status where appropriate.

When there was no statistically significant heterogeneity we used the fixed-effect meta-analysis model. When we observed moderate statistically significant heterogeneity within groups that we could not explain by subgroup or sensitivity analyses we used a randomeffects meta-analysis model to synthesize the data. When a pooled meta-analysis result was considered to be meaningless because of clinical or substantial statistical heterogeneity the results are presented in a forest plot without a pooled estimate of effect.

Data presented as medians and ranges are presented in tables and described in the narrative. Highly skewed continuous data (where the SDs were larger than the means) are only presented in tables.

\section{Subgroup analysis and investigation of heterogeneity}

Due to the small number of included trials or each comparison, the investigation of heterogeneity was not necessary or possible. In 
future updates of this Cochrane review we may perform subgroup analyses by: HIV status, nutritional status at baseline, presence of co-morbidities, and specific micronutrient level at baseline.

\section{Sensitivity analysis}

We have planned to perform a sensitivity analysis to investigate the robustness of the results to the 'Risk of bias' components. However, there were too few included trials for each comparison for this to be possible.

\section{Figure 1. Study flow diagram.}

23 studies (from 24 records)
included in previous version of
the review

41 records (32 publishe studies, 9 ongoing studies) identified through database searching (2011 to 2014)

\section{RES U L T S}

\section{Description of studies}

\section{Results of the search}

The original search (June 2008) identified 47 articles, and the updated search (July 2011) identified a further 17 articles. The searches conducted in December 2014 and updated in February 2016 identified 48 published articles and 16 ongoing studies. In total the current review includes data from 39 reports, covering 35 individually randomized controlled trials (RCTs) (see Figure 1).

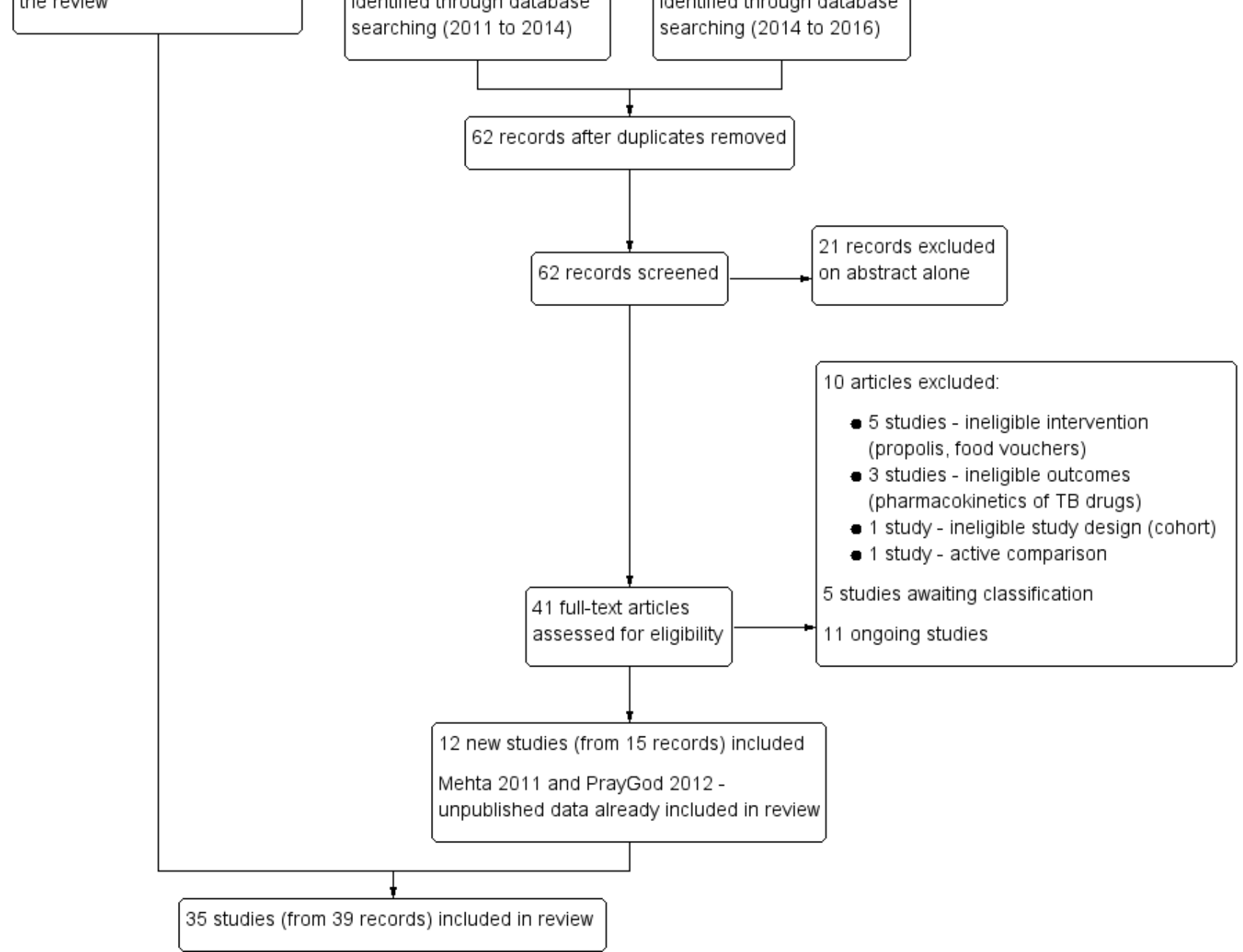

\section{Included studies}

\section{Participants}

The 35 trials included 8285 participants. Twenty-eight trials included only adults being treated for pulmonary tuberculosis, and three trials also included adults with extrapulmonary tuberculosis (Wejse 2008 GNB; Jahnavi 2010 IND; Sudarsanam 2010 IND). Likewise of four studies in children, one included only pulmonary tuberculosis (Hanekom 1997 ZAF), and three also included extrapulmonary tuberculosis (Morcos 1998 EGY; Mehta 2011 TZA; Lodha 2014 IND).

\section{HIV status}

Eleven trials specifically included people with HIV, and presented some results separately for HIV positive and HIV negative participants (Schön 2003 ETH; Range 2005 TZA; Semba 2007 MWI; Villamor 2008 TZA; Wejse 2008 GNB; Lawson 2010 NGA; Mehta 2011 TZA; Sudarsanam 2010 IND; Schön 2011 ETH; Ralph 2013 IDN; 
Jeremiah 2014 TZA). Four of the trials that presented results for HIVpositive and HIV-negative participants separately used stratified randomization (Villamor 2008 TZA; Wejse 2008 GNB; Sudarsanam 2010 IND; Jeremiah 2014 TZA), but six tested participants for HIV following randomization (Schön 2003 ETH; Range 2005 TZA; Semba 2007 MWI; Lawson 2010 NGA; Mehta 2011 TZA; Schön 2011 ETH), and therefore the subgroup analyses by HIV status cannot be said to be truly randomized. Four trials included both HIV-positive and HIV-negative individuals and reported on numbers but did not present results separately (Martineau 2011 GBR; Praygod 2011a TZA; Visser 2011 ZAF; Tukvadze 2015 GEO). One trial included only HIV-positive participants (Praygod 2011b TZA). None of the HIV-positive participants were receiving antiretroviral treatment. One trial was stopped early when antiretrovirals became locally available (Semba $2007 \mathrm{MWI}$ ). Eleven trials excluded people with HIV infection (Hanekom 1997 ZAF; Paton 2004 SGP; Pérez-Guzmán 2005 MEX; Nursyam 2006 IDN; Armijos 2010 MEX; Jahnavi 2010 IND; Paliliewu 2013 IDN; Lodha 2014 IND; Daley 2015 IND; Farazi 2015 IRN; Mily 2015 BGD), and eight trials did not mention HIV infection (Morcos 1998 EGY; Karyadi 2002 IDN; Seyedrezazadeh 2006 IRN; Martins 2009 TLS; Pakasi 2010 IDN; Kota 2011 IND; Ginawi 2013 IND; Singh 2013 IND).

\section{Study site}

Trials were undertaken in the following locations.

- Africa: Egypt (Morcos 1998 EGY), Guinnea-Bissau (Wejse 2008 GNB), Ethiopia (Schön 2003 ETH; Schön 2011 ETH), Tanzania (Range 2005 TZA; Villamor 2008 TZA; Mehta 2011 TZA; Praygod 2011b TZA; Praygod 2011a TZA; Jeremiah 2014 TZA), Malawi (Semba 2007 MWI), Nigeria (Lawson 2010 NGA), and South Africa (Hanekom 1997 ZAF; Visser 2011 ZAF).

- Asia: Singapore (Paton 2004 SGP), Indonesia (Karyadi 2002 IDN; Nursyam 2006 IDN; Pakasi 2010 IDN; Paliliewu 2013 IDN; Ralph 2013 IDN), Iran (Seyedrezazadeh 2006 IRN; Farazi 2015 IRN), Bangladesh (Mily 2015 BGD), and India (Jahnavi 2010 IND; Sudarsanam 2010 IND; Kota 2011 IND; Ginawi 2013 IND; Singh 2013 IND; Lodha 2014 IND; Daley 2015 IND).

- Oceania: Timor Leste (Martins 2009 TLS).

- North America: Mexico (Pérez-Guzmán 2005 MEX; Armijos 2010 MEX).

- Europe: UK (Martineau 2011 GBR) and Georgia (Tukvadze 2015 GEO).

\section{Interventions}

Seven trials assessed macronutrient supplementation (Paton 2004 SGP; Pérez-Guzmán 2005 MEX; Martins 2009 TLS; Jahnavi 2010 IND; Sudarsanam 2010 IND; Praygod 2011b TZA; Jeremiah 2014 TZA), six trials assessed multi-micronutrient supplementation (Range 2005 TZA; Semba 2007 MWI; Villamor 2008 TZA; Mehta 2011 TZA; Praygod 2011a TZA; Lodha 2014 IND), and 21 trials assessed single or dual micronutrient supplementation. The remaining trial assessed the effect of supplementation with Channa striata capsules (Paliliewu 2013 IDN). C. striata is a fresh-water fish found in most tropical and subtropical countries.

\section{Sample size}

Eleven of the 35 trials included less than 100 participants in their final analysis. To aid interpretation and inform future research we have calculated the optimal sample size to reliably demonstrate some suggested clinically important results (Appendix 3; Appendix 4).

As micronutrients are a cheap and easily administered intervention, even a small effect on tuberculosis treatment outcomes might be considered clinically important. For example, to demonstrate a reduction in death from the worldwide average of $5 \%$ to just $4 \%$ (a relative risk reduction of $20 \%$ ); a sample size of over 13,000 participants would be necessary. This is far above the data included in this Cochrane Review. Similarly an increase in successful cure rate from $80 \%$ to $84 \%$ would require almost 3000 participants.

For full details of the included trials see the 'Characteristics of included studies' table.

\section{Excluded studies}

We excluded 17 studies that we had thought were eligible after initial screening for the reasons we have given in the 'Characteristics of excluded studies' table. Five trials are currently awaiting classification pending further information from the author (Chandra 2004; Guzman-Rivero 2013; Nagrale 2013; Nawas 2013; Al Mamun 2014). In addition we are aware of 17 potentially relevant ongoing or unpublished trials; see the 'Characteristics of ongoing studies' table.

\section{Risk of bias in included studies}

We have displayed the 'Risk of bias' assessments in a table and summarised these results in Figure 2. 
Figure 2. 'Risk of bias' summary: review authors' judgements about each 'Risk of bias' item for each included study.

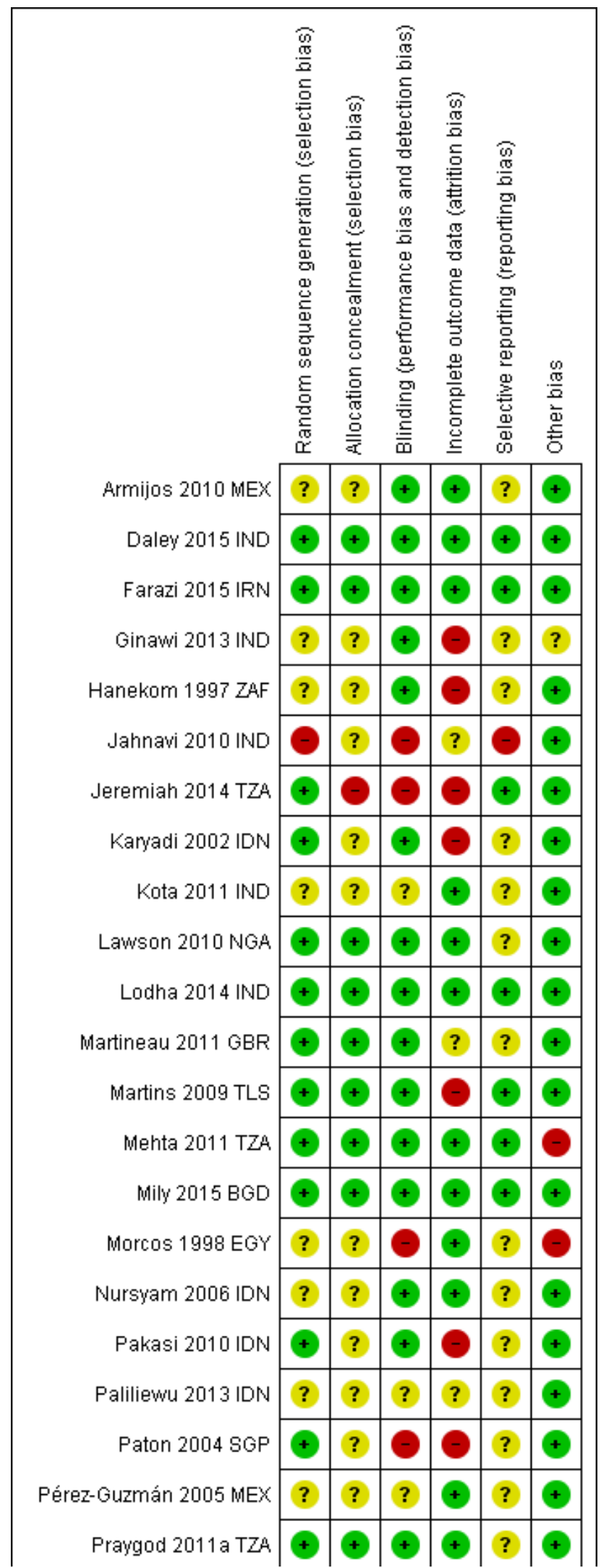

Nutritional supplements for people being treated for active tuberculosis (Review) 
Figure 2. (Continued)

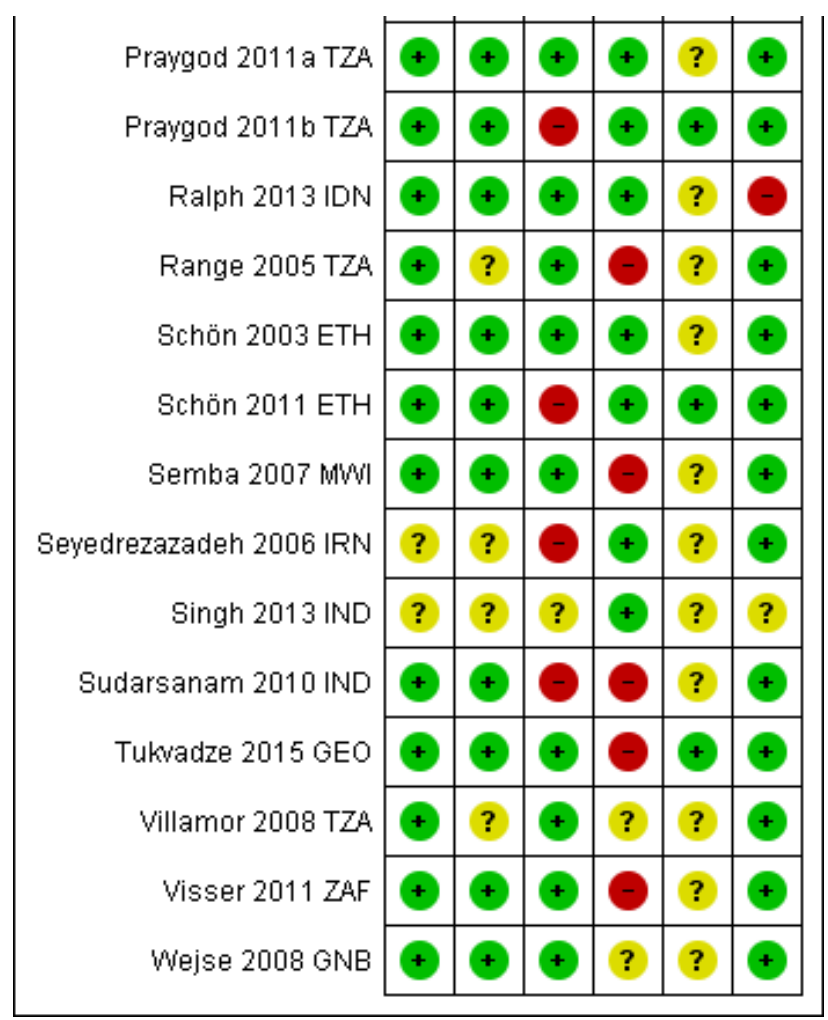

\section{Allocation}

Twenty-four trials described an adequate method of generating a truly random allocation sequence (Karyadi 2002 IDN; Schön 2003 ETH; Paton 2004 SGP; Range 2005 TZA; Semba 2007 MWI; Villamor 2008 TZA; Wejse 2008 GNB; Martins 2009 TLS; Lawson 2010 NGA; Pakasi 2010 IDN; Sudarsanam 2010 IND; Martineau 2011 GBR; Mehta 2011 TZA; Praygod 2011a TZA; Praygod 2011b TZA; Schön 2011 ETH; Visser 2011 ZAF; Ralph 2013 IDN; Jeremiah 2014 TZA; Lodha 2014 IND; Daley 2015 IND; Farazi 2015 IRN; Mily 2015 BGD; Tukvadze 2015 GEO). The other trials did not report how the random sequences were generated although all were described as "randomized".

Eighteen trials described an adequate method of ensuring allocation concealment (Schön 2003 ETH; Semba 2007 MWI; Wejse 2008 GNB; Martins 2009 TLS; Lawson 2010 NGA; Sudarsanam 2010 IND; Martineau 2011 GBR; Mehta 2011 TZA; Praygod 2011a TZA; Praygod 2011b TZA; Schön 2011 ETH; Visser 2011 ZAF; Ralph 2013 IDN; Lodha 2014 IND; Daley 2015 IND; Farazi 2015 IRN; Mily 2015 BGD; Tukvadze 2015 GEO). The other trials did not provide sufficient information to determine if the allocation sequence was truly concealed from the person allocating participants to the treatment groups.

\section{Blinding}

It is generally not possible to blind patients to macronutrient supplementation. However, it is possible to blind the outcome assessors but only one of the six studies reports an attempt to do this (Martins 2009 TLS).
Twenty-one of the 27 trials assessing micronutrients used placebos and adequately blinded participants and study staff to be considered at low risk of bias.

\section{Incomplete outcome data}

We considered 12 studies at high risk of bias for some outcomes due to high losses to follow-up (that is, loss to follow-up $>10 \%$ overall, between groups or within a group (Hanekom 1997 ZAF; Karyadi 2002 IDN; Paton 2004 SGP; Range 2005 TZA; Semba 2007 MWI; Martins 2009 TLS; Pakasi 2010 IDN; Sudarsanam 2010 IND; Visser 2011 ZAF; Ginawi 2013 IND; Jeremiah 2014 TZA; Tukvadze 2015 GEO).

\section{Selective reporting}

Although treatment outcomes in tuberculosis such as cure, and treatment completion are well established in tuberculosis programmes only one trial reported cure (Sudarsanam 2010 IND), and five reported treatment completion (Martins 2009 TLS; Jahnavi 2010 IND; Pakasi 2010 IDN; Sudarsanam 2010 IND; Farazi 2015 IRN). We were unable to retrieve trial protocols.

\section{Other potential sources of bias}

One trial did not adequately describe baseline nutritional status (Morcos 1998 EGY), one trial had a large imbalance in HIV status at baseline (Mehta 2011 TZA), and one trial had appreciable difference in both HIV status and severity of chest X-ray at baseline (Ralph 2013 IDN). 


\section{Effects of interventions}

See: Summary of findings for the main comparison 'Summary of findings' table 1; Summary of findings 2 'Summary of findings' table 2

\section{Macronutrients}

\subsection{Increased energy supplementation (average daily requirement for a male adult: 2500 kcal)}

Six trials examined the effects of providing macronutrient supplements through the health service.

- In Timor Leste, adults with pulmonary tuberculosis and a mean weight of $43.3 \mathrm{~kg}$ (31\% of participants had a BMI of less than $16 \mathrm{~kg} / \mathrm{m}^{2}$ ) were randomized to nutritional advice plus a daily cooked meal or nutritional advice alone (Martins 2009 TLS). The daily midday meal (administered for two months during the intensive phase) consisted of a bowl of meat, kidney beans, and vegetable stew with rice. During the continuation phase participants in the supplement group also received a weekly food parcel containing unprepared red kidney beans, rice, and oil adequate for one meal per day.

- In India, adults with pulmonary tuberculosis and a BMI of less than $19 \mathrm{~kg} / \mathrm{m}^{2}$ were randomized to receive a macronutrient and micronutrient supplement plus standard care versus standard care alone (Sudarsanam 2010 IND). The supplement consisted of three daily servings of a cereal and lentil mixture (providing 930 $\mathrm{kcal}$ and $31.5 \mathrm{~g}$ protein) and a once-a-day multivitamin tablet. Participants were given a month's supply of supplement at a time.

- The remaining four trials compared daily high energy supplements with: nutritional advice alone (Paton 2004 SGP; Jahnavi 2010 IND); a single multi-micronutrient biscuit (Praygod 2011b TZA); or no supplement (Jeremiah 2014 TZA). The supplements were described as 'sweetballs' (made from wheat flour, caramel, ground nuts, and vegetable ghee) (Jahnavi 2010 IND), high energy 'packets' (Paton 2004 SGP), and high energy 'biscuits' (Praygod 2011b TZA; Jeremiah 2014 TZA) (see Appendix 5). None of the studies estimated the total daily energy intake, but the supplement provided between 600 and $3690 \mathrm{kcal}$ per day on top of the regular diet. All four studies recruited people with mean BMI below $20 \mathrm{~kg} / \mathrm{m}^{2}$.

Only two trials measured total dietary intake. Both trials confirmed that supplementation had increased nutritional intake compared to dietary advice alone, and not simply substituted food that patients might have obtained elsewhere (Paton 2004 SGP; Sudarsanam 2010 IND).

\section{Tuberculosis treatment outcomes}

The number of deaths reported from these trials was very low, and trials were too small to reliably detect or exclude important differences in mortality (risk ratio (RR) $0.34,95 \%$ confidence interval (CI) 0.10 to 1.20; four trials, 567 participants; Analysis 1.1), or cure (RR $0.91,95 \% \mathrm{Cl} 0.59$ to 1.41 ; one trial, 102 participants; Analysis 1.2). Jahnavi 2010 IND found a statistically significant difference in treatment completion in favour of supplementation, but this was not seen in the larger trial conducted in Timor Leste (two trials, 365 participants, Analysis 1.3).
Jahnavi 2010 IND also found that more participants given supplements were smear negative at eight weeks, while Martins 2009 TLS and Jeremiah 2014 TZA found no statistically significant difference (RR 1.08, 95\% Cl 0.86 to 1.37; three trials, 222 participants; Analysis 1.4).

\section{Nutritional recovery and quality of life}

Effects on weight gain were mixed (five trials, 689 participants, Analysis 1.5). The daily hot meal was associated with an extra 1.7 $\mathrm{kg}$ weight gain at eight weeks $(95 \% \mathrm{Cl} 0.1$ to $3.2 ; \mathrm{P}=0.04$; authors' own figures), and $2.6 \mathrm{~kg}$ at eight months $(95 \% \mathrm{Cl} 0.1$ to $5.2 ; \mathrm{P}=$ 0.04; authors' own figures; Martins 2009 TLS), whereas the monthly ration pack was not associated with important differences (change in lean body mass, and percentage body fat were not significantly different between groups; $\mathrm{P}=0.479$ and $\mathrm{P}=0.573$ respectively; authors' own figures; Sudarsanam 2010 IND).

Of the trials evaluating high energy supplements, the two smaller trials in HIV-negative participants found that supplementation resulted in significantly more weight gain than advice alone at six weeks (MD $1.73 \mathrm{~kg}, 95 \% \mathrm{Cl} 0.81$ to 2.65; one trial, 34 participants; Analysis 1.5 ) and 12 weeks, respectively (MD $2.6 \mathrm{~kg}, 95 \% \mathrm{Cl} 1.74$ to 3.46; one trial, 100 participants; Analysis 1.5). Paton 2004 SGP further quantified this as an increase in lean body mass (MD $1.13 \mathrm{~kg}, 95 \% \mathrm{Cl} 0.37$ to 1.89 ; one trial, 34 participants), with no significant difference in total fat mass. However, in Tanzania Praygod 2011b TZA found no significant difference in weight gain with supplementation in HIV-positive participants at eight or 20 weeks (one trial, 332 participants, Analysis 1.5). Similarly, Jeremiah 2014 TZA found no difference in final mean weight between the supplement and no supplement group after two months of supplementation (one trial, 92 participants, Analysis 1.5).

Three trials of high energy supplements (Paton 2004 SGP; Jahnavi 2010 IND; Praygod 2011b TZA) report changes in maximum grip strength, and again a statistically significant benefit was seen in the small trials of HIV-negative participants but not the larger trial of HIV-positive participants although the data appear skewed (three trials, 466 participants, Analysis 1.6).

Jahnavi 2010 IND and Paton 2004 SGP also reported that the benefits on weight gain and grip strength were accompanied by improvements in some quality of life scores. It was not possible to assess whether these difference were statistically significant because the data appeared highly skewed (the SDs were larger than the means for most outcomes); see Analysis 1.7 and Appendix 6.

\subsection{Altered dietary composition}

One very small trial of 21 participants compared a high cholesterol diet ( $2500 \mathrm{kcal}$ per day with $800 \mathrm{mg}$ cholesterol per day) with a diet with a similar nutritional profile but lower in cholesterol $(2500 \mathrm{kcal}$ per day with $250 \mathrm{mg}$ cholesterol per day) for eight weeks in adults being treated for sputum-culture positive pulmonary tuberculosis (Pérez-Guzmán 2005 MEX).

\section{Tuberculosis treatment outcomes}

This trial did not report on death, cure, or treatment completion.

Fewer participants in the high cholesterol group were still sputumculture positive at two weeks compared with those in the normal cholesterol group (RR of remaining sputum positive at two weeks $0.22,95 \% \mathrm{Cl} 0.06$ to 0.77 ; one trial, 20 participants, Analysis 2.1 ), 
the difference was not significant at four weeks, and at eight weeks all participants in both groups were sputum-culture negative. Self reported cough and dyspnoea are reported to have decreased at the same rate in both groups (figures not given).

\section{Nutritional recovery and quality of life}

This trial did not report on any aspect of the participant's nutritional recovery or quality of life.

\section{Micronutrients}

\subsection{Multivitamins and trace elements}

Four trials in adults being treated for sputum test positive or negative pulmonary tuberculosis (Range 2005 TZA; Semba 2007 MWI; Villamor 2008 TZA; Praygod 2011a TZA) and two trials in children (Mehta 2011 TZA; Lodha 2014 IND) compared daily multiple micronutrient supplements (containing a range of vitamins and trace elements), with placebo. The exact doses of the individual constituents ranged from one to 10 times the dietary reference intake (DRI), and are given in Appendix 1. In summary: vitamin A (1 to $3 \times \mathrm{DRI})$, B vitamins ( 1 to $10 \times \mathrm{DRI}$ ), vitamin C ( 1 to $5 \times \mathrm{DRI}$ ), vitamin $\mathrm{D}$ (approximately $1 \times \mathrm{DRI})$, vitamin $\mathrm{E}$ (1 to $10 \times \mathrm{DRI}$ ), zinc ( 1 to $5 \times \mathrm{DRI})$, and selenium (1 to $4 \times \mathrm{DRI})$.

In two trials participants received daily supplements for two months (Mehta 2011 TZA; Praygod 2011a TZA), one trial for six months (Lodha 2014 IND), one trial for eight months (Range 2005 TZA), and in two trials they received daily supplements for 24 months (Semba 2007 MWI; Villamor 2008 TZA).

\section{Tuberculosis treatment outcomes}

In trials with HIV negative people the number of deaths from tuberculosis was low and the trials substantially underpowered to demonstrate an effect, Consequently, the $95 \% \mathrm{Cl}$ is wide and includes clinically important benefit and harm (RR 0.86 , $95 \% \mathrm{Cl} 0.46$ to 1.60 , four trials, 1219 participants, Analysis 3.1). Deaths were more common in trials with HIV positive people not taking antiretroviral therapy, but again no differences between micronutrients and placebo were demonstrated (RR 0.92, 95\% Cl 0.69 to 1.23 , three trials, 1429 participants, Analysis 3.1).

Lodha 2014 IND reported no difference in tuberculosis treatment completion at six months between micronutrients (with and without zinc) and placebo (one trial, 302 participants, Analysis 3.2).

There was no statistically significant difference between the supplement and control groups in the numbers of participants who remained sputum-culture or sputum-smear positive at one month (two trials, 1020 participants, Analysis 3.3) or two months (two trials, 731 participants, Analysis 3.4).

Lodha 2014 IND and Mehta 2011 TZA reported no appreciable difference in chest $x$-ray clearance (after two or six months of supplementation) between the supplemented children and the placebo children at follow-up (two trials, 497 participants, Analysis 3.5).

\section{Nutritional recovery and quality of life}

Five trials reported changes in weight or body mass using a variety of parameters, and only Range 2005 TZA reported statistically significant effects (see Table 1).
Range 2005 TZA found that participants receiving multiple micronutrients had gained significantly more weight at seven months than those in the placebo group. This was a $2 \times 2$ factorial study and the difference in weight was appreciable in both treatment groups compared to placebo. In the treatment arm that received both high dose multivitamins and high dose zinc, the weight gain appeared clinically important (MD $2.37 \mathrm{~kg}, 95 \% \mathrm{Cl}$ 2.21 to 2.53; one trial, 192 participants, Analysis 3.6). However, in the treatment arm that received high-dose multivitamins alone, the weight gain was minimal (MD $0.30 \mathrm{~kg}, 95 \% \mathrm{Cl} 0.17$ to 0.43 ; one trial, 198 participants, Analysis 3.6). In Lodha 2014 IND, multi-micronutrient supplementation with or without zinc did not consistently alter children's weight, BMI-for-age z score or heightfor-age z score (one trial, 198 participants; Analysis 3.7).

One study, Praygod 2011a TZA, found an appreciable improvement in mean handgrip strength at two months but not five months (mean difference (change in handgrip strength) $1.22 \mathrm{~kg}, 95 \%$ $\mathrm{Cl} 0.49$ to 1.95; one trial, 771 participants; Analysis 3.8). The clinical importance of this difference is unclear. Consistent with the change in weight, this increase was only present in HIV-negative participants.

\subsection{Individual micronutrients}

\section{Vitamin A (DRI: $900 \mu \mathrm{g} / 3000$ IU per day)}

\section{Supplement dosing regimes}

Three trials directly compared vitamin A given alone versus placebo (Ginawi 2013 IND: vitamin A 5000 IU; Hanekom 1997 ZAF: vitamin A 200,000 IU on Day 0 and Day 1; Pakasi 2010 IDN: vitamin A 5000 IU daily). In addition, seven trials combined vitamin A with zinc (see Comparison 6: Zinc plus vitamin A versus placebo), and five studies gave vitamin $\mathrm{A}$ as part of a multi-micronutrient supplement (see Comparison 3: Multivitamin and trace element tablets versus placebo).

\section{Serum vitamin A concentrations at baseline and follow-up}

Seven studies report on measures of vitamin A status, but Pakasi 2010 IDN and Visser 2011 ZAF reported data as median plasma levels so could not be included in the meta-analysis, and Semba 2007 MWI only presented data graphically (see Table 2). Only Semba 2007 MWI reports a difference that was statistically significant in favour of supplements, but this difference (at eight months) is unlikely to be of clinical significance.

In four trials in adults and one in children, mean serum vitamin A level substantially increased in both intervention and control arms regardless of supplementation, and there was no statistically significant difference between the groups (one trial, 85 participants; Analysis 4.1; three trials, 242 participants; Analysis 4.2; Table 2).

\section{Tuberculosis treatment outcomes}

Supplementation with vitamin A alone or in combination with other micronutrients appears to have little or no effect on mortality (eight trials, 3308 participants; Analysis 4.3), but these trials, even the larger ones, were significantly underpowered to rule out a clinically important effect.

Only Pakasi 2010 IDN reported on treatment completion and found no statistically significant effect (one trial, 158 participants, Analysis 4.4). Hanekom 1997 ZAF reported that more children in 
the supplement group remained symptomatic after six weeks of tuberculosis treatment than in the control group, but this was not statistically significant (one trial, 76 participants, Analysis 4.5). The trial authors also reported no statistically significant differences in respiratory symptoms at three months, or in chest $\mathrm{x}$-ray resolution; but specific data on these outcomes were not provided.

Supplementation with vitamin A alone had no effect on the number of participants who were sputum smear negative after two weeks, one month, or two months (two trials, 224 participants, Analysis 4.6). Pakasi 2010 IDN reported that all participants in the vitamin $A$ and placebo arm were smear negative at two months.

\section{Nutritional recovery and quality of life}

Hanekom 1997 ZAF reported that the mean weight $\mathrm{z}$ score at baseline was -1.41 (SD 1.41) in the supplement group, and -1.44 (SD 1.34) in the placebo group (it is unclear whether this is weight for age or weight for height). The trial authors also reported that no statistically significant differences in change-in-weight $z$ scores were recorded at any time-point, but the specific data for this outcome was not provided.

Pakasi 2010 IDN reports that the mean BMI at baseline was 16.5 $\mathrm{kg} / \mathrm{m}^{2}$ (SD 2.2) in the supplement group and $16.4 \mathrm{~kg} / \mathrm{m}^{2}$ (SD 2.5) in the placebo group. There was no statistically significant difference in mean BMI between groups at two or six months (one trial, 158 participants, Analysis 4.7). Pakasi 2010 IDN also reported that there were no statistically significant differences in mid upper arm circumference (MUAC) or percentage body fat (Analysis 4.8).

\section{Zinc (DRI: 11 mg/day)}

\section{Supplement dosing regimes}

Five trials directly compared daily zinc given alone versus placebo (Ginawi 2013 IND: 15 mg zinc sulphate; Lodha 2014 IND: 20 mg elemental zinc; Range 2005 TZA: zinc 45 mg daily; Lawson 2010 NGA: 90 mg elemental zinc weekly; Pakasi 2010 IDN: 15 mg zinc sulphate daily). In addition, seven trials combined vitamin $A$ with zinc (see Comparison 6: zinc plus vitamin A versus placebo), and four trials gave zinc as part of a multi-micronutrient supplement (see comparison 3: Multivitamin and trace element tablets versus placebo).

\section{Serum zinc concentrations at baseline and follow-up}

Five studies report mean plasma zinc levels at baseline and during follow-up (see Table 3). Pakasi 2010 IDN and Armijos 2010 MEX report mean zinc levels within the normal range at baseline. Ginawi 2013 IND and Karyadi 2002 IDN reported that 30\% of the participants had low zinc levels (less than $10.7 \mu \mathrm{mol} / \mathrm{L}$ ) and in Lodha 2014 IND approximately 50\% of the participants had zinc levels greater than $65 \mu \mathrm{g} / \mathrm{dL}$.

Overall, daily supplementation with zinc sulphate increased serum zinc concentrations after two months and six months compared to placebo (four trials, 472 participants, Analysis 5.1; Table 3), with more consistent effects at six months.

\section{Tuberculosis treatment outcomes}

No effect on mortality has been seen with zinc alone or in combination with other micronutrients (seven trials, 2862 participants, Analysis 5.2, Analysis 5.3). These trials, even the larger ones, are significantly underpowered to rule out a clinically important effect.

There was no appreciable differences in treatment completion between the zinc alone and placebo groups (two trials, 353 participants, Analysis 5.4), and there were no differences between the groups in the numbers who remained sputum-culture positive at four weeks (three trials, 783 participants, Analysis 5.5) or eight weeks (five trials, 1076 participants, Analysis 5.5). Furthermore, Lodha 2014 IND reports no difference in chest X-ray clearance after six months between the zinc and placebo groups (one trial, 201 participants, Analysis 5.6).

\section{Nutritional recovery and quality of life}

One trial in children in India found no difference in mean weight $(\mathrm{kg})$, weight-for-age $\mathrm{z}$ score, BMI-for-age $\mathrm{z}$ score or height-for-age z score after two months or six months supplementation with zinc alone (one trial, 201 participants, Analysis 5.7; Analysis 5.10; Analysis 5.11; Analysis 5.12). Similarly, Pakasi 2010 IDN found no difference in BMI or body fat (\%) in adults at two or six months (one trial, 162 participants, Analysis 5.8 and Analysis 5.9; Pakasi 2010 IDN), and Lawson 2010 NGA presented data on changes in BMI graphically, and BMI appeared to improve at the same rate in all groups (Lawson 2010 NGA).

Range 2005 TZA reported a very small but statistically significant decrease in weight gain with supplementation compared to placebo (MD $-0.21 \mathrm{~kg}, 95 \% \mathrm{Cl}-0.36$ to -0.06 ; one trial 183 participants; Analysis 5.7).

Vitamin A plus zinc (DRI: vitamin A $900 \mu \mathrm{g} / 3000 \mathrm{IU}$, zinc $11 \mathrm{mg}$ per day)

\section{Supplement dosing regimes}

Seven studies in adults with sputum positive pulmonary tuberculosis compared the combination of vitamin A and zinc versus placebo (Ginawi 2013 IND: vitamin A $5000 \mathrm{IU}$ and $15 \mathrm{mg}$ zinc sulphate; Singh 2013 IND: 25000 IU vitamin A and $50 \mathrm{mg}$ zinc sulphate, once daily for 10 days and then thrice weekly until six months; Karyadi 2002 IDN: vitamin A 5000 IU and zinc 15 mg daily for six months; Armijos 2010 MEX: vitamin A 5000 IU plus zinc 50 mg daily for four months; Lawson 2010 NGA: vitamin A 5000 IU/day plus 90 mg elemental zinc/week for six months; Pakasi 2010 IDN: vitamin A 5000 IU plus 15 mg zinc sulphate daily for six months; Visser 2011 ZAF: vitamin A 100,000 IU at baseline plus zinc $15 \mathrm{mg}$ for five days per week for two months).

\section{Tuberculosis treatment outcomes}

Four trials reported on deaths that occurred during the trial. In HIV negative participants there were no statistically significant differences in risk of death between those who received zinc and vitamin A or placebo (four trials, 430 participants, Analysis 6.1), but in HIV-positive participants the effect did reach statistical significance (RR 5.94, 95\% Cl 1.07 to 32.96; two trials, 136 participants; Analysis 6.1). However, both of these analyses are substantially underpowered to have confidence in these effects.

Only Pakasi 2010 IDN reported on treatment completion and found no statistically significant difference between the groups (one trial, 152 participants; Analysis 6.2). Overall, there is no statistically significant difference between supplementation and placebo in the number of participants who remain sputum-smear positive at one month or two months (seven trials, 726 participants, 
Analysis 6.3). One study, Armijos 2010 MEX, did find a statistically significant difference in sputum positivity at three months in favour of supplementation (RR $0.12,95 \% \mathrm{Cl} 0.02$ to 0.84 ; one trial, 33 participants; Analysis 6.3), but the difference was not significant at two or four months. Visser 2011 ZAF found no statistically significant difference in time to smear or culture conversion (one trial, 154 participants; $\mathrm{P}=0.15$ and $\mathrm{P}=0.38$ respectively, authors' own figures).

\section{Nutritional recovery and quality of life}

Karyadi 2002 IDN reported a statistically significant increase in mean body weight at six months (MD $3.10 \mathrm{~kg}, 95 \% \mathrm{Cl} 0.74$ to 5.46; one trial, 80 participants; Analysis 6.4), but there were no differences in any other nutritional parameters (see Table 4 and Analysis 6.5; Analysis 6.6; Analysis 6.7; Analysis 6.8; Analysis 6.9; Analysis 6.10; Analysis 6.11; Analysis 6.12). There was no statistically significant differences between intervention and control arms in any of the other three trials that reported changes in BMI or weight.

Two trials reported on changes in Karnofsy score, a rating scale of a person's ability to perform activities of daily living ranging from 0 (dead) to 100 (normal). Karyadi 2002 IDN reported that supplementation resulted in a small but statistically significant difference in Karnofsky score at six months (MD 2.5\%, 95\% Cl 0.91 to 4.09; one trial 80 participants; Analysis 6.13), while Lawson 2010 NGA found no difference at two or six months but only presented data graphically (one trial, 233 participants). A difference in Karnofsky score of $2.5 \%$ is unlikely to be of clinical significance.

\section{Vitamin D (DRI for adults: 5 to $15 \mu \mathrm{g} / 200$ to 600 IU per day)}

\section{Supplement dosing regimes}

Eight trials evaluated vitamin D supplementation versus placebo: Morcos 1998 EGY: 1000 IU daily for eight weeks; Nursyam 2006 IDN: 250 ug daily for six weeks; Ralph 2013 IDN: 50,000 IU daily for eight weeks; Mily 2015 BGD: 5000 IU daily for eight weeks; Tukvadze 2015 GEO: 50000 IU three times a week for eight weeks, then every two weeks for eight weeks; Wejse 2008 GNB: 100,000 IU at 0, 5, and 8 months; Daley 2015 IND and Martineau 2011 GBR: 2.5 mg on days $0,14,28$, and 42 ).

In addition, one trial evaluated vitamin $\mathrm{D}$ combined with arginine (Ralph 2013 IDN: 50,000 IU plus arginine $6 \mathrm{~g}$ daily for eight weeks), two trials evaluated vitamin D combined with calcium (Singh 2013 IND: 250 IU plus calcium $500 \mathrm{mg}$ daily for 10 days then three times a week; Kota 2011 IND: 60,000 IU per week plus calcium $1000 \mathrm{mg}$ per day for 3 months), and four trials of multi-micronutrients included vitamin $\mathrm{D}$ in standard daily doses (see comparison 3 ).

\section{Vitamin D levels at baseline and follow-up (deficient $\leq 50 \mathrm{nmol} / \mathrm{L}$, and} insufficient $\leq 75 \mathrm{nmol} / \mathrm{L}$ )

Seven trials reported vitamin D status at baseline and during followup, although only four trials provided data that we could include in a meta-analysis of the effect of Vitamin $D$ supplementation on Vitamin D levels at follow-up (see Analysis 7.1; Table 5).

In four studies where the mean serum vitamin D levels were in the deficient range at baseline, there were large improvements at eight weeks with vitamin D compared to placebo (Martineau 2011 GBR: MD $78.60,95 \%$ Cl 54.17 to 103.03; Kota 2011 IND: MD 28.00, 95\% Cl 20.29 to 35.71; Mily 2015 BGD and Tukvadze 2015 GEO presented graphically, see Table 5). In two additional studies where the mean serum vitamin D levels were in the normal or insufficient range at baseline, there were no statistically significant differences at eight weeks (Wejse 2008 GNB: MD 2.00, 95\% Cl -7.76 to 11.76), or six months (Daley 2015 IND: MD $8.60,95 \% \mathrm{Cl}-6.29$ to 23.49 ).

\section{Tuberculosis treatment outcomes}

There were no statistically significant differences in the number of deaths between those receiving vitamin $\mathrm{D}$ (any formulation) or placebo regardless of HIV status (seven trials, 2649 participants, Analysis 7.2; Analysis 7.3).

Only Ralph 2013 IDN reported on cure, for which there was no statistically significant difference between the vitamin D and the placebo groups (one trial, 76 participants, Analysis 7.4). Wejse 2008 GNB also found no statistically significant difference in recovery, as defined by a newly developed tuberculosis scoring system (one trial, 348 participants, Analysis 7.5). This system rates the patient's condition on a scale of zero to 13 , based on signs and symptoms and anthropometric measurements (Wesje 2008).

Overall, there were no statistically significant differences in the proportion of people that remained sputum positive at any time point from four weeks to eight months (seven trials, 1197 participants, Analysis 7.6). One trial of daily supplementation, Nursyam 2006 IDN, showed a statistically significant difference in the proportion of participants who remained sputum positive at six weeks (RR $0.06,95 \% \mathrm{Cl} 0.00$ to 0.95 ; one trial, 67 participants, Analysis 7.6); but the difference was not significant two weeks later. One additional trial, Kota 2011 IND, also reported finding a statistically significant difference but only presented the $P$ value $(P$ $=0.067$ ).

\section{Nutritional recovery and quality of life}

There were no statistically significant differences in mean BMI after six to eight weeks of supplementation (four trials, 430 participants, Analysis 7.7), or in mean body weight (two trials, 150 participants, Analysis 7.8). Wejse 2008 GNB also reported no statistically significant difference in weight gain at eight months but only reported the $P$ value (one trial, 359 participants, $P=0.9$, authors' own figures), and Ralph 2013 IDN reported no statistically significant difference in the proportions gaining less than 5\%, 5\% to $9.9 \%$, or greater than $10 \%$ weight.

Daley 2015 IND reported that mean Karnofsky score increased in both groups, with no statistically significant difference at eight weeks (one trial, 212 participants, Analysis 7.9).

\section{Adverse events}

Five trials reported adverse events, which we have summarized in Table 6. There were no important differences in reported adverse events between the supplemented and the placebo groups.

\section{Vitamin E and selenium capsules (DRI: vitamin E $15 \mathrm{mg}$, selenium $55 \mu \mathrm{g}$ per day)}

One trial compared a daily vitamin E (140 mg) and selenium (200 $\mu \mathrm{g})$ supplement with placebo in adults being treated for sputum-smear positive pulmonary tuberculosis (Seyedrezazadeh 2006 IRN).

The trial authors reported the median plasma vitamin $\mathrm{E}$ and selenium levels at baseline and at eight weeks. They reported that the median level of both micronutrients rose in the supplement group and decreased in the placebo group. We were unable to 
assess whether these differences between groups were statistically significant (Appendix 8). In addition, one study that gave multimicronutrients, including vitamin $\mathrm{E}(133 \mathrm{mg})$ and selenium $(65 \mu \mathrm{g})$, measured the vitamin $E$ and selenium levels at baseline and during follow-up (Semba $2007 \mathrm{MWI}$ ). The trial authors reported that both vitamin E and selenium levels were "significantly higher" in the supplement group after eight months, but only presented the data graphically.

\section{Tuberculosis treatment outcomes}

No deaths were reported and this trial did not report cure or treatment completion.

There was no statistically significant difference between the supplement and placebo groups in the numbers of participants who were sputum-smear positive at $15,30,45$, and 60 days after the start of antituberculous treatment (one trial, 35 participants, Analysis 9.1).

\section{Nutritional recovery and quality of life}

The trial authors reported a 'constant increment' in BMI for the two months of treatment with no statistically significant differences between the groups, but did not present these data.

\section{Arginine (currently considered a conditionally essential amino acid,} depending on the developmental stage and health status of the individual)

Four trials compared daily supplementation with arginine $(1 \mathrm{mg}$ daily: Schön 2003 ETH and Schön 2011 ETH; 1000 mg twice daily for 30 days: Farazi 2015 IRN; and 6 mg daily for eight weeks: Ralph 2013 IDN) with either placebo (Schön 2003 ETH; Ralph 2013 IDN; Farazi 2015 IRN) or a biscuit that contained trace amounts of arginine (0.1 mg arginine, Schön 2011 ETH). The trials were all conducted in adults being treated for smear-positive pulmonary tuberculosis. Farazi 2015 IRN only included HIV-negative participants. The percentage of HIV-positive participants in the other three trials ranged from 13\% (Ralph 2013 IDN) to 52\% (Schön 2003 ETH).

\section{Tuberculosis treatment outcomes}

The included trials reported a total of 12 deaths. There was no significant difference in the risk of death between the arginine supplemented group and the placebo group (three trials, 394 participants, Analysis 8.1). There was also no significant difference in the proportion of participants who were cured (two trials, 279 participants, Analysis 8.2), or sputum smear or culture positive at four or eight weeks of follow-up (four trials, 464 participants, Analysis 8.3). Schön 2003 ETH reported a statistically significant increase in sputum-smear conversion in HIV-negative participants receiving arginine; however, our analysis of the data showed a non-significant difference between groups in the numbers of participants still sputum-smear positive at eight weeks (one trial, 56 participants, Analysis 8.3).

At two weeks Schön 2003 ETH reported that compared to the placebo group, fewer HIV-negative participants in the arginine group reported cough (RR $0.71,95 \% \mathrm{Cl} 0.53$ to 0.96 ; one trial, 56 participants, Analysis 8.4). Similarly, at eight weeks significantly fewer participants in the arginine group reported cough compared to those in the placebo group (RR $0.78,95 \% \mathrm{Cl} 0.61$ to 0.99; three trials, 348 participants, Analysis 8.4); this difference should be viewed with caution as only Farazi 2015 IRN provided baseline data that showed no difference in cough symptoms between groups.

\section{Nutritional recovery and quality of life}

In two studies there was no significant difference in weight gain (Schön 2003 ETH only presented the data graphically) or the proportion of participants with weight gain greater than $10 \%$ (Schön 2011 ETH; one trial, 170 participants, Analysis 8.5) between the arginine and placebo or low arginine groups. In a recent study, arginine supplementation significantly reduced the number of participants with a BMI of less than 18.5 after one $(P=0.032)$ and two $(P=0.04)$ months of antituberculous treatment compared to placebo (Farazi 2015 IRN).

\section{Other trials}

One small trial compared supplementation with $C$. striata capsules (6 g per day), for four months, with organoleptically-matched placebo on sputum and cytokine conversion in 36 HIV-negative participants with sputum smear positive pulmonary tuberculosis (Paliliewu 2013 IDN).

\section{Tuberculosis treatment outcomes}

This trial did not report on death, cure, or treatment completion. The rate of sputum smear conversion was greater in the supplemented group compared to placebo group. However, these differences were not statistically significant at any of the time points measured.

\section{Nutritional recovery and quality of life}

This outcome was not reported.

\section{DISCUSSION}

\section{Summary of main results}

\section{Macronutrient supplementation}

The included trials were too small to reliably prove or exclude clinically important benefits on mortality, cure, or treatment completion (very low quality evidence). One small trial from India did find a statistically significant benefit on treatment completion, and clearance of the bacteria from the sputum, but these findings have not been confirmed in larger trials elsewhere.

The provision of free food or high-energy nutritional products probably does produce a modest increase in weight gain during treatment for active tuberculosis, although this was not consistent across all included trials (moderate quality evidence). Two small studies provide some evidence that quality of life may also be improved but the trials were too small to have much confidence in the result (low quality evidence).

\section{Micronutrient supplementation}

Multi-micronutrients may have little or no effect on mortality in HIV-negative people with tuberculosis (low quality evidence), and probably have little or no effect on mortality in HIV-positive patients who are not taking anti-retroviral therapy (moderate quality evidence). There is insufficient evidence to know if multi-micronutrients improve cure, treatment completion, or the proportion of tuberculosis patients remaining sputum positive during the first eight weeks (very low quality evidence).

Multi-micronutrients may have little or no effect on weight gain during treatment (low quality evidence), although one of the three studies did find a substantial benefit in one study arm. No studies 
assessed the effect of multi-micronutrient supplementation on quality of life.

\section{Individual micronutrients}

Although low vitamin A levels are common in tuberculosis, plasma levels probably increase following initiation of tuberculosis treatment regardless of supplementation. There is no evidence that supplementation in doses up to three times the DRI has a beneficial effect on tuberculosis treatment outcomes, or nutritional recovery.

$B$ vitamins have been given in doses up to 10 times the DRI as part of multi-micronutrient supplementation. There is no evidence of an effect on mortality from tuberculosis. Due to the paucity of trials we cannot make any further conclusions about the effect of this vitamin on other tuberculosis outcomes.

Vitamin C has only been evaluated as part of multi-micronutrient supplements. Doses of vitamin C up to five times the DRI had no effect on tuberculosis mortality. Due to the paucity of trials we cannot make any further conclusions about the effect of this vitamin on other tuberculosis outcomes.

Vitamin D supplementation appears to improve plasma levels compared to placebo when participants are deficient at the start of supplementation, but may not have any clinically important effects on early sputum conversion.

Vitamin $E$ has only been assessed in combination with other vitamins or selenium. The dose used was up to 10 times the DRI. None of these trials show any significant benefit or harm with supplementation, but supplementation probably does improve blood levels of both vitamin $\mathrm{E}$ and selenium.

There is some evidence that plasma zinc levels increase during the first six months of supplementation, but no convincing evidence of other benefits.

\section{Overall completeness and applicability of evidence}

The included studies were generally too small and too limited to make broad conclusions on the presence or absence of clinically important benefits of nutritional supplementation on tuberculosis treatment outcomes.

Although the included studies are from low- and middle-income countries, they may not reflect the food-insecure settings where most supplementation programmes take place, and where the benefit may plausibly be greatest.

Where a supplement has so far not shown any benefit, this may also be an issue relating to the dose used as people recovering from tuberculosis may have micronutrient requirements which are higher than healthy people, however there is currently no evidence to support this.

In addition, it should be noted that most of the HIV-positive participants in these trials were not taking antiretroviral therapy.

\section{Quality of the evidence}

We assessed the quality of evidence using the GRADE methodology, and displayed the results in two 'Summary of findings' tables (Summary of findings for the main comparison; Summary of findings 2). 'Moderate' quality evidence implies we can have some confidence in the result, but further research evidence would still be helpful. 'Low' and 'very low' quality reflect decreasing levels of confidence in the result.

The quality of evidence was mainly downgraded under 'directness' and 'precision'. Directness is an assessment of how well the evidence matches the PICO question being asked (population, intervention, control, outcome). Because nutritional deficiencies are likely to differ widely among populations, it is difficult to generalize the results of one or two trials to other settings or subgroups. Precision involves an assessment of the statistical and clinical significance of the result, and also whether the sample size of the trials is adequate to reliably detect an effect. Most of these trials were small and well below the optimal information size for the outcomes that were being measured.

\section{Potential biases in the review process}

We minimized biases in the review process by performing a comprehensive search of the literature for relevant published, unpublished, and ongoing trials and by independently selecting and appraising the studies, and extracting the data in duplicate. Where data was missing, we sought additional information and data directly from the study authors where this was possible to do so. We did not conduct an extensive hand-search for grey literature. Therefore, the review is at risk of publication bias from less prominent trials. We attempted to reduce this risk by identifying relevant conference abstracts and registered ongoing trials. The search of the trials registry to identify trial protocols and ongoing trials yielded 16 potentially relevant trial protocols. These will require further assessment and exploration to either: 1 ) link them to trials already included in the review; or 2) if not included, to attempt to obtain the completed trial reports. This task is time-consuming and has to be balanced against feasibility and time constraints.

\section{Agreements and disagreements with other studies or reviews}

Nutritional supplementation in HIV-positive patients without tuberculosis has been assessed by two further Cochrane reviews (Irlam 2010; Grobler 2013).

Grobler 2013 found 14 small trials that compared macronutrient supplementation with no supplementation and concluded that although there was evidence that supplementation increased both energy and protein intake, there was no evidence of a clinical benefit on either nutritional- or HIV-related outcomes.

Irlam 2010 assessed 30 trials that compared micronutrients with placebo from both developed and developing countries. The authors concluded that multi-micronutrient supplements have significant benefits in HIV-positive pregnant women and children. In children there was also evidence of a reduction in mortality with vitamin $\mathrm{A}$, and a reduction in diarrhoeal morbidity with zinc.

\section{AUTHORS' CONCLUSIONS}

\section{Implications for practice}

There is insufficient research to know whether routinely providing free food or energy supplements results in better tuberculosis treatment outcomes, but limited evidence suggests it probably improves weight gain. 
Although blood levels of some vitamins may be low in patients starting treatment for active tuberculosis, there is currently no reliable evidence that routinely supplementing above recommended daily amounts has clinical benefits.

\section{Implications for research}

High quality studies of food provision to tuberculosis patients in food-insecure settings are urgently needed to support the continued expenditure on food support to tuberculosis programmes. In designing these studies, researchers, and programme managers need to be clear about the aim of food provision. Whilst an effect on mortality would provide strong advocacy for continued financial support, if the primary aim is to promote adherence, or to mitigate the catastrophic financial consequences of the illness, then these are the outcomes that should be measured, and appropriate comparison interventions should be selected. If the primary aim is to reduce mortality, then future trials must be large enough to reliably detect or exclude an effect.

The failure to demonstrate a beneficial effect with micronutrient supplementation does not imply that one does not exist. Further studies, perhaps using higher doses, would still be beneficial but should have adequate sample sizes to reliably detect or exclude clinically important benefits. It would also be useful if some standardization of outcome measurements could be made.

For nutritional recovery it seems important to assess changes in weight and lean body mass during the first two months of treatment rather than as a single measure at the end of treatment. It is also essential that measures of how this translates into improved quality of life and physical functioning are made, as weight gain on its own is of little interest.

\section{ACKNOWLEDGEMENTS}

We are grateful to Professor Jimmy Volmink and Katharine Abba, the authors of previous versions of this Cochrane review, who have now stepped down from the author team for this review update.

This document is an output from a project funded by the UK Department for International Development (DFID) (Grant: 5242) for the benefit of low- and middle-income countries. The views expressed are not necessarily those of DFID. Stellenbosch University, Stellenbosch, South Africa, and Christian Medical College, Vellore, India provided additional support for the review authors.

David Sinclair is supported by the Effective Health Care Research Consortium. This Consortium and the editorial base of the Cochrane Infectious Diseases Group is funded by UK aid from the UK Government for the benefit of developing countries (Grant: 5242). The views expressed in this publication do not necessarily reflect UK government policy.

The Contact Editor for this review update was Dr Mical Paul.

We thank the following authors of the included studies for providing us with vital additional (unpublished) information regarding their respective studies: Saurabh Mehta, Anna Ralph, Sushil Kabra, Kidola Jeremiah, and Peter Daley. 


\section{R E F E R E N C E S}

\section{References to studies included in this review}

Armijos 2010 MEX \{published data only\}

Armijos RX, Weigel MM, Chacon R, Flores L, Campos A. Adjunctive micronutrient supplementation for pulmonary tuberculosis. Salud Pública de México 2010;52(3):185-9.

\section{Daley 2015 IND \{published data only\}}

Daley P, Jagannathan V, John KR, Sarojini J, Latha A, Vieth R, et al. Adjunctive vitamin $D$ for treatment of active tuberculosis in India: a randomised, double-blind, placebo-controlled trial. The Lancet. Infectious Diseases 2015;15(5):528-34.

\section{Farazi 2015 IRN \{published data only\}}

Farazi A, Shafaat O, Sofian M, Kahbazi M. Arginine adjunctive therapy in active tuberculosis. Tuberculosis Research and Treatment 2015;2015:205016. [DOI: 10.1155/2015/205016]

\section{Ginawi 2013 IND \{published data only\}}

Ginawi IA, Ahmed MQ, Ahmad I, Al-Hazimi AM. Effect of zinc and vitamin a supplementation along with inter-tubercular treatment in pulmonary tuberculosis in north Indian patients. International Journal of Pharmaceutical Sciences and Research 2013;4(9):3426-31.

\section{Hanekom 1997 ZAF \{published data only\}}

Hanekom WA, Potgeiter S, Hughes EJ, Malan $\mathrm{H}$, Kessow G, Hussey GD. Vitamin A status and therapy in childhood pulmonary tuberculosis. Journal of Pediatrics 1997;131(6):925-7.

\section{Jahnavi 2010 IND \{published data only\}}

Jahnavi G, Sudha CH. Randomised controlled trial of food supplements in patients with newly diagnosed tuberculosis and wasting. Singapore Medical Journal 2010;51(12):957-62.

\section{Jeremiah 2014 TZA \{published data only\}}

Jeremiah K, Denti P, Chigutsa E, Faurholt-Jepsen D, PrayGod G, Range $\mathrm{N}$, et al. Nutritional supplementation increases rifampin exposure among tuberculosis patients co-infected with HIV. Antimicrobial Agents and Chemotherapy 2014;58(6):3468-74.

\section{Karyadi 2002 IDN \{published data only\}}

Karyadi E, West CE, Schultink W, Nelwan RH, Gross R, Amin Z, et al. A double-blind, placebo-controlled study of vitamin $A$ and zinc supplementation in persons with tuberculosis in Indonesia: effects on clinical response and nutritional status. American Journal of Clinical Nutrition 2002;75(4):720-7.

\section{Kota 2011 IND \{published data only\}}

Kota SK, Jammula S, Kota SK, Tripathy PR, Panda S, Modi KD. Effect of vitamin D supplementation in type 2 diabetes patients with pulmonary tuberculosis. Diabetes and Metabolic Syndrome: Clinical Research \& Reviews 2011;5(2):85-9.

\section{Lawson 2010 NGA \{published data only\}}

Lawson L, Thacher TD, Yassin MA, Onuoha NA, Usman A, Emenyonu NE, et al. Randomized controlled trial of zinc and vitamin $\mathrm{A}$ as co-adjuvants for the treatment of pulmonary tuberculosis. Tropical Medicine and International Health 2010;15(12):1481-90.

\section{Lodha 2014 IND \{published data only\}}

Lodha R, Mukherjee A, Singh V, Singh S, Friis H, FaurholtJepsen $\mathrm{D}$, et al. Effect of micronutrient supplementation on treatment outcomes in children with intrathoracic tuberculosis: a randomized controlled trial. American Journal of Clinical Nutrition 2014;100(5):1287-97.

\section{Martineau 2011 GBR \{published data only\}}

Martineau AR, Timms PM, Bothamley GH, Hanifa Y, Islam K, Claxton AP, et al. High-dose vitamin $\mathrm{D}_{3}$ during intensivephase antimicrobial treatment for pulmonary tuberculosis: a double-blind randomised controlled trial. Lancet 2011;377(9761):242-50.

\section{Martins 2009 TLS \{published data only\}}

Martins N, Morris P, Kelly PM. Food incentives to improve completion of tuberculosis treatment: randomised controlled trial in Dili, Timor-Leste. BMJ 2009;229:b4248.

Mehta 2011 TZA \{published and unpublished data\}

* Mehta S, Mugusi FM, Bosch RJ, Aboud S, Chatterjee A, Finkelstein $\mathrm{JL}$, et al. A randomized trial of multivitamin supplementation in children with tuberculosis in Tanzania. Nutrition Journal 2011;10:120.

NCT00145184. Effect of Multivitamin Supplements on Clinical and Immunological Response in Childhood Tuberculosis. https://clinicaltrials.gov/ct2/show/NCT00145184 (accessed 4 February 2016).

\section{Mily 2015 BGD \{published data only\}}

* Mily A, Rekha RS, Kamal SM, Arifuzzaman AS, Rahim Z, Khan L, et al. Significant effects of oral phenylbutyrate and vitamin D3 adjunctive therapy in pulmonary tuberculosis: a randomized controlled trial. PLoS One 2015;10(9):e0138340. [DOI: 10.1371/ journal.pone.0138340]

\section{Morcos 1998 EGY \{published data only\}}

Morcos MM, Gabr AA, Samual S, Kamel M, el Baz M, el Beshry M, et al. Vitamin $D$ administration to tuberculous children and its value. Bollettino Chimico Farmaceutico 1998;137(5):157-64.

\section{Nursyam 2006 IDN \{published data only\}}

Nursyam EW, Amin Z, Rumende CA. The effects of vitamin $D$ as supplementary treatment in patients with moderately advanced pulmonary tuberculosis lesion. Acta Medica Indonesiana 2006;38(1):3-5.

\section{Pakasi 2010 IDN $\{$ published data only\}}

Pakasi TA, Karyadi E, Suratih NMD, Salean M, Darmawidjaja N, Bor $\mathrm{H}$, et al. Zinc and vitamin A supplementation fails to reduce sputum conversion time in severely malnourished pulmonary tuberculosis patients in Indonesia. Nutrition Journal 2010;9:41. 
Paliliewu 2013 IDN \{published data only\}

Paliliewu N, Datau EA, Matheos JC, Surachmanto EE. Channa striatus capsules induces cytokine conversion in pulmonary tuberculosis patients. Journal of Experimental and Integrative Medicine 2013;3(3):237-42.

\section{Paton 2004 SGP $\{$ published data only\}}

Paton NI, Chua YK, Earnest A, Chee CB. Randomized controlled trial of nutritional supplementation in patients with newly diagnosed tuberculosis and wasting. American Journal of Clinical Nutrition 2004;80(2):460-5.

\section{Pérez-Guzmán 2005 MEX \{published data only\}}

Pérez-Guzmán C, Vargas MH, Quiñonez F, Bazavilvazo N, Aguilar A. A cholesterol-rich diet accelerates bacteriologic sterilization in pulmonary tuberculosis. Chest 2005;127(2):643-51.

\section{Praygod 2011a TZA \{published data only\}}

Praygod G, Range N, Faurholt-Jepsen D, Jeremiah K, FaurholtJepsen M, Aabye MG, et al. Daily multi-micronutrient supplementation during tuberculosis treatment increases weight and grip strength among HIV-uninfected but not HIVinfected patients in Mwanza, Tanzania. The Journal of Nutrition 2011;141(4):685-91

\section{Praygod 2011b TZA \{published data only\}}

* Praygod G, Range N, Faurholt-Jepsen D, Jeremiah K, Faurholt-Jepsen M, Aabye MG, et al. Daily multi-micronutrient supplementation during tuberculosis treatment increases weight and grip strength among HIV-uninfected but not HIVinfected patients in Mwanza, Tanzania. The Journal of Nutrition 2011;141:685-91.

Praygod G, Range N, Faurholt-Jepsen D, Jeremiah K, FaurholtJepsen M, Aabye MG, et al. The effect of energy-protein supplementation on weight, body composition and handgrip strength among pulmonary tuberculosis HIV-co-infected patients: randomised controlled trial in Mwanza, Tanzania. The British Journal of Nutrition 2012;107(2):263-71.

\section{Ralph 2013 IDN \{published data only\}}

Ralph AP, Waramori G, Pontororing GJ, Kenangalem E, Wiguna A, Tjitra E, et al. L-arginine and vitamin D adjunctive therapies in pulmonary tuberculosis: a randomised, doubleblind, placebo-controlled trial. PLoS One 2013;8(8):e70032.

\section{Range 2005 TZA \{published data only\}}

* Range N, Andersen AB, Magnussen P, Mugomela A, Friis H. The effect of micronutrient supplementation on treatment outcome in patients with pulmonary tuberculosis: a randomised controlled trial in Mwanza, Tanzania. Tropical Medicine and International Health 2005;10(9):826-32.

Range N, Changalucha J, Krarup H, Magnussen P, Andersen AB, Friis $\mathrm{H}$. The effect of multi-vitamin/mineral supplementation on mortality during treatment of pulmonary tuberculosis: a randomised two-by-two factorial trial in Mwanza, Tanzania. British Journal of Nutrition 2006;95(4):762-70.

\section{Schön 2003 ETH \{published data only\}}

Schön T, Elias D, Moges F, Melese E, Tessema T, Stendahl O, et al. Arginine as an adjuvant to chemotherapy improves clinical outcomes in active tuberculosis. European Respiratory Journal 2003;21(3):483-8.

\section{Schön 2011 ETH \{published data only\}}

Schön T, Idh J, Westman A, Elias D, Abate E, Diro E, et al. Effects of a food supplement rich in arginine in patients with smear positive pulmonary tuberculosis - a randomised trial. Tuberculosis 2011;91(5):370-7.

\section{Semba 2007 MWI \{published data only\}}

Semba RD, Kumwenda J, Zijlstra E, Ricks MO, van Lettow M, Whalen $\mathrm{C}$, et al. Micronutrient supplements and mortality of HIV-infected adults with pulmonary TB: a controlled clinical trial. International Journal of Tuberculosis and Lung Disease 2007;11(8):854-9.

\section{Seyedrezazadeh 2006 IRN \{published data only\}}

Seyedrezazadeh E, Ostadrahimi A, Mahboob S, Asadi Y, Ghaemmagami J, Pourmogaddam M. Effect of vitamin E and selenium supplementation on oxidative stress status in pulmonary tuberculosis patients. Respirology 2008;13(2):294-8.

* Seyedrezazadeh E, Ostradrahimi AR, Mahboob SA, Assadi Y, Ansarin K, Sakoori P, et al. Vitamin E-selenium supplement and clinical responses of active pulmonary tuberculosis. Tanaffos 2006;5(2):49-55.

\section{Singh 2013 IND \{published data only\}}

Singh AKr, Gogoi JB, Pant NC, Mittal P, Juyal V, Mukherjee S. A study on the role of vitamins and minerals supplementation in the treatment of tuberculosis. Indian Journal of Public Health Research and Development 2013;4(2):26-30.

\section{Sudarsanam 2010 IND \{published data only\}}

Sudarsanam TD, John J, Kang G, Mahendri V, Gerrior J, Franciosa $\mathrm{M}$, et al. Pilot randomized trial of nutritional supplementation in patients with tuberculosis and HIVtuberculosis coinfection receiving directly observed shortcourse chemotherapy for tuberculosis. Tropical Medicine and International Health 2011;16(6):699-706.

\section{Tukvadze 2015 GEO \{published data only\}}

Frediani J, Tukvadze N, Sanikidze E, Kipiani M, Hebbar G, Tangpricha V, et al. Drug susceptibility influences macronutrient intake and body composition in tuberculosis patients. The FASEB Journal 2014;28(Supplement 1):1014.4.

* Tukvadze N, Sanikidze E, Kipiani M, Hebbar G, Easley KA, Shenvi N, et al. High-dose vitamin D3 in adults with pulmonary tuberculosis: a double-blind randomised controlled trial. American Journal of Clinical Nutrition 2015;102(5):1059-69.

\section{Villamor 2008 TZA \{published and unpublished data}

Villamor E, Mugusi F, Urassa W, Bosch R J, Saathoff E, Matsumoto K, et al. A trial of the effect of micronutrient supplementation on treatment outcome, $T$ cell counts, morbidity, and mortality in adults with pulmonary tuberculosis. The Journal of Infectious Diseases 2008;197(11):1499-505. 
Visser 2011 ZAF \{published data only\}

Visser ME, Grewal HMS, Swart EC, Dhansay MA, Walzl G, Swanevelder S, et al. The effect of vitamin A and zinc supplementation on treatment outcomes in pulmonary tuberculosis: a randomized controlled trial. American Journal of Clinical Nutrition 2011;93(1):93-100.

Wejse 2008 GNB \{published and unpublished data\}

Wejse C, Gomes VF, Rabna P, Gustafson P, Aaby P, Lisse IM, et al. Vitamin $D$ as supplementary treatment for tuberculosis - a double-blind randomised placebo-controlled trial. American Journal of Respiratory and Critical Care Medicine 2009;179(9):843-50.

\section{References to studies excluded from this review}

Denti 2015 \{published data only\}

Denti P, Jeremiah K, Chigutsa E, Faurholt-Jepsen D, PrayGod G, Range $\mathrm{N}$, et al. Pharmacokinetics of isoniazid, pyrazinamide, and ethambutol in newly diagnosed pulmonary TB patients in Tanzania. PLoS One 2015;10(10):e0141002.

\section{Dibari 2013 \{published data only\}}

Dibari F, Bahwere P, Huerga H, Irena A H, Owino V, Collins S, et al. Development of a cross-over randomized trial method to determine the acceptability and safety of novel ready-to-use therapeutic foods. Nutrition 2013;29(1):107-12.

\section{Gwinup 1981 \{published data only\}}

Gwinup G, Randazzo G, Elias A. The influence of vitamin $D$ on serum calcium in tuberculosis. Acta Endocrinologica 1981;97(1):114-7.

\section{Hasan 2015 \{published data only\}}

Hasan H, Rini YP. The effect of propolis on the level of interleukin-10 in multidrug resistance tuberculosis patient. Respirology 2015; Vol. 20, issue Suppl. 3:1-160 (Abstract ID 869).

\section{Kawai 2014 \{published data only\}}

Kawai K, Meydani SN, Urassa W, Wu D, Mugusi FM, Saathoff E, et al. Micronutrient supplementation and T cell-mediated immune responses in patients with tuberculosis in Tanzania. Epidemiology and Infection 2014;142(7):1505-9.

\section{Khandelwal 2014 \{published data only\}}

Khandelwal D, Gupta N, Mukherjee A, Lodha R, Singh V, Grewal HM, et al. Vitamin D levels in Indian children with intrathoracic tuberculosis. Indian Journal of Medical Research 2014;140(4):531-7.

\section{Lin 2014 \{published data only\}}

Lin HC, Yu MC, Liu HJ, Bai KJ. Impact of food intake on the pharmacokinetics of first-line antituberculosis drugs in Taiwanese tuberculosis patients. Journal of the Formosan Medical Association 2014;113(5):291-7.

Lutge 2013 \{published data only\}

Lutge E, Lewin S, Volmink J, Friedman I, Lombard C. Economic support to improve tuberculosis treatment outcomes in South
Africa: a pragmatic cluster-randomized controlled trial. Trials 2013;14:154.

\section{Martineau 2009 \{published data only\}}

Martineau AR, Nanzer AM, Satkunam KR, Packe GE, Rainbow SJ, Maunsell ZJ, et al. Influence of a single oral dose of vitamin D(2) on serum 25-hydroxyvitamin D concentrations in tuberculosis patients. The International Journal of Tuberculosis and Lung Disease 2009;13(1):119-25.

Mbala 1998 \{published data only\}

Mbala L, Matendo R, Nkailo R. Is vitamin B6 supplementation of isoniazid therapy useful in childhood tuberculosis. Tropical Doctor 1998;28(2):103-4.

Narang 1984 \{published data only\}

Narang NK, Gupta RC, Jain MK. Role of vitamin D in pulmonary tuberculosis. Journal of the Association of Physicians of India 1984;32(2):185-8.

\section{Oluboyede 1978 \{published data only\}}

Oluboyede OA, Onadeko BO. Observation on haematological patterns in pulmonary tuberculosis in Nigerians. Journal of Tropical Medicine and Hygiene 1978;81(5):91-5.

\section{Permatasari 2014 \{published data only\}}

Permatasari A, Hasan $\mathrm{H}$. The effect of ethanol extract propolis (EEP) on the level of IFN-F and superoxide dismutase (SOD) activities in patients with MDR tuberculosis. Respirology 2014; Vol. 19, issue Suppl. 3:1-62 (Abstract 0-Q-012).

\section{Ramakrishnan 1961 \{published data only\}}

Ramakrishnan CV, Rajendran K, Jacob PG, Fox W, Radhakrishnan $\mathrm{S}$. The role of diet in the treatment of pulmonary tuberculosis. An evaluation in a controlled chemotherapy study in home and sanatorium patients in South India. Bulletin of the World Health Organization 1961;25:339-59.

\section{Samsidi 2013 \{published data only\}}

Samsidi S, Ridwan H, Kusharto C M, Sulaeman A, Alisjahbana B. Efficacious of synbiotic and nutrients supplement on stimulated of secretory immunoglobulin a (SIGA) in treated pulmonary tuberculosis patients. Annals of Nutrition and Metabolism 2013;20th International Congress of Nutrition; Sept 15-20 2013; Granada, Spain:407.

Shi 2001 \{published data only\}

Shi XY, Xiao JQ, Yi JY, Zhu YQ, Deng CS. Influence of partial parenteral nutrition with fat emulsion on nutritional status in patients with abdominal tuberculosis. Journal of Clinical Internal Medicine 2001;18(2):120-1.

\section{Srivastava 2011 \{published data only\}}

Srivastava GN, Chaudhry S, Kumar H, Singh SK. Vitamin$D$ supplementation in patients with new smear positive pulmonary tuberculosis (PTB) with reference to sputum conversion [Abstract]. European Respiratory Journal 2011;38(Supplement 55):2588. 


\section{References to studies awaiting assessment}

Al Mamun 2014 \{published data only\}

Al Mamun SMA. Effects and rationale of micronutrients supplementation in the treatment of smear positive pulmonary tuberculosis patients. Chest Journal 2014; Vol. 145, issue 3 Meeting Abstracts.

\section{Chandra 2004 \{published data only\}}

Chandra RK. Nutrient supplementation as adjunct therapy in pulmonary tuberculosis. International Journal for Vitamin and Nutritional Research 2004;74(2):144-6.

\section{Guzman-Rivero 2013 \{published data only\}}

Guzman-Rivero M, Sejas E, Medina M, Verduguez-Orellana A, Akesson B. Changes in clinical status, nutritional and biochemical biomarkers in pulmonary tuberculosis patients receiving zinc supplementation in addition to conventional treatment (Abstract). Annals of Nutrition and Metabolism 2013;63(Supplement 1):1104.

\section{Nagrale 2013 \{published data only\}}

Nagrale D, Mahakalkar S, Gaur S. Supplementation of Nacetylcysteine as an adjuvant in treatment of newly diagnosed pulmonary tuberculosis patients: A prospective, randomized double blind, placebo controlled study (Abstract). European Respiratory Journal 2013;42(Suppl 57):P2833.

\section{Nawas 2013 \{published data only\}}

Nawas MA, Burhan E, Soepandi P, Isbaniah F, Agustin H. Double blind randomized placebo-controlled trial in tuberculosis patients with tuberculosis treatment supplemented with morrinda-zinger extract: The speed of sputum conversion (Abstract). Respirology 2013;18(Supplement 4):9.

\section{References to ongoing studies}

\section{ChiCTR-IPR-15006395 \{unpublished data only\}}

ChiCTR-IPR-15006395. The influence and mechanism of vitamin D3 supplementation on the treatment outcomes of tuberculosis patients of different glucose tolerance. http:// www.chictr.org.cn/showproj.aspx?proj=10964 (accessed 4 February 2016).

\section{ChiCTR-TRC-12002546 \{published and unpublished data\}}

Wang Q, Ma A, Bygbjerg IC, Han X, Liu Y, Zhao S, et al. Rationale and design of a randomized controlled trial of the effect of retinol and vitamin D supplementation on treatment in active pulmonary tuberculosis patients with diabetes. BMC Infectious Diseases 2013;13:104. [DOI: 10.1186/1471-2334-13-104]

\section{ChicTR-TRC-14005241 \{unpublished data only\}}

ChiCTR-TRC-14005241. A prospective study of oral nutritional supplement in perioperative application with pulmonary tuberculosis patients. http://apps.who.int/trialsearch/ Trial2.aspx?trialid=ChiCTR-TRC-14005241 (accessed 28 August 2015).

\section{IRCT201112178429N1 \{unpublished data only\}}

IRCT201112178429N1. Effect of zinc supplementation in improving pulmonary tuberculosis patients in Qom. http://www.irct.ir/searchresult.php? keyword=\&id=8429\&number=1\&prt=2840\&total=10\&m=1 (accessed 28 August 2015).

\section{IRCT201211179855N2 \{unpublished data only\}}

IRCT201211179855N2. Randomized, double-blind, placebocontrolled trial of L-Arginine supplementation for the treatment of pulmonary tuberculosis. http://www.irct.ir/searchresult.php? id=9855\&number $=2$ (accessed 28 August 2015)

ISRCTN16469166 \{unpublished data only\}

ISRCTN16469166. Nutrition and wasting in tuberculosis (TB): Can nutritional supplementation in TB patients improve body weight gain, body composition and treatment outcome? www.controlled-trials.com/ISRCTN16469166/ISRCTN16469166 (accessed 10 October 2007).

\section{NCT00507000 \{unpublished data only\}}

NCT00507000. Role of oral vitamin D as an adjunct therapy in category I pulmonary tuberculosis along with assessment of immunological parameters. clinicaltrials.gov/ct2/show/ NCT00507000 (accessed 10 October 2007).

NCT00698386 \{unpublished data only\}

NCT00698386. Efficacy of oral zinc administration as an adjunct therapy in new pulmonary tuberculosis (Category I) patients. https://clinicaltrials.gov/ct2/show/NCT00698386 (accessed 21 July 2011).

\section{NCT00788320 \{unpublished data only\}}

NCT00788320. Antimicrobial peptide LL-37 (cathelicidin) production in active tuberculosis disease: role of vitamin D supplementation. https://clinicaltrials.gov/ct2/show/ NCT00788320 (accessed 21 July 2011).

NCT01635153 \{published data only\}

NCT01635153. Effects of a protein calorie supplement in HIV-infected women with tuberculosis (DarDar). https:// clinicaltrials.gov/ct2/show/NCT01635153 (accessed 31 August 2015).

\section{NCT01657656 \{published data only\}}

NCT01657656. Vitamin D supplementations as adjunct to antituberculosis drugs in Mongolia. https://clinicaltrials.gov/ct2/ show/record/NCT01657656 (accessed 31 August 2015).

\section{NCT01722396 \{published data only\}}

NCT01722396. Pharmacogenetics of vitamin D supplementation in tuberculosis. https://clinicaltrials.gov/ct2/show/ NCT01722396 (accessed 31 August 2015).

NCT01992263 \{unpublished data only\}

NCT01992263. A trial of vitamin D supplementation among tuberculosis patients in South India. https://clinicaltrials.gov/ ct2/show/NCT01992263 (accessed 31 August 2015).

NCT02169570 \{unpublished data only\}

NCT02169570. Effect of supplementary vitamin D in patients with diabetes mellitus and pulmonary tuberculosis (EVIDENT). https://clinicaltrials.gov/ct2/show/NCT02169570 (accessed 31 August 2015). 
NCT02464683 \{unpublished data only\}

NCT02464683. Effect of vitamin D as adjunctive therapy in patients with pulmonary evolution tuberculosis (Vitamin D). https://clinicaltrials.gov/ct2/show/NCT02464683 (accessed 4 February 2016).

\section{NCT02554318 \{unpublished data only\}}

NCT02554318. The effect of fermented soybean supplementation on the body weight and physical function of tuberculosis patients with standard therapy in Indonesia. https://clinicaltrials.gov/show/NCT02554318 (accessed 4 February 2016).

\section{Additional references}

Aaron 2004

Aaron L, Saadoun D, Calatroni I, Launay O, Mémain N, Vincent V, et al. Tuberculosis in HIV-infected patients: a comprehensive review. Clinical Microbiology and Infection 2004;10(5):388-98.

\section{Arthur 2003}

Arthur JR, McKenziey RC, Beckett GJ. Selenium in the Immune System. The Journal of Nutrition 2003;133(5 Suppl 1):1457S-9S.

\section{Barry 2009}

Barry CE 3rd, Boshoff HI, Dartois V, Dick T, Ehrt S, Flynn J, et al. The spectrum of latent tuberculosis: rethinking the biology and intervention strategies. Nature Reviews. Microbiology 2009;7(12):845-55.

\section{Cegielski 2004}

Cegielski JP, McMurray DN. The relationship between malnutrition and tuberculosis, evidence from studies in humans and experimental animals. International Journal of Tuberculosis and Lung Disease 2004;8(3):286-98.

\section{Chandra 1996}

Chandra RK. Nutrition, immunity and infection: from basic knowledge of dietary manipulation of immune responses to practical application of ameliorating suffering and improving survival. Proceedings of the National Academy of Sciences of the United States of America 1996;93(25):14304-7.

\section{Corbett 2003}

Corbett EL, Watt CJ, Walker N, Maher D, Williams BG, Raviglione MC, et al. The growing burden of tuberculosis: global trends and interactions with the HIV epidemic. Archives of Internal Medicine 2003;163(9):1009-21.

\section{Davies 1985}

Davies PD, Brown RC, Woodhead JS. Serum concentrations of vitamin D metabolites in untreated tuberculosis. Thorax 1985;40(3):187-90.

\section{Grobler 2013}

Grobler L, Siegfried N, Visser ME, Mahlungulu SS, Volmink J. Nutritional interventions for reducing morbidity and mortality in people with HIV. Cochrane Database of Systematic Reviews 2013, Issue 2. [DOI: 10.1002/14651858.CD004536.pub3]

\section{Harries 2006}

Harries AD, Dye C. Tuberculosis. Annals of Tropical Medicine and Parasitology 2006;100(5-6):415-31.

\section{Irlam 2010}

Irlam JH, Visser MME, Rollins NN, Siegfried N. Micronutrient supplementation in children and adults with HIV infection. Cochrane Database of Systematic Reviews 2010, Issue 12. [DOI: 10.1002/14651858.CD003650.pub3]

\section{Kamolratanakul 1999}

Kamolratanakul P, Sawert H, Kongsin S, Lertmaharit S, Sriwongsa J, Na-Songkhla S, et al. Economic impact of tuberculosis at the household level. International Journal of Tuberculosis and Lung Disease 1999;3(7):596-602.

\section{Lefebvre 2011}

Carol Lefebvre, Eric Manheimer, Julie Glanville, on behalf of the Cochrane Information Retrieval Methods Group. Chapter 6: Searching for studies. In: Higgins J, Green S (editors). Cochrane Handbook for Systematic Reviews of Interventions Version 5.1.0 [updated March 2011]. The Cochrane Collaboration, 2011. http://handbook.cochrane.org/chapter_6/6_4_11_1_the_ cochrane_highly_sensitive_search_strategies_for.htm.

\section{Lounis 2001}

Lounis N, Truffot-Pernot C, Grosset J, Gordeuk VR, Boelaert JR. Iron and Mycobacterium tuberculosis infection. Journal of Clinical Virology 2001;20(3):123-6.

\section{Louw 1992}

Louw JA, Werbeck A, Louw MEJ, Kotze TJvW, Cooper R, Labadarios D. Blood vitamin concentrations during the acute phase response. Critical Care Medicine 1992;20(7):934-41.

\section{Lutge 2009}

Lutge EE, Knight SE, Volmink J. Incentives for improving patient adherence to anti-tuberculosis treatment. Cochrane Database of Systematic Reviews 2009, Issue 3. [DOI: 10.1002/14651858.CD007952]

\section{Macallan 1999}

Macallan DC. Malnutrition in tuberculosis. Diagnostic Microbiology and Infectious Disease 1999;34(2):153-7.

\section{Meyers 2006}

National Academy of Sciences. Dietary Reference Intakes: The Essential Guide to Nutrient Requirements. 6th Edition. Washington DC: National Academies Press, 2006.

\section{nMaster 1.0 [Computer program]}

Department of Biostatistics, Christian Medical College. nMaster 1.0. Version 1.0. Vellore: Department of Biostatistics, Christian Medical College, (accessed 9 May 2016).

\section{Nnoaham 2008}

Nnoaham KE, Clarke A. Low serum vitamin D levels and tuberculosis: a systematic review and meta-analysis. International Journal of Epidemiology 2008;37(1):113-9. 


\section{Plit 1998}

Plit MI, Theron AJ, Fickl H, van Rensburg CE, Pendel S, Anderson R. Influence of antimicrobial chemotherapy and smoking status on plasma concentrations of vitamin C, vitamin E, beta-carotene, acute phase reactants, iron and lipid peroxides in patients with pulmonary tuberculosis. International Journal of Tuberculosis and Lung Disease 1998;2(7):590-9.

\section{RevMan 2014 [Computer program]}

The Nordic Cochrane Centre, The Cochrane Collaboration. Review Manager (RevMan). Version 5.3. Copenhagen: The Nordic Cochrane Centre, The Cochrane Collaboration, 2014.

\section{Saunders 2007}

Saunders BM, Britton WJ. Life and death in the granuloma: immunopathology of tuberculosis. Immunology and Cell Biology 2007;85(2):103-11.

\section{Schluger 1998}

Schluger NW, Rom WN. The host immune response to tuberculosis. American Journal of Respiratory Critical Care Medicine 1998;157(3 Pt 1):679-91.

\section{Semba 1998}

Semba RD. The role of vitamin A and related retinoids in immune function. Nutrition Reviews 1998;56(1 Pt 2):S38-48.

\section{Shankar 1998}

Shankar AH, Prasad AS. Zinc and immune function: the biological basis of altered resistance to infection. American Journal of Clinical Nutrition 1998;68(2 Suppl):447S-63S.

\section{Stephensen 2001}

Stephensen CB. Vitamin A, infection, and immune function. Annual Review of Nutrition 2001;21:167-92.

\section{Taneja 1990}

Taneja DP. Observations of serum zinc in patients with pulmonary tuberculosis. Journal of the Indian Medical Association 1990;88(10):280-1.

\section{van Lettow 2003}

van Lettow M, Fawzi WW, Semba RD. Triple trouble: the role of malnutrition in tuberculosis and human immunodeficiency virus coinfection. Nutrition Reviews 2003;61(3):81-90.

\section{Wesje 2008}

Wesje C, Gustafson P, Nielson J, Gomes VF, Aaby P, Anderson PL, et al. TB score: Signs and symptoms from tuberculosis patients in a low-resource setting have predictive value and may be used to assess clinical course. Scandinavian Journal of Infectious Diseases 2008;40(2):111-20.

\section{WFP 2007}

Ba M, Strauss A. Getting started: WFP food assistance in the context of tuberculosis care and treatment. World Food Programme, 2007.

\section{WHO 2009}

World Health Organization. Global Tuberculosis Control. A short update to the 2009 report. Geneva: World Health Organization, 2009.

\section{WHO 2010}

World Health Organization. Treatment of Tuberculosis Guidelines. 4th Edition. Geneva: World Health Organization, 2010.

\section{WHO 2014}

World Health Organization. Global Tuberculosis Report 2014. Geneva: World Health Organization, 2014.

\section{Wintergerst 2007}

Wintergerst ES, Maggini S, Hornig DH. Contribution of Selected Vitamins andTrace Elements to Immune Function. Annals of Nutrition \& Metabolism 2007;51(4):301-23.

\section{Wyss 2001}

Wyss K, Kilima P, Lorenz N. Costs of tuberculosis for households and health care providers in Dar es Salaam, Tanzania. Tropical Medicine \& International Health 2001;6(1):60-8.

\section{Zachariah 2002}

Zachariah R, Spielmann MP, Harries AD, Salaniponi FM. Moderate to severe malnutrition in patients with tuberculosis is a risk factor associated with early death. Transactions of the Royal Society of Tropical Medicine and Hygiene 2002;96(3):291-4.

\section{Zumla 2000}

Zumla A, Malon P, Henderson J, Grange JM. Impact of HIV infection on tuberculosis. Postgraduate Medical Journal 2000;76(895):259-68.

\section{References to other published versions of this review \\ Abba 2006}

Abba K, Sudarsanam TD, Grobler L, Volmink JA. Nutritional supplements for people being treated for active tuberculosis. Cochrane Database of Systematic Reviews 2006, Issue 3. [DOI: 10.1002/14651858.CD006086]

\section{Abba 2008}

Abba K, Sudarsanam TD, Grobler L, Volmink J. Nutritional supplements for people being treated for active tuberculosis. Cochrane Database of Systematic Reviews 2008, Issue 4. [DOI: 10.1002/14651858.CD006086.pub2]

\section{Sinclair 2011}

Sinclair D, Abba K, Grobler L, Sudarsanam TD. Nutritional supplements for people being treated for active tuberculosis. Cochrane Database of Systematic Reviews 2011, Issue 11. [DOI: 10.1002/14651858.CD006086.pub3]

* Indicates the major publication for the study 
CHARACTERISTICS OF STUDIES

Characteristics of included studies [ordered by study ID]

Armijos 2010 MEX

Methods
Study design: randomized controlled trial (RCT).
Study dates and duration: recruited August 2005 to July 2006, follow-up 6 months.
Standard care: all participants received directly observed antituberculous therapy, per Instituto Mex-
icano del Seguro Social (IMSS) guidelines: 2 months of isoniazid/rifampin/pyrazinamide/ethambutol
followed by 4 months of isoniazid and rifampin.

Number: 39 enrolled; 33 analysed.
Inclusion criteria: adults aged 18 to 65 years, smear positive pulmonary tuberculosis, informed consent.
Exclusion criteria: pregnancy, breast feeding, used corticosteroids, human immunodeficiency virus
(HIV), diabetes, or another serious co-morbidity.
Baseline characteristics
-
Nutritional status: $\mathrm{mean}$ body mass index (BMI) (standard deviation (SD)): $20.4 \mathrm{~kg} / \mathrm{m}^{2}$ (5.0) treatment
- HIV status: all negative.
- Multidrug-resistant/extensively drug-resistant tuberculosis (MDR/XDR-TB): not described.
- Vitamin A status $\mu \mathrm{gg} / \mathrm{dL}(\mathrm{SD}): 29.4$ (13.3) supplement group versus 29.8 (13.8) placebo group; normal
- Zange.

Interventions

Group 1: vitamin A $5000 \mathrm{IU} /$ day (as retinyl acetate) plus zinc $50 \mathrm{mg} /$ day (as zinc chelate) for 4 months.

Group 2: placebo with identical appearance.

\begin{tabular}{ll}
\hline Outcomes & Deaths during study. \\
- Percentage remaining smear positive at $1,2,3,4$, and 5 months. \\
- Mean zinc, retinol, and albumin levels at 0,2 , and 6 months. \\
Not included in review: mean monthly intake of zinc and vitamin A, measures of immune response at 0, \\
2, and 6 months. \\
\hline Location: Ciudad Juárez, México. \\
Setting: IMSS outpatient services. \\
Funding: Center for Border Health Research, UTEP-UTSPH Hispanic Health Disparities Research Center.
\end{tabular}

\section{Risk of bias}

\begin{tabular}{lll}
\hline Bias & Authors' judgement & Support for judgement \\
\hline $\begin{array}{l}\text { Random sequence genera- } \\
\text { tion (selection bias) }\end{array}$ & Unclear risk & The trial authors described it as "randomised", but gave no further details. \\
\hline $\begin{array}{l}\text { Allocation concealment } \\
\text { (selection bias) }\end{array}$ & Unclear risk & $\begin{array}{l}\text { "A co-investigator not involved in data collection or analysis maintained the } \\
\text { study codes and allocated the supplements". }\end{array}$ \\
\hline $\begin{array}{l}\text { Blinding (performance } \\
\text { bias and detection bias) } \\
\text { All outcomes }\end{array}$ & Low risk & $\begin{array}{l}\text { "Placebo group subjects received organoleptically identical, matched place- } \\
\text { bo...Subject codes remained sealed until after data analysis". }\end{array}$ \\
\hline
\end{tabular}


Armijos 2010 MEX (Continued)

Incomplete outcome data Low risk The analysis included 33/39 (85\%) randomized participants. The trial authors (attrition bias)

clearly stated the reasons for drop-out.

All outcomes

\begin{tabular}{|c|c|c|}
\hline $\begin{array}{l}\text { Selective reporting (re- } \\
\text { porting bias) }\end{array}$ & Unclear risk & $\begin{array}{l}\text { We could not retrieve the trial protocol. Trial participants were followed-up to } \\
6 \text { months but treatment completion and cure were not reported. }\end{array}$ \\
\hline
\end{tabular}

Other bias Low risk We did not identify any other sources of bias.

Study design: RCT.
Study dates and duration: January 2010 to August 2011 (enrolment), follow-up completed by February
2012.
Standard care: both groups received standard category 1 tuberculosis treatment according to Indian
national guidelines.

Participants

Number: 247 randomized (121 to vitamin D group, 126 to placebo).

Vitamin D group: 101/121 included in primary analysis.

Placebo group: 110/126 included in primary analysis.

Inclusion: HIV-negative participants aged 18 to 75 years with pulmonary tuberculosis (at least 1 documented positive sputum smear) who had received 1 dose or less of tuberculosis treatment

Exclusion: participants with multidrug-resistant tuberculosis, pre-existing liver or kidney disease, concurrent steroid or cytotoxic drug treatment, metastatic malignant disease, pregnancy or lactation, active diarrhoea, hyper-calcaemia (corrected serum calcium $>2.62 \mathrm{mmol} / \mathrm{L}$ ), or those who were not expected to survive for 180 days.

Baseline characteristics

- Nutritional status: mean BMI \pm SD: $18.2 \pm 2.9 \mathrm{~kg} / \mathrm{m}^{2}$ vitamin D group versus $17.8 \pm 3.0 \mathrm{~kg} / \mathrm{m}^{2}$ placebo.

- HIV status: all negative.

- MDR/XDR-TB: excluded.

- Mean vitamin D status \pm SD (mmol/L): $63.1 \pm 46.6$ vitamin $D$ group versus $62.2 \pm 51.0$ placebo group.

Interventions Both groups received antituberculous treatment and were not provided with any advice about changing their diet or sun exposure.

Vitamin D group: 4 doses of tasteless, odourless $2.5 \mathrm{mg}$ vitamin D3 oil (100,000 IU per dose) orally once every 2 weeks for 8 weeks.

Placebo group: identical Miglyol (the dosing regime is not clearly stated but we assume that it was identical to that of the vitamin D).

Outcomes

Primary outcome: time to sputum culture conversion (time to first negative culture).

Secondary outcome: time to sputum culture conversion (time to first of 2 consecutive negative cultures), time to smear conversion (time to first negative smear and time to first of 2 consecutive negative smears), proportion of participants who had positive cultures at 56 days, Karnofsky performance status and body mass index (BMI) at 56 days, rate of rise in time to detection in culture and 25-hydroxyvitamin-D concentration at day 180 .

Primary safety outcome: incidence of hypercalcaemia (corrected serum calcium $>2.62 \mathrm{mmol} / \mathrm{L}$ ). 
Secondary safety outcome: rate of serious adverse events (death, admission to hospital, life-threatening illness, persistent disability, congenital anomaly, or predefined disease-related complications of tuberculosis infection), and adverse events (any untoward medical occurrence after study drug).

Notes

Baseline characteristics: mostly similar between groups, but the placebo group had slightly more men than the vitamin $D$ group, and there were slightly more participants with isoniazid monoresistance in the vitamin D group $(14 / 121 ; 12 \%)$ compared to the placebo group $(8 / 126 ; 6 \%)$. It is unclear whether these differences were appreciably different or not.

Setting: 13 clinics in Vellore and Krishnagiri districts of Tamil Nadu, India.

Funding: Dalhousie University and Infectious Diseases Training and Research Centre.

Trial registration: NCT00366470.

\section{Risk of bias}

Bias Authors' judgement Support for judgement

Random sequence genera- Low risk tion (selection bias)

Bottles containing vitamin D or placebo were randomized by computer into permuted blocks of 4 without stratification, then labelled with serial study numbers in their randomized order. The randomization code was maintained in Canada and only after the database was locked was the code broken.

$\begin{array}{ll}\begin{array}{l}\text { Allocation concealment } \\ \text { (selection bias) }\end{array} & \text { Low risk } \\ & \begin{array}{l}\text { The trial authors stated that neither the participant nor the clinical and labora- } \\ \text { tory investigators and personnel in India were aware of treatment assignment. } \\ \text { As each participant was recruited, the next serially numbered bottle was as- } \\ \text { signed to the participant by study personnel. Both treatments were stored in } \\ \text { identical dark glass dropper bottles at room temperature and protected from } \\ \text { light. }\end{array}\end{array}$

Blinding (performance Low risk bias and detection bias) All outcomes
The trial authors state that neither the patient nor the clinical and laboratory investigators and personnel in India were aware of treatment assignment. The randomization code was maintained in Canada by 1 investigator. After the database was locked, the code was broken and analysis was done with knowledge of assignment. Both treatments were stored in identical dark glass dropper bottles at room temperature and protected from light. Both treatments were oil-based and were tasteless and odourless.

Incomplete outcome data Low risk
(attrition bias)

(attrition bias)

All outcomes

Participants receiving 1 dose of intervention and with at least 2 sputum culture results were included in the primary analysis. Participants with only 1 culture result were excluded: Vitamin $D$ group $=8 / 121(7 \%)$ and placebo group $=5 / 126$ (4\%).

\begin{tabular}{|c|c|c|}
\hline $\begin{array}{l}\text { Selective reporting (re- } \\
\text { porting bias) }\end{array}$ & Low risk & $\begin{array}{l}\text { Primary and secondary outcomes reported in the publication match those set } \\
\text { out in the protocol. }\end{array}$ \\
\hline
\end{tabular}

Other bias Low risk


Farazi 2015 IRN

\begin{tabular}{|c|c|}
\hline Methods & $\begin{array}{l}\text { Study design: RCT. } \\
\text { Study dates and duration: recruited December } 2012 \text { to May 2014, follow-up } 4 \text { weeks. } \\
\text { Standard care: all participants received directly observed antituberculous therapy (isoniazid, pyrazi- } \\
\text { namide, rifampicin, and ethambutol for } 2 \text { months followed by isoniazid and ethambutol for } 6 \text { months). }\end{array}$ \\
\hline Participants & $\begin{array}{l}\text { Number: } 63 \text { randomized ( } 32 \text { in arginine group, } 31 \text { in placebo group). } \\
\text { Sex: arginine group } 46.9 \% \text { male; placebo group } 51.6 \% \text { male. } \\
\text { Inclusion: new cases smear-positive pulmonary TB } 15 \text { years or older. } \\
\text { Exclusion: hospitalization, pregnancy, clinical signs of comorbidity (diabetes, malignancy, hepatic/re- } \\
\text { nal failure, HIV-positive), L-arginine supplementation during the past month, and allergic reactions to L- } \\
\text { arginine. } \\
\text { Baseline characteristics } \\
\text { - Nutritional status (BMI < } 18.5 \mathrm{~kg} / \mathrm{m}^{2} \text { ): arginine } 46.9 \% \text {; placebo } 45.2 \% \text {. } \\
\text { - HIV status: all HIV-negative. } \\
\text { MDR/XDR-TB: not reported on. }\end{array}$ \\
\hline
\end{tabular}

Interventions

Both groups received anti-TB treatment.

Arginine group: $1000 \mathrm{mg}$ pure L-arginine hydrochloride; twice daily for 30 days.

Placebo group: $1000 \mathrm{mg}$ sugar (capsules identical to L-arginine capsule); twice daily for 30 days.

\begin{tabular}{ll}
\hline Outcomes & Treatment success. \\
& - Sputum conversion. \\
& - Weight gain. \\
Not included in review: ESR, CRP. \\
\hline Notes \\
Location: Markazi Province, Iran. \\
Setting: clinics. \\
Funding: Arak University of Medical Science.
\end{tabular}

\section{Risk of bias}

\begin{tabular}{lll}
\hline Bias & Authors' judgement & Support for judgement \\
\hline $\begin{array}{l}\text { Random sequence genera- } \\
\text { tion (selection bias) }\end{array}$ & Low risk & "random number tables". \\
\hline $\begin{array}{l}\text { Allocation concealment } \\
\text { (selection bias) }\end{array}$ & Low risk & $\begin{array}{l}\text { "Preparation of the randomization envelopes was performed by a member of } \\
\text { the staff who was not directly involved in the study and a sealed copy of the } \\
\text { treatment code was kept by the project leader until all data had been collected } \\
\text { and analyzed". }\end{array}$ \\
\hline $\begin{array}{l}\text { Blinding (performance } \\
\text { bias and detection bias) }\end{array}$ & Low risk & "identical capsules of L-arginine...or placebo". \\
\hline $\begin{array}{l}\text { Incomplete outcome data } \\
\text { (attrition bias) }\end{array}$ & Low risk & Supplement: $2 / 34(6 \%)$. \\
\hline
\end{tabular}


Farazi 2015 IRN (Continued)

All outcomes

$\begin{array}{ll}\begin{array}{l}\text { Selective reporting (re- } \\ \text { porting bias) }\end{array} & \text { Low risk } \\ \end{array}$

\begin{tabular}{ll}
\hline Other bias & Bow risk \\
& Funding source: Arak University of Medical Sciences. \\
& Conflicts of interest: all trial authors declared no conflict of interest.
\end{tabular}

Ginawi 2013 IND

\begin{tabular}{ll}
\hline Methods & Study design: RCT. \\
Study dates and duration: not stated. \\
Standard care: not stated. \\
Number: 178 randomized, 127 analysed. \\
Inclusion criteria: category 1 pulmonary tuberculosis patients attending the DOTS centre. \\
Exclusion criteria: those who did not take medication regularly (missing even 1 dose in the first 2 \\
months), had severe adverse reactions, or drug-resistant tuberculosis. \\
Baseline characteristics \\
- Nutritional status: not stated. \\
- HIV status: not stated. \\
- MDR/XDR-TB: excluded. \\
- Vitamin A status $\mu \mathrm{g} / \mathrm{dL}$ (SD): unclear if it is baseline data or \% increase from baseline.
\end{tabular}

Interventions

Placebo group: lactose only.

Vitamin A group: 1500 retinol equivalents (5000 IU) vitamin A (as retinyl acetate).

Zinc group: $15 \mathrm{mg}$ zinc (as zinc sulfate).

Vitamin A and zinc group: 1500 retinol equivalents (5000 IU) vitamin A (as retinyl acetate) and $15 \mathrm{mg}$ zinc (as zinc sulfate).

Supplement and placebo were given to the participants with the antituberculous drugs on DOTS day.

\begin{tabular}{ll}
\hline Outcomes & $\begin{array}{l}\text { Sputum positivity: sputum smear negative for tubercle bacilli at } 2 \text { months. } \\
\text { - Blood chemistry: haemoglobin, white blood cell count, erythrocyte sedimentation rate (ESR), serum } \\
\text { albumin, serum retinol, and serum zinc concentration at } 2 \text { and } 6 \text { months. }\end{array}$ \\
\hline Notes & Location: Lucknow, North India. \\
& Setting: not stated. \\
& Funding: not stated. \\
\hline
\end{tabular}

\section{Risk of bias}


Ginawi 2013 IND (Continued)

Random sequence genera- Unclear risk Not described.
tion (selection bias)

Allocation concealment $\quad$ Unclear risk Not described.
(selection bias)

$\begin{array}{ll}\text { Blinding (performance } & \text { Low risk } \\ \text { bias and detection bias) } & \begin{array}{l}\text { The trial authors described the trial as a double blind, placebo-controlled trial. } \\ \text { Supplement and placebo capsules were indistinguishable in appearance both } \\ \text { externally and internally. }\end{array}\end{array}$

\begin{tabular}{|c|c|c|}
\hline $\begin{array}{l}\text { Incomplete outcome data } \\
\text { (attrition bias) } \\
\text { All outcomes }\end{array}$ & High risk & $\begin{array}{l}\text { The trial authors stated that they excluded non-compliant participants, partic- } \\
\text { ipants who experienced severe adverse reactions, and participants with drug- } \\
\text { resistant tuberculosis from the analysis. The trial authors did not describe rea- } \\
\text { sons for loss to follow-up of } 51 \text { participants. } \\
178 \text { participants randomized. } \\
127 \text { participants completed the trial. } \\
28.6 \% \text { loss to follow-up (> } 10 \% \text { therefore high risk of bias). }\end{array}$ \\
\hline $\begin{array}{l}\text { Selective reporting (re- } \\
\text { porting bias) }\end{array}$ & Unclear risk & $\begin{array}{l}\text { We were unable to obtain the trial protocol so it is unclear if there is selective } \\
\text { outcome reporting in this instance. }\end{array}$ \\
\hline Other bias & Unclear risk & $\begin{array}{l}\text { Baseline comparability: no significant difference in biochemical status at base- } \\
\text { line. No information on age, gender, or nutritional status at baseline. } \\
\text { Conflicts of interest: not reported. } \\
\text { Funding: no information provided on funding resources. }\end{array}$ \\
\hline
\end{tabular}

Study design: RCT.
Study dates and duration: dates not stated, follow-up 3 months.
Standard care: all participants received directly observed antituberculous therapy, without any routine
multivitamin preparations.

Number: 110 enrolled; 85 analysed.
Inclusion criteria: children aged under 15 years with pulmonary tuberculosis.
Exclusion criteria: HIV-positive.
Baseline characteristics
- Nutritional status: mean weight z score (SD): -1.41 (1.41) treatment group versus -1.44 (1.34) control
group.
- HIV status: all negative.
- VDR/XDR-TB: not described.
range 20 to 80.

Interventions

Group 1: vitamin A 200,000 IU; 2 doses before beginning antituberculous therapy.

Group 2: placebo with identical appearance. 
Hanekom 1997 ZAF (Continued)

Outcomes - Resolution of respiratory symptoms at 6 weeks and 3 months.

- Change-in-weight z scores.

- Vitamin A levels at baseline, 6 weeks, and 3 months.

Not included in review: chest X-ray changes, retinol binding protein, and prealbumin levels: at baseline, 6 weeks, and 3 months.

Lotes
Setting: children's hospital (outpatient or inpatient not stated in report).
Funding: the Glaxo 'Action TB' International Research Initiative, Medical Research Council of South
Africa.

\section{Risk of bias}

\begin{tabular}{lll}
\hline Bias & Authors' judgement & Support for judgement \\
\hline $\begin{array}{l}\text { Random sequence genera- } \\
\text { tion (selection bias) }\end{array}$ & Unclear risk & $\begin{array}{l}\text { The trial authors described the trial as "randomised"; but did not provide any } \\
\text { further details. }\end{array}$ \\
\hline $\begin{array}{l}\text { Allocation concealment } \\
\text { (selection bias) }\end{array}$ & Unclear risk & None described. \\
\hline $\begin{array}{l}\text { Blinding (performance } \\
\text { bias and detection bias) } \\
\text { All outcomes }\end{array}$ & Low risk & $\begin{array}{l}\text { The trial authors described the trial as "double blind", with an "identical ap- } \\
\text { pearing placebo". No comment on outcome assessors. }\end{array}$ \\
\hline $\begin{array}{l}\text { Incomplete outcome data } \\
\text { (attrition bias) }\end{array}$ & High risk & $\begin{array}{l}\text { The trial enrolled 110 participants, of which 15 were later excluded for not at- } \\
\text { tending the last follow-up appointment and 10 for not meeting the inclusion } \\
\text { criteria. The trial authors presented data for 76 of the remaining } 85 \text { (85\%) par- } \\
\text { ticipants. }\end{array}$ \\
\hline $\begin{array}{l}\text { Selective reporting (re- } \\
\text { porting bias) }\end{array}$ & Unclear risk & $\begin{array}{l}\text { We were unable to retrieve the trial protocol. There was no evidence of selec- } \\
\text { tive reporting. }\end{array}$ \\
\hline \begin{tabular}{l} 
Other bias \\
\hline
\end{tabular} & Low risk & \begin{tabular}{l} 
We did not identify any other sources of bias. \\
\hline
\end{tabular}
\end{tabular}

\section{Jahnavi 2010 IND}

$\begin{array}{ll}\text { Methods } & \text { Study design: RCT. } \\ & \text { Study dates and duration: August to December 2005, follow-up 1-year. } \\ \text { Standard care: all participants received directly observed antituberculous therapy according to the Re- } \\ \text { vised National Tuberculosis Control Programme, India, without any routine multivitamin preparations. }\end{array}$


Jahnavi 2010 IND (Continued)

- HIV status: all negative.

- MDR/XDR-TB: unknown.

- Micronutrient status: not assessed at baseline.

Interventions

Group 1: Control group: standard tuberculosis treatment as per the Revised National Tuberculosis Control Programme. A general instruction to "increase food intake".

Group 2: targeted dietary advice to reach $35 \mathrm{kcal} / \mathrm{kg} / \mathrm{day}$ and food supplements that consisted of "sweet balls" made of wheat flour, caramel, groundnuts, vegetable ghee, sprouted gram, and nuts each containing $6 \mathrm{~g}$ protein and $600 \mathrm{kcal}$ - consumed daily under supervision for 3 months.

\begin{tabular}{ll}
\hline Outcomes & Body weight at baseline and 3 months. \\
- Maximum grip strength and timed stand test at baseline and 3 months. \\
- Quality of life at baseline and 3 months. \\
- Sputum conversion at 2, 4, and 6 months. \\
- Deaths during study.
\end{tabular}

Notes

Location: Krishna district, Andhrapradesh, India.

Setting: community-based catchment area of 1 medical college and 1 DOTS centre.

Funding: University of Padova, Italy.

\section{Risk of bias}

\begin{tabular}{|c|c|c|}
\hline Bias & Authors' judgement & Support for judgement \\
\hline $\begin{array}{l}\text { Random sequence genera- } \\
\text { tion (selection bias) }\end{array}$ & High risk & $\begin{array}{l}\text { "randomisation performed by randomly shuffling the envelopes that con- } \\
\text { tained the study codes". }\end{array}$ \\
\hline $\begin{array}{l}\text { Allocation concealment } \\
\text { (selection bias) }\end{array}$ & Unclear risk & $\begin{array}{l}\text { The trial did not describe this, but given that the envelopes with codes were } \\
\text { shuffled it would seem adequate. }\end{array}$ \\
\hline $\begin{array}{l}\text { Blinding (performance } \\
\text { bias and detection bias) } \\
\text { All outcomes }\end{array}$ & High risk & $\begin{array}{l}\text { The trial did not make any attempt to blind the participants; the trial report } \\
\text { does not mention whether or not the outcome assessors were blinded. }\end{array}$ \\
\hline $\begin{array}{l}\text { Incomplete outcome data } \\
\text { (attrition bias) } \\
\text { All outcomes }\end{array}$ & Unclear risk & There were no apparent losses to follow-up. \\
\hline $\begin{array}{l}\text { Selective reporting (re- } \\
\text { porting bias) }\end{array}$ & High risk & $\begin{array}{l}\text { Despite } 1 \text { year of follow-up, the trial authors only reported outcomes at } 3 \\
\text { months, and incompletely reported sputum conversion. }\end{array}$ \\
\hline Other bias & Low risk & We did not identify any other sources of bias. \\
\hline
\end{tabular}

Study dates and duration: September 2010 to August 2011.

Standard care: treatment was given as FDC tablets, each contained Isoniazid $(75 \mathrm{mg}$ ), rifampin (150 $\mathrm{mg}$ ), pyrazinamide $(400 \mathrm{mg})$, and ethambutol $(275 \mathrm{mg}$ ) during the intensive phase, and for continua- 
Jeremiah 2014 TZA (Continued)

tion phase the tablet contained isoniazid $(75 \mathrm{mg})$ and rifampicin $(150 \mathrm{mg})$ only. If body weight $<50 \mathrm{~kg}$ then 3 tablets, and $>50 \mathrm{~kg} 4$ tablets.

\section{Participants}

Number: 469 screened, 100 randomized (by HIV status).

Inclusion criteria: sputum smear positive pulmonary tuberculosis patients 15 years or older, regardless of HIV status, with written informed consent.

Exclusion criteria: HIV-positive participants on ART, pregnant women, terminally sick patients unlikely to survive $>48 \mathrm{hrs}$, and non-residents of Mwanza City.

\section{Baseline characteristics}

- Nutritional status: median BMI $\left(\mathrm{kg} / \mathrm{m}^{2}\right)$ pulmonary tuberculosis-positive/HIV-positive supplement group: 19.4; 18.3, 20.5 pulmonary tuberculosis positive/HIV-positive no supplement group: 18.8; 17.4, 20.1, pulmonary tuberculosis positive/HIV-negative supplement group: 18; 16.9, 19.7. Pulmonary tuberculosis positive/HIV-negative no supplement group: 18.6; 17.3,19.6. Median weight (kg): pulmonary tuberculosis positive/HIV-positive supplement group: 52.3; 49.9, 56.6. pulmonary tuberculosis positive/HIV-positive no supplement group: 51.9; 49.2, 56.1. Pulmonary tuberculosis positive/HIVnegative supplement group: 50.7 ; 48.2, 57.7. Pulmonary tuberculosis positive/HIV-negative no supplement group: 52; 44.6, 58.8.

- HIV status: median CD4 cell count; IQR cells/ $\mu \mathrm{L}$ pulmonary tuberculosis-positive/HIV-positive supplement: 243.5; 140.5, 337.5 pulmonary tuberculosis-positive/HIV-positive no supplement: 168; 64, 338 pulmonary tuberculosis positive/HIV-negative supplement: $611 ; 457 ; 726$ pulmonary tuberculosis positive/HIV-negative no supplement: 637; 433, 812.

- MDR/XDR-TB: not described.

Interventions

- Group 1: pulmonary tuberculosis-positive/HIV-positive and Group 2: pulmonary tuberculosis positive/HIV-negative: no supplement.

- Group 3: pulmonary tuberculosis-positive/HIV-positive and Group 4: pulmonary tuberculosis positive/HIV-negative: daily 5 high energy and vitamin/mineral enriched biscuit bars containing about $1000 \mathrm{kcal}$ and additional vitamins and minerals (including zinc and selenium). Produced by Compact A/S. Supplement provided during first 2 months of tuberculosis treatment. Intake monitored by patient treatment supporter.

Basic biscuit ( $30 \mathrm{~g}$ ): $4.5 \mathrm{~g}$ protein, $615 \mathrm{~kJ}$ energy, $120 \mathrm{mg}$ phosphorous, $120 \mathrm{mg}$ calcium, $36 \mathrm{mg}$ magnesium, $70 \mathrm{mg}$ sodium, $150 \mathrm{mg}$ potassium, and traces $<1 \mathrm{mg}$ of iron and zinc.

Biscuit with additional micronutrients: as above plus $1.5 \mathrm{mg}$ vitamin A, $20 \mathrm{mg}$ thiamin, $20 \mathrm{mg}$ riboflavin, $25 \mathrm{mg}$ vitamin B6, $50 \mu \mathrm{g}$ vitamin B12, $0.8 \mathrm{mg}$ folic acid, $40 \mathrm{mg}$ niacin, $200 \mathrm{mg}$ vitamin C, $60 \mathrm{mg}$ vitamin $\mathrm{E}$, $5 \mu \mathrm{g}$ vitamin $\mathrm{D}, 0.2 \mathrm{mg}$ selenium, $5 \mathrm{mg}$ copper, $30 \mathrm{mg}$ zinc.

$\begin{array}{ll}\text { Outcomes } & \text { - Mortality at } 2 \text { months. } \\ & \text { - Median weight gain at } 2 \text { months. } \\ & \text { Sputum culture at } 2 \text { months. }\end{array}$

Not included in review: pharmacokinetics of rifampin and genotype of organic anion-transporting polypeptide encoded by SLCO1B1 rs149032 responsible for hepatic drug disposition.

Notes Location: Mwanza, Tanzania.

Setting: urban and suburban clinics.

Funding: Danish Ministry of Foreign Affairs (DANIDA, DFC file no. 09-026RH) through Denmark's International Development Cooperation.

\section{Risk of bias}


Jeremiah 2014 TZA (Continued)

Random sequence genera- Low risk The trial authors stated that simple randomization, stratified by HIV status, tion (selection bias) was computed using the website www.randomization.com.

Allocation concealment High risk (selection bias)
This was an open-label trial, therefore it is likely that the people allocating the treatment where aware of which treatment group they were allocating the participants to.
Blinding (performance High risk

bias and detection bias)

All outcomes
This was an open-label trial, therefore the participants and personnel were not blinded to the treatment. It is unclear if the outcome assessors were blinded to the treatment.

\begin{tabular}{|c|c|c|}
\hline $\begin{array}{l}\text { Incomplete outcome data } \\
\text { (attrition bias) }\end{array}$ & High risk & The trial authors stated that they analysed all available data. \\
\hline All outcomes & & $\begin{array}{l}\text { Intervention arm: } 2 / 51 \text { (4\%) lost to follow-up (died or defaulted); no supple- } \\
\text { ment arm: } 6 / 49(12 \%) \text { lost to follow-up (died or defaulted). }\end{array}$ \\
\hline
\end{tabular}

\begin{tabular}{lll}
\hline $\begin{array}{l}\text { Selective reporting (re- } \\
\text { porting bias) }\end{array}$ & Low risk & $\begin{array}{l}\text { We obtained the protocol obtained. The primary and secondary outcomes re- } \\
\text { ported in the publication are in line with those set out in the protocol. }\end{array}$ \\
\hline Other bias & Low risk & We did not identify any other sources of bias. \\
\hline
\end{tabular}

Study design: RCT.
Study dates and duration: December 1997 to December 1998, follow-up 6 months.
Standard care: all participants received directly observed antituberculous therapy in line with WHO
recommendations: 2 RHZE/4HR.

Number: 110 enrolled; 80 analysed.
Inclusion criteria: adults aged 15 to 55 years, 3 positive sputum smears, clinical and radiological signs
consistent with pulmonary tuberculosis.
Exclusion criteria: previous antituberculous therapy, drug resistance, extra-pulmonary tuberculosis,
pregnancy, lactation, use of corticosteroids, vitamin $\mathrm{A}$, zinc, or iron in the previous month, moderate to
severe injury or surgery in the previous month, diabetes, renal failure, liver disease, neoplasm, or con-
gestive heart failure.
Baseline characteristics
- Nutritional status: BMI < $18.5 \mathrm{~kg} / \mathrm{m}^{2}: 25 / 40$ treatment group versus $26 / 40$ placebo group.
- HIV status: not mentioned.
- MDR/XDR-TB: excluded.
- Vitamin A status: mean plasma retinol $\mu \mathrm{mol} / \mathrm{L}(\mathrm{SD}): 0.82$ (0.04) supplement group versus 0.90 (0.04)
placebo group; normal range $>0.7$.
- Zinc status: mean plasma zinc $\mu \mathrm{mol} / \mathrm{L}(\mathrm{SD}): 11.52(0.26)$ supplement group versus 11.15 (0.28) placebo
group; normal range $>10.7$.

Interventions

Group 1: daily capsules of vitamin A $5000 \mathrm{IU}$ and zinc $15 \mathrm{mg}$ (as zinc sulphate) for 6 months.

Group 2: placebo (lactose).

Outcomes

- Sputum-culture positive at 0, 2, and 6 months.

- Body weight at 0, 2, and 6 months.

- BMI at 0, 2, and 6 months. 
Karyadi 2002 IDN (Continued)

- MUAC, body fat percentage.

- Karnofsky score at 0, 2, and 6 months.

- Blood retinol and zinc levels.

Not included in the review: biceps, triceps, subscapular, and supra-iliac skinfold thickness; blood haemoglobin, zinc protoporphyrin, $x$-ray changes.

Notes

Location: Jakarta, Indonesia.

Setting: pulmonary outpatient clinics of 1 public hospital and 3 health centres.

Funding: Gesellschaft fur Technische Zusammenarbeit (GTZ) GmbH, Eschborn, Germany; the Neys-van Hoogstraten Foundation; the Directorate General of Communicable Disease Control and Environmental Health, Indonesia; the Integrated Excellent Research Project, Ministry of Research and Technology Indonesia; PT Kimia Farma, Indonesia provided the supplements and placebo; PT Indo Farma provided the tuberculosis drugs.

\section{Risk of bias}

\begin{tabular}{lll}
\hline Bias & Authors' judgement & Support for judgement \\
\hline $\begin{array}{l}\text { Random sequence genera- } \\
\text { tion (selection bias) }\end{array}$ & Low risk & $\begin{array}{l}\text { "We used a table with randomly assorted digits to allocate patients into } 2 \\
\text { groups". }\end{array}$ \\
\hline $\begin{array}{l}\text { Allocation concealment } \\
\text { (selection bias) }\end{array}$ & Unclear risk & $\begin{array}{l}\text { The trial authors did not describe the method of allocation concealment but } \\
\text { seems likely given the description of blinding. }\end{array}$ \\
\hline $\begin{array}{l}\text { Blinding (performance } \\
\text { bias and detection bias) } \\
\text { All outcomes }\end{array}$ & Low risk & $\begin{array}{l}\text { "Supplements and placebo were indistinguishable". "The authors, health staff, } \\
\text { and patients were unaware of the treatment code until the study was complet- } \\
\text { ed". }\end{array}$ \\
\hline $\begin{array}{l}\text { Incomplete outcome data } \\
\text { (attrition bias) }\end{array}$ & High risk & $\begin{array}{l}\text { The trial authors appear to have added 2 exclusion criteria post-hoc: partic- } \\
\text { ill outcomes } \\
\text { participants who had severe adverse drug effects. The trial authors analysed } \\
80 / 110 \text { (72\%) participants. }\end{array}$ \\
\hline $\begin{array}{l}\text { Selective reporting (re- } \\
\text { porting bias) }\end{array}$ & Unclear risk & $\begin{array}{l}\text { We were unable to retrieve the trial protocol. Although cure is a standard out- } \\
\text { come for tuberculosis programmes, this was not reported. }\end{array}$ \\
\hline \begin{tabular}{l} 
Other bias \\
\hline
\end{tabular} & Low risk & \begin{tabular}{l} 
We did not identify any other sources of bias. \\
\hline
\end{tabular}
\end{tabular}

\section{Kota 2011 IND}

Methods
Study design: RCT.
Study dates and duration: not stated.
Standard care: all participants received intensive phase antimicrobial treatment comprising of isoni-
azid, rifampicin, pyrazinamide, and ethambutol. All participants were adjusted for oral hypoglycaemic
agents and insulin for glycaemic control.

Participants

Number: 45 enrolled, (15 excluded), 30 randomized and included in the final analysis.

Inclusion criteria: older than 15 years, newly diagnosed pulmonary tuberculosis patients, poorly controlled Type 2 diabetes mellitus ( $\mathrm{HbA} 1 \mathrm{C}>7 \%$ ) and serum $25(\mathrm{OH}) \mathrm{D}<20 \mathrm{ng} / \mathrm{mL}$. Pulmonary tuberculosis diagnosis based on 1 of the following criteria: at least 2 positive sputum smears (from 3), 1 positive smear and typical picture of lung infiltration on chest X-ray. 
Kota 2011 IND (Continued)

Exclusion criteria: younger than 15 years, patients already on ATT, serum $25(\mathrm{OH}) \mathrm{D}>2 \mathrm{ng} / \mathrm{mL}$, diseases affecting vitamin D metabolism such as malabsorption, renal failure, or with prolonged immobilization.

Baseline characteristics

- Nutritional status: mean weight $(\mathrm{kg} \pm \mathrm{SD})$ supplement group: $49.1 \mathrm{~kg} \pm 4.5$, control: $44.6 \pm 5.6$.

- HIV status: not stated.

- MDR/XDR-TB: not stated.

- Vitamin D 25-(OH) D (ng/mL) status: supplement group $12.8 \pm 4.5$, control group: $11.1 \pm 4.7$.

- Vitamin A and zinc status: not reported.

Interventions Group 1: vitamin D supplement along with intensive phase ATT. Oral cholecalciferol sachets (60,000 IU/ week) and calcium carbonate $(1000 \mathrm{mg} /$ day).

Group 2: no vitamin D supplement just intensive phase ATT.

The trial authors did not state the duration of the intervention.

\begin{tabular}{ll}
\hline Outcomes & - Vitamin D levels every 4 weeks for 12 weeks. \\
- Sputum smear conversion every 4 weeks for 12 weeks. \\
- Fasting blood sugar and post lunch blood sugar monthly. \\
- HbA1C monthly. \\
- ESR monthly.
\end{tabular}

Notes Location: Medwin Hospital, Hyderabad, India.

Setting: hospital setting (inpatient).

Funding: not reported.

\section{Risk of bias}

\begin{tabular}{|c|c|c|}
\hline Bias & Authors' judgement & Support for judgement \\
\hline $\begin{array}{l}\text { Random sequence genera- } \\
\text { tion (selection bias) }\end{array}$ & Unclear risk & The trial authors did not describe the randomization process. \\
\hline $\begin{array}{l}\text { Allocation concealment } \\
\text { (selection bias) }\end{array}$ & Unclear risk & $\begin{array}{l}\text { The trial authors did not mention whether treatment allocation was concealed } \\
\text { or not. }\end{array}$ \\
\hline $\begin{array}{l}\text { Blinding (performance } \\
\text { bias and detection bias) } \\
\text { All outcomes }\end{array}$ & Unclear risk & The trial authors did not describe any aspect of blinding in the paper. \\
\hline $\begin{array}{l}\text { Incomplete outcome data } \\
\text { (attrition bias) } \\
\text { All outcomes }\end{array}$ & Low risk & $\begin{array}{l}\text { According to data provided, the trial authors included all of the participants } \\
\text { randomized at baseline in the final analysis at } 12 \text { weeks. }\end{array}$ \\
\hline $\begin{array}{l}\text { Selective reporting (re- } \\
\text { porting bias) }\end{array}$ & Unclear risk & $\begin{array}{l}\text { We were unable to obtain the study protocol so it is unclear if all of the pro- } \\
\text { posed outcomes have been reported on. }\end{array}$ \\
\hline Other bias & Low risk & We did not identify any other sources of bias. \\
\hline
\end{tabular}

Methods Study design: RCT.


Lawson 2010 NGA (Continued)

Study dates and duration: September 2003 to June 2005, follow-up 6 months.

Standard care: all participants received standard National Tuberculosis Programme treatment for tuberculosis: $2 \mathrm{RHZE} / 4 \mathrm{HE}$.

Number: 350 enrolled.
Inclusion criteria: adults aged > 15 years with sputum positive pulmonary tuberculosis.
Exclusion criteria: previous antituberculous therapy, pregnancy, lactation, use of corticosteroids or
zinc in the previous month, major surgery in the previous month, diabetes, severe cardiovascular/renal
or hepatic disease, currently taking oral contraceptives, unable to return.
Baseline characteristics
- Nutritional status: mean BMI (SD): $19.8 \mathrm{~kg} / \mathrm{m}^{2}(3.3)$ placebo group, $21.3 \mathrm{~kg} / \mathrm{m}^{2}(4.7)$ zinc plus placebo
group, 19.6 (3.5) zinc plus vitamin A group.
- HIV status: $45 \%$ HIV-positive placebo group, $49 \%$ zinc plus placebo group, $42 \%$ zinc plus vitamin A
group.
- MDR/XDR-TB: not mentioned.
- Vitamin A status: not reported.

Interventions Group 1: placebos (similar in appearance to zinc and vitamin A tablets).

Group 2: 90 mg of elemental zinc per week plus daily placebo.

Group 3: $90 \mathrm{mg}$ of elemental zinc per week plus $1500 \mathrm{mcg}$ retinol equivalents (5000IU vitamin A) weekly.

Supplements were observed for 2 months then given as monthly supplies for the next 4 months.

\begin{tabular}{|c|c|c|}
\hline Outcomes & \multicolumn{2}{|c|}{$\begin{array}{l}\text { - Time to sputum smear conversion. } \\
\text { - Chest X-ray scores at } 2 \text { and } 6 \text { months. } \\
\text { - } \text { BMI at } 2 \text { and } 6 \text { months. } \\
\text { - Karnofsky score at } 2 \text { and } 6 \text { months. } \\
\text { - Deaths during the trial. } \\
\text { Not included in the review: ESR and haemoglobin values. }\end{array}$} \\
\hline Notes & \multicolumn{2}{|c|}{$\begin{array}{l}\text { Location: Abuja, Nigeria. } \\
\text { Setting: } 8 \text { district hospitals. } \\
\text { Funding: no sources stated. }\end{array}$} \\
\hline \multicolumn{3}{|l|}{ Risk of bias } \\
\hline Bias & Authors' judgement & Support for judgement \\
\hline $\begin{array}{l}\text { Random sequence genera- } \\
\text { tion (selection bias) }\end{array}$ & Low risk & $\begin{array}{l}\text { "Prepared the allocation sequence using random numbers generated in } \\
\text { Minitab...using permuted block randomisation with four different black sizes". }\end{array}$ \\
\hline $\begin{array}{l}\text { Allocation concealment } \\
\text { (selection bias) }\end{array}$ & Low risk & $\begin{array}{l}\text { "One of the investigators who was not on the site prepared the allocation se- } \\
\text { quence....and the randomisation sequence was kept at the Liverpool School of } \\
\text { Tropical Medicine Treatment...allocation was designated by a lettered code } \\
\text { and concealed from the investigators and subjects until data analysis was } \\
\text { completed". }\end{array}$ \\
\hline
\end{tabular}


Lawson 2010 NGA (Continued)
Blinding (performance
Low risk
"Placebo tablets resembled the supplement tablets".
bias and detection bias)

All outcomes

$\begin{array}{lll}\begin{array}{l}\text { Incomplete outcome data } \\ \text { (attrition bias) } \\ \text { All outcomes }\end{array} & \text { Low risk } & \begin{array}{l}\text { There were } 14 \text { of } 116 \text { in the placebo group, } 15 \text { of } 117 \text { in the zinc group, and } 21 \\ \text { of } 117 \text { in the zinc and vitamin A group lost to follow-up. }\end{array} \\ \begin{array}{l}\text { Selective reporting (re- } \\ \text { porting bias) }\end{array} & \text { Unclear risk } & \begin{array}{l}\text { We were unable to retrieve the trial protocol. There was no evidence of selec- } \\ \text { tive reporting. }\end{array}\end{array}$

Other bias Low risk We were unable to identify any other sources of bias.

Lodha 2014 IND

Methods
Study design: RCT.
Study dates and duration: January 2008 to June 2012.
Standard care: all children had 2 months intensive phase that used 3 or 4 drugs (isoniazid, rifampicin,
pyrazinamide, and ethambutol) followed by 4 months of isoniazid and rifampicin. Category 3 treat-
ment was isoniazid, rifampicin, and pyrazinamide for 2 months followed by 4 months of rifampicin and
isoniazid.

Daily doses were based on weight: 5 to $7 \mathrm{mg}$ isoniazid/kg; 10 to $13 \mathrm{mg}$ rifampicin/kg; 35 to $40 \mathrm{mg}$ pyrazinamide/kg; 20 to $25 \mathrm{mg}$ ethambutol $/ \mathrm{kg}$.

In case of non-response (clinical or radiological) antituberculous therapy was changed to 2 months streptomycin, isoniazid, rifampicin, pyrazinamide, and ethambutol; followed by 1 month of isoniazid, rifampicin, and ethambutol; and 5 months of isoniazid, rifampicin, and ethambutol. Any child who did not respond on this regimen and for whom an alternative diagnosis was ruled out was started on 2 nd line antituberculous therapy, which included an injection of kanamycin, ofloxacin, and ethionamide and an additional drug (cycloserine or co-amoxiclav).

Participants were followed up every 2 weeks in the first 2 months, and then every 4 weeks for the remaining 4 months of ATT treatment.

Participants

Number: 403 randomized. At 2 months: data on 393 children; at 6 months: data on 381 children.

Inclusion criteria: children 6 months to 15 years who presented with any of the following symptoms were considered tuberculosis suspects and screened: cough $>2$ weeks with no improvement after 7 to 10 days amoxicillin, fever $>2$ weeks with no improvement during 7 to 10 days amoxicillin, recent unexplained weight loss or failure to thrive, unusual or unexplained fatigue or lethargy or subtle clinical symptoms and history of close contact with adult tuberculosis patient. All had chest X-ray and tuberculin skin test. If the chest $X$-ray was consistent with intrathoracic tuberculosis, the child was considered to have tuberculosis. The trial enrolled children with newly diagnosed probable intrathoracic tuberculosis with or without extrapulmonary lesions.

Exclusion criteria: bilateral pedal oedema; known HIV infection; history of antituberculous therapy or isoniazid prophylaxis > 4 weeks; signs of upper airway obstruction; $\mathrm{O}_{2}$ saturation < $92 \%$; signs of renal, hepatic, or cardiovascular disease; inability to attend follow-up session for reading of the skin test; documented intake of zinc continuously $>2$ weeks in the 4 weeks preceding enrolment; CNS, osteoarticular, pericardial or renal tuberculosis; history of contact with a documented case of drug-resistant tuberculosis; or were non-residents of Delhi.

Baseline characteristics

- Nutritional status (weight-for-age $\mathrm{z}$ score): $\mathrm{MN}+\mathrm{Z}$ group $-2.72 \pm 1.85$; $\mathrm{MN}$ group $-2.8 \pm 1.6$; zinc group $-2.5 \pm 1.5$; placebo $-2.8 \pm 1.6$. 
Lodha 2014 IND (Continued)

- HIV status: HIV-negative only.

- MDR/XDR-TB (n/N tested): MN+Z group 1/18 (5.6\%); MN group 1/29 (3.4\%); zinc group 1: 1/21 (4.8\%), placebo group $2 / 26(7.9 \%)$.

- Serum zinc concentration < $65 \mu \mathrm{g} / \mathrm{dL}$ (n/N): MN + Z 60/102; MN 51/100; zinc 53/101; placebo 55/100.

\begin{tabular}{|c|c|}
\hline Interventions & $\begin{array}{l}\text { All children received antituberculous therapy. } \\
\text { Supplemented daily for } 6 \text { months. } \\
\text { Zinc group: zinc ( } 20 \text { mg elemental zinc). } \\
\text { Micronutrient group: micronutrients (vitamin A, thiamine, riboflavin, vitamins B6 and B12, folic acid, } \\
\text { niacin, vitamin C, vitamin E, vitamin D, selenium, and copper) without zinc. } \\
\text { Micronutrient + zinc group: micronutrients (as above) in combination with zinc ( } 20 \text { mg elemental zinc). } \\
\text { Placebo group: placebo. }\end{array}$ \\
\hline Outcomes & $\begin{array}{l}\text { - Change in weight-for-age } z \text { score at } 6 \text { months and resolution of pulmonary lesions using chest X-ray } \\
\text { at } 6 \text { months. } \\
\text { - Height-for-age } z \text { score. } \\
\text { - Mid upper arm circumference. } \\
\text { - Triceps skin fold thickness. } \\
\text { - BMI-for-age } z \text { score at } 2 \text { and } 6 \text { months. } \\
\text { - Resolution of symptoms at } 2 \text { months (as reported by parents). } \\
\text { - Proportion of children requiring extension of intensive phase of therapy at } 2 \text { months. } \\
\text { - Improvement in chest X-ray at } 2 \text { months. }\end{array}$ \\
\hline
\end{tabular}

Notes

Location: Delhi, India. All India Institute of Medical Sciences \& Kalawati Saran Children Hospital associated with Lady Hardinge Medical College.

Setting: urban, hospital.

Funding: Norwegian Programme for Development, Research and Education and Research council of Norway and Global Health and Vaccination Research GLOBVAC.

\section{Risk of bias}

\begin{tabular}{lll}
\hline Bias & Authors' judgement & Support for judgement \\
\hline $\begin{array}{ll}\text { Random sequence genera- } \\
\text { tion (selection bias) }\end{array}$ & Low risk & $\begin{array}{l}\text { Adequate randomization described: a scientist who was not involved in the da- } \\
\text { ta collection and analysis, generated random-allocation sequences in permut- } \\
\text { ed blocks of variable sizes separately for the } 2 \text { sites. Separate sequences were } \\
\text { generated for the age groups } 6 \text { months to } 3 \text { years, } 4 \text { to } 6 \text { years, } 7 \text { to } 9 \text { years, and } \\
10 \text { to } 15 \text { years. }\end{array}$ \\
\end{tabular}

\begin{tabular}{ll}
\hline $\begin{array}{l}\text { Allocation concealment } \\
\text { (selection bias) }\end{array}$ & Low risk \\
& $\begin{array}{l}\text { Bottles that contained the micronutrient supplements were serially numbered } \\
\text { for each stratum for the } 2 \text { sites. The } 4 \text { study syrup preparations had a similar } \\
\text { packaging, appearance, and smell. The participant, physician, and laboratory } \\
\text { personnel were blinded to the intervention. }\end{array}$
\end{tabular}

\begin{tabular}{ll}
\hline $\begin{array}{l}\text { Blinding (performance } \\
\text { bias and detection bias) }\end{array}$ & Low risk \\
$\begin{array}{ll}\text { All outcomes } & \text { The } 4 \text { study syrup preparations had a similar packaging, appearance, and } \\
& \text { smell. The participant, physician, and laboratory personnel were blinded to } \\
& \text { the intervention. They maintained masking during the data analysis by coding } \\
\text { treatment allocation with } 4 \text { letters. }\end{array}$
\end{tabular}

$\begin{array}{ll}\begin{array}{l}\text { Incomplete outcome data } \\ \text { (attrition bias) }\end{array} & \text { Low risk } \\ \text { All outcomes } & \text { Loss to follow-up overall } \\ \end{array}$


Lodha 2014 IND (Continued)

6 month loss to follow-up per group:

Micronutrient + zinc group: 8/102 (8\%)

Micronutrient group: 4/100 (4\%)

Zinc group: 7/101 (7\%)

Placebo group: 3/100 (3\%)

Selective reporting (re- Low risk
porting bias)

We obtained the study protocol and the trial authors reported all outcomes in the paper that they listed in the protocol. Five additional outcomes were listed in the protocol and will likely be reported in future papers.

- Interferon gamma responses to M. tuberculosis antigens ESAT6 and CF10 by quantiferon assay at baseline, 2 months, and 6 months of treatment.

- To study effect of zinc supplementation on ocular toxicity in children receiving ethambutol by VER.

- To document drug resistance $(S, I, R, E)$ patterns among children with culture confirmed tuberculosis.

- To document genotypic strain diversity among children with culture confirmed tuberculosis, also associations between strain type and disease severity and drug resistance.

- To document the spectrum of mycobacterial species by culture in children clinically suspected of having pulmonary tuberculosis.

Other bias Low risk

Baseline characteristics: most demographic and clinical profiles were comparable at baseline. However, there were some differences regarding sex distribution, parental educational level, diagnosis, and energy and zinc intakes before enrolment.

Fundings: non-biased source of funding.

\section{Martineau 2011 GBR}

Methods Study design: RCT.

Study dates and duration: January 2007 to July 2009, follow-up 8 weeks.

Standard care: All participants received directly observed antituberculous therapy: 2RHZE.

Participants Number: 146 enrolled; 128 in primary analysis.

Inclusion criteria: adults aged over 18 years, newly diagnosed sputum positive pulmonary tuberculosis.

Exclusion criteria: known intolerance to vitamin D or antituberculous therapy, sarcoidosis, hyperparathyroidism, nephrolithiasis, HIV infection, pulmonary silicosis, malignancy, renal or hepatic failure, oral corticosteroids, cytotoxic drugs or other immunosuppressant therapy in the last month, antituberculous therapy for $>7$ days in the preceding 6 months, currently taking antituberculous therapy other than RHZE, known rifampicin resistance, serum corrected calcium $>2.65 \mathrm{mmol} / \mathrm{L}$, aspartate transaminase or alanine transaminase $>120 \mathrm{IU} / \mathrm{L}$, total serum bilirubin $>40 \mu \mathrm{mol} / \mathrm{L}$, serum creatinine $>$ $250 \mu \mathrm{mol} / \mathrm{L}$, pregnant or breastfeeding.

Baseline characteristics

- Nutritional status: mean BMI (SD): $20.1 \mathrm{~kg} / \mathrm{m}^{2}$ (3.1) supplement group versus $20.2 \mathrm{~kg} / \mathrm{m}^{2}$ (2.7) placebo group.

- HIV status: $5 \%$ positive supplement group versus $3 \%$ positive placebo group.

- MDR/XDR-TB: rifampicin resistant isolate: $0 \%$ supplement group versus $4 \%$ placebo group. 
Martineau 2011 GBR (Continued)

- Vitamin D status: mean serum 25-hydroxyvitamin D nmol/L (SD): 21.1 (20.0) supplement group versus 21.3 (19.0) placebo group; normal range $>75 \mathrm{nmol} / \mathrm{L}$.

Interventions

Group 1: 4 oral doses of $2.5 \mathrm{mg}$ vitamin $\mathrm{D}_{3}$ (Viganol oil, Merck Serono) on or before day 7 after the start of tuberculosis treatment, day 14 , day 28 , and day 42.

Group 2: an organoleptically identical placebo (Miglyol Oil, Caesar and Loretz) given as above.

- Median time to sputum conversion.
- Serious adverse events.
- Other adverse events.
- Death.
- Mean serum 25-hydroxyvitamin D at baseline and day 56.

Not included in the review: haemoglobin level, mean corpuscular volume, total white blood cell count, lymphocyte count, monocyte count, neutrophil count, platelet count, erythrocyte sedimentation rate, C-reactive protein levels, chest radiography zones affected.

\begin{tabular}{ll}
\hline Notes & Location: London, UK. \\
Setting: 10 National Health Service Trusts. \\
Funding: British Lung Foundation.
\end{tabular}

\section{Risk of bias}

\begin{tabular}{|c|c|c|}
\hline Bias & Authors' judgement & Support for judgement \\
\hline $\begin{array}{l}\text { Random sequence genera- } \\
\text { tion (selection bias) }\end{array}$ & Low risk & $\begin{array}{l}\text { "generated a random sequence using a computer program that assigned the } \\
\text { term active or placebo to the numbers } 1 \text { to } 200 \text { by permuted block randomisa- } \\
\text { tion with blocks of } 10 \text { ". }\end{array}$ \\
\hline $\begin{array}{l}\text { Allocation concealment } \\
\text { (selection bias) }\end{array}$ & Low risk & $\begin{array}{l}\text { "The packs were then assigned a randomisation number according to this } \\
\text { computer generated randomisation sequence", "Study staff who assigned pa- } \\
\text { tients to the active drug or placebo had no knowledge of the next assignment } \\
\text { in the sequence, because they did not have access to the study code", "Treat- } \\
\text { ment allocation was concealed from patients and study staff". }\end{array}$ \\
\hline \multirow{3}{*}{$\begin{array}{l}\text { Blinding (performance } \\
\text { bias and detection bias) } \\
\text { All outcomes }\end{array}$} & Low risk & "organoleptically identical placebo". \\
\hline & & $\begin{array}{l}\text { "adverse events judged to be potentially related to vitamin } \mathrm{D} \text { by physicians un- } \\
\text { aware of allocation". }\end{array}$ \\
\hline & & "Those analysing the data were not masked to group assignment". \\
\hline $\begin{array}{l}\text { Incomplete outcome data } \\
\text { (attrition bias) } \\
\text { All outcomes }\end{array}$ & Unclear risk & $\begin{array}{l}\text { The trial authors reported outcomes on an intention-to-treat basis. The num- } \\
\text { ber of participants lost to follow-up ( } 3 \text { in the placebo group and } 6 \text { in the place- } \\
\text { bo group) and the reasons were clearly reported for each group. }\end{array}$ \\
\hline $\begin{array}{l}\text { Selective reporting (re- } \\
\text { porting bias) }\end{array}$ & Unclear risk & $\begin{array}{l}\text { We were unable to retrieve the trial protocol. There was no evidence of selec- } \\
\text { tive outcome reporting. }\end{array}$ \\
\hline Other bias & Low risk & We did not identify any other sources of bias. \\
\hline
\end{tabular}

Methods Study design: RCT.


Martins 2009 TLS (Continued)

Study dates and duration: March 2005 to November 2005, follow-up 8 months.

Standard care: all participants received routine care including drugs (DOTS), default tracing, and clinical monitoring according to National TB Control Program guidelines: 2RHZE/6HE.

Participants

Number: 270 enrolled; numbers presented varies for each outcome.

Inclusion criteria: adults aged $>18$ years, pulmonary tuberculosis diagnosed by positive sputum criteria or NTP guidelines, willingness to receive treatment from the clinic for 8 months.

Exclusion criteria: pregnancy, previous treatment for tuberculosis for $>1$ month, unable to agree to complete treatment, unwilling to attend for a daily meal, chose community DOT.

Description: adults aged $>18$ years.

Baseline characteristics

- Nutritional status: BMI < $18.5 \mathrm{~kg} / \mathrm{m}^{2}: 108 / 137$ treatment group versus $105 / 133$ control group.

- HIV status: not mentioned.

- MDR/XDR-TB: not mentioned.

- Described as poor; $80 \%$ had no formal income, food was readily available but expensive.

Interventions

Group 1: a daily meal (intensive phase; week 1 to 8 ) followed by a food parcel (continuation phase; week 9 to 32). The meal consisted of a bowl of meat, kidney beans, and vegetable stew with rice. The food parcel contained unprepared red kidney beans, rice, and oil adequate for 1 meal per day.

Group 2: verbal and written nutritional advice concerning locally available food that would constitute a balanced diet.

\begin{tabular}{ll}
\hline Outcomes & Treatment completion at 8 months. \\
- Mean weight gain $(\%)$ at 8 weeks and 32 weeks. \\
- Cough clearance at 4,8, and 32 weeks. \\
- Sputum clearance. \\
- Adverse events. \\
Not included in review: mean compliance, default rate. \\
Location: Dili, Timor-Leste. \\
Setting: 3 primary care clinics. \\
Funding: the UNICEF/UNDP/World Bank/WHO Special Programme for Research and Training in Tropical \\
Diseases, Australian National Health and Research Council.
\end{tabular}

Risk of bias

\begin{tabular}{lll}
\hline Bias & Authors' judgement & Support for judgement \\
\hline $\begin{array}{l}\text { Random sequence genera- } \\
\text { tion (selection bias) }\end{array}$ & Low risk & $\begin{array}{l}\text { "An independent statistician computer generated a random allocation se- } \\
\text { quence with randomly varying block sizes in Stata (version 8)". }\end{array}$ \\
\hline $\begin{array}{l}\text { Allocation concealment } \\
\text { (selection bias) }\end{array}$ & Low risk & $\begin{array}{l}\text { "The sequence was concealed from all investigators with sequentially num- } \\
\text { bered opaque sealed envelopes prepared distant from the study site". }\end{array}$ \\
\hline $\begin{array}{l}\text { Blinding (performance } \\
\text { bias and detection bias) } \\
\text { All outcomes }\end{array}$ & Low risk & $\begin{array}{l}\text { "Both participants and treatment providers were aware of an individual's allo- } \\
\text { cation status after randomisation. An independent observer, who was blinded } \\
\text { to the intervention received by the patients, however, determined the primary } \\
\text { outcome". }\end{array}$ \\
\hline
\end{tabular}

Nutritional supplements for people being treated for active tuberculosis (Review) 
Martins 2009 TLS (Continued)

Incomplete outcome data High risk High levels of missing data for the outcomes of cough clearance $(28 \%$ inter(attrition bias) vention versus $27 \%$ control at 8 weeks) and weight gain (12\% intervention ver-

All outcomes sus $9 \%$ control at 8 weeks, $29 \%$ intervention versus $33 \%$ control at 32 weeks). These could significantly affect the result.

\begin{tabular}{lll}
\hline $\begin{array}{l}\text { Selective reporting (re- } \\
\text { porting bias) }\end{array}$ & Low risk & $\begin{array}{l}\text { We were unable to retrieve the trial protocol. There was no evidence of selec- } \\
\text { tive reporting. }\end{array}$ \\
\hline Other bias & Low risk & We did not identify any other sources of bias. \\
\hline
\end{tabular}

\section{Mehta 2011 TZA}

Methods Study design: RCT.

Standard care: all participants received antituberculous therapy (6 months DOT: isoniazid $50 \mathrm{mg}$, rifampicin $200 \mathrm{mg}$, ethambutol 10 to $15 \mathrm{mg} / \mathrm{kg}$, and pyrazinamide 20 to $30 \mathrm{mg} / \mathrm{kg}$ daily for 2 months; isoniazid $50 \mathrm{mg}$ and rifampicin $200 \mathrm{mg}$ daily for 4 months) and were visited at home by the study nurse every 2 weeks.

Study dates and duration: May 2005 to September 2007. Follow-up 8 weeks.

Participants Number: 255 enrolled and randomized; outcomes presented for 237.

Inclusion criteria: aged 6 weeks to 5 years; loss of > $10 \%$ maximum weight or failure to gain weight for 2 months; cough with wheeze for $\geq 4$ weeks; history of household contact with a probable or confirmed tuberculosis case in the past 6 months; pyrexia of unknown origin; painless swelling in a group of cervical lymph nodes; children who were diagnosed with tuberculosis in the past 5 years and have received antituberculous therapy for a period $<4$ weeks. Positive TST $(\geq 10 \mathrm{~mm}$ induration in HIV-negative and $\geq 5 \mathrm{~mm}$ in HIV-positive; after 48 to 72 hours) or with chest X-ray indicative of tuberculosis (based on unequivocal lymphadenopathy or military tuberculosis) eligible for enrolment.

Exclusion criteria: children who had been treated with antituberculous therapy exceeding 4 weeks in the past 1 year.

Baseline characteristics

- Nutritional status: median (IQR) MUAC cm: 13.0 (11.9 to 14.25 ) multivitamin group versus 13.0 (11.2 to 14.0) placebo group; weight (kg): 8.48 multivitamin group versus 7.95 placebo group.

- HIV status: $39.1 \%$ HIV-positive in the multivitamin group, $29.1 \%$ HIV-positive in the placebo group.

- MDR/XDR-TB: not mentioned.

- Micronutrient status: not documented.

Interventions

Group 1: multivitamin supplements daily for the first 2 months. Composition: vitamin B1 $0.5 \mathrm{mg}$, vitamin B2 $0.6 \mathrm{mg}$, niacin $4 \mathrm{mg}$, vitamin B6 $0.6 \mathrm{mg}$, folate $130 \mu \mathrm{g}$, vitamin B12 $1 \mu \mathrm{g}$, vitamin C $60 \mathrm{mg}$, and vitamin E $8 \mathrm{mg}$.

- Age $<6$ months: 1 capsule daily.

- Age 7 to 36 months: 2 capsules daily.

- Age $>36$ months: 3 capsules daily.

Group 2: placebo daily for the first 2 months.

Outcomes $\quad$ Weight gain at 2 months.

Not included in this review: height, MUAC, and triceps skin-fold thickness changes at 2 months, clearance on chest $\mathrm{x}$-ray at 2 months, immunological outcomes. 
Mehta 2011 TZA (Continued)

Notes

Location: Dar Es Salaam, Tanzania.

Setting: hospital paediatric clinic.

Registration number: NCT00145184.

Source of funding: National Institutes of Health Grant, the Harvard School of Public Health.

\section{Risk of bias}

\begin{tabular}{|c|c|c|}
\hline Bias & Authors' judgement & Support for judgement \\
\hline $\begin{array}{l}\text { Random sequence genera- } \\
\text { tion (selection bias) }\end{array}$ & Low risk & $\begin{array}{l}\text { An off-site statistician generated the randomization sequence; a list from } 1 \text { to } \\
400 \text { was prepared according to this randomization sequence in blocks of } 20 \text {. }\end{array}$ \\
\hline $\begin{array}{l}\text { Allocation concealment } \\
\text { (selection bias) }\end{array}$ & Low risk & $\begin{array}{l}\text { At enrolment, the trial staff assigned each eligible child to the next numbered } \\
\text { bottle of regimen at the site. The statistician kept the randomization list confi- } \\
\text { dential, with the exception of the pharmaceutical company that prepared the } \\
\text { blinded treatment. }\end{array}$ \\
\hline $\begin{array}{l}\text { Blinding (performance } \\
\text { bias and detection bias) } \\
\text { All outcomes }\end{array}$ & Low risk & $\begin{array}{l}\text { To minimize the risk of loss of blinding, the regimen bottles, with no visual dif- } \\
\text { ference between active regimen and placebo, were received from the man- } \\
\text { ufacturer without any identification; the study staff then labelled the bottles } \\
\text { with the participant's initials and identification number. Both the clinicians } \\
\text { and the participants were blinded to the study regimen. }\end{array}$ \\
\hline $\begin{array}{l}\text { Incomplete outcome data } \\
\text { (attrition bias) } \\
\text { All outcomes }\end{array}$ & Low risk & $\begin{array}{l}\text { Losses to follow-up were low: } 2.3 \% \text { supplement group versus } 1.6 \% \text { placebo } \\
\text { group. }\end{array}$ \\
\hline $\begin{array}{l}\text { Selective reporting (re- } \\
\text { porting bias) }\end{array}$ & Low risk & $\begin{array}{l}\text { Although we were unable to retrieve the trial protocol, there was no evidence } \\
\text { of selective reporting. }\end{array}$ \\
\hline Other bias & High risk & $\begin{array}{l}\text { There was a large difference in HIV status between the intervention and con- } \\
\text { trol groups at baseline. }\end{array}$ \\
\hline
\end{tabular}

\section{Mily 2015 BGD}

Study design: RCT.
Standard care: all participants received antituberculous therapy (isonizaid $75 \mathrm{mg}$, rifampicin 150
mg, pyrazinamide $400 \mathrm{mg}$, and ethambutol $275 \mathrm{mg}$ for 2 months, followed by rifampicin $150 \mathrm{mg}$ plus
isonizaid $75 \mathrm{mg}$ for $4 \mathrm{months}$ ), given under direct observation.

Study dates and duration: December 2010 to December 2013. Follow-up 24 weeks.

Participants Number: 288 enrolled and randomized.

Inclusion criteria: age > 18 years, newly diagnosed sputum smear-positive tuberculosis, consent.

Exclusion criteria: pregnancy and lactation, relapse tuberculosis, HIV infection, hypercalcaemia, regular intake of vitamin D, diabetes, cardiovascular, hepatic and renal diseases and malignancy, suspicion of prolonged drug abuse.

Baseline characteristics

- Nutritional status: mean weight (kg): males: 47.9 vitamin D group versus 46.3 placebo group; females: 38.4 vitamin $\mathrm{D}$ group versus 39.8 placebo group. 
Mily 2015 BGD (Continued)

- HIV status: excluded.

- MDR/XDR-TB: not mentioned.

- Micronutrient status: mean plasma $25(\mathrm{OH}) \mathrm{D}_{3}$ level: 28.0 vitamin $\mathrm{D}$ group versus 28.1 placebo group.

Group 1: vitamin D 5000 IU daily for 8 weeks.
Group 2: placebo.
Not included in the review:
Group 3: 4-phenylbutyrate 500 mg twice daily.
Group 4: vitamin D plus 4-phenylbutyrate.
- Culture conversion at 4 weeks.
- Time to sputum conversion.
- Witamin D levels.
- Adverse events.
Not included in this review: Cough remission, CXR changes, normalization of fever, immunological mea-
sures.
Location: Dhaka, Bangladesh.
Setting: National Institute of the Diseases of the Chest Hospital (NIDCH).
Registration number: NCT01580007.
Source of funding: International Centre for Diarrheal Disease Research, Bangladesh, Sida Agreement
support Grant 384, and Swedish Strategic Foundation, and the Swedish Heart-Lung Foundation.

\section{Risk of bias}

\begin{tabular}{|c|c|c|}
\hline Bias & Authors' judgement & Support for judgement \\
\hline $\begin{array}{l}\text { Random sequence genera- } \\
\text { tion (selection bias) }\end{array}$ & Low risk & "computer-generated randomization sequence". \\
\hline $\begin{array}{l}\text { Allocation concealment } \\
\text { (selection bias) }\end{array}$ & Low risk & $\begin{array}{l}\text { "Independent assistants from the Hospital pharmacy prepared the study med- } \\
\text { ication packs (PBA and placebo tablets; with identical appearance, colour and } \\
\text { taste), and labelled these tablets with a randomization number". }\end{array}$ \\
\hline $\begin{array}{l}\text { Blinding (performance } \\
\text { bias and detection bias) } \\
\text { All outcomes }\end{array}$ & Low risk & "placebo with identical appearance, colour and taste". \\
\hline $\begin{array}{l}\text { Incomplete outcome data } \\
\text { (attrition bias) } \\
\text { All outcomes }\end{array}$ & Low risk & Losses to follow-up in the first 8 weeks were low. \\
\hline $\begin{array}{l}\text { Selective reporting (re- } \\
\text { porting bias) }\end{array}$ & Low risk & $\begin{array}{l}\text { We were unable to retrieve the trial protocol. There was no evidence of selec- } \\
\text { tive reporting. }\end{array}$ \\
\hline Other bias & Low risk & We did not identify any other sources of bias. \\
\hline
\end{tabular}


Morcos 1998 EGY

\begin{tabular}{|c|c|}
\hline Methods & $\begin{array}{l}\text { Study design: RCT. } \\
\text { Study dates and duration: not stated. } \\
\text { Standard care: all participants received standard anti-tuberculous therapy: HRS for } 2 \text { months (beyond } \\
2 \text { months therapy is not described). }\end{array}$ \\
\hline Participants & $\begin{array}{l}\text { Number: } 24 \text { enrolled; outcomes presented for } 24 . \\
\text { Inclusion criteria: children with active tuberculosis; pulmonary or extrapulmonary. } \\
\text { Exclusion criteria: none stated. } \\
\text { Baseline characteristics } \\
\text { - } \quad \text { Nutritional status: not stated. } \\
\text { - HIV status: not mentioned. } \\
\text { - MDR/XDR-TB: not mentioned. } \\
\text { - Vitamin D1: the mean vitamin D level at baseline is not given for the separate groups. }\end{array}$ \\
\hline Interventions & $\begin{array}{l}\text { Group 1: usual treatment plus vitamin D (1000 IU/day) for } 8 \text { weeks. } \\
\text { Group 2: usual treatment. }\end{array}$ \\
\hline Outcomes & $\begin{array}{l}\text { - Body weight before and after treatment. } \\
\text { - Vitamin D levels. }\end{array}$ \\
\hline Notes & $\begin{array}{l}\text { Location: Cairo, Egypt. } \\
\text { Setting: inpatients and outpatients at a children's hospital. } \\
\text { Funding: not stated. }\end{array}$ \\
\hline
\end{tabular}

\section{Risk of bias}

\begin{tabular}{lll}
\hline Bias & Authors' judgement & Support for judgement \\
\hline $\begin{array}{l}\text { Random sequence genera- } \\
\text { tion (selection bias) }\end{array}$ & Unclear risk & $\begin{array}{l}\text { "randomly divided into 2 groups". The trial authors did not provide any further } \\
\text { details. }\end{array}$ \\
\hline $\begin{array}{l}\text { Allocation concealment } \\
\text { (selection bias) }\end{array}$ & Unclear risk & The trial authors did not describe any allocation concealment. \\
\hline $\begin{array}{l}\text { Blinding (performance } \\
\text { bias and detection bias) } \\
\text { All outcomes }\end{array}$ & High risk & The trial authors did not describe any blinding and did not use a placebo. \\
\hline $\begin{array}{l}\text { Incomplete outcome data } \\
\text { (attrition bias) } \\
\text { All outcomes }\end{array}$ & Low risk & No losses to follow-up: 24/24 (100\%) analysed. \\
\hline $\begin{array}{l}\text { Selective reporting (re- } \\
\text { porting bias) }\end{array}$ & Unclear risk & We were unable to retrieve the trial protocol. \\
\hline \begin{tabular}{l} 
Other bias \\
\hline
\end{tabular} & High risk & The trial authors did not state important baseline characteristics.
\end{tabular}


Nursyam 2006 IDN

\begin{tabular}{|c|c|}
\hline Methods & $\begin{array}{l}\text { Study design: RCT. } \\
\text { Study dates and duration: January } 2001 \text { to August 2001, follow-up } 8 \text { weeks. } \\
\text { Standard care: all participants received antituberculous therapy in accordance with DOTS program, } \\
\text { first category: } 2 \mathrm{RHZE/4RH.}\end{array}$ \\
\hline Participants & $\begin{array}{l}\text { Number: } 67 \text { enrolled; outcomes presented for } 67 . \\
\text { Inclusion criteria: adults aged } 15 \text { to } 59 \text { with sputum-culture positive pulmonary tuberculosis and mod- } \\
\text { erately advanced lesion. } \\
\text { Exclusion criteria: corticosteroids or immunosuppressive treatment, AIDS, renal failure, diabetes melli- } \\
\text { tus, liver cirrhosis, measles, malignancies, leprosy, or severe nutritional deficiency. } \\
\text { Baseline characteristics } \\
\text { - Nutritional status: mean BMI (SD): } 16.87 \mathrm{~kg} / \mathrm{m}^{2}(2.06) \text { treatment group versus } 17.68 \mathrm{~kg} / \mathrm{m}^{2}(2.54) \text { place- } \\
\text { bo group. } \\
\text { - HIV status: negative. } \\
\text { - MDR/XDR-TB: not described. } \\
\text { - Described as: } 67.2 \% \text { had low income, } 71.6 \% \text { were low in nutritional status. } \\
\text { - Vitamin D status at baseline not described. }\end{array}$ \\
\hline
\end{tabular}

Interventions

Group 1: vitamin D (0.25 mg/day for the first 6 weeks).

Group 2: placebo.

\begin{tabular}{ll}
\hline Outcomes & Sputum-culture positive at 6 weeks. \\
& Out at 0 and 6 weeks. \\
& Outcomes not included in this review: $x$-ray improvement at 6 weeks, default rate. \\
\hline Notes & Location: Jakarta, Indonesia. \\
& Setting: outpatients at a pulmonary clinic.
\end{tabular}

\section{Risk of bias}

\begin{tabular}{lll}
\hline Bias & Authors' judgement & Support for judgement \\
\hline $\begin{array}{l}\text { Random sequence genera- } \\
\text { tion (selection bias) }\end{array}$ & Unclear risk & The trial authors described it as "randomised"; but gave no further details. \\
\hline $\begin{array}{l}\text { Allocation concealment } \\
\text { (selection bias) }\end{array}$ & Unclear risk & The trial authors did not describe allocation concealment. \\
\hline $\begin{array}{l}\text { Blinding (performance } \\
\text { bias and detection bias) }\end{array}$ & Low risk & $\begin{array}{l}\text { The trial authors described the trial as "double blind" and stated "the placebo } \\
\text { were manufactured in the same shape and size". They did no provide any fur- } \\
\text { ther details. }\end{array}$ \\
\hline $\begin{array}{l}\text { Incomplete outcome data } \\
\begin{array}{l}\text { (attrition bias) } \\
\text { All outcomes }\end{array}\end{array}$ & Low risk & $\begin{array}{l}\text { There were no losses to follow-up. The trial authors analysed 67/67 (100\%) for } \\
\text { sputum conversion at 6 weeks. }\end{array}$ \\
\hline $\begin{array}{l}\text { Selective reporting (re- } \\
\text { porting bias) }\end{array}$ & Unclear risk & $\begin{array}{l}\text { We were unable to retrieve the trial protocol. There was no evidence of selec- } \\
\text { tive reporting. }\end{array}$ \\
\hline \begin{tabular}{l} 
Other bias \\
\hline
\end{tabular} & Low risk & \begin{tabular}{l} 
We did not identify any other sources of bias. \\
\hline
\end{tabular}
\end{tabular}




\begin{tabular}{|c|c|}
\hline Methods & $\begin{array}{l}\text { Study design: RCT. } \\
\text { Study dates and duration: January } 2004 \text { to December 2005, follow-up } 6 \text { months. } \\
\text { Standard care: all participants received antituberculous therapy in accordance with DOTS program; } \\
\text { 2RHZE (daily)/4HR (thrice weekly), given by a treatment partner who was paid if the participant suc- } \\
\text { cessfully completed treatment. }\end{array}$ \\
\hline Participants & $\begin{array}{l}\text { Number: } 300 \text { enrolled; } 76 \text { zinc; } 72 \text { vitamin A; } 66 \text { vitamin A + zinc; } 86 \text { placebo - } 255 \text { completed } 6 \text { months } \\
\text { and were analysed. } \\
\text { Inclusion criteria: adults aged } 15 \text { to } 55 \text {, newly diagnosed sputum AFB positive pulmonary tuberculosis. } \\
\text { Exclusion criteria: pregnancy, lactation, underlying chronic, or degenerative diseases. } \\
\text { Baseline characteristics } \\
\text { - Nutritional status: mean BMI (SD): } 16.5 \mathrm{~kg} / \mathrm{m}^{2} \text { (2.2) Zinc; } 16.5 \mathrm{~kg} / \mathrm{m}^{2}(2.2) \mathrm{Vit} \mathrm{A} ; 16.6 \mathrm{~kg} / \mathrm{m}^{2} \text { (2.1) zinc + } \\
\text { vitamin A, and } 16.4 \mathrm{~kg} / \mathrm{m}^{2}(2.5) \text { in the placebo group. } \\
\text { - HIV status: not mentioned. } \\
\text { - MDR/XDR-TB: not mentioned. } \\
\text { - Vitamin A status: median plasma retinol } \mu \mathrm{mol} / \mathrm{L} \text { (IQR): } 0.75(0.5 \text { to } 1.0) \text { zinc; } 0.7(0.5 \text { to } 1.5) \text { vitamin A; } \\
\text { 0.7(0.4 to } 1.1) \text { zinc + vitamin A and } 0.7(0.5 \text { to } 1.0) \text { placebo group. } \\
\text { - Zinc status: mean plasma zinc } \mu \mathrm{mol} / \mathrm{L}(\mathrm{SD}): 11.6(2.2) \text { zinc; } 11.9(3.0) \text { vitamin A; } 12.1(3.0) \text {, zinc + vitamin } \\
\text { A and } 11.8(2.4) \text { placebo group. }\end{array}$ \\
\hline
\end{tabular}

Interventions
Zinc group: 15 mg zinc sulphate daily for 6 months as a capsule.
Vitamin A group: 5000 IU (1500 retinol equivalents) daily as a capsule.
Zinc + vitamin A group: both the above capsules for 6 months.
Placebo group: lactose capsule daily for 6 months.

\begin{tabular}{l} 
- Sputum smear conversion weekly for 8 weeks. \\
- Anthropometry: weight, BMI, skin folds, percentage body fat. \\
- Blood tests: plasma zinc, vltamin A. \\
- Deaths during study. \\
Not included in this review: chest X-ray cavity size, C-reactive protein, ESR, Hemoglobin, leukocyte \\
count, and serum albumin. \\
\hline Location: Nusa Tenggara Timur Province, Indonesia. \\
Setting: community-based trial. \\
Funding: Canadian International Development Agency through World Vision International Indonesi- \\
a:Food integrated to Hinder TB Project (WVI-FIGHT Project).
\end{tabular}

\section{Risk of bias}

\begin{tabular}{lll}
\hline Bias & Authors' judgement & Support for judgement \\
\hline $\begin{array}{l}\text { Random sequence genera- } \\
\text { tion (selection bias) }\end{array}$ & Low risk & "randomisation was done using a computer program". \\
\hline $\begin{array}{l}\text { Allocation concealment } \\
\text { (selection bias) }\end{array}$ & Unclear risk & $\begin{array}{l}\text { "a treatment code was given to each subject". The trial authors did not provide } \\
\text { any further details. }\end{array}$ \\
\hline
\end{tabular}


Pakasi 2010 IDN (Continued)

Blinding (performance Low risk "All capsules were identical in shape, colour and size". bias and detection bias) All outcomes

\begin{tabular}{|c|c|c|}
\hline $\begin{array}{l}\text { Incomplete outcome data } \\
\text { (attrition bias) } \\
\text { All outcomes }\end{array}$ & High risk & There was greater than $10 \%$ loss to follow-up in each group. \\
\hline $\begin{array}{l}\text { Selective reporting (re- } \\
\text { porting bias) }\end{array}$ & Unclear risk & $\begin{array}{l}\text { We were unable to retrieve the trial protocol. There was no evidence of selec- } \\
\text { tive reporting. }\end{array}$ \\
\hline
\end{tabular}

Other bias Low risk We did not identify any other sources of bias.

Paliliewu 2013 IDN

Study design: RCT.
Study dates and duration: not described.
Standard care: short course directly observed antibiotic therapy. Intensive 60 -day treatment with isoni-
azid ( $300 \mathrm{mg} /$ day), rifampicin (600 $\mathrm{mg} /$ day), pyrazinamide $(1600 \mathrm{mg} / \mathrm{day})$, and ethambutol (1200 mg/
day) followed by a sustained 45 -dose therapeutic phase with isoniazid ( $800 \mathrm{mg} / \mathrm{dose})$ and rifampicin
(600 $\mathrm{mg} /$ dose).

Number: 36 enrolled.
Inclusion criteria: 14 to 50 years, $\geq 2$ sputum smear positive, minimal-medium radiological lesion, 16
to $23 \mathrm{mg} / \mathrm{kg}^{2}$ (BMI), $\geq 2.5$ to $4.5 \mathrm{~g} / \mathrm{dL}$ albumin levels and no prior history of tuberculosis or tuberculosis
treatment.
Exclusion criteria: pregnant, breast feeding, used corticosteroids, had HIV, diabetes or another serious
co morbidity.
Baseline characteristics
- Nutritional status: not stated.
- HIV status: not stated.
- MDR/XDR-TB: not stated.
- Micronutrient levels not stated.
- Sputum positivity: 18 (100\%) in intervention group, 18 (100\%) in placebo group.

Interventions Channa striata group: $C$. striata capsules, 4 months supplementation with $2 \mathrm{~g} / \mathrm{day}, 3$ times/day of $C$. striata for 12 weeks.

Placebo group: organoleptically matched placebo with identical dosage regime.

\begin{tabular}{ll}
\hline Outcomes & Percentage sputum conversion. \\
& - Disease signs \& symptoms - cough, haemoptysis, dyspnoea, fever, night sweats, fatigue. \\
- & Laboratory indicators- AST, ALT, creatinine, uric acid, albumin. \\
\hline Notes & Location: IFN- Indonesia. \\
& Setting: clinic, patients attending Department of Internal Medicine, University of Sam Ratulangi, Mana- \\
do, North Sulawesi, Indonesia. & \\
Funding: research grant from PT. Royal Medicalink Pharmalab, Makassar South Sulawessi, Indonesia.
\end{tabular}


Paliliewu 2013 IDN (Continued)

Risk of bias

\begin{tabular}{lll}
\hline Bias & Authors' judgement & Support for judgement \\
\hline $\begin{array}{l}\text { Random sequence genera- } \\
\text { tion (selection bias) }\end{array}$ & Unclear risk & The trial authors did not describe how the random sequence was generated. \\
\hline $\begin{array}{l}\text { Allocation concealment } \\
\text { (selection bias) }\end{array}$ & Unclear risk & The trial authors did not explicitly describe this process. \\
\hline $\begin{array}{l}\text { Blinding (performance } \\
\text { bias and detection bias) } \\
\text { All outcomes }\end{array}$ & Unclear risk & $\begin{array}{l}\text { Participants were blinded to the treatment allocation as organoleptically iden- } \\
\text { tical capsules were provided to both groups at similar times. Blinding of study } \\
\text { personnel and outcome assessors was not described. }\end{array}$ \\
\hline $\begin{array}{l}\text { Incomplete outcome data } \\
\text { (attrition bias) } \\
\text { All outcomes }\end{array}$ & Unclear risk & $\begin{array}{l}\text { The trial authors did not provide any information on the number of partici- } \\
\text { pants lost to follow-up. }\end{array}$ \\
\hline $\begin{array}{l}\text { Selective reporting (re- } \\
\text { porting bias) }\end{array}$ & Unclear risk & $\begin{array}{l}\text { We were unable to obtain a copy of the trial protocol so it is unclear if the au- } \\
\text { thors presented data on all of the stipulated outcomes. }\end{array}$ \\
\hline $\begin{array}{l}\text { Other bias } \\
\text { Baseline comparability: figure in paper provides information on the sex, clin- } \\
\text { ical signs, and symptoms and lab indicators at baseline. There was no differ- } \\
\text { ence in any of these variables at baseline. }\end{array}$ \\
$\begin{array}{l}\text { Funding source: research grant from PT. Royal Medicalink Pharmalab. } \\
\text { Conflict of interest: not stated. }\end{array}$ \\
\hline
\end{tabular}

Paton 2004 SGP

Study design: RCT.
Study dates and duration: November 2000 to July 2002. Follow-up 24 weeks.
Standard care: all participants received combination antituberculous drug treatment, ancillary care,
and follow-up according to standard protocols of the Tuberculosis Control Unit.
Participants Number: 36 enrolled; outcomes presented for 34 .
Inclusion criteria: adults aged 18 to 69 years, with pulmonary tuberculosis and a body mass index $<20$ $\mathrm{kg} / \mathrm{m}^{2}$.
Exclusion criteria: diabetes or other severe underlying disease, concomitant corticosteroid or immuno- suppressive therapy, HIV-positive or considered to be at risk of HIV and refused testing, history of non- compliance to tuberculosis therapy, unable to tolerate conventional regimen, required inpatient care.
Baseline characteristics
- Nutritional status: mean BMI (SD): $16.7 \mathrm{~kg} / \mathrm{m}^{2}$ (1.5) supplement group versus $17.9 \mathrm{~kg} / \mathrm{m}^{2}$ (1.9) control group.
- HIV status: all negative.
- MDR/XDR-TB: not mentioned.
- Description: no comment on the social economic status of participants.

Interventions

Group 1: a target energy intake was calculated for each participant and advice given to them on how to reach this target based on a 24-hour food diary; participants were also supplied with high-energy oral nutritional supplements (6.25 g protein, $20.2 \mathrm{~g}$ carbohydrate, $4.29 \mathrm{~g}$ fat, $150 \mathrm{kcal} / 100 \mathrm{~mL}$ ) and advised

Nutritional supplements for people being treated for active tuberculosis (Review) 
Paton 2004 SGP (Continued)

to consume 2 packets/day between meals ( $600 \mathrm{kcal}$ total), which increased to 3 packets/day if tolerated, until they reached a body mass index of 20 or usual body weight.

Group 2: participants were advised to increase their food intake and given advice to address any imbalances in their diet based on a 24-hour food diary.

\begin{tabular}{ll}
\hline Outcomes & Body weight, total lean mass, and total fat mass. \\
- Change in maximum grips strength and time stands test. \\
- Change in quality of life score.
\end{tabular}

Not included in the review: total energy intake; total energy intake from normal diet.

Outcomes measured at 6,12 , and 24 weeks.

Location: Singapore.
Setting: outpatients attending a tuberculosis control unit.
Funding: National Medical Research Council of Singapore, Ensure donated by Abbott Laboratories.

\section{Risk of bias}

\begin{tabular}{|c|c|c|}
\hline Bias & Authors' judgement & Support for judgement \\
\hline $\begin{array}{l}\text { Random sequence genera- } \\
\text { tion (selection bias) }\end{array}$ & Low risk & $\begin{array}{l}\text { "The randomisation was } 1: 1 \text { for the } 2 \text { groups and was performed by random- } \\
\text { ly shuffling opaque envelopes containing study codes. Preparation of the ran- } \\
\text { domisation envelopes was performed by a member of the staff who was not } \\
\text { directly involved in the study". }\end{array}$ \\
\hline $\begin{array}{l}\text { Allocation concealment } \\
\text { (selection bias) }\end{array}$ & Unclear risk & See above. The trial authors did not report any further details. \\
\hline $\begin{array}{l}\text { Blinding (performance } \\
\text { bias and detection bias) } \\
\text { All outcomes }\end{array}$ & High risk & $\begin{array}{l}\text { None described. Given the nature of the intervention, only outcome assessors } \\
\text { could reasonably have been blinded but the trial authors did not describe this. }\end{array}$ \\
\hline $\begin{array}{l}\text { Incomplete outcome data } \\
\text { (attrition bias) } \\
\text { All outcomes }\end{array}$ & High risk & $\begin{array}{l}\text { Losses to follow-up were low at } 6 \text { weeks (3\%), but high at } 24 \text { weeks: } 21 \% \text { in the } \\
\text { supplement group versus 35\% in the advice only group. }\end{array}$ \\
\hline $\begin{array}{l}\text { Selective reporting (re- } \\
\text { porting bias) }\end{array}$ & Unclear risk & $\begin{array}{l}\text { We were unable to retrieve the trial protocol. There was no evidence of selec- } \\
\text { tive reporting. }\end{array}$ \\
\hline Other bias & Low risk & We did not identify any other sources of bias. \\
\hline
\end{tabular}

\section{Praygod 2011a TZA}

Methods Study design: RCT.

Study dates and duration: April 2006 to March 2009, follow-up 5 months.

Standard care: all participants received standardized antituberculous drug treatment for 6 to 8 months according to national guidelines: $2 \mathrm{RHZE} / 6 \mathrm{HE}$.

Pumber: 865 enrolled.
Inclusion criteria: adults aged > 15 years, with new or relapse pulmonary tuberculosis.


Praygod 2011a TZA (Continued)

Exclusion criteria: extra-pulmonary tuberculosis, terminal illness, pregnancy, sputum-positive patients with HIV co-infection.

Note: the trial included patients with sputum-negative pulmonary tuberculosis and HIV co-infection.

Baseline characteristics

- Nutritional status: mean BMI (SD): $18.9 \mathrm{~kg} / \mathrm{m}^{2}(2.8)$ intervention group versus $18.9 \mathrm{~kg} / \mathrm{m}^{2}$ (3.1) control group.

- HIV status: $27 \%$ HIV-positive intervention group versus $29 \%$ control group.

- MDR/XDR-TB: not mentioned.

- Description: no comment on the social economic status of participants.

- Micronutrient status: at baseline not reported.

Interventions

Group 1: the intervention group received a daily energy-protein similar to the control biscuit but with additional: $1.5 \mathrm{mg}$ vitamin A, $20 \mathrm{mg}$ thiamin, $20 \mathrm{mg}$ riboflavin, $25 \mathrm{mg}$ vitamin B6, $50 \mu \mathrm{g}$ vitamin B12, 0.8 $\mathrm{mg}$ folic acid, $40 \mathrm{mg}$ niacin, $200 \mathrm{mg}$ vitamin C, $60 \mathrm{mg}$ vitamin E, $5 \mu \mathrm{g}$ vitamin D, $0.2 \mathrm{mg}$ selenium, $5 \mathrm{mg}$ copper, $30 \mathrm{mg}$ zinc.

Group 2: the control group received a daily energy-protein biscuit for the first 60 days of treatment. Composition: 4.5 g protein, $615 \mathrm{~kJ}$ energy, $120 \mathrm{mg}$ phosphorous, $120 \mathrm{mg}$ calcium, $36 \mathrm{mg}$ magnesium, 70 $\mathrm{mg}$ sodium, $150 \mathrm{mg}$ potassium, and traces $<1 \mathrm{mg}$ of iron and zinc

Outcomes

- Body weight, arm fat area, arm muscle area at 0, 2, and 5 months.

- Maximum hand grips strength at 0,2, and 5 months.

Notes Location: Mwanza, Tanzania.

Setting: 4 tuberculosis clinics serving urban and suburban patients.

Funding: the Danish Council for Independant Research, Danida and the University of Copenhagen.

Clinical trial registry number: NCT00311298.

\section{Risk of bias}

\begin{tabular}{lll}
\hline Bias & Authors' judgement & Support for judgement \\
\hline $\begin{array}{l}\text { Random sequence genera- } \\
\text { tion (selection bias) }\end{array}$ & Low risk & $\begin{array}{l}\text { "Allocation to treatment arms followed a computer-generated randomisation } \\
\text { sequence using permuted blocks of ten". }\end{array}$ \\
\hline $\begin{array}{l}\text { Allocation concealment } \\
\text { (selection bias) }\end{array}$ & Low risk & $\begin{array}{l}\text { "The random sequence was used by a designated research staff member who } \\
\text { was not involved in any clinical work in TB clinics to arrange and label the sup- } \\
\text { plement packs with identity numbers ranging from } 1 \text { to } 1500 . \text { During the study, } \\
\text { the randomisation sequence and code were kept in a safe cabinet and were ac- } \\
\text { cessible only to the research staff. Recruitment of study participants was done } \\
\text { by clinic staff. Then the same designated research staff assigned the recruit- } \\
\text { ed patient an identity number and sent the corresponding nutritional supple- } \\
\text { ment pack to the respective clinic". }\end{array}$
\end{tabular}

$\begin{array}{ll}\begin{array}{l}\text { Blinding (performance } \\ \text { bias and detection bias) }\end{array} & \text { Low risk } \\ \begin{array}{ll}\text { All outcomes } & \text { "Both control and experimental supplements were of the same size and colour } \\ \text { but had slightly different tastes and were wrapped in grey-coloured paper box } \\ \text { with } 6 \text { bars each". }\end{array}\end{array}$

\begin{tabular}{ll}
\hline $\begin{array}{l}\text { Incomplete outcome data } \\
\text { (attrition bias) }\end{array}$ & Low risk \\
All outcomes & $\begin{array}{l}\text { Loss to follow-up at } 2 \text { months and } 5 \text { months were } 10.2 \% \text { and } 18.0 \% \text { respec- } \\
\text { tively. However, the proportion lost to follow-up did not differ significantly be- } \\
\text { tween the groups. }\end{array}$
\end{tabular}


Praygod 2011a TZA (Continued)

Selective reporting (re- Unclear risk Outcomes reported in the publication match those set out in the protocol. porting bias) However, mortality, a secondary outcome was not reported on.
Other bias

Low risk
The baseline characteristics of the 2 arms were comparable.

Funding: Danish council for independent research - Medical sciences; Danida through Consultative Research Committee for Development Research; University of Copenhagen.

Conflict of interest: all trial authors reported no conflicts of interest.

\section{Praygod 2011b TZA}

\begin{tabular}{|c|c|}
\hline Methods & $\begin{array}{l}\text { Study design: RCT. } \\
\text { Study dates and duration: April } 2006 \text { to March 2009, follow-up } 5 \text { months. } \\
\text { Standard care: all participants received standardized antituberculous drug treatment for } 6 \text { to } 8 \text { months } \\
\text { according to national guidelines: } 2 \mathrm{RHZE} / 6 \mathrm{HE} \text {. }\end{array}$ \\
\hline Participants & $\begin{array}{l}\text { Number: } 377 \text { randomized. } \\
\text { Inclusion criteria: adults aged > } 15 \text { years, with new or relapse sputum-positive pulmonary tuberculosis } \\
\text { with HIV co-infection. } \\
\text { Exclusion criteria: extra-pulmonary tuberculosis, terminal illness, pregnancy. } \\
\text { Baseline characteristics } \\
\text { - Nutritional status: mean BMI (SD): } 18.7 \mathrm{~kg} / \mathrm{m}^{2}(2.9) \text { intervention group versus } 18.5 \mathrm{~kg} / \mathrm{m}^{2}(2.8) \mathrm{control} \\
\text { group. } \\
\text { - HIV status: all HIV positive. } \\
\text { - MDR/XDR-TB: not mentioned. } \\
\text { - Description: no comment on the social economic status of participants. }\end{array}$ \\
\hline
\end{tabular}

Interventions

Group 1: the intervention group received 6 daily energy-protein biscuits for the first 60 days of treatment, of which 1 contained the additional micronutrients.

Group 2: the control group received 1 daily energy-protein biscuit with additional micronutrients.

Basic biscuit: composition: 4.5 g protein, $615 \mathrm{~kJ}$ energy, $120 \mathrm{mg}$ phosphorous, $120 \mathrm{mg}$ calcium, $36 \mathrm{mg}$ magnesium, $70 \mathrm{mg}$ sodium, $150 \mathrm{mg}$ potassium, and traces $<1 \mathrm{mg}$ of iron and zinc.

Biscuit with additional micronutrients: as above plus $1.5 \mathrm{mg}$ vitamin $\mathrm{A}, 20 \mathrm{mg}$ thiamin, $20 \mathrm{mg}$ riboflavin, $25 \mathrm{mg}$ vitamin B6, $50 \mu \mathrm{g}$ vitamin B12, $0.8 \mathrm{mg}$ folic acid, $40 \mathrm{mg}$ niacin, $200 \mathrm{mg}$ vitamin C, $60 \mathrm{mg}$ vitamin $\mathrm{E}$, $5 \mu \mathrm{g}$ vitamin $\mathrm{D}, 0.2 \mathrm{mg}$ selenium, $5 \mathrm{mg}$ copper, $30 \mathrm{mg}$ zinc.

Outcomes

- Body weight, arm fat area, arm muscle area at 0, 2, and 5 months.

- Maximum hand grips strength at 0,2, and 5 months.

Notes

Location: Mwanza, Tanzania.

Setting: 4 tuberculosis clinics serving urban and suburban patients.

Funding: The Danish Council for Independant Research, Danida and the University of Copenhagen.

Clinical trial registry number: NCT00311298.

\section{Risk of bias}

Nutritional supplements for people being treated for active tuberculosis (Review) 
Praygod 2011b TZA (Continued)

\begin{tabular}{lll} 
Bias & Authors' judgement & Support for judgement \\
\hline $\begin{array}{l}\text { Random sequence genera- } \\
\text { tion (selection bias) }\end{array}$ & Low risk & $\begin{array}{l}\text { "Computer-generated randomisation sequence, using permuted blocks of } \\
\text { ten". }\end{array}$ \\
\hline $\begin{array}{l}\text { Allocation concealment } \\
\text { (selection bias) }\end{array}$ & Low risk & $\begin{array}{l}\text { "The allocation sequence was used by designated research staff to sequential- } \\
\text { ly arrange and label supplement packs with identity numbers ranging from } 1 \\
\text { to } 500 . \text { During the study the randomisation sequence and code were kept in } \\
\text { a safe cabinet only accessible by designated research staff. Recruitment was } \\
\text { done by clinic staff. The same designated research staff not employed at the } \\
\text { study clinics assigned an identity number to the recruited patient and sent the } \\
\text { corresponding nutritional pack to the respective clinic". }\end{array}$
\end{tabular}

Blinding (performance High risk Blinding was not possible due to the nature of the intervention.

bias and detection bias)

All outcomes

\begin{tabular}{ll}
$\begin{array}{l}\text { Incomplete outcome data } \\
\text { (attrition bias) }\end{array}$ & Low risk \\
All outcomes & $\begin{array}{l}\text { At } 2 \text { and } 5 \text { months, } 12.2 \% \text { and } 19.1 \% \text { of participants were lost to follow-up. } \\
\text { However, the proportions lost to follow-up were similar across the interven- } \\
\text { tion and control arms of the study. }\end{array}$ \\
\hline
\end{tabular}

\begin{tabular}{|c|c|c|}
\hline $\begin{array}{l}\text { Selective reporting (re- } \\
\text { porting bias) }\end{array}$ & Low risk & $\begin{array}{l}\text { Outcomes reported in the publication match those set out in the protocol. } \\
\text { However, mortality, a secondary outcome was not reported on. }\end{array}$ \\
\hline
\end{tabular}

Other bias Low risk The baseline characteristics of the 2 arms were comparable.

Funding: Danish council for Independent Research - Medical sciences; Danida through Consultative Research Committee for Development Research; University of Copenhagen.

Conflict of interest: all trial authors reported no conflicts of interest.

Pérez-Guzmán 2005 MEX

Study design: RCT.
Study dates and duration: March 2001 to January 2002, follow-up 8 weeks.
Standard care: all participants received a short-course regimen with 4 antituberculous drugs under the
DOTS strategy according to WHO guidelines.
Number: 21 enrolled; outcomes presented for 21.
Inclusion criteria: adults aged 17 to 60 years with sputum-culture positive pulmonary tuberculosis.
Exclusion criteria: diabetes mellitus; HIV-positive; signs of coronary heart disease.
Baseline characteristics
- Nutritional status: mean BMI (SEM): $19.9 \mathrm{~kg} / \mathrm{m}^{2}(1.2)$ intervention group versus $19.2 \mathrm{~kg} / \mathrm{m}^{2}(0.8)$ normal
diet group.
- HIV status: excluded.
- MDR/XDR-TB: not reported

Interventions

Group 1: normal diet containing 2500 calories a day, $16 \%$ protein, $54 \%$ carbohydrate, and $30 \%$ lipids for 8 weeks; included $250 \mathrm{mg}$ cholesterol/day. 
Pérez-Guzmán 2005 MEX (Continued)

Group 2: high cholesterol diet containing 2500 kcal per day, $16 \%$ protein, $54 \%$ carbohydrate, and $30 \%$ lipids for 8 weeks; included $850 \mathrm{mg}$ cholesterol/day.

Outcomes - Sputum-culture positive at end of weeks 2, 4, and 8.

Not included in the review: mean number of colony-forming units and acid-fast bacilli in sputum smear; self reported severity of cough, sputum production, and dyspnoea.

Outcomes measured at weeks $1,2,3,4,5,6,7$, and 8 .

\begin{tabular}{l} 
Location: Mexico City, Mexico. \\
Setting: hospital inpatients. \\
Funding: none declared. \\
\hline
\end{tabular}

\section{Risk of bias}

\begin{tabular}{|c|c|c|}
\hline Bias & Authors' judgement & Support for judgement \\
\hline $\begin{array}{l}\text { Random sequence genera- } \\
\text { tion (selection bias) }\end{array}$ & Unclear risk & $\begin{array}{l}\text { The trial authors described the trial as "randomised"; but did not provide any } \\
\text { further details. }\end{array}$ \\
\hline $\begin{array}{l}\text { Allocation concealment } \\
\text { (selection bias) }\end{array}$ & Unclear risk & The trial authors did not describe allocation concealment. \\
\hline $\begin{array}{l}\text { Blinding (performance } \\
\text { bias and detection bias) } \\
\text { All outcomes }\end{array}$ & Unclear risk & "Patients were unaware of the group to which they had been assigned". \\
\hline $\begin{array}{l}\text { Incomplete outcome data } \\
\text { (attrition bias) } \\
\text { All outcomes }\end{array}$ & Low risk & No loss to follow-up. $21 / 21$ (100\%). \\
\hline $\begin{array}{l}\text { Selective reporting (re- } \\
\text { porting bias) }\end{array}$ & Unclear risk & $\begin{array}{l}\text { We were unable to retrieve the trial protocol. There was no evidence of selec- } \\
\text { tive reporting. }\end{array}$ \\
\hline Other bias & Low risk & We did not identify any other sources of bias. \\
\hline
\end{tabular}

\section{Ralph 2013 IDN}

\begin{tabular}{ll}
\hline Methods & Study design: RCT. \\
& Study dates and duration: June 2008 to February 2010. \\
& Standard care: participants received directly observed antituberculous therapy: weight-dosed ri- \\
& fampicin, isoniazid, pyrazinamide, ethambutol daily for 2 months; then rifampicin, isoniazid 3 times a \\
& week for 4 months.
\end{tabular}


Ralph 2013 IDN (Continued)

Baseline characteristics

- Nutritional status: arginine + vitamin D group $49 \pm 8.9 \mathrm{~kg}$; arginine group $47.9 \pm 9 \mathrm{~kg}$; vitamin D group $48.1 \pm 6.6 \mathrm{~kg}$; placebo group $48.7 \pm 5.5 \mathrm{~kg}$.

- HIV status: arginine + vitamin D group $28 \%$ HIV-positive; arginine group $6 \%$ HIV-positive; vitamin D group 15\% HIV-positive; placebo group 5\% HIV-positive.

- MDR/XDR-TB: not reported.

- Vitamin D levels: not reported.

- Arginine levels: not reported.

Difference in sex, HIV status, and X-ray severity at baseline.

Interventions

L-Arginine + vitamin D group: active L-arginine (L-arginine hydrochloride, Argimax $\left.{ }^{\circledR}\right) 6 \mathrm{~g}$ (6 tablets) daily for 8 weeks and active cholecalciferol (vitamin D3, Calciferol Strong ${ }^{\circledR}$ ) 50,000 IU (1250 mcg, 1 tablet) at baseline and on day 28.

L-Arginine + placebo vitamin D group: active L-arginine (L-arginine hydrochloride, $\left.\operatorname{Argimax}^{\circledR}\right) 6 \mathrm{~g}(6$ tablets) daily for 8 weeks and placebo cholecalciferol: 1 tablet at baseline, 1 tablet at 28 days.

Placebo L-arginine + vitamin D group: placebo L-arginine: 6 tablets daily for 8 weeks and active cholecalciferol (vitamin D3, Calciferol Strong ${ }^{\circledR}$ ) 50,000 IU (1250 mcg, 1 tablet) at baseline and on day 28.

Placebo group: placebo L-arginine: 6 tablets daily for 8 weeks and placebo cholecalciferol: 1 tablet at baseline, 1 tablet at 28 days.

Outcomes

- Proportion of participants with negative sputum culture on liquid medium at 4 weeks.

- Composite clinical severity score at week 8 (points allocated on weight change, forced expiratory value $\left(\mathrm{FEV}_{1}\right)$, cough and presence/absence of sputum and haemoptysis.

- Safety (death, hospitalization, hypercalcaemia).

- Sputum smear conversion time ( $\geq 2$ consecutive negative smears without a subsequent positive).

- Change in 6 minute walk test.

- Modified St George's respiratory questionnaire.

- Chest X-ray severity score ( 0,8 , and 24 weeks).

- FEV1.

- Primary endpoint stratified by HIV and ethnicity.

- Serious adverse events: death, hospitalization, and life-threatening conditions.

- Adverse events: new symptoms or hypercalcaemia.

Notes Location: Timika, Indonesia.

Setting: Timika tuberculosis clinic and community hospital.

Funding: Australian Respiratory Council, Royal Australasian College of Physicians Covance Award (APR), National Health and Medical Research Council of Australia.

Trial registration: NCT00677339.

\section{Risk of bias}

\begin{tabular}{lll}
\hline Bias & Authors' judgement & Support for judgement \\
\hline $\begin{array}{ll}\text { Random sequence genera- } \\
\text { tion (selection bias) }\end{array}$ & Low risk & $\begin{array}{l}\text { Block random allocation sequence stratified by ethnicity (Papuan/non- } \\
\text { Papuan) was generated and remained concealed from all investigators } \\
\text { throughout study. Independent assistants prepared packs labelling them with } \\
\text { a code corresponding to the randomization sequence. }\end{array}$
\end{tabular}


Ralph 2013 IDN (Continued)

Allocation concealment Low risk Participants were assigned the next sequential code and dispensed an opaque (selection bias) envelope containing study medication. Active and placebo medications appeared identical.

$\begin{array}{ll}\begin{array}{l}\text { Blinding (performance } \\ \text { bias and detection bias) }\end{array} & \text { Low risk } \\ \text { All outcomes } & \begin{array}{l}\text { Randomization sequence was unknown to all investigators. Independent as- } \\ \text { sistants labelled medication packs with codes corresponding to random se- } \\ \text { quence. Active and placebo medications appeared identical. }\end{array}\end{array}$

Incomplete outcome data Low risk
(attrition bias)

The trial authors stated that they conducted a modified intention-to-treat All outcomes analysis. They kept participants in the arm to which they were randomized, but excluded protocol violators and participants lost to follow-up from the final analysis.

Loss to follow-up per arm at end of 4 weeks (primary outcomes time point)

- L-arginine + vitamin D: 4/50 (8\%).

- L-arginine: $3 / 50(6 \%)$.

- Vitamin D: $3 / 50(6 \%)$.

- Placebo: $2 / 50(4 \%)$.

(Loss to follow-up $<10 \%$ ).

\begin{tabular}{|c|c|c|}
\hline $\begin{array}{l}\text { Selective reporting (re- } \\
\text { porting bias) }\end{array}$ & Unclear risk & $\begin{array}{l}\text { We were unable to retrieve the trial protocol. There was no evidence of selec- } \\
\text { tive reporting. }\end{array}$ \\
\hline
\end{tabular}

Other bias High risk Baseline comparability: there were differences in sex, HIV status, and X-ray
severity between groups at baseline.

Funding sources: non-commercial funding sources.

Conflict of interest: the trial authors stated there were no competing interests.

Other: grouping the data could lead to confounders.

\section{Range 2005 TZA}

Study design: RCT with $2 \times 2$ factorial design.
Study dates and duration: August 2001 to July 2002, follow-up 7 months.
Standard care: all participants received antituberculous therapy according to WHO guidelines.

\section{Participants}

Number: 530 enrolled; 31 later found ineligible and excluded; number with available outcomes data varied by outcome.

Inclusion criteria: adults aged $>15$ years, sputum-culture or sputum-smear positive pulmonary tuberculosis.

Exclusion criteria: returning to treatment after default or previous treatment failure; thought unlikely to survive; pregnant or lactating.

Baseline characteristics

- Nutritional status: mean BMI (SD): $18.3 \mathrm{~kg} / \mathrm{m}^{2}$ (2.5) zinc + multivitamins group versus $18.0 \mathrm{~kg} / \mathrm{m}^{2}(2.5)$ multivitamin + placebo group versus $17.8 \mathrm{~kg} / \mathrm{m}^{2}$ (2.5) zinc+placebo group versus $18.7 \mathrm{~kg} / \mathrm{m}^{2}(2.7)$ placebo group.

- HIV status: $39 \%$ zinc + multivitamins group versus $46 \%$ multivitamin + placebo group versus $47 \%$ zinc + placebo group versus $38 \%$ placebo group.

- MDR/XDR-TB: not mentioned. 
Range 2005 TZA (Continued)

- Zinc or micronutrient status at baseline not given.

Interventions $\quad$ Factorial design, giving daily supplements or placebo for 8 months.

Group 1: zinc 45 mg plus placebo.

Group 2: multivitamin and mineral tablet (vitamin A $1.5 \mathrm{mg}$, vitamin B1 $20 \mathrm{mg}$, vitamin B2 $20 \mathrm{mg}$, vitamin B6 $25 \mathrm{mg}$, vitamin B12 $50 \mu$ g, folic acid $0.8 \mathrm{mg}$, niacin $40 \mathrm{mg}$, vitamin C $200 \mathrm{mg}$, vitamin D3 $5 \mu \mathrm{g}$, vitamin E $60 \mathrm{mg}$, selenium $0.2 \mathrm{mg}$, and copper $5 \mathrm{mg}$ ) plus placebo.

Group 3: zinc $4 \mathrm{mg}$ plus multivitamin and mineral tablet (as above).

Group 4: placebo plus placebo.

\begin{tabular}{ll}
\hline Outcomes & Death before 8 months. \\
- Sputum positive at weeks 2,4 , and 8. \\
Not included in the review: HIV viral load and CD4 count at baseline and 8 weeks. \\
\hline Lotes & Location: Mwanza region, Tanzania. \\
& Setting: outpatients at 5 health facilities. \\
\hline
\end{tabular}

\section{Risk of bias}

\begin{tabular}{|c|c|c|}
\hline Bias & Authors' judgement & Support for judgement \\
\hline $\begin{array}{l}\text { Random sequence genera- } \\
\text { tion (selection bias) }\end{array}$ & Low risk & $\begin{array}{l}\text { "Before recruitment of patients, all the letters on the containers were replaced } \\
\text { with study serial numbers from } 1 \text { to } 550 \text { based on the computer-generated } \\
\text { random sequences, using permuted blocks of four". }\end{array}$ \\
\hline $\begin{array}{l}\text { Allocation concealment } \\
\text { (selection bias) }\end{array}$ & Unclear risk & $\begin{array}{l}\text { "The codes for the MVM and Zn tablets remained in a sealed envelope, and } \\
\text { were only broken after completion of the initial data analysis". }\end{array}$ \\
\hline $\begin{array}{l}\text { Blinding (performance } \\
\text { bias and detection bias) } \\
\text { All outcomes }\end{array}$ & Low risk & $\begin{array}{l}\text { "Placebo tablets were identical in colour, shape and size to the corresponding } \\
\text { white } \mathrm{Zn} \text { and green MVM tablets". }\end{array}$ \\
\hline $\begin{array}{l}\text { Incomplete outcome data } \\
\text { (attrition bias) } \\
\text { All outcomes }\end{array}$ & High risk & $\begin{array}{l}\text { Loss to follow-up: mortality: } 9 \% \text { zinc group versus } 14 \% \text { placebo group, weight } \\
\text { gain: } 22 \% \text { zinc group versus } 22 \% \text { placebo group. These could significantly alter } \\
\text { the result. }\end{array}$ \\
\hline $\begin{array}{l}\text { Selective reporting (re- } \\
\text { porting bias) }\end{array}$ & Unclear risk & $\begin{array}{l}\text { We were unable to retrieve the trial protocol. There was no evidence of selec- } \\
\text { tive reporting. }\end{array}$ \\
\hline Other bias & Low risk & We did not identify any other sources of bias. \\
\hline
\end{tabular}

\section{Schön 2003 ETH}

Methods Study design: RCT.

Study dates and duration: recruited December 2000 to December 2001. Follow-up 8 weeks.

Standard care: all participants received DOTS in line with Ethopian National Guidelines.

Participants Number: 120 enrolled, outcomes presented for 115.


Exclusion criteria: admitted to hospital; pregnant; signs of any concomitant disease other than HIV; or lived too far away to take part in the directly observed therapy short Direct Observed Treatment ShortCourse (DOTS) programme.

Baseline characteristics

- Nutritional status: Mean weight in HIV-negative group: $47.8 \mathrm{~kg}$ intervention group versus $45.3 \mathrm{~kg}$ control group, mean weight in HIV-positive group: $45.0 \mathrm{~kg}$ intervention group versus $45.3 \mathrm{~kg}$ control group.

- HIV status: $52 \%$ HIV-positive.

- MDR/XDR-TB: not mentioned.

Interventions Group 1: arginine capsules (1 g arginine) daily for 4 weeks.

Group 2: placebo.

\begin{tabular}{ll}
\hline Outcomes & Death during 8 weeks follow-up. \\
- Sputum positive at week 8. \\
- Cough at weeks 2 and 8. \\
- Weight gain at $1,2,4$, and 8 weeks. \\
$\begin{array}{ll}\text { Not included in the review: serum arginine, citrulline, and nitric oxide metabolite levels at weeks } 0,2, \\
\text { and } 8 .\end{array}$ \\
\hline Lotes \\
Setting: Outpatient DOTS programme.
\end{tabular}

\section{Risk of bias}

\begin{tabular}{lll}
\hline Bias & Authors' judgement & Support for judgement \\
\hline $\begin{array}{l}\text { Random sequence genera- } \\
\text { tion (selection bias) }\end{array}$ & Low risk & "Randomized in blocks of six (performed by the state pharmacy of Sweden)". \\
\hline $\begin{array}{l}\text { Allocation concealment } \\
\text { (selection bias) }\end{array}$ & Low risk & $\begin{array}{l}\text { "The study was double blinded and a sealed copy of the treatment code was } \\
\text { kept by the project leader until all data had been collected and analysed". }\end{array}$ \\
\hline $\begin{array}{l}\text { Blinding (performance } \\
\text { bias and detection bias) } \\
\text { All outcomes }\end{array}$ & Low risk & $\begin{array}{l}\text { Described as "double blind" and placebos were used: the trial authors did not } \\
\text { give any further details. }\end{array}$ \\
\hline $\begin{array}{l}\text { Incomplete outcome data } \\
\text { (attrition bias) } \\
\text { All outcomes }\end{array}$ & Low risk & $\begin{array}{l}\text { There were 115/120 included in the final analysis(96\%). Three of these died, } 2 \\
\text { moved out of the study area. }\end{array}$ \\
\hline $\begin{array}{l}\text { Selective reporting (re- } \\
\text { porting bias) }\end{array}$ & Unclear risk & $\begin{array}{l}\text { We were unable to retrieve the trial protocol. There was no evidence of selec- } \\
\text { tive reporting. }\end{array}$ \\
\hline \begin{tabular}{l} 
Other bias \\
\hline
\end{tabular} & Low risk & \begin{tabular}{l} 
We did not identify any sources of bias. \\
\hline
\end{tabular}
\end{tabular}

Schön 2011 ETH

$\begin{array}{ll}\text { Methods } & \text { Study design: RCT. } \\ & \text { Study dates and duration: recruited February } 2004 \text { to December 2006. Follow-up until August } 2007 .\end{array}$


Schön 2011 ETH (Continued)

Standard care: all participants received DOTS in line with Ethopian National Guidelines.

Number randomized: 80.
Inclusion criteria: newly diagnosed sputum smear positive older than 15 years.
Exclusion criteria: admitted to hospital; peanut allergy, pregnant; signs of any concomitant disease
other than HIV; previous treatment for tuberculosis.
Baseline characteristics
- Nutritional status: high arginine group - mean BMI: $16.995 \% \mathrm{Cl} 16.4$ to 17.4 ; low arginine group - mean
BMI 16.4 95\%Cl 16 to 16.8 .
- HIV status: high arginine group - $37 \%$ HIV-positive; low arginine group - $32 \%$ HIV-positive.
MDR/XDR-TB: not mentioned.

Interventions All participants received antituberculous therapy.

High arginine group: $30 \mathrm{~g}$ peanuts ( $1 \mathrm{~g}$ arginine, $750 \mathrm{~kJ}$ ) daily for 4 weeks.

Low arginine group: $30 \mathrm{~g}$ wheat cracker $(0.1 \mathrm{~g}$ arginine, $623 \mathrm{~kJ})$ daily for 4 weeks.

Primary outcome: cure rate (smear positive at start of Rx, completed Rx, and smear negative at end of $\mathrm{Rx}$ and 1 previous occasion).

Secondary outcomes: sputum smear conversion, weight gain, sedimentation rate, reduction of cough, and chest $\mathrm{X}$-ray improvement at 2 months.

Not eligible for review: levels of nitric oxide (NO) metabolites in urine and NO in exhaled air at 2 weeks and 2 months.

Location: Gondar, Ethiopia.
Setting: DOTS clinic at Gondar University Hospital.
Funding: Swedish Heart and Lung Foundation.
Trial number: NCT00857402.

\section{Risk of bias}

\begin{tabular}{lll}
\hline Bias & Authors' judgement & Support for judgement \\
\hline $\begin{array}{l}\text { Random sequence genera- } \\
\text { tion (selection bias) }\end{array}$ & Low risk & $\begin{array}{l}\text { The Department of Epidemiology at the Karolinska Institute, Sweden per- } \\
\text { formed randomization in blocks of } 6 .\end{array}$ \\
\hline $\begin{array}{l}\text { Allocation concealment } \\
\text { (selection bias) }\end{array}$ & Low risk & $\begin{array}{l}\text { The randomization code was concealed in } 180 \text { sealed individual envelopes. } \\
\text { The envelopes were only opened when the person was enrolled in the study. }\end{array}$ \\
\hline $\begin{array}{l}\text { Blinding (performance } \\
\text { bias and detection bias) } \\
\text { All outcomes }\end{array}$ & High risk & $\begin{array}{l}\text { Blinding was not possible due to the nature of the intervention (wheat cracker } \\
\text { versus peanuts). }\end{array}$ \\
\hline
\end{tabular}

Incomplete outcome data Low risk Regarding loss to follow-up, $7 / 180$ (4\%) did not complete the supplement. (attrition bias)

All outcomes

\begin{tabular}{lll}
\hline $\begin{array}{l}\text { Selective reporting (re- } \\
\text { porting bias) }\end{array}$ & Low risk & $\begin{array}{l}\text { Outcomes reported on in the published study match those set out in the study } \\
\text { protocol. }\end{array}$ \\
\hline Other bias & Low risk & There were no differences in baseline characteristics between the 2 groups.
\end{tabular}




\begin{tabular}{|c|c|}
\hline Methods & $\begin{array}{l}\text { Study design: RCT. } \\
\text { Study dates and duration: July } 1999 \text { to February 2005, follow-up } 24 \text { months. } \\
\text { Standard care: all participants received standard antituberculous therapy as recommended by the } \\
\text { Malawi NTP: } 2 \text { RHZE/6HE. }\end{array}$ \\
\hline Participants & $\begin{array}{l}\text { Number: } 1148 \text { enrolled; number with available outcomes data varied by outcome. } \\
\text { Inclusion criteria: adults aged } 18 \text { to } 60 \text { years, sputum positive pulmonary tuberculosis. } \\
\text { Exclusion criteria: planning to move away from the study area within the next } 2 \text { years; already taking vi- } \\
\text { tamin supplements; already being treated for tuberculosis; previously treated for tuberculosis. } \\
\text { Baseline characteristics } \\
\text { - Nutritional status: geometric mean BMI (SD): HIV-positive participants } 18.3 \mathrm{~kg} / \mathrm{m}^{2}(2.5) \text { supplement } \\
\text { group versus } 18.1 \mathrm{~kg} / \mathrm{m}^{2}(2.5) \text { placebo group; HIV-negative participants } 18.5 \mathrm{~kg} / \mathrm{m}^{2}(2.6) \text { supplement } \\
\text { group versus } 18.8 \mathrm{~kg} / \mathrm{m}^{2}(2.9) \text { placebo group. } \\
\text { - HIV status: } 71 \% \mathrm{HIV-positive} \mathrm{supplement} \mathrm{group} \mathrm{versus} 74 \% \text { placebo group. } \\
\text { - MDR/XDR-TB: not mentioned. }\end{array}$ \\
\hline
\end{tabular}

Group 2: daily placebo.

\begin{tabular}{ll}
\hline Outcomes & Death after 8 months follow-up. \\
& Vitamin A, vitamin E, and selenium levels at 8 months. \\
\hline Notes & Location: Zomba and Blantyre, Malawi. \\
& Setting: participants diagnosed at a hospital clinic and treated at a community clinic near where they \\
& lived. \\
& Funding: the National Institutes of Health; the Fogarty International Centre. \\
\hline
\end{tabular}

\section{Risk of bias}

\begin{tabular}{lll}
\hline Bias & Authors' judgement & Support for judgement \\
\hline $\begin{array}{l}\text { Random sequence genera- } \\
\text { tion (selection bias) }\end{array}$ & Low risk & $\begin{array}{l}\text { "A computer random number generator was used to generate a random allo- } \\
\text { cation schedule in permuted blocks of 10". }\end{array}$ \\
\hline $\begin{array}{l}\text { Allocation concealment } \\
\text { (selection bias) }\end{array}$ & Low risk & $\begin{array}{l}\text { "Treatment assignment was concealed by pre-packing study supplements in } \\
\text { sequentially numbered series according to the allocation schedule". }\end{array}$ \\
$\begin{array}{l}\text { Blinding (performance } \\
\text { bias and detection bias) } \\
\text { All outcomes }\end{array}$ & Low risk & $\begin{array}{l}\text { "Both the study staff and the participants were blinded to the treatment as- } \\
\text { signment". }\end{array}$ \\
\hline
\end{tabular}


Semba 2007 MWI (Continued)

"The placebo and active supplements were of identical appearance in size, shape and colour. The placebo and active supplements were packed in identical opaque, white plastic bottles with sealed caps".

$\begin{array}{ll}\begin{array}{l}\text { Incomplete outcome data } \\ \text { (attrition bias) }\end{array} & \text { High risk }\end{array}$

All outcomes

the placebo group.

\begin{tabular}{|c|c|c|}
\hline $\begin{array}{l}\text { Selective reporting (re- } \\
\text { porting bias) }\end{array}$ & Unclear risk & $\begin{array}{l}\text { We were unable to retrieve the trial protocol. There was no evidence of selec- } \\
\text { tive reporting. }\end{array}$ \\
\hline
\end{tabular}
porting bias) tive reporting.

Other bias Low risk We did not identify any other potential sources of bias identified.

\begin{tabular}{|c|c|}
\hline Methods & $\begin{array}{l}\text { Study design: RCT. } \\
\text { Study dates and duration: recruited April } 2003 \text { to May 2004. Follow-up } 60 \text { days. } \\
\text { Standard care: all participants received the same antituberculous standard therapy in accordance with } \\
\text { the DOTS strategy. }\end{array}$ \\
\hline Participants & $\begin{array}{l}\text { Number: } 42 \text { enrolled; outcomes data available for } 37 \text {. } \\
\text { Inclusion criteria: adults (age range not stated), with sputum positive tuberculosis. } \\
\text { Exclusion criteria: previous antituberculous treatment; concurrent use of supplements containing sele- } \\
\text { nium and vitamin E; illicit drug addiction; signs of severe effects of antituberculous drug treatment dur- } \\
\text { ing treatment. } \\
\text { Baseline characteristics } \\
\text { - Nutritional status: median BMI (IQR): men } 19.6 \mathrm{~kg} / \mathrm{m}^{2}(16.0 \text { to } 27.1) \text { supplements group versus } 21.0 \\
\mathrm{~kg} / \mathrm{m}^{2}(16.8 \text { to } 23.1) \text { placebo group; women } 19.5 \mathrm{~kg} / \mathrm{m}^{2}(16.6 \text { to } 25.8) \text { supplements group versus } 22.0 \\
\left.\mathrm{~kg} / \mathrm{m}^{2} \text { (17.0 to } 26.7\right) \text { in placebo group. } \\
\text { - } \mathrm{HIV} \mathrm{status:} \mathrm{not} \mathrm{mentioned.} \\
\text { - MDR/XDR-TB: not mentioned. }\end{array}$ \\
\hline
\end{tabular}

Interventions

Group 1: daily supplements containing vitamin E (140 mg) and selenium (200 $\mathrm{\mu g})$ for 4 months.

Group 2: placebo.
Outcomes $\quad$ Sputum positive at days $15,30,45$, and 60 .
- Change in body mass index at 2 months.
Not included in the review: number of lung cavities; cavity surface area; and mean lesion area at 0,2 , and 6 months.

Notes
Location: Tabriz, Iran.
Setting: outpatient clinic at research centre.
Funding: the Tuberculosis and Lung Disease Research Centre.

\section{Risk of bias}

Bias Authors' judgement Support for judgement


Seyedrezazadeh 2006 IRN (Continued)
Random sequence genera- Unclear risk
The trial authors described the sequence generation as "randomised", but did tion (selection bias) not provide any further details.

$\begin{aligned} & \text { Allocation concealment } \\ & \text { (selection bias) }\end{aligned}$ Unclear risk The trial authors did not describe any allocation concealment.

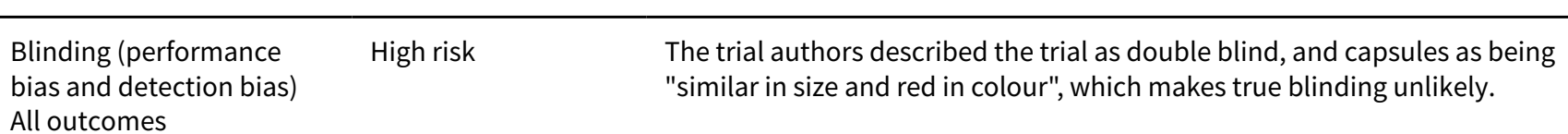

\begin{tabular}{|c|c|c|}
\hline $\begin{array}{l}\text { Incomplete outcome data } \\
\text { (attrition bias) } \\
\text { All outcomes }\end{array}$ & Low risk & Regarding losses to follow-up, $37 / 37$ (100\%) participants were eligible. \\
\hline $\begin{array}{l}\text { Selective reporting (re- } \\
\text { porting bias) }\end{array}$ & Unclear risk & $\begin{array}{l}\text { We were unable to retrieve the trial protocol. There was no evidence of selec- } \\
\text { tive reporting. }\end{array}$ \\
\hline Other bias & Low risk & We did not identify any other sources of bias. \\
\hline
\end{tabular}

\section{Singh 2013 IND}

Study design: RCT.
Study dates and duration: September to October 2010 (enrolment), 6 months study period (Oct 2010 to
March 2011).
Standard care: initial 2-month phase of antituberculous therapy. The trial authors did not describe the
precise content of the tuberculosis treatment.
Number: 40 enrolled and randomized. 37 included in the final analysis (3 excluded because of poor
compliance).
Inclusion criteria: newly diagnosed sputum smear positive pulmonary tuberculosis patients taking not
more than 7 days of antituberculous therapy aged 18 to 60 years.
Exclusion criteria: known history of drug resistant tuberculosis and renal disease.
Baseline characteristics
- Nutritional status: mean BMI kg/m² placebo group: 17.7 ; vitamin D and calcium group: 16.37 , vitamin
A and zinc group: 17.52 (no SDs provided).
- HIV status: not reported.
- MDR/XDR-TB: not mentioned.

Control group: antituberculous therapy only.

Vitamin D and calcium group: tablet containing vitamin D and calcium (250 IU of vitamin D3, and 500 $\mathrm{mg}$ as calcium carbonate). One tablet per day for first 10 days, then 3 tablets per week for the remainder of the 2 months.

Vitaimn A and zinc group: zinc tablet (50 mg elemental zinc as zinc sulphate) and vitamin A tablet (25,000 IU vitamin A as vitamin A palmitate). One vitamin A tablet and 1 zinc tablet per day for first 10 days, then 3 tablets of each per week for the remainder of the 2 months. 
Singh 2013 IND (Continued)

Time to sputum smear conversion.

Weight gain at enrolment and 60 days (no SDs provided).

BMI at enrolment and 60 days (no SDs provided).

Not relevant to review: neutrophil count at enrolment and 60 days; lymphocyte count at enrolment and 60 days; serum alanine transaminase and aspartate transaminase at enrolment and 60 days; serum haemoglobin at enrolment and end of 2 months ( 60 days).

Notes Location: India, HNB hospital attached to the Veer Chandra Singh Garhwali Govt. Medical Science and Research Institute, Srinagar - Pauri Garhwal (Uttarakhand).

Setting: hospital.

Funding: not reported.

\section{Risk of bias}

Bias Authors' judgement Support for judgement

Random sequence genera- Unclear risk The trial authors did not describe this and simply stated randomly assigned. tion (selection bias)

\begin{tabular}{lll}
\hline $\begin{array}{l}\text { Allocation concealment } \\
\text { (selection bias) }\end{array}$ & Unclear risk & The trial authors did not describe this. \\
\hline $\begin{array}{l}\text { Blinding (performance } \\
\text { bias and detection bias) } \\
\text { All outcomes }\end{array}$ & Unclear risk & $\begin{array}{l}\text { The trial authors did not describe blinding of participants, personnel, and out- } \\
\text { come assessors. }\end{array}$ \\
\hline
\end{tabular}

\begin{tabular}{|c|c|c|}
\hline $\begin{array}{l}\text { Incomplete outcome data } \\
\text { (attrition bias) } \\
\text { All outcomes }\end{array}$ & Low risk & $\begin{array}{l}\text { There were } 40 \text { patients randomized to the } 3 \text { groups. The trial excluded } 3 \text { pa- } \\
\text { tients due to non-compliance and excluded them from the analysis ( } 8 \% \text { loss to } \\
\text { follow-up). }\end{array}$ \\
\hline
\end{tabular}

\begin{tabular}{|c|c|c|}
\hline $\begin{array}{l}\text { Selective reporting (re- } \\
\text { porting bias) }\end{array}$ & Unclear risk & $\begin{array}{l}\text { We were unable to obtain the study protocol, and therefore there is unclear } \\
\text { risk of selective outcome reporting. In the abstract the trial authors stated that } \\
\text { the aim of the study was to assess sputum conversion and blood profiles dur- } \\
\text { ing the initial phase of tuberculosis treatment. They reported on these out- } \\
\text { comes. }\end{array}$ \\
\hline Other bias & Unclear risk & $\begin{array}{l}\text { The trial authors did not report baseline characteristics. There was no descrip- } \\
\text { tion of funding sources or conflict of interest statement. }\end{array}$ \\
\hline
\end{tabular}

\section{Sudarsanam 2010 IND}

Study design: RCT.
Study dates and duration: recruitment January to Nov 2005, follow-up 1 year.
Standard care: All participants received the same antituberculous standard therapy in accordance with
the DOTS strategy.

Participants

Number: 103 enrolled, 99 analysed at 6 months, 91 at 1 year.

Inclusion criteria: age > 12 years, either sputum positive tuberculosis or clinical and radiological evidence of pulmonary tuberculosis or biopsy proven extra pulmonary tuberculosis, informed consent 
Sudarsanam 2010 IND (Continued)

Exclusion criteria: relapse of previous antituberculous treatment, end stage renal or liver disease, CD4 count $>200$ (if HIV-positive), BMI $<19 \mathrm{~kg} / \mathrm{m}^{2}$, patients not from Vellore.

Baseline characteristics

- Nutritional status: mean BMI supplement: $17.2 \mathrm{~kg} / \mathrm{m}^{2}$; mean BMI no supplement: $18.2 \mathrm{~kg} / \mathrm{m}^{2}$.

- HIV status: 20 out of 103 were HIV co-infected.

- MDR/XDR-TB: not mentioned.

- All participants belonged to lower socioeconomic strata.

- Micronutrient status at baseline not described.

Interventions

Group 1: macronutrient and micronutrient supplementation for 6 months. The macronutrient was a ready-to-serve powder, given as monthly rations to supply $930 \mathrm{kcal}$ and $31.5 \mathrm{~g}$ protein per day 3 divided servings. The micronutrient as a once-a-day multivitamin tablet containing: copper sulphate $0.1 \mathrm{mg}$, D-pantheol $1 \mathrm{mg}$, dibasic calcium phosphate $35 \mathrm{mg}$, folic acid $500 \mu \mathrm{g}$, magnesium oxide $0.15 \mathrm{mg}$, manganese sulphate $0.01 \mathrm{mg}$, nicotinamide $25 \mathrm{mg}$, potassium iodide $0.025 \mathrm{mg}$, vitamin A $5000 \mathrm{IU}$, vitamin B1 $2.5 \mathrm{mg}$, vitamin B12 $2.5 \mu \mathrm{g}$, vitamin B2 $2.5 \mathrm{mg}$, vitamin B6 $2.5 \mathrm{mg}$, vitamin C $40 \mathrm{mg}$, vitamin D3 200 $\mathrm{IU}$, vitamin E $7.5 \mathrm{mg}$, zinc sulphate $50 \mathrm{mg}$.

Group 2: dietary advice alone.

\begin{tabular}{ll}
\hline Outcomes & Death. \\
& - Cure. \\
& - Treatment completion. \\
& - Weight gain.
\end{tabular}

Not included in the review: adherence.

Notes Location: Vellore, India.

Setting: tuberculosis clinics.

Funding: The Fogarty AIDS International Research and Training Program.

\section{Risk of bias}

\begin{tabular}{|c|c|c|}
\hline Bias & Authors' judgement & Support for judgement \\
\hline $\begin{array}{l}\text { Random sequence genera- } \\
\text { tion (selection bias) }\end{array}$ & Low risk & "a computer generated randomisation code". \\
\hline $\begin{array}{l}\text { Allocation concealment } \\
\text { (selection bias) }\end{array}$ & Low risk & $\begin{array}{l}\text { "Allocation was concealed, the randomisation codes were in opaque en- } \\
\text { velopes opened by the dietician after dietary counselling". }\end{array}$ \\
\hline $\begin{array}{l}\text { Blinding (performance } \\
\text { bias and detection bias) } \\
\text { All outcomes }\end{array}$ & High risk & "There were no attempts made to blind any of the study team or participants". \\
\hline $\begin{array}{l}\text { Incomplete outcome data } \\
\text { (attrition bias) } \\
\text { All outcomes }\end{array}$ & High risk & $3.9 \%$ were lost to follow-up at 6 months and $11.7 \%$ at 1 year. \\
\hline $\begin{array}{l}\text { Selective reporting (re- } \\
\text { porting bias) }\end{array}$ & Unclear risk & $\begin{array}{l}\text { We were unable to retrieve the trial protocol. There was no evidence of selec- } \\
\text { tive reporting. }\end{array}$ \\
\hline Other bias & Low risk & We did not identify any other sources of bias. \\
\hline
\end{tabular}


Tukvadze 2015 GEO

\begin{tabular}{|c|c|}
\hline Methods & $\begin{array}{l}\text { Study design: RCT. } \\
\text { Standard care: all participants received antituberculous therapy (isonizaid, rifampicin, pyrazinamide, } \\
\text { and ethambutol - no further details given), given under direct observation. } \\
\text { Study dates and duration: July } 2009 \text { to April 2012. Follow-up } 16 \text { weeks. }\end{array}$ \\
\hline Participants & $\begin{array}{l}\text { Number: } 199 \text { enrolled and randomized. } \\
\text { Inclusion criteria: age }>18 \text { years, newly diagnosed pulmonary tuberculosis disease with a positive AFB } \\
\text { sputum smear, < } 7 \text { days of antituberculous drug therapy before entry, informed consent. } \\
\text { Exclusion criteria: previous tuberculosis, extrapulmonary tuberculosis, pregnancy or lactation, a histo- } \\
\text { ry of hypercalcaemia, nephrolithiasis, hyperparathyroidism, sarcoidosis, organ transplant, hepatic cir- } \\
\text { rhosis, seizures, or cancer in the past } 5 \text { years, baseline plasma calcium concentration }>2.6 \mathrm{mmol} / \mathrm{L} \text {, cre- } \\
\text { atinine concentration }>250 \mathrm{mmol} / \mathrm{L} \text {, or aspartate aminotransferase concentrations }>3 \text { times the upper } \\
\text { limit of normal, renal replacement therapy, corticosteroid use in the past } 30 \text { days, current use of cyto- } \\
\text { toxic or immunosuppressive drugs, known MDR-TB before study enrolment, current imprisonment. } \\
\text { Baseline characteristics } \\
\text { - Nutritional status: BMI < } 18.5 \mathrm{~kg} / \mathrm{m}^{2}: 18 \% \text { vitamin D group versus } 28 \% \text { placebo group. } \\
\text { - HIV status: } 191 / 199 \text { were tested. } 1 \% \mathrm{HIV} \text { positive in the vitamin D group versus } 3 \% \text { HIV positive in the } \\
\text { placebo group. } \\
\text { - MDR/XDR-TB: isoniazid and rifampicin resistance: } 12 \% \text { vitamin D group versus } 11 \% \text { placebo group. } \\
\text { - Micronutrient status: plasma } 25(\mathrm{OH}) \mathrm{D}_{3} \text { below } 30 \mathrm{nmol} / \mathrm{L} \text { : } 92 \% \text { vitamin D group versus } 92 \% \text { placebo } \\
\text { group. }\end{array}$ \\
\hline
\end{tabular}

Interventions Vitamin D group: 50,000 IU vitamin $D_{3} 3$ times a week for 8 consecutive weeks followed by 50,000 IU every 2 weeks for a further 8 weeks.

Placebo group: placebo tablet for similar dosing regime.

- Time to sputum culture conversion.
- Culture conversion at 8 weeks.
- Vitamin D levels at baseline and every 2 weeks of follow-up.
- Adverse effects.
Not included in this review: calcium level every 4 weeks, multiple subgroup analyses looking at predic-
tors of culture conversion.

Notes

Location: Tbilisi, Georgia.

Setting: National Centre for TB and Lung Disease and affiliated clinics.

Registration number: NCT00918086.

Source of funding: National Institutes of Health Grant, the Emory University Global Health Institute.

Additional publications: Frediani JK, et al (2015) Macronutrient intake and body composition changes during antituberculous therapy in adults, Clinical Nutrition, http://dx.doi.org/10.1016/ j.clnu.2015.02.007

\section{Risk of bias}

\begin{tabular}{lll}
\hline Bias & Authors' judgement & Support for judgement \\
\hline $\begin{array}{ll}\text { Random sequence genera- } \\
\text { tion (selection bias) }\end{array}$ & Low risk & $\begin{array}{l}\text { "Treatment assignments were generated by the Emory University-based study } \\
\text { biostatistician and implemented locally through a distributed study database } \\
\text { with }\end{array}$
\end{tabular}


Tukvadze 2015 GEO (Continued)

the use of a randomized permuted block algorithm stratified by clinical center site".

\begin{tabular}{|c|c|c|}
\hline $\begin{array}{l}\text { Allocation concealment } \\
\text { (selection bias) }\end{array}$ & Low risk & $\begin{array}{l}\text { "All study medication bottles had a unique bottle number to allow for blinded } \\
\text { dispensing". }\end{array}$ \\
\hline $\begin{array}{l}\text { Blinding (performance } \\
\text { bias and detection bias) } \\
\text { All outcomes }\end{array}$ & Low risk & $\begin{array}{l}\text { "The study drugs vitamin D3 and the placebo were identical in shape and } \\
\text { colour". The trial authors did not report blinding of outcome assessors. }\end{array}$ \\
\hline $\begin{array}{l}\text { Incomplete outcome data } \\
\text { (attrition bias) } \\
\text { All outcomes }\end{array}$ & High risk & $\begin{array}{l}20 / 100(20 \%) \text { were lost to follow-up or discontinued intervention in the vita- } \\
\text { min D group versus } 30 / 99(30 \%) \text { in the placebo group. }\end{array}$ \\
\hline $\begin{array}{l}\text { Selective reporting (re- } \\
\text { porting bias) }\end{array}$ & Low risk & $\begin{array}{l}\text { We were unable to retrieve the trial protocol. There was no evidence of selec- } \\
\text { tive reporting. }\end{array}$ \\
\hline Other bias & Low risk & We did not identify any other sources of bias. \\
\hline
\end{tabular}

Villamor 2008 TZA

\begin{tabular}{|c|c|}
\hline Methods & $\begin{array}{l}\text { Study design: RCT. } \\
\text { Study dates and duration: April } 2000 \text { to April 2005, follow-up } 24 \text { months. } \\
\text { Standard care: all participants received standard antituberculous treatment following the DOTS } \\
\text { scheme: } 2 \text { RHZE/ } 6 \mathrm{HE} \text {. }\end{array}$ \\
\hline Participants & $\begin{array}{l}\text { Number: } 887 \text { enrolled, number with available outcomes data varied by outcome. } \\
\text { Inclusion criteria: adults aged } 18 \text { to } 65 \text { years, sputum positive pulmonary tuberculosis. } \\
\text { Exclusion criteria: Karnofsky score < } 40 \% \text {; pregnant; received more than } 4 \text { weeks of antituberculous } \\
\text { therapy in the past year; plans to move away from the study area within the next } 2 \text { years } \\
\text { Baseline characteristics. } \\
\text { - Nutritional status: mean BMI (SD): } 18.9 \mathrm{~kg} / \mathrm{m}^{2}(2.5) \text { in HIV-negative placebo group versus } 18.9 \mathrm{~kg} / \mathrm{m}^{2} \\
(2.5) \text { in HIV-negative supplement group, } 19.6 \mathrm{~kg} / \mathrm{m}^{2}(2.9) \text { in HIV-positive placebo group versus } 19.3 \mathrm{~kg} / \\
\mathrm{m}^{2}(2.8) \text { in HIV-positive supplement group. } \\
\text { - HIV status: } 53 \% \text { HIV-positive in supplement group versus } 53 \% \text { in placebo group. } \\
\text { - MDR/XDR-TB: not mentioned. } \\
\text { - Description: > } 85 \% \text { had primary school education. } \\
\text { - Micronutrient status at baseline not described. }\end{array}$ \\
\hline
\end{tabular}

Interventions $\quad$ For 24 months

Group 1: daily oral dose in tablet form of mixed micronutrients containing retinol (5000 IU), vitamin B1 $(20 \mathrm{mg})$, vitamin B2 $(20 \mathrm{mg})$, vitamin B6 $(25 \mathrm{mg})$, niacin $(100 \mathrm{mg})$, vitamin B12 $(50 \mu \mathrm{g})$, vitamin C (500 $\mathrm{mg})$, vitamin E (200 mg), folic acid (0.8 mg), and selenium (100 $\mathrm{\mu g})$.

Group 2: placebo.

$\begin{array}{ll}\text { - } & \text { Sputum-culture positive at } 1 \text { month. } \\ \text { - Recurrence of positive culture between } 1 \text { and } 8 \text { months. } \\ \text { - Mortality within } 2 \text { years. } \\ \text { - Nutritional parameters: body weight, mid-upper arm circumference, fat-mass, fat-free mass. }\end{array}$


Villamor 2008 TZA (Continued)

Not included in the review: CD4, CD8, CD3 count and HIV viral load, haemoglobin, albumin levels, peripheral neuropathy, and genital ulcers.

Lotes
Setting: 5 outpatient clinics.
Funding: The National Institute of Allergy and Infectious Diseases, US Department of Agriculture.

\section{Risk of bias}

\begin{tabular}{|c|c|c|}
\hline Bias & Authors' judgement & Support for judgement \\
\hline $\begin{array}{l}\text { Random sequence genera- } \\
\text { tion (selection bias) }\end{array}$ & Low risk & $\begin{array}{l}\text { "Consenting subjects were randomly assigned in computer-generated permut- } \\
\text { ed blocks of } 20 \text { ". }\end{array}$ \\
\hline $\begin{array}{l}\text { Allocation concealment } \\
\text { (selection bias) }\end{array}$ & Unclear risk & The trial authors did not describe any allocation concealment. \\
\hline $\begin{array}{l}\text { Blinding (performance } \\
\text { bias and detection bias) } \\
\text { All outcomes }\end{array}$ & Low risk & $\begin{array}{l}\text { "Active tablets and placebo were indistinguishable in size, taste, and colour. } \\
\text { All clinical and research staff were unaware of the subjects' treatment assign- } \\
\text { ment". }\end{array}$ \\
\hline $\begin{array}{l}\text { Incomplete outcome data } \\
\text { (attrition bias) } \\
\text { All outcomes }\end{array}$ & Unclear risk & $\begin{array}{l}\text { There were } 628 / 725(85 \%) \text { for sputum-culture positive at } 1 \text { month; for mortal- } \\
\text { ity the trial authors included all participants in the analysis up to the point of } \\
\text { loss to follow-up if before end of trial, and presented hazard ratios. }\end{array}$ \\
\hline $\begin{array}{l}\text { Selective reporting (re- } \\
\text { porting bias) }\end{array}$ & Unclear risk & $\begin{array}{l}\text { We were unable to retrieve the trial protocol. There was no evidence of selec- } \\
\text { tive reporting. }\end{array}$ \\
\hline Other bias & Low risk & We did not identify any other sources of bias. \\
\hline
\end{tabular}

\section{Visser 2011 ZAF}

Methods Study design: RCT.

Study dates and duration: May 2005 to August 2008, follow-up 8 weeks.

Standard care: all participants received antituberculous therapy: 2 RHZE plus pyridoxine $25 \mathrm{mg} /$ day.
Participants
Number: 154 enrolled; 124 completed study.
Inclusion criteria: 18 to 60 years old, 2 positive sputum smears for acid-fast bacilli or 1 positive plus sug- gestive chest $\mathrm{X}$-ray findings, written informed consent to a HIV test.
Exclusion criteria: previous treatment of tuberculosis, known or suspected multidrug resistant tubercu- losis, clinical evidence of extrapulmonary tuberculosis or liver disease, renal failure, congestive heart failure or neoplasm, pregnancy.
Baseline characteristics
- Nutritional status: mean BMI (SD): males; supplement group $18.9 \mathrm{~kg} / \mathrm{m}^{2}(2.7)$ versus $19.0 \mathrm{~kg} / \mathrm{m}^{2}$ (2) placebo group, females; supplement group $23.0 \mathrm{~kg} / \mathrm{m}^{2}$ (4.3) versus $21.6 \mathrm{~kg} / \mathrm{m}^{2}$ (4.8) placebo group.
- HIV status: $9 \%$ HIV positive supplement group versus $11 \%$ HIV-positive placebo group.
- MDR/XDR-TB: excluded.
- Median retinol (range): $21.1 \mu \mathrm{g} / \mathrm{dL}$ (15.1 to 27.8 ) supplement group versus 21.2 (15.7 to 28.9 ) placebo group (normal range: $>20 \mu \mathrm{g} / \mathrm{dL}$ ). 
Visser 2011 ZAF (Continued)

- Median Zinc (range): $62 \mu \mathrm{g} / \mathrm{dL}$ (53 to 71.8 ) supplement group versus 59 (51.8 to 65.3 ) placebo group (normal range: $>70 \mu \mathrm{g} / \mathrm{dL}$ ).
Group 1: a single capsule that contained 200,000 IU vit A (retinyl palmitate) within 24 hours of starting tuberculosis treatment plus $15 \mathrm{mg}$ zinc (zinc gluconate) daily for 5 days per week for 8 weeks.

Group 2: placebo capsule (sunflower oil) within 24 hours of starting tuberculosis treatment plus placebo tablet (starch/gelatin base) daily for 5 days per week for 8 weeks.

- Death.
- Sputum-smear positive at baseline and 8 weeks.
- Adverse events.
- Weight gain at 2 months.
- Arm muscle circumference at 2 months.
- Vitamin A and zinc status at 2 and 8 weeks.
Outcomes not included in review: adherence, lung cavities at 2 months, copper, CRP, albumin, haemo-
globin, WBC, and neutrophil levels at 2 and 8 weeks.
Location: Cape Town, South Africa.
Setting: primary care tuberculosis clinics.
Funding: research grants from the National Research Foundation South Africa, the Norwegian Pro-
gramme for Development, Research and Higher Education, the Research Council of Norway, the Na-
tional Research Foundation, the South African Sugar Association, and the Fogarty International Cen-
tre. The South African Department of Health and Pharma Natura Pty donated the vitamin A and place-
bo capsules respectively.

\section{Risk of bias}

\begin{tabular}{|c|c|c|}
\hline Bias & Authors' judgement & Support for judgement \\
\hline $\begin{array}{l}\text { Random sequence genera- } \\
\text { tion (selection bias) }\end{array}$ & Low risk & $\begin{array}{l}\text { "computer-generated permuted blocks of } 8 \text {, generated by an independent epi- } \\
\text { demiologist". }\end{array}$ \\
\hline $\begin{array}{l}\text { Allocation concealment } \\
\text { (selection bias) }\end{array}$ & Low risk & $\begin{array}{l}\text { "Treatment allocations was concealed by prepackaging supplements in se- } \\
\text { quentially numbered packets according to the allocation schedule". }\end{array}$ \\
\hline $\begin{array}{l}\text { Blinding (performance } \\
\text { bias and detection bias) } \\
\text { All outcomes }\end{array}$ & Low risk & $\begin{array}{l}\text { "Active and placebo capsules and tablets for both groups were identical in } \\
\text { size, shape and colour. All research team members as well as laboratory staff } \\
\text { involved in the trial were blinded". }\end{array}$ \\
\hline $\begin{array}{l}\text { Incomplete outcome data } \\
\text { (attrition bias) } \\
\text { All outcomes }\end{array}$ & High risk & $\begin{array}{l}\text { Loss to follow-up was high in both groups: } 12 / 77 \text { (16\%) supplement group ver- } \\
\text { sus } 19 / 77 \text { placebo group }(25 \%) \text {. }\end{array}$ \\
\hline $\begin{array}{l}\text { Selective reporting (re- } \\
\text { porting bias) }\end{array}$ & Unclear risk & $\begin{array}{l}\text { We were unable to retrieve the trial protocol. There was no evidence of selec- } \\
\text { tive reporting. }\end{array}$ \\
\hline Other bias & Low risk & $\begin{array}{l}\text { "Because of a change in national policy in April } 200815 \text { participants received } \\
\text { TB treatment } 7 \text { days per week with unsupervised weekend doses". } \\
\text { Comment: this was unlikely to introduce significant bias. }\end{array}$ \\
\hline
\end{tabular}


Wejse 2008 GNB

\begin{tabular}{|c|c|}
\hline Methods & $\begin{array}{l}\text { Study design: RCT. } \\
\text { Study dates and duration: November } 2003 \text { to December 2005, follow-up } 12 \text { months. } \\
\text { Standard care: all participants received antituberculous therapy: } 2 \text { RHZE/6HE. }\end{array}$ \\
\hline Participants & $\begin{array}{l}\text { Number: } 367 \text { enrolled; number with available outcomes data varied by outcome. } \\
\text { Inclusion criteria: adults aged > } 15 \text { years, diagnosis of tuberculosis by smear positive (pulmonary tuber- } \\
\text { culosis) or WHO clinical criteria (extrapulmonary tuberculosis). } \\
\text { Exclusion criteria: none stated. } \\
\text { Baseline characteristics } \\
\text { - Nutritional status: mean BMI (range): } 18.8 \mathrm{~kg} / \mathrm{m}^{2} \text { (12 to } 33 \text { ) treatment group versus } 18.5 \mathrm{~kg} / \mathrm{m}^{2} \text { (12 to } \\
27 \text { ) placebo group. } \\
\text { - HIV status: } 39 \% \text { HIV-positive supplement group versus } 33 \% \text { HIV-positive placebo group. } \\
\text { - MDR/XDR-TB: not mentioned. } \\
\text { - Mean serum } 25 \text {-hydroxyvitamin } \mathrm{D}_{3} \mathrm{nmol} / \mathrm{L} \text { (SD): } 77.5(23.8) \text { supplement group versus } 79.1 \text { (21.8) place- } \\
\text { bo group (normal range: }>75 \mathrm{nmol} / \mathrm{L} \text { ). } \\
\text { - Described as a poor urban population. }\end{array}$ \\
\hline
\end{tabular}

Interventions Vitamin D group: 3 doses cholecalciferol $(100,000 \mathrm{IU})$ in drinkable ampoules; given at start of treatment, 5 months, and 8 months.

Placebo group: vegetable oil without cholecalciferol.

- Death at 12 months in HIV-positive and HIV-negative participants.
- Sputum-smear positive at baseline, 2 weeks, 4 weeks, 6 weeks, 2 months, 5 months, and 8 months.
- Adverse events.
- Weight gain at 8 months.
- Changes in tuberculosis score at 2, 5, and 8 months.
Outcomes not included in review: change in CD4 count at 8 months.

Notes Location: Guinnea-Bassau.

Setting: 3 health centres and a tuberculosis hospital in a demographic surveillance area.

\section{Risk of bias}

\begin{tabular}{lll}
\hline Bias & Authors' judgement & Support for judgement \\
\hline $\begin{array}{l}\text { Random sequence genera- } \\
\text { tion (selection bias) }\end{array}$ & Low risk & $\begin{array}{l}\text { "The random allocation sequence was computer generated; a list of continu- } \\
\text { ous study numbers was generated with a random allocation to treatment } 1 \text { or } \\
2 " .\end{array}$ \\
\hline $\begin{array}{l}\text { Allocation concealment } \\
\text { (selection bias) }\end{array}$ & Low risk & "Study numbers were consecutive and given to patients by the field assistant \\
& & $\begin{array}{l}\text { at inclusion, and patients were recorded in a book with pre-written study num- } \\
\text { bers and allocation sequence number } 1 \text { or 2", "A physician gave the trial infor- } \\
\text { mation and obtained consent...a trial nurse administered study medicine ac- } \\
\text { cording to sequence number". }\end{array}$ \\
\hline $\begin{array}{l}\text { Blinding (performance } \\
\text { bias and detection bias) }\end{array}$ & Low risk & $\begin{array}{l}\text { "Study medicine was provided in identical containers labelled lot 204 (alloca- } \\
\text { tion sequence number 1) or lot 205 (allocation sequence number 2)". }\end{array}$ \\
\hline \hline
\end{tabular}


Wejse 2008 GNB (Continued)

Incomplete outcome data Unclear risk Imbalanced attrition: 20/187 (11\%) supplement group versus 10/180 placebo (attrition bias) group (6\%).

All outcomes

$\begin{array}{ll}\begin{array}{l}\text { Selective reporting (re- } \\ \text { porting bias) }\end{array} & \begin{array}{l}\text { We were unable to retrieve the trial protocol. There was no evidence of selec- } \\ \text { tive reporting. }\end{array}\end{array}$

Other bias Low risk We did not identify any other sources of bias.

Abbreviations: $\mathrm{RCT}$ = randomised controlled trial; AIDS = acquired immune deficiency syndrome; HIV = human immunodeficiency virus; $\mathrm{E}=$ ethambutol; $\mathrm{H}=$ isoniazid; $\mathrm{R}=$ rifampicin; $\mathrm{S}=$ streptomycin; $\mathrm{Z}=$ pyrazinamide; $\mathrm{CRP}=\mathrm{C}$-reactive protein; $\mathrm{CD} 4 / \mathrm{CD} 8 / \mathrm{CD} 3=\mathrm{a}$ measure of immunological function in HIV-positive people; MDR = multidrug-resistant TB; XDR = extensively drug-resistant TB; DOTS = directly observed therapy short course; TST = tuberculin skin testing; $\mathrm{BMI}=$ body mass index; $\mathrm{CXR}=$ chest $\mathrm{X}$-ray; $\mathrm{ESR}=$ erythrocyte sedimentation rate; $\mathrm{WBC}=$ white blood cell count; $2 \mathrm{RHZE} / 4 \mathrm{HE}=2$ months of isoniazid, rifampin, prazinamide, and ethambutol followed by 4 months of ethambutol and isoniazid; $2 \mathrm{RHZE} / 4 \mathrm{HR}=2$ months of isoniazid, rifampin, prazinamide, and ethambutol followed by 4 months of rifampin and isoniazid; $\mathrm{INH}=$ isoniazid; $2 \mathrm{RHZE} / 6 \mathrm{HE}=2$ months of isoniazid, rifampin, prazinamide, and ethambutol followed by 6 months of ethambutol and isoniazid.

Characteristics of excluded studies [ordered by study ID]

\begin{tabular}{|c|c|}
\hline Study & Reason for exclusion \\
\hline Denti 2015 & Ineligible outcomes: pharmacokinetics. \\
\hline Dibari 2013 & Ineligible intervention. Looks at acceptability of ready to eat foods. \\
\hline Gwinup 1981 & $\begin{array}{l}\text { Outcomes were irrelevant to this Cochrane review's objectives (assessed effect of vitamin supple- } \\
\text { mentation on serum calcium levels in people with tuberculosis). }\end{array}$ \\
\hline Hasan 2015 & Ineligible intervention: propolis. \\
\hline Kawai 2014 & Ineligible outcomes: linked to Villamor 2008 TZA. \\
\hline Khandelwal 2014 & Ineligible study design: cohort study. \\
\hline Lin 2014 & Ineligible intervention; no relevant outcomes. \\
\hline Lutge 2013 & Ineligible intervention; food vouchers. \\
\hline Martineau 2009 & Excluded as evaluates a single dose of vitamin D. \\
\hline Mbala 1998 & $\begin{array}{l}\text { Outcomes were not relevant to review's objectives (assessed neurological and neuropsychiatric } \\
\text { symptoms in children being treated for tuberculosis using isoniazid with or without vitamin B6 } \\
\text { supplementation). }\end{array}$ \\
\hline Narang 1984 & $\begin{array}{l}\text { Groups were not randomly allocated, participants not being treated for active tuberculosis, and } \\
\text { outcomes were not relevant to review's objectives. }\end{array}$ \\
\hline Oluboyede 1978 & It was unclear whether the groups were randomized; we were unable to contact the trial authors. \\
\hline Permatasari 2014 & Ineligible intervention: propolis. \\
\hline Ramakrishnan 1961 & Groups were not randomized to different dietary interventions. \\
\hline Samsidi 2013 & Ineligible control/comparison; the control group received milk-based protein supplement. \\
\hline
\end{tabular}




\begin{tabular}{ll}
\hline Study & Reason for exclusion \\
\hline Shi 2001 & $\begin{array}{l}\text { The study authors assessed only partial parenteral nutrition, which we excluded from this } \\
\text { Cochrane review. }\end{array}$ \\
\hline Srivastava 2011 & The study only provided vitamin D for 5 days. \\
\hline
\end{tabular}

Characteristics of studies awaiting assessment [ordered by study ID]

\begin{tabular}{ll}
\hline Al Mamun 2014 & RCT \\
\hline Pethods & Smear-positive tuberculosis participants ( $=111)$ \\
\hline Interventions & Vitamin A (5000 IU daily) + zinc (15 mg daily) \\
& Placebo \\
\hline Outcomes & Smear conversion, radiology, haemoglobin, erythrocyte sedimentation rate, C-reactive protein \\
\hline Notes & $\begin{array}{l}\text { The abstract does not provide any data for any of the measured outcomes. We contacted the study } \\
\text { authors but did not receive a response }\end{array}$ \\
\hline
\end{tabular}

Chandra 2004

\begin{tabular}{ll}
\hline Methods & RCT \\
\hline Participants & Number: 44 enrolled (28 men and 16 women) \\
\hline Interventions & Group 1: 3 tablets 3 times weekly of multiple micronutrients \\
& Group 2: placebo \\
\hline Outcomes & Sputum-smear test positive at 2, 3, 5, and 6 months \\
& Chest x-ray findings positive at 3 and 6 months \\
\hline Notes & $\begin{array}{l}\text { Location: India } \\
\text { Setting: unclear } \\
\text { Information still pending: Ranjit Kumar Chandra is a researcher in the field of nutrition and im- } \\
\text { munology who has been accused of committing scientific fraud by the British Medical Journal. A ju- } \\
\text { ry trial in July } 2015 \text { concluded that the allegations of fraud were truthful. Due to these allegations, } \\
\text { a number of his scientific articles have been subject to retraction (see https://en.wikipedia.org/wi- } \\
\text { ki/Ranjit_Chandra). }\end{array}$ \\
\hline
\end{tabular}

Guzman-Rivero 2013

Methods RCT (pilot study)


Guzman-Rivero 2013 (Continued)
Participants
Pulmonary tuberculosis patients

\begin{tabular}{ll}
\hline Interventions & Antituberculous treatment combined with zinc ( $45 \mathrm{mg} /$ day) or placebo for 3 months \\
\hline Outcomes & Clinical outcomes, sputum clearance, radiological improvement and nutritional status \\
\hline Notes & Conference abstracts (2) \\
& Information still pending: \\
& $\begin{array}{l}\text { Neither of the abstracts provides data for any of the measured outcomes. We contacted the au- } \\
\text { thors for information but have not received a response. }\end{array}$ \\
\hline
\end{tabular}

Nagrale 2013

\begin{tabular}{ll}
\hline Methods & RCT \\
\hline Participants & Newly diagnosed sputum positive pulmonary tuberculosis \\
\hline Interventions & Antituberculous treatment with $\mathrm{N}$-acetylcysteine $(600 \mathrm{mg}, 2$ tablets daily ) or placebo for 2 months \\
\hline Outcomes & Sputum conversion, radiological improvement, DTH response, glutathione peroxidase levels \\
\hline Notes & Conference abstract \\
& $\begin{array}{l}\text { Information still pending: } \\
\text { The abstract does not provide any data for any of the measured outcomes. We contacted the study } \\
\text { authors in May } 2015 \text { for full text but did not receive a response }\end{array}$
\end{tabular}

Nawas 2013

\begin{tabular}{ll}
\hline Methods & RCT; November 2010 to October 2011 \\
\hline Participants & 100 newly diagnosed sputum positive pulmonary tuberculosis \\
\hline Interventions & $\begin{array}{l}\text { Antituberculous treatment (fixed-dose combination) with Morinda citrifolia (125 mg) and Zinger of- } \\
\text { ficinale }(125 \mathrm{mg}) \text { extract or placebo }\end{array}$ \\
\hline Outcomes & Sputum conversion at 6 months \\
\hline Notes & $\begin{array}{l}\text { Conference abstract } \\
\text { Information still pending: the abstract does not provide any data for any of the measured out- } \\
\text { comes. We contacted the study authors in May } 2015 \text { for the full-text article but did not receive a re- } \\
\text { sponse }\end{array}$ \\
\hline
\end{tabular}

Abbreviations: $\mathrm{RCT}=$ randomised controlled trial; $\mathrm{N}=$ number of participants.

Characteristics of ongoing studies [ordered by study ID] 


\section{ChicTR-IPR-15006395}

Trial name or title

The influence and mechanism of vitamin D3 supplementation on the treatment outcomes of tuberculosis patients of different glucose tolerance.

\begin{tabular}{ll}
\hline Methods & RCT. \\
\hline Participants & $\begin{array}{l}\text { Inclusion criteria: new diagnosed tuberculosis, sputum smear positive, aged } \geq 18, \text { stable address. } \\
\text { Exclusion criteria: HIV-positive, tumour, pregnant or lactating women, injured lately, adjusted cal- } \\
\text { cium concentration > 2.65 mmol/L. } \\
\text { Gender: both. }\end{array}$ \\
\hline Interventions & NTB: vitamin D3; HTB: vitamin D3; NTB: control; HTB: control. \\
\hline Outcomes & Primary: treatment outcomes; CD4+/CD8+; quantity of life (SF-36v2). \\
\hline Starting date & Secondary: oxidative stress; serum 25(OH)D. \\
\hline Contact information & 25 May 2015. \\
\hline Notes & kevin_1971@126.com \\
\hline
\end{tabular}

\section{ChicTR-TRC-12002546}

\begin{tabular}{|c|c|}
\hline Trial name or title & $\begin{array}{l}\text { The effect and mechanism of retinol and vitamin A supplementation in patients with diabetes and } \\
\text { pulmonary TB. }\end{array}$ \\
\hline Methods & RCT. \\
\hline Participants & $\begin{array}{l}\text { Inclusion criteria: participants with pulmonary tuberculosis and diabetes, aged } 18 \text { to } 75 \text { years, diag- } \\
\text { nosed by the golden criteria of pulmonary tuberculosis and diabetes; no vitamin or mineral supple- } \\
\text { ment } 1 \text { month before the screening. } \\
\text { Exclusion criteria: no severe complications of diabetes including diabetic eye diseases, renal dis- } \\
\text { ease and foot disease, etc; pregnancy or lactation women; cancer; coronary heart disease; recent } \\
\text { suffered trauma or recent surgery. }\end{array}$ \\
\hline \multirow[t]{4}{*}{ Interventions } & Vitamin D (400 IU/d). \\
\hline & Vitamin A (2000 IU/d). \\
\hline & Vitamin D (400 IU/d) + vitamin A (2000 IU/d). \\
\hline & Placebo control. \\
\hline Outcomes & $\begin{array}{l}\text { Retinol; vitamin } D \text {; fasting glucose; fasting insulin; CD4+/D8+; protein kinase C (PKC); blood lym- } \\
\text { phocyte proliferation. }\end{array}$ \\
\hline Starting date & 20 October 2012. \\
\hline Contact information & kevin_1971@126.com; maiguo@public.qd.sd.cn \\
\hline Notes & China. \\
\hline
\end{tabular}




\section{ChiCTR-TRC-14005241}

Trial name or title A prospective study of oral nutritional supplement in perioperative application with pulmonary TB patients.

\begin{tabular}{ll}
\hline Interventions & Nutrison Fibre + normal diet or normal diet. \\
\hline Outcomes & Serum albumin and pre-albumin, weight, T cell subset. \\
\hline Starting date & From 01 October 2014 to 01 October 2016. \\
\hline Contact information & daoren_000113@126.com \\
\hline Notes & Shenzhen, China. \\
& Hospital setting. \\
\hline
\end{tabular}

\section{IRCT201112178429N1}

Trial name or title Effect of zinc supplementation in improving pulmonary TB patients in Qom.

\begin{tabular}{ll}
\hline Methods & RCT. \\
\hline Participants & $\begin{array}{l}\text { Inclusion criteria: active tuberculosis and filling the informed consent. } \\
\text { Exclusion criteria: diseases such as cancer, stroke, immunosuppressive diseases, and not agreeing } \\
\text { to take mineral supplement or placebo. }\end{array}$
\end{tabular}

Interventions

Intervention 1: zinc supplement (30 mg zinc) every second day for 6 months.

Intervention 2: placebo every second day for 6 months.

\section{Outcomes}

Radiological signs: timepoint: at baseline, 2 months, and 6 months later. Method of measurement: chest radiology.

Smear negative: timepoint: at baseline, 2 months, and 6 months later. Method of measurement: smear.

Stop coughing: timepoint: at baseline, 2 months and 6 months later. Method of measurement: physical exam.

Stop fever: timepoint: at baseline, 2 months and 6 months later. Method of measurement: physical exam.

\begin{tabular}{ll}
\hline Starting date & 21 January 2012. \\
\hline Contact information & fpourfallah@pasteur.ac.ir
\end{tabular}

Nutritional supplements for people being treated for active tuberculosis (Review) 
IRCT201112178429N1 (Continued)

Notes
Recruitment complete.
Iran.

Iran.

\section{IRCT201211179855N2}

Trial name or title

Methods RCT.

Randomized, double-blind, placebo-controlled trial of L-arginine supplementation for the treatment of pulmonary TB.

\begin{tabular}{ll}
\hline Participants & Inclusion criteria: adults over 15 years; new cases of positive sputum smear. \\
& Exclusion criteria: pregnant women; aged under 15 years; patients who during the past month re- \\
ceived L-arginine; sensitivity to L-arginine.
\end{tabular}

Interventions

Intervention 1: standard antituberculous treatment for 6 months plus L-arginine, $2 \mathrm{~g}$ daily in first month.

Intervention 2: standard 6-month antituberculous treatment plus placebo $2 \mathrm{~g}$ daily in first month.

\begin{tabular}{ll} 
Outcomes & Improved para-clinical tests. Timepoint: day 14, 28, 42, and 56. Measurement method: check of \\
CRP. & Improved para-clinical tests. Timepoint: day 14, 28, 42, and 56. Measurement method: check of \\
& ESR. \\
& Improved para-clinical tests. Timepoint: day 14, 28, 42, and 56. Measurement method: check of \\
& CBC. \\
& Weight gain: timepoint: 0 and 56. Measurement method: weight measurement. \\
& $\begin{array}{l}\text { Improve of life quality: timepoint: } 0 \text { and } 56 . \text { Measurement method: standard questionnaire of } \\
\text { GHQ-28. }\end{array}$ \\
\hline Starting date & 21 December 2012. \\
\hline Contact information & farazialiasghar@yahoo.com \\
gakbarifard@yahoo.com
\end{tabular}

\section{ISRCTN16469166}

Trial name or title Nutrition and wasting in TB: Can nutritional supplementation in TB patients improve body weight gain, body composition and treatment outcome?

\begin{tabular}{ll}
\hline Methods & RCT. \\
\hline Participants & Expected enrolment: adults $>18$ years with sputum positive pulmonary tuberculosis. \\
\hline Interventions & $\begin{array}{l}\text { Standard treatment plus nutritional supplementation (supplements containing } 450 \mathrm{kcal} \text { energy } \\
\text { plus a wide range of vitamins and minerals in doses of approximately half the required daily in- } \\
\text { takes (but no iron)). }\end{array}$
\end{tabular}


ISRCTN16469166 (Continued)

- Standard treatment only.

Secondary: micronutrient status and production of inflammatory cytokines.

\section{Starting date} 15 May 2007.

Anticipated end date: 1 January 2008.
Dr Frank Wieringa (wieringa@tiscali.nl), Dept. of Internal Medicine, Hasan Sadikin Hospital, Bandung, Indonesia.

We attempted to contact the author for results on 25 January 2010 and 05 May 2010 with no reply.

Location: Indonesia.

Registration number: ISRCTN16469166.

Source of funding: Netherlands Organisation for Scientific Research (The Netherlands).

We contacted the trial authors for information on 20 July 2015.

There was no sign of publication of the data (PubMed search).

\section{NCT00507000}

\begin{tabular}{|c|c|}
\hline Trial name or title & $\begin{array}{l}\text { Role of oral vitamin D as an adjunct therapy in Category I pulmonary TB along with assessment of } \\
\text { immunological parameters. }\end{array}$ \\
\hline Methods & RCT. \\
\hline Participants & Adults aged 18 to 60 years with newly diagnosed sputum-smear positive pulmonary tuberculosis. \\
\hline Interventions & $\begin{array}{l}\text { - Cholecalciferol (vitamin D) and calcium carbonate. } \\
\text { - Placebo (lactose granules). }\end{array}$ \\
\hline Outcomes & $\begin{array}{l}\text { Primary: time to becoming sputum-smear negative. } \\
\text { Secondary: relapse rate; safety assessment; immune function. }\end{array}$ \\
\hline Starting date & $\begin{array}{l}\text { May } 2008 . \\
\text { Anticipated end date: September } 2010 .\end{array}$ \\
\hline Contact information & $\begin{array}{l}\text { Dr Ravinder Goswami (gosravinder@hotmail.com), Department of Endocrinology and Metabolism, } \\
\text { All India Institue of Medical Sciences, New Delhi, India. }\end{array}$ \\
\hline Notes & $\begin{array}{l}\text { Location: India. } \\
\text { Registration number: NCT00507000. } \\
\text { Source of funding: Indian Council of Medical Research; Ministry of Science and Technology, India. } \\
\text { We contacted the trial authors for information. } \\
\text { There was no sign of publication of the data (PubMed search). }\end{array}$ \\
\hline
\end{tabular}


NCT00698386

Trial name or title

Efficacy of oral zinc administration as an adjunct therapy in new pulmonary TB (Category I) patients.

\begin{tabular}{ll}
\hline Methods & RCT. \\
\hline Participants & Adults with newly diagnosed smear positive pulmonary tuberculosis. \\
\hline Interventions & 50 mg zinc as zinc sulphate daily for 6 months during DOTS versus placebo. \\
\hline Outcomes & $\begin{array}{l}\text { Time to sputum conversion, cure rate, relapse, adverse events, patient and physician global assess- } \\
\text { ment of cure. }\end{array}$ \\
\hline Starting date & February 2008. \\
\hline Contact information & Surendra K Sharma, MD, PhD, All India Institute of Medical Sciences, New Delhi. \\
& surensk@gmail.com, sksharma@aiims.ac.in \\
\hline Notes & Location: India. \\
& Registration number: NCT0069386. \\
& Source of funding: Ministry of Science and Technology, India. \\
We contacted the trial authors for information. & No sign of publication of the data (PubMed search).
\end{tabular}

\section{NCT00788320}

Trial name or title

Antimicrobial peptide LL-37 (cathelicidin) production in active TB disease: role of vitamin D supplementation.

\begin{tabular}{ll}
\hline Methods & RCT. \\
\hline Participants & Adults aged > 18 years with newly diagnosed pulmonary tuberculosis. \\
\hline Interventions & $\begin{array}{l}\text { Drug: vitamin D3. } \\
\text { Drug: placebo. }\end{array}$ \\
\hline Outcomes & LL-37 level, time to sputum conversion, vitamin D and calcium levels. \\
\hline Starting date & October 2008. \\
\hline Contact information & Not stated. \\
\hline Notes & Location: USA. \\
Registration number: NCT00788320. \\
Source of funding: Emory University. \\
$\begin{array}{l}\text { This study has been withdrawn prior to enrolment (inadequate enrolment). See https://clinicaltri- } \\
\text { als.gov/ct2/show/NCT00788320 for details. }\end{array}$
\end{tabular}


NCT01635153

\section{Trial name or title}

Methods RCT.

RCT.
Effects of a protein calorie supplement in HIV-infected women with TB DarDar.

Inclusion criteria: female, HIV, age > 18, CD4 > 50, BMI > 16 new tuberculosis diagnosis, not on anti-retroviral therapy, residence in Dar es Salaam.

Exclusion Criteria: current anti-retroviral therapy, serious co-morbidities.

\section{Interventions}

Group 1: micronutrient supplement.

Group 2: protein calorie supplement.

Outcomes Primary outcomes: change in CD4 count (time frame: baseline to 8 months).

Secondary outcomes: body mass index at 6 months (time frame: baseline to 6 months); proportion of subjects who achieve 100 cell count increase in CD4 cell count (Time frame: baseline to 8 months).

\begin{tabular}{ll}
\hline Starting date & May 2012. \\
\hline Contact information & Charles F von Reyn, MD, Geisel School of Medicine at Dartmouth. \\
\hline Notes & Active, not recruiting. \\
\hline
\end{tabular}

\section{NCT01657656}

\begin{tabular}{ll}
\hline Trial name or title & Vitamin D supplementations as adjunct to anti-TB drugs in Mongolia. \\
\hline Methods & RCT. \\
\hline Participants & $\begin{array}{l}\text { Inclusion criteria: sputum positive tuberculosis patients. } \\
\text { Exclusion criteria: abnormal LFTs at baseline (2.5 times upper limit of normal), as they will be at } \\
\text { higher risk of developing drug-induced hepatitis. }\end{array}$ \\
\hline Interventions & Vitamin D (does not state what comparator group receiving). \\
\hline Outcomes & $\begin{array}{l}\text { The primary endpoint will be time to sputum culture conversion from positive to negative (time } \\
\text { frame: } 8 \text { weeks). }\end{array}$ \\
\hline Starting date & October 2012. \\
\hline Contact information & gdavaasa@hsph.harvard.edu (Ganmaa Davaasambuu). \\
\hline Notes & Study status: completed. \\
\hline
\end{tabular}

\section{NCT01722396}

Trial name or title Pharmacogenetics of Vitamin D Supplementation in TB.


NCT01722396 (Continued)

\begin{tabular}{ll} 
Methods & Open label study of vitamin D supplementation. \\
\hline Participants & Patients with active or latent tuberculosis. \\
\hline Interventions & $\begin{array}{l}\text { Active tuberculosis patients take } 100,000 \text { units of vitamin D every } 8 \text { weeks during their tuberculosis } \\
\text { treatment. }\end{array}$ \\
\hline Outcomes & Ex vivo responses of monocytes to vitamin D (time frame: 0 and 8 weeks). \\
\hline Starting date & March 2011. \\
\hline Contact information & Alice Turner, University of Birmingham. \\
\hline Notes & Status: completed.
\end{tabular}

\section{NCT01992263}

\section{Trial name or title}

\section{Methods}

Participants
A trial of vitamin D supplementation among TB patients in South India.

RCT.

Inclusion criteria: 18 to 60 years old, active tuberculosis diagnosis by GeneXpert ${ }^{\circledR}$; HIV infection status (according to AMC HIV clinic medical records of enzyme-linked immunosorbent assay (ELISA) results).

Exclusion criteria: children ( $<18$ years of age) and older than 60 years, pregnant at baseline, other severe complications or illnesses requiring hospitalisation, received tuberculosis treatment for greater than 4 weeks in the past 5 years, refused to participate, residing in a geographic location $>1$ hour from AMC (by public transit).

\begin{tabular}{ll}
\hline Interventions & Vitamin D (2000 IU/4000 IU/600 IU) or placebo. \\
\hline Outcomes & Primary outcomes \\
& - Cell-mediated immunological markers (T cells) (time frame: 1 year). \\
- Immune function (time frame: 1 year). & - Serum $25(\mathrm{OH}) \mathrm{D}$ concentrations (time frame: 1 year). \\
Secondary outcomes \\
- HIV disease progression (time frame: 1 year). \\
- tuberculosis treatment outcomes (time frame: 1 year).
\end{tabular}

\section{NCT02169570}

Trial name or title

Effect of supplementary vitamin D in patients with diabetes mellitus and pulmonary TB (EVIDENT). 
NCT02169570 (Continued)

Methods RCT.
Inclusion criteria: 30 to 60 years; patients having both tuberculosis and type $2 \mathrm{DM}$; consenting to participate; no history of previous ATT; plan to have ATT and DM treatment.

Exclusion criteria: pregnant women; patients with extra-pulmonary tuberculosis or multi-drug resistant (MDR)-tuberculosis or relapse cases, hepatic or renal diseases or HIV infection, hypo- or hyper-parathyroidism; patients on corticosteroids, or immunosuppressive, or thiazides diuretics, or any other drugs known to interfere with vitamin D levels.
Interventions

Calcium; placebo calcium; placebo vitamin D; vitamin D.

\begin{tabular}{ll}
\hline Starting date & December 2014. \\
\hline Contact information & nadia.shah@live.com \\
\hline Notes & Pakistan. \\
& Status: not yet recruiting. \\
\hline
\end{tabular}

\section{NCT02464683}

\begin{tabular}{ll}
\hline Trial name or title & Effect of vitamin D as adjunctive therapy in patients with pulmonary evolution TB (Vitamin D). \\
\hline Methods & RCT. \\
\hline Participants & $\begin{array}{l}\text { Inclusion criteria: men and women over } 18 \text { and under } 65 \text { years old, with tuberculosis confirmed by } \\
\text { positive smear and positive culture, without documented evidence of previous treatment for tu- } \\
\text { berculosis, with haemoglobin values greater than } 10 \mathrm{~g} / \mathrm{dL} \text {, and written consent. }\end{array}$ \\
& $\begin{array}{l}\text { Exclusion criteria: HIV-positive, no written consent, chronic lung disease, clinical evidence of infec- } \\
\text { tious or chronic inflammatory disease processes such as: rheumatoid arthritis, systemic lupus ery- } \\
\text { thematosus (SLE), Sjögren Sx, dermatomyositis, scleroderma, seronegative arthritis, gout, inflam- } \\
\text { matory bowel disease, chronic active hepatitis, glomerulonephritis, rheumatic fever and cardiac } \\
\text { disease, cancer, and history of alcohol or drug abuse. }\end{array}$
\end{tabular}

\begin{tabular}{ll}
\hline Interventions & Vitamin D (200 IU) or placebo daily for 60 days. \\
\hline Outcomes & Determination of cytokines. \\
\hline Starting date & April 2014. \\
\hline Contact information & Martha Torres Rojas, PhD marthatorres98@yahoo.com \\
\hline \hline
\end{tabular}

Nutritional supplements for people being treated for active tuberculosis (Review) 
NCT02464683 (Continued)

\begin{tabular}{|c|c|}
\hline Methods & RCT. \\
\hline Participants & $\begin{array}{l}\text { Inclusion criteria: newly diagnosed adult male and female tuberculosis active patients with clinical } \\
\text { evidences of active tuberculosis symptoms (positive or negative sputum smears, positive chest X- } \\
\text { ray that compatible with a diagnosis of tuberculosis); no history of previous antituberculous treat- } \\
\text { ment. } \\
\text { Exclusion criteria: heavy smoker (> } 20 \text { cigarettes per day); pregnancy and lactation; extrapul- } \\
\text { monary tuberculosis; known allergy to soybean; clinical evidences of any underlying disease. }\end{array}$ \\
\hline Interventions & Fermented soybean. \\
\hline Outcomes & Body weight, body mass index, handgrip strength, 6-minute walk test. \\
\hline Starting date & October 2013. \\
\hline Contact information & Michael B Krawinkel, Prof Dr University of Gleesen. \\
\hline Notes & Uncertain what the comparison group received. \\
\hline
\end{tabular}

\section{DATA AND ANALYSES}

\section{Comparison 1. Macronutrient supplementation}

\begin{tabular}{lllll}
\hline $\begin{array}{l}\text { Outcome or subgroup } \\
\text { title }\end{array}$ & No. of studies & $\begin{array}{l}\text { No. of partici- } \\
\text { pants }\end{array}$ & Statistical method & Effect size \\
\hline $\begin{array}{l}\text { 1 Death (1 year of fol- } \\
\text { low-up) }\end{array}$ & 4 & 567 & Risk Ratio (M-H, Fixed, 95\% Cl) & $0.34[0.10,1.20]$ \\
\hline 1.1 HIV-positive & 2 & 72 & Risk Ratio (M-H, Fixed, 95\% Cl) & $0.60[0.12,3.01]$ \\
\hline 1.2 HIV-negative & 3 & 230 & Risk Ratio (M-H, Fixed, 95\% Cl) & $0.18[0.02,1.48]$ \\
\hline 1.3 Unknown HIV status & 1 & 265 & Risk Ratio (M-H, Fixed, 95\% Cl) & $0.0[0.0,0.0]$ \\
\hline 2 Cured (at 6 months) & 1 & 102 & Risk Ratio (M-H, Random, 95\% Cl) & $1.38[0.46,4.14]$ \\
\hline 2.1 HIV-positive & 1 & 22 & Risk Ratio (M-H, Random, 95\% Cl) & $0.85[0.53,1.35]$ \\
\hline 2.2 HIV-negative & 1 & 80 & Risk Ratio (M-H, Random, 95\% Cl) & Subtotals only \\
\hline 3 Treatment completion & 2 & & $0.91[0.59,1.41]$ \\
\hline
\end{tabular}




\begin{tabular}{|c|c|c|c|c|}
\hline $\begin{array}{l}\text { Outcome or subgroup } \\
\text { title }\end{array}$ & No. of studies & $\begin{array}{l}\text { No. of partici- } \\
\text { pants }\end{array}$ & Statistical method & Effect size \\
\hline 3.1 HIV-negative & 1 & 100 & Risk Ratio (M-H, Random, 95\% Cl) & $1.20[1.04,1.37]$ \\
\hline 3.2 Unknown HIV status & 1 & 265 & Risk Ratio (M-H, Random, 95\% Cl) & $0.98[0.86,1.12]$ \\
\hline $\begin{array}{l}4 \text { Sputum negative at } 8 \\
\text { weeks }\end{array}$ & 3 & 222 & Risk Ratio (M-H, Random, 95\% Cl) & $1.08[0.86,1.37]$ \\
\hline 5 Mean weight gain & 5 & & Mean Difference (IV, Random, 95\% CI) & Subtotals only \\
\hline 5.1 After 6 weeks & 1 & 34 & Mean Difference (IV, Random, 95\% CI) & $1.73[0.81,2.65]$ \\
\hline 5.2 After 8 weeks & 3 & 689 & Mean Difference (IV, Random, 95\% CI) & $0.78[-0.05,1.60]$ \\
\hline 5.3 After 12 weeks & 1 & 100 & Mean Difference (IV, Random, 95\% CI) & $2.6[1.74,3.46]$ \\
\hline $\begin{array}{l}5.4 \text { After } 20 \text { weeks ( } 12 \\
\text { weeks post supplemen- } \\
\text { tation) }\end{array}$ & 1 & 306 & Mean Difference (IV, Random, 95\% CI) & $-0.20[-1.34,0.94]$ \\
\hline 5.5 After 24 weeks & 1 & 26 & Mean Difference (IV, Random, 95\% CI) & $1.78[-0.25,3.81]$ \\
\hline 5.6 After 32 weeks & 1 & 265 & Mean Difference (IV, Random, 95\% CI) & $2.60[0.52,4.68]$ \\
\hline $\begin{array}{l}6 \text { Change in maximum } \\
\text { grip strength }(\mathrm{kg})\end{array}$ & 3 & & Mean Difference (IV, Random, 95\% CI) & Subtotals only \\
\hline 6.1 At 6 weeks & 1 & 34 & Mean Difference (IV, Random, 95\% CI) & $3.44[0.78,6.10]$ \\
\hline 6.2 At 8 weeks & 1 & 332 & Mean Difference (IV, Random, 95\% CI) & $0.50[-0.63,1.63]$ \\
\hline 6.3 At 12 weeks & 1 & 100 & Mean Difference (IV, Random, 95\% CI) & $1.50[1.08,1.92]$ \\
\hline 6.4 At 20 weeks & 1 & 303 & Mean Difference (IV, Random, 95\% CI) & $1.30[-0.11,2.71]$ \\
\hline 6.5 At 24 weeks & 1 & 26 & Mean Difference (IV, Random, 95\% CI) & $0.39[-3.05,3.83]$ \\
\hline $\begin{array}{l}7 \text { Change in quality of life } \\
\text { score }\end{array}$ & 1 & & Mean Difference (IV, Random, 95\% CI) & Totals not selected \\
\hline 7.1 At 6 weeks & 1 & & Mean Difference (IV, Random, 95\% CI) & $0.0[0.0,0.0]$ \\
\hline 7.2 At 24 weeks & 1 & & Mean Difference (IV, Random, 95\% CI) & $0.0[0.0,0.0]$ \\
\hline
\end{tabular}

\section{Analysis 1.1. Comparison 1 Macronutrient supplementation, Outcome 1 Death (1 year of follow-up).}

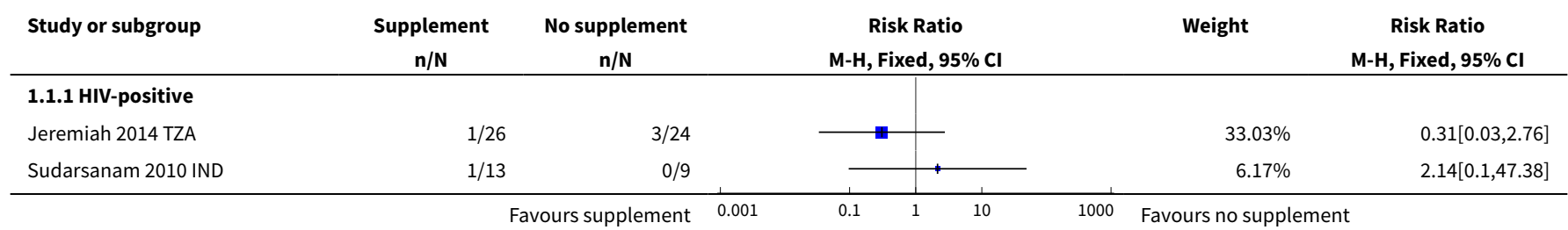




\begin{tabular}{|c|c|c|c|c|c|}
\hline Study or subgroup & $\begin{array}{c}\text { Supplement } \\
\mathrm{n} / \mathrm{N}\end{array}$ & $\begin{array}{c}\text { No supplement } \\
\mathrm{n} / \mathrm{N} \\
\end{array}$ & $\begin{array}{c}\text { Risk Ratio } \\
\text { M-H, Fixed, 95\% Cl }\end{array}$ & Weight & $\begin{array}{c}\text { Risk Ratio } \\
\text { M-H, Fixed, 95\% Cl }\end{array}$ \\
\hline Subtotal $(95 \% \mathrm{Cl})$ & 39 & 33 & & $39.2 \%$ & $0.6[0.12,3.01]$ \\
\hline \multicolumn{6}{|c|}{ Total events: 2 (Supplement), 3 (No supplement) } \\
\hline \multicolumn{6}{|c|}{ Heterogeneity: $\mathrm{Tau}^{2}=0 ; \mathrm{Chi}^{2}=1.01, \mathrm{df}=1(\mathrm{P}=0.32) ; \mathrm{I}^{2}=0.51 \%$} \\
\hline \multicolumn{6}{|c|}{ Test for overall effect: $Z=0.63(P=0.53)$} \\
\hline \multicolumn{6}{|l|}{ 1.1.2 HIV-negative } \\
\hline Jahnavi 2010 IND & $0 / 50$ & $2 / 50$ & $\begin{array}{l}-1 \\
\end{array}$ & $26.46 \%$ & $0.2[0.01,4.06]$ \\
\hline Jeremiah 2014 TZA & $0 / 25$ & $0 / 25$ & & & Not estimable \\
\hline Sudarsanam 2010 IND & $0 / 37$ & $3 / 43$ & $\longrightarrow$ & $34.34 \%$ & $0.17[0.01,3.1]$ \\
\hline Subtotal $(95 \% \mathrm{Cl})$ & 112 & 118 & & $60.8 \%$ & $0.18[0.02,1.48]$ \\
\hline \multicolumn{6}{|c|}{ Total events: 0 (Supplement), 5 (No supplement) } \\
\hline \multicolumn{6}{|c|}{ Heterogeneity: $\mathrm{Tau}^{2}=0 ; \mathrm{Chi}^{2}=0.01, \mathrm{df}=1(\mathrm{P}=0.93) ; \mathrm{I}^{2}=0 \%$} \\
\hline \multicolumn{6}{|c|}{ Test for overall effect: $Z=1.6(P=0.11)$} \\
\hline \multicolumn{6}{|c|}{ 1.1.3 Unknown HIV status } \\
\hline Martins 2009 TLS & $0 / 136$ & $0 / 129$ & & & Not estimable \\
\hline Subtotal $(95 \% \mathrm{CI})$ & 136 & 129 & & & Not estimable \\
\hline \multicolumn{6}{|c|}{ Total events: 0 (Supplement), 0 (No supplement) } \\
\hline \multicolumn{6}{|c|}{ Heterogeneity: Not applicable } \\
\hline \multicolumn{6}{|c|}{ Test for overall effect: Not applicable } \\
\hline Total $(95 \% \mathrm{Cl})$ & 287 & 280 & & $100 \%$ & $0.34[0.1,1.2]$ \\
\hline \multicolumn{6}{|c|}{ Total events: 2 (Supplement), 8 (No supplement) } \\
\hline \multicolumn{6}{|c|}{ Heterogeneity: $\operatorname{Tau}^{2}=0 ; \mathrm{Chi}^{2}=1.72, \mathrm{df}=3(\mathrm{P}=0.63) ; \mathrm{I}^{2}=0 \%$} \\
\hline \multicolumn{6}{|c|}{ Test for overall effect: $Z=1.68(P=0.09)$} \\
\hline Test for subgroup differ & $78, \mathrm{df}=1(\mathrm{P}=0.38)$, & & & & \\
\hline
\end{tabular}

\section{Analysis 1.2. Comparison 1 Macronutrient supplementation, Outcome 2 Cured (at 6 months).}

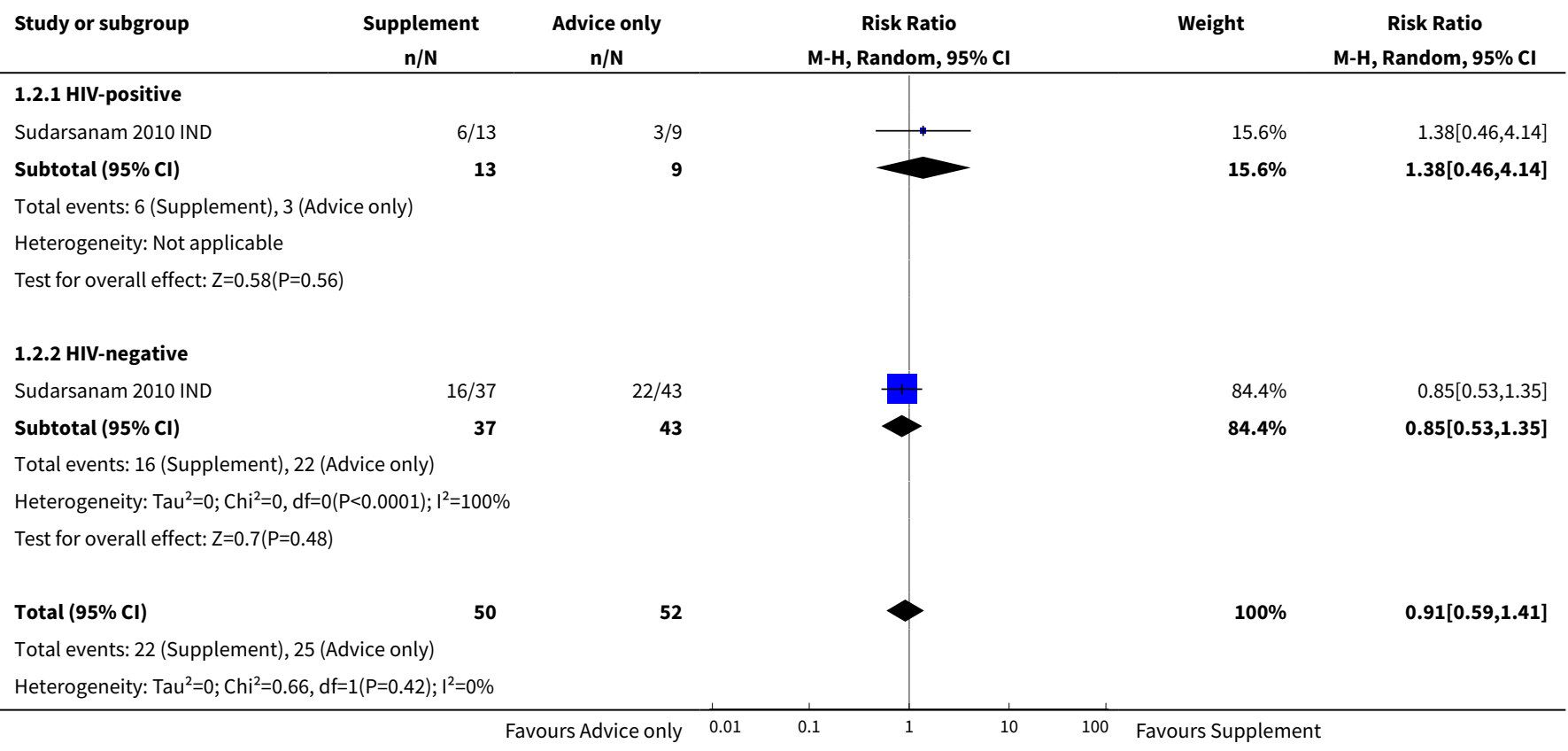

Nutritional supplements for people being treated for active tuberculosis (Review) 


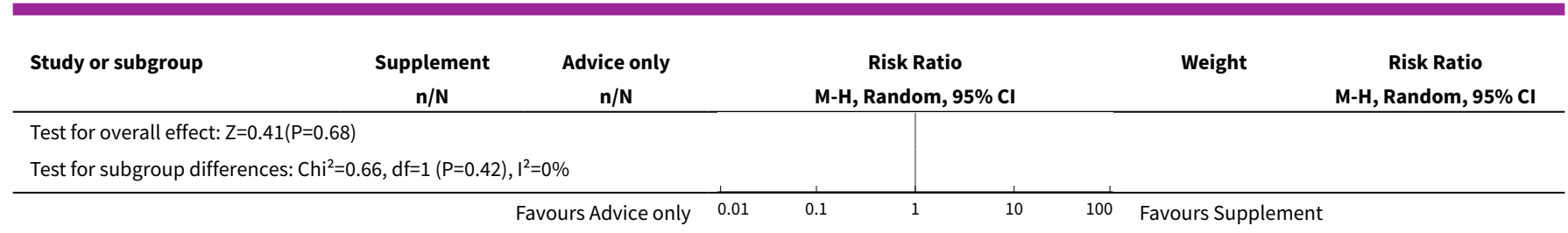

\section{Analysis 1.3. Comparison 1 Macronutrient supplementation, Outcome 3 Treatment completion.}

\begin{tabular}{|c|c|c|c|c|c|}
\hline Study or subgroup & $\begin{array}{c}\text { Supplement } \\
n / N\end{array}$ & $\begin{array}{c}\text { No supplement } \\
\mathrm{n} / \mathrm{N} \\
\end{array}$ & $\begin{array}{c}\text { Risk Ratio } \\
\text { M-H, Random, } 95 \% \text { Cl }\end{array}$ & Weight & $\begin{array}{c}\text { Risk Ratio } \\
\text { M-H, Random, } 95 \% \mathrm{Cl}\end{array}$ \\
\hline \multicolumn{6}{|l|}{ 1.3.1 HIV-negative } \\
\hline Jahnavi 2010 IND & $49 / 50$ & $41 / 50$ & & $100 \%$ & $1.2[1.04,1.37]$ \\
\hline Subtotal $(95 \% \mathrm{Cl})$ & 50 & 50 & & $100 \%$ & $1.2[1.04,1.37]$ \\
\hline \multicolumn{6}{|c|}{ Total events: 49 (Supplement), 41 (No supplement) } \\
\hline \multicolumn{6}{|c|}{ Heterogeneity: Not applicable } \\
\hline \multicolumn{6}{|c|}{ Test for overall effect: $Z=2.57(P=0.01)$} \\
\hline \multicolumn{6}{|c|}{ 1.3.2 Unknown HIV status } \\
\hline Martins 2009 TLS & $103 / 136$ & $100 / 129$ & & $100 \%$ & $0.98[0.86,1.12]$ \\
\hline Subtotal $(95 \% \mathrm{Cl})$ & 136 & 129 & & $100 \%$ & $0.98[0.86,1.12]$ \\
\hline \multicolumn{6}{|c|}{ Total events: 103 (Supplement), 100 (No supplement) } \\
\hline \multicolumn{6}{|c|}{ Heterogeneity: Not applicable } \\
\hline \multicolumn{6}{|c|}{ Test for subgroup differences: $\mathrm{Chi}^{2}=4.32, \mathrm{df}=1(\mathrm{P}=0.04), \mathrm{I}^{2}=76.85 \%$} \\
\hline
\end{tabular}

\section{Analysis 1.4. Comparison 1 Macronutrient supplementation, Outcome 4 Sputum negative at 8 weeks.}

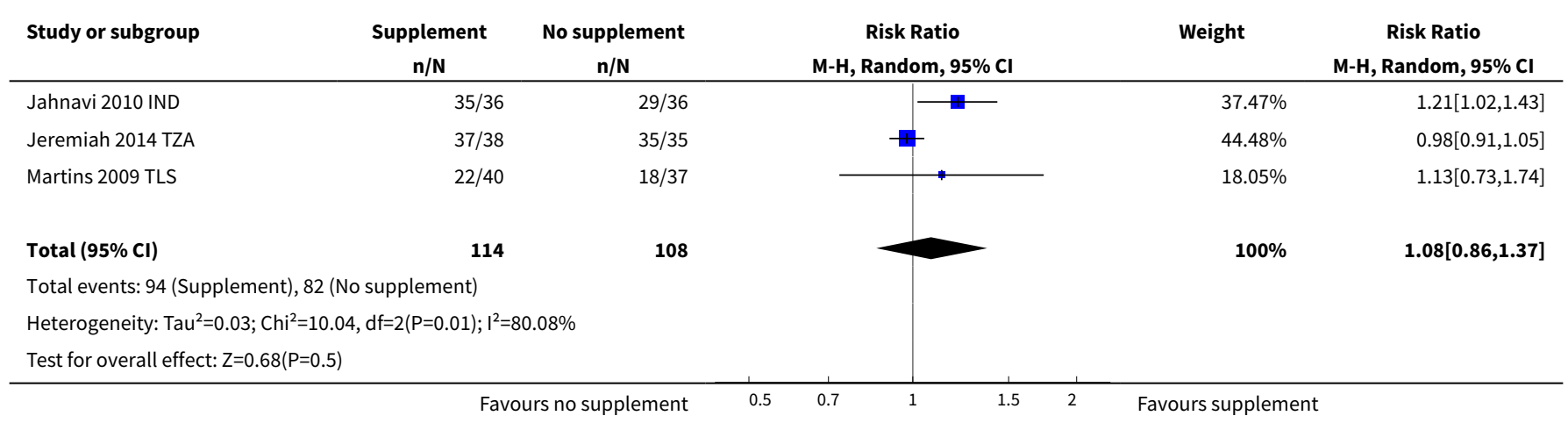

Analysis 1.5. Comparison 1 Macronutrient supplementation, Outcome 5 Mean weight gain.

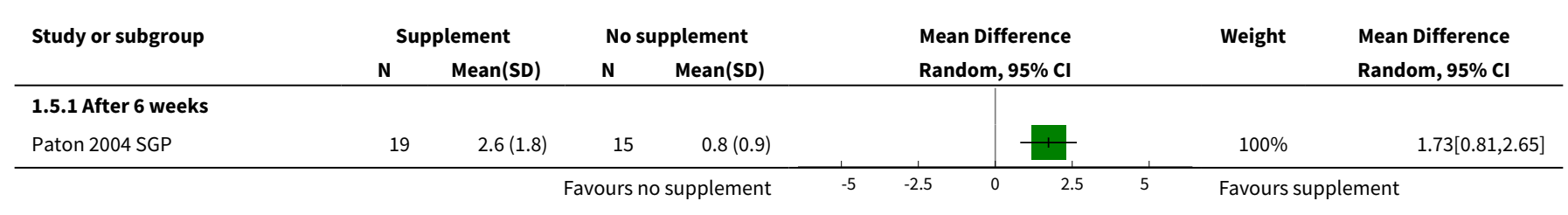




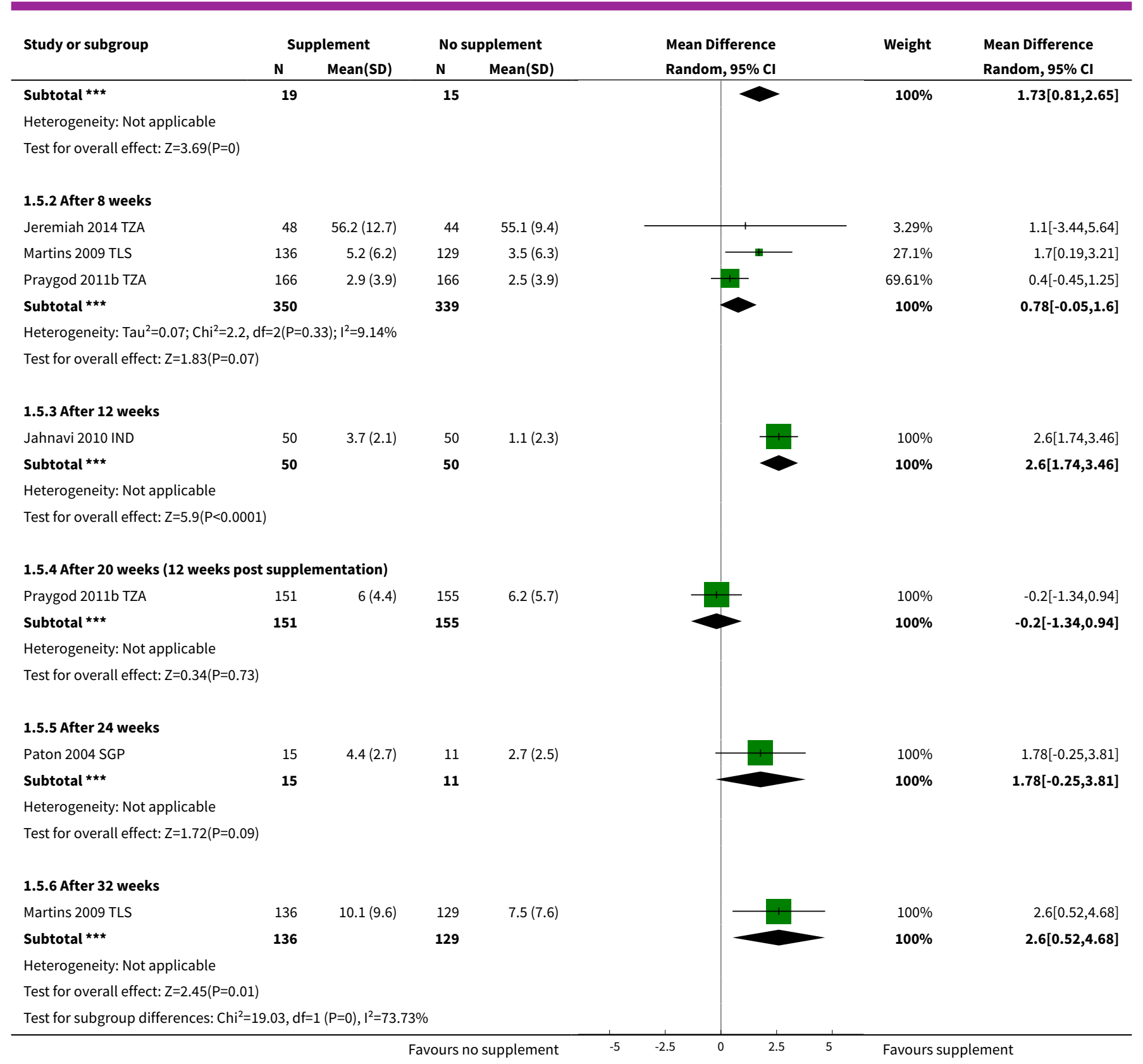

\section{Analysis 1.6. Comparison 1 Macronutrient supplementation, Outcome 6 Change in maximum grip strength (kg).}

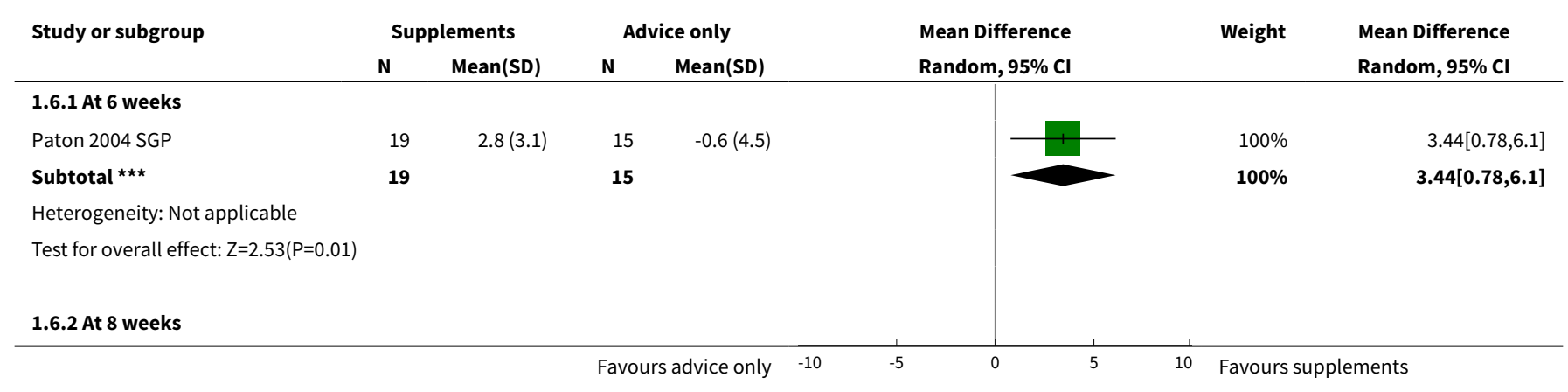

Nutritional supplements for people being treated for active tuberculosis (Review) 


\begin{tabular}{|c|c|c|c|c|c|c|c|}
\hline \multirow[t]{2}{*}{ Study or subgroup } & \multicolumn{2}{|c|}{ Supplements } & \multicolumn{2}{|c|}{ Advice only } & \multirow{2}{*}{$\begin{array}{l}\text { Mean Difference } \\
\text { Random, } 95 \% \mathrm{Cl}\end{array}$} & \multirow[t]{2}{*}{ Weight } & \multirow{2}{*}{$\begin{array}{l}\text { Mean Difference } \\
\text { Random, 95\% Cl }\end{array}$} \\
\hline & $\mathbf{N}$ & $\operatorname{Mean}(\mathrm{SD})$ & $\mathbf{N}$ & Mean(SD) & & & \\
\hline Praygod 2011b TZA & 165 & $2.3(5.2)$ & 167 & $1.8(5.3)$ & & $100 \%$ & $0.5[-0.63,1.63]$ \\
\hline Subtotal $\star \star \star ~$ & 165 & & 167 & & & $100 \%$ & $0.5[-0.63,1.63]$ \\
\hline \multicolumn{8}{|c|}{ Heterogeneity: Not applicable } \\
\hline \multicolumn{8}{|c|}{ Test for overall effect: $Z=0.87(P=0.39)$} \\
\hline \multicolumn{8}{|l|}{ 1.6.3 At 12 weeks } \\
\hline Jahnavi 2010 IND & 50 & $3.9(1.2)$ & 50 & $2.4(0.9)$ & & $100 \%$ & $1.5[1.08,1.92]$ \\
\hline 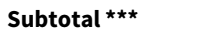 & 50 & & 50 & & & $100 \%$ & $1.5[1.08,1.92]$ \\
\hline \multicolumn{8}{|c|}{ Heterogeneity: $\mathrm{Tau}^{2}=0 ; \mathrm{Chi}^{2}=0, \mathrm{df}=0(\mathrm{P}<0.0001) ; \mathrm{I}^{2}=100 \%$} \\
\hline \multicolumn{8}{|c|}{ Test for overall effect: $Z=7.07(P<0.0001)$} \\
\hline \multicolumn{8}{|l|}{ 1.6.4 At 20 weeks } \\
\hline Praygod 2011b TZA & 150 & $6(6.3)$ & 153 & $4.7(6.3)$ & & $100 \%$ & $1.3[-0.11,2.71]$ \\
\hline 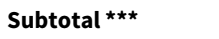 & 150 & & 153 & & & $100 \%$ & $1.3[-0.11,2.71]$ \\
\hline \multicolumn{8}{|c|}{ Heterogeneity: Not applicable } \\
\hline \multicolumn{8}{|c|}{ Test for overall effect: $Z=1.8(P=0.07)$} \\
\hline \multicolumn{8}{|l|}{ 1.6.5 At 24 weeks } \\
\hline Paton 2004 SGP & 15 & $3.2(3.9)$ & 11 & $2.8(4.8)$ & & $100 \%$ & $0.39[-3.05,3.83]$ \\
\hline Subtotal $\star \star \star$ & 15 & & 11 & & & $100 \%$ & $0.39[-3.05,3.83]$ \\
\hline \multicolumn{8}{|c|}{ Heterogeneity: Not applicable } \\
\hline \multicolumn{8}{|c|}{ Test for overall effect: $\mathrm{Z}=0.22(\mathrm{P}=0.82)$} \\
\hline \multicolumn{8}{|c|}{ Test for subgroup differences: $\mathrm{Chi}^{2}=5.26, \mathrm{df}=1(\mathrm{P}=0.26), \mathrm{I}^{2}=23.95 \%$} \\
\hline
\end{tabular}

Analysis 1.7. Comparison 1 Macronutrient supplementation, Outcome 7 Change in quality of life score.

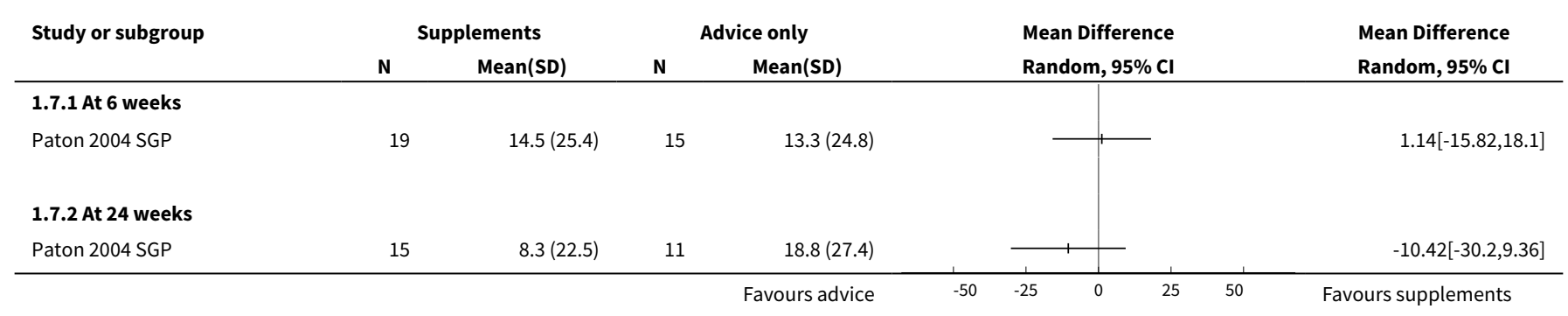

\section{Comparison 2. High cholesterol ( $850 \mathrm{mg} /$ day) versus low cholesterol ( $250 \mathrm{mg} / \mathrm{day}$ ) diet}

\begin{tabular}{lllll}
\hline $\begin{array}{l}\text { Outcome or subgroup } \\
\text { title }\end{array}$ & No. of studies & $\begin{array}{l}\text { No. of partici- } \\
\text { pants }\end{array}$ & Statistical method & Effect size \\
\hline $\begin{array}{l}1 \text { Sputum-culture posi- } \\
\text { tive }\end{array}$ & 1 & Risk Ratio (M-H, Fixed, 95\% Cl) & Totals not selected \\
\hline 1.1 At baseline & 1 & Risk Ratio (M-H, Fixed, 95\% Cl) & $0.0[0.0,0.0]$ \\
\hline 1.2 At 2 weeks & 1 & Risk Ratio (M-H, Fixed, $95 \% \mathrm{Cl})$ & $0.0[0.0,0.0]$ \\
\hline
\end{tabular}




\begin{tabular}{lllll}
\hline $\begin{array}{l}\text { Outcome or subgroup } \\
\text { title }\end{array}$ & No. of studies & $\begin{array}{l}\text { No. of partici- } \\
\text { pants }\end{array}$ & Statistical method & Effect size \\
\hline 1.3 At 4 weeks & 1 & Risk Ratio (M-H, Fixed, 95\% Cl) & $0.0[0.0,0.0]$ \\
\hline 1.4 At 8 weeks & 1 & Risk Ratio (M-H, Fixed, 95\% Cl) & $0.0[0.0,0.0]$ \\
\hline
\end{tabular}

\section{Analysis 2.1. Comparison 2 High cholesterol ( $850 \mathrm{mg} / \mathrm{day}$ ) versus low} cholesterol (250 mg/day) diet, Outcome 1 Sputum-culture positive.

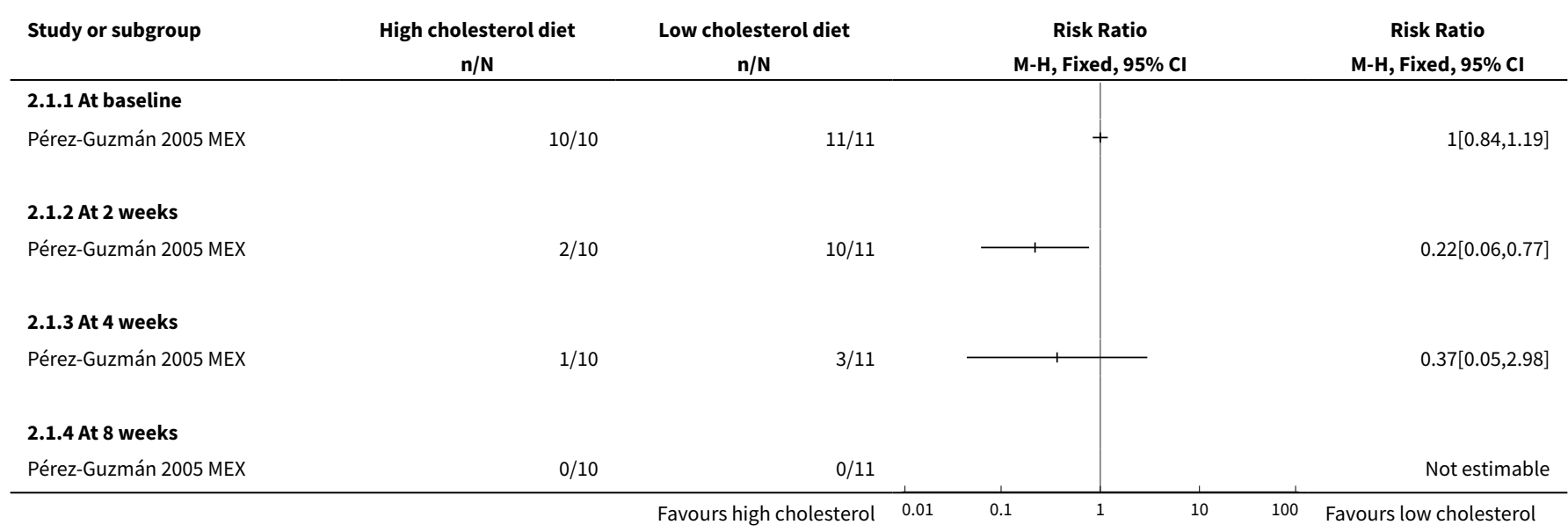

\section{Comparison 3. Multivitamin and trace element tablets versus placebo}

\begin{tabular}{|c|c|c|c|c|}
\hline Outcome or subgroup title & No. of studies & $\begin{array}{l}\text { No. of partici- } \\
\text { pants }\end{array}$ & Statistical method & Effect size \\
\hline $\begin{array}{l}1 \text { Death during follow-up in adults } \\
\text { and children }\end{array}$ & 5 & 2902 & $\begin{array}{l}\text { Risk Ratio (M-H, Random, 95\% } \\
\mathrm{Cl} \text { ) }\end{array}$ & $0.96[0.79,1.18]$ \\
\hline 1.1 HIV-negative individuals & 4 & 1218 & $\begin{array}{l}\text { Risk Ratio (M-H, Random, 95\% } \\
\mathrm{Cl} \text { ) }\end{array}$ & $0.86[0.46,1.60]$ \\
\hline 1.2 HIV-positive individuals & 3 & 1429 & $\begin{array}{l}\text { Risk Ratio (M-H, Random, 95\% } \\
\mathrm{Cl} \text { ) }\end{array}$ & $0.92[0.69,1.23]$ \\
\hline $\begin{array}{l}\text { 1.3 HIV-positive and HIV-negative } \\
\text { individuals }\end{array}$ & 1 & 255 & $\begin{array}{l}\text { Risk Ratio (M-H, Random, 95\% } \\
\text { Cl) }\end{array}$ & $1.59[0.53,4.72]$ \\
\hline $\begin{array}{l}2 \text { Tuberculosis treatment comple- } \\
\text { tion }\end{array}$ & 1 & 302 & Risk Ratio (M-H, Fixed, 95\% Cl) & $0.99[0.95,1.04]$ \\
\hline $\begin{array}{l}3 \text { Sputum-smear or sputum-cul- } \\
\text { ture positive at } 1 \text { month }\end{array}$ & 2 & 1020 & $\begin{array}{l}\text { Risk Ratio (M-H, Random, 95\% } \\
\text { Cl) }\end{array}$ & $0.92[0.63,1.35]$ \\
\hline $\begin{array}{l}\text { 3.1 Mixed HIV-positive and HIV- } \\
\text { negative }\end{array}$ & 1 & 392 & $\begin{array}{l}\text { Risk Ratio (M-H, Random, 95\% } \\
\text { Cl) }\end{array}$ & $1.20[0.99,1.45]$ \\
\hline
\end{tabular}




\begin{tabular}{|c|c|c|c|c|}
\hline Outcome or subgroup title & No. of studies & $\begin{array}{l}\text { No. of partici- } \\
\text { pants }\end{array}$ & Statistical method & Effect size \\
\hline 3.2 HIV-negative individuals only & 1 & 306 & $\begin{array}{l}\text { Risk Ratio (M-H, Random, 95\% } \\
\mathrm{Cl} \text { ) }\end{array}$ & $0.73[0.47,1.13]$ \\
\hline 3.3 HIV-positive individuals only & 1 & 322 & $\begin{array}{l}\text { Risk Ratio (M-H, Random, 95\% } \\
\text { Cl) }\end{array}$ & $0.77[0.45,1.31]$ \\
\hline $\begin{array}{l}4 \text { Sputum-smear or sputum-cul- } \\
\text { ture positive at } 2 \text { months }\end{array}$ & 2 & 731 & Risk Ratio (M-H, Fixed, 95\% Cl) & $0.89[0.59,1.35]$ \\
\hline $\begin{array}{l}5 \text { Clearance of chest X-ray at } 6 \\
\text { months }\end{array}$ & 2 & 497 & Risk Ratio (M-H, Fixed, 95\% Cl) & $1.03[0.90,1.18]$ \\
\hline 6 Weight & 3 & & $\begin{array}{l}\text { Mean Difference (IV, Fixed, 95\% } \\
\text { Cl) }\end{array}$ & $\begin{array}{l}\text { Totals not select- } \\
\text { ed }\end{array}$ \\
\hline $\begin{array}{l}6.1 \text { After } 2 \text { months of supplemen- } \\
\text { tation }\end{array}$ & 2 & & $\begin{array}{l}\text { Mean Difference (IV, Fixed, 95\% } \\
\text { CI) }\end{array}$ & $0.0[0.0,0.0]$ \\
\hline $\begin{array}{l}6.2 \text { After } 5 \text { months follow-up ( } 3 \\
\text { months post supplementation) }\end{array}$ & 1 & & $\begin{array}{l}\text { Mean Difference (IV, Fixed, 95\% } \\
\mathrm{CI} \text { ) }\end{array}$ & $0.0[0.0,0.0]$ \\
\hline $\begin{array}{l}6.3 \text { After } 6 \text { months supplementa- } \\
\text { tion (children) }\end{array}$ & 1 & & $\begin{array}{l}\text { Mean Difference (IV, Fixed, 95\% } \\
\mathrm{Cl} \text { ) }\end{array}$ & $0.0[0.0,0.0]$ \\
\hline $\begin{array}{l}\text { 6.4 After } 7 \text { months of supplemen- } \\
\text { tation }\end{array}$ & 1 & & $\begin{array}{l}\text { Mean Difference (IV, Fixed, 95\% } \\
\mathrm{CI} \text { ) }\end{array}$ & $0.0[0.0,0.0]$ \\
\hline $\begin{array}{l}7 \text { Anthropometrical changes at fol- } \\
\text { low-up }\end{array}$ & 1 & & $\begin{array}{l}\text { Mean Difference (IV, Fixed, 95\% } \\
\mathrm{CI} \text { ) }\end{array}$ & $\begin{array}{l}\text { Totals not select- } \\
\text { ed }\end{array}$ \\
\hline $\begin{array}{l}7.1 \text { Weight-for-age } z \text { score at } 2 \\
\text { months }\end{array}$ & 1 & & $\begin{array}{l}\text { Mean Difference (IV, Fixed, 95\% } \\
\mathrm{Cl} \text { ) }\end{array}$ & $0.0[0.0,0.0]$ \\
\hline $\begin{array}{l}7.2 \text { Weight-for-age } z \text { score at } 6 \\
\text { months }\end{array}$ & 1 & & $\begin{array}{l}\text { Mean Difference (IV, Fixed, 95\% } \\
\mathrm{CI} \text { ) }\end{array}$ & $0.0[0.0,0.0]$ \\
\hline 7.3 Weight $(\mathrm{kg})$ at 2 months & 1 & & $\begin{array}{l}\text { Mean Difference (IV, Fixed, 95\% } \\
\mathrm{CI} \text { ) }\end{array}$ & $0.0[0.0,0.0]$ \\
\hline 7.4 Weight $(\mathrm{kg})$ at 6 months & 1 & & $\begin{array}{l}\text { Mean Difference (IV, Fixed, 95\% } \\
\mathrm{Cl} \text { ) }\end{array}$ & $0.0[0.0,0.0]$ \\
\hline $\begin{array}{l}7.5 \text { Height-for-age } z \text { score at } 2 \\
\text { months }\end{array}$ & 1 & & $\begin{array}{l}\text { Mean Difference (IV, Fixed, 95\% } \\
\mathrm{CI} \text { ) }\end{array}$ & $0.0[0.0,0.0]$ \\
\hline $\begin{array}{l}7.6 \text { Height-for-age } z \text { score at } 6 \\
\text { months }\end{array}$ & 1 & & $\begin{array}{l}\text { Mean Difference (IV, Fixed, 95\% } \\
\mathrm{CI} \text { ) }\end{array}$ & $0.0[0.0,0.0]$ \\
\hline 7.7 BMI z score at 2 months & 1 & & $\begin{array}{l}\text { Mean Difference (IV, Fixed, 95\% } \\
\mathrm{CI} \text { ) }\end{array}$ & $0.0[0.0,0.0]$ \\
\hline 7.8 BMI z score at 6 months & 1 & & $\begin{array}{l}\text { Mean Difference (IV, Fixed, 95\% } \\
\mathrm{CI} \text { ) }\end{array}$ & $0.0[0.0,0.0]$ \\
\hline
\end{tabular}




\begin{tabular}{lllll}
\hline Outcome or subgroup title & No. of studies & $\begin{array}{l}\text { No. of partici- } \\
\text { pants }\end{array}$ & Statistical method & Effect size \\
\hline $\begin{array}{l}\text { 8 Mean change in handgrip } \\
\text { strength (kg) }\end{array}$ & 1 & 1480 & $\begin{array}{l}\text { Mean Difference (IV, Fixed, 95\% } \\
\text { Cl) }\end{array}$ & 1.16 [0.50, 1.81] \\
\hline 8.1 At 2 months & 1 & 771 & $\begin{array}{l}\text { Mean Difference (IV, Fixed, 95\% } \\
\text { CI) }\end{array}$ & 1.22 [0.49, 1.95] \\
\hline 8.2 At 5 months & 1 & 709 & $\begin{array}{l}\text { Mean Difference (IV, Fixed, 95\% } \\
\text { CI) }\end{array}$ & $0.90[-0.56,2.36]$ \\
\hline
\end{tabular}

Analysis 3.1. Comparison 3 Multivitamin and trace element tablets versus placebo, Outcome 1 Death during follow-up in adults and children.

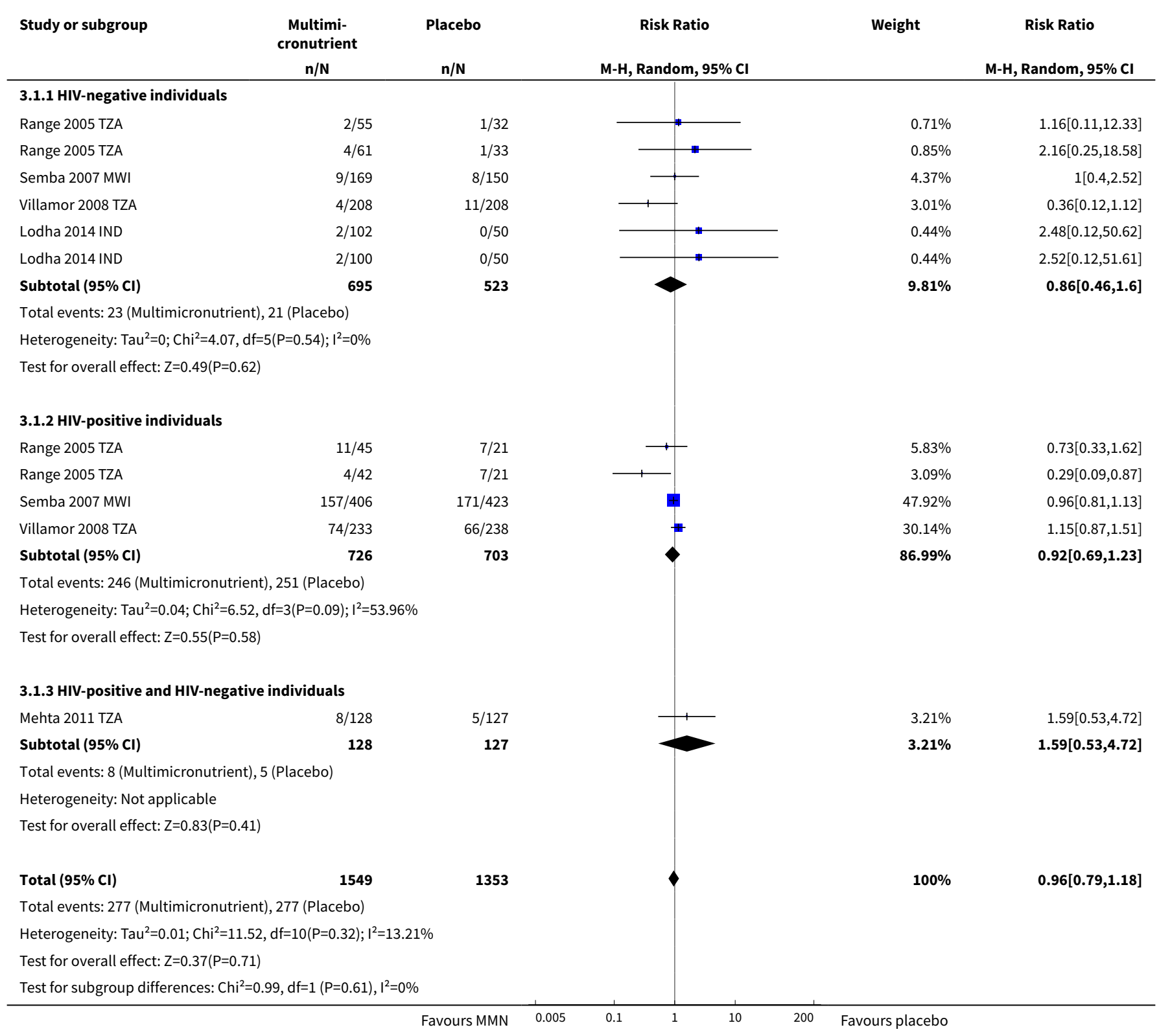


Analysis 3.2. Comparison 3 Multivitamin and trace element tablets versus placebo, Outcome 2 Tuberculosis treatment completion.

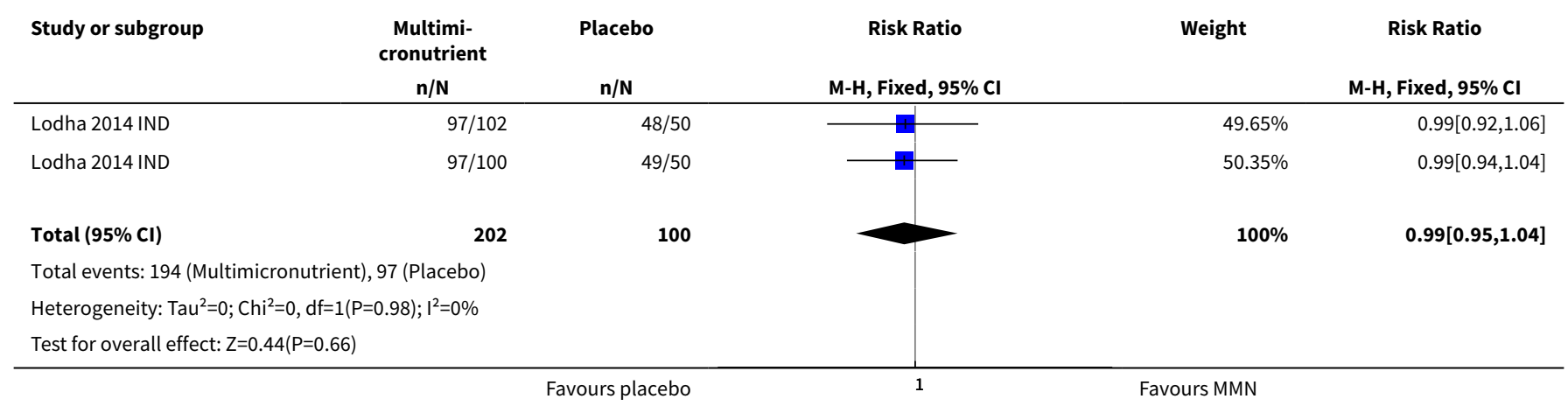

Analysis 3.3. Comparison 3 Multivitamin and trace element tablets versus placebo, Outcome 3 Sputum-smear or sputum-culture positive at 1 month.

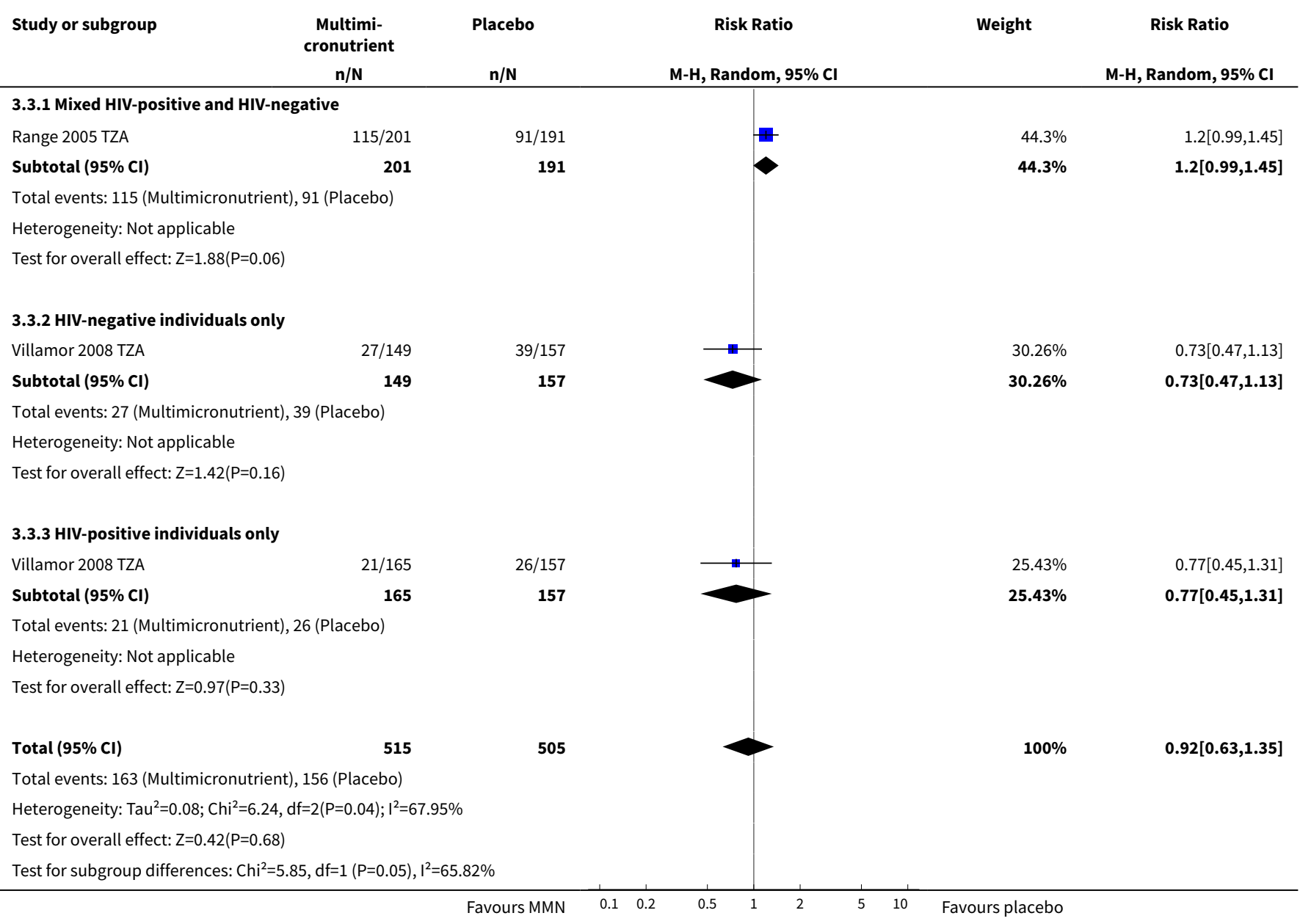


Analysis 3.4. Comparison 3 Multivitamin and trace element tablets versus placebo, Outcome 4 Sputum-smear or sputum-culture positive at $\mathbf{2}$ months.

\begin{tabular}{|c|c|c|c|c|c|}
\hline Study or subgroup & $\begin{array}{c}\text { Multimi- } \\
\text { cronutrient } \\
\mathrm{n} / \mathrm{N}\end{array}$ & $\begin{array}{l}\text { Placebo } \\
\text { n/N }\end{array}$ & $\begin{array}{c}\text { Risk Ratio } \\
\text { M-H, Fixed, 95\% Cl }\end{array}$ & Weight & $\begin{array}{c}\text { Risk Ratio } \\
\text {-H, Fixed, 95\% Cl }\end{array}$ \\
\hline Lodha 2014 IND & $12 / 102$ & $5 / 50$ & 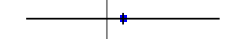 & $16.11 \%$ & $1.18[0.44,3.16]$ \\
\hline Lodha 2014 IND & $10 / 100$ & $4 / 50$ & $\longrightarrow$ & $12.8 \%$ & $1.25[0.41,3.79]$ \\
\hline Range 2005 TZA & $23 / 219$ & $29 / 210$ & $+1+10$ & $71.08 \%$ & $0.76[0.46,1.27]$ \\
\hline \multicolumn{6}{|c|}{ Total events: 45 (Multimicronutrient), 38 (Placebo) } \\
\hline \multicolumn{6}{|c|}{ Heterogeneity: $\mathrm{Tau}^{2}=0 ; \mathrm{Chi}^{2}=1.03, \mathrm{df}=2(\mathrm{P}=0.6) ; \mathrm{I}^{2}=0 \%$} \\
\hline Test for overall effect & & & & & \\
\hline
\end{tabular}

Analysis 3.5. Comparison 3 Multivitamin and trace element tablets versus placebo, Outcome 5 Clearance of chest X-ray at 6 months.

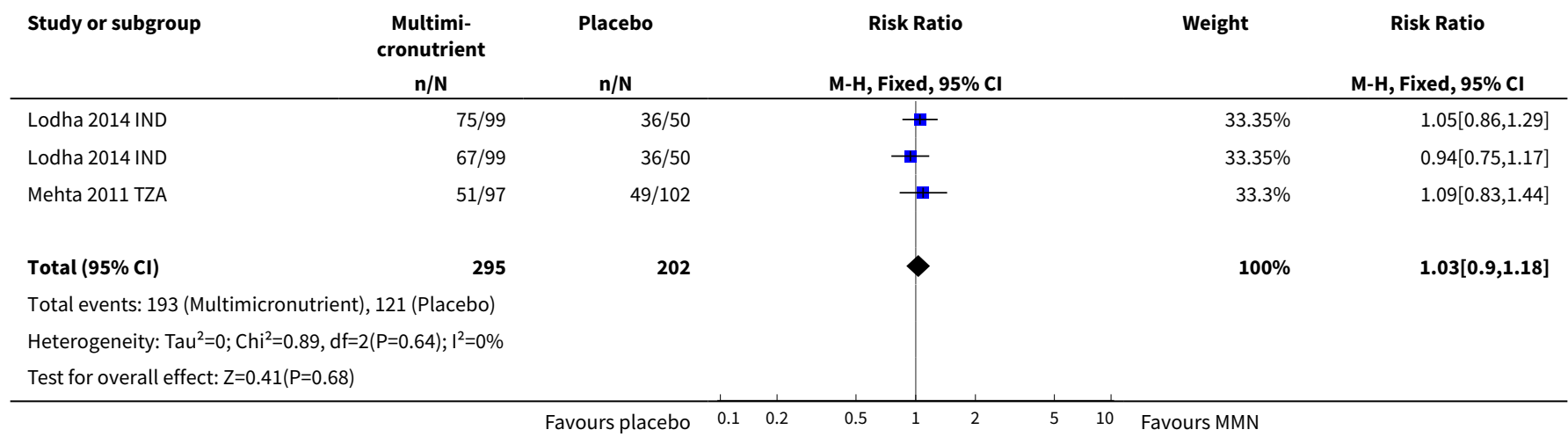

Analysis 3.6. Comparison 3 Multivitamin and trace element tablets versus placebo, Outcome 6 Weight.

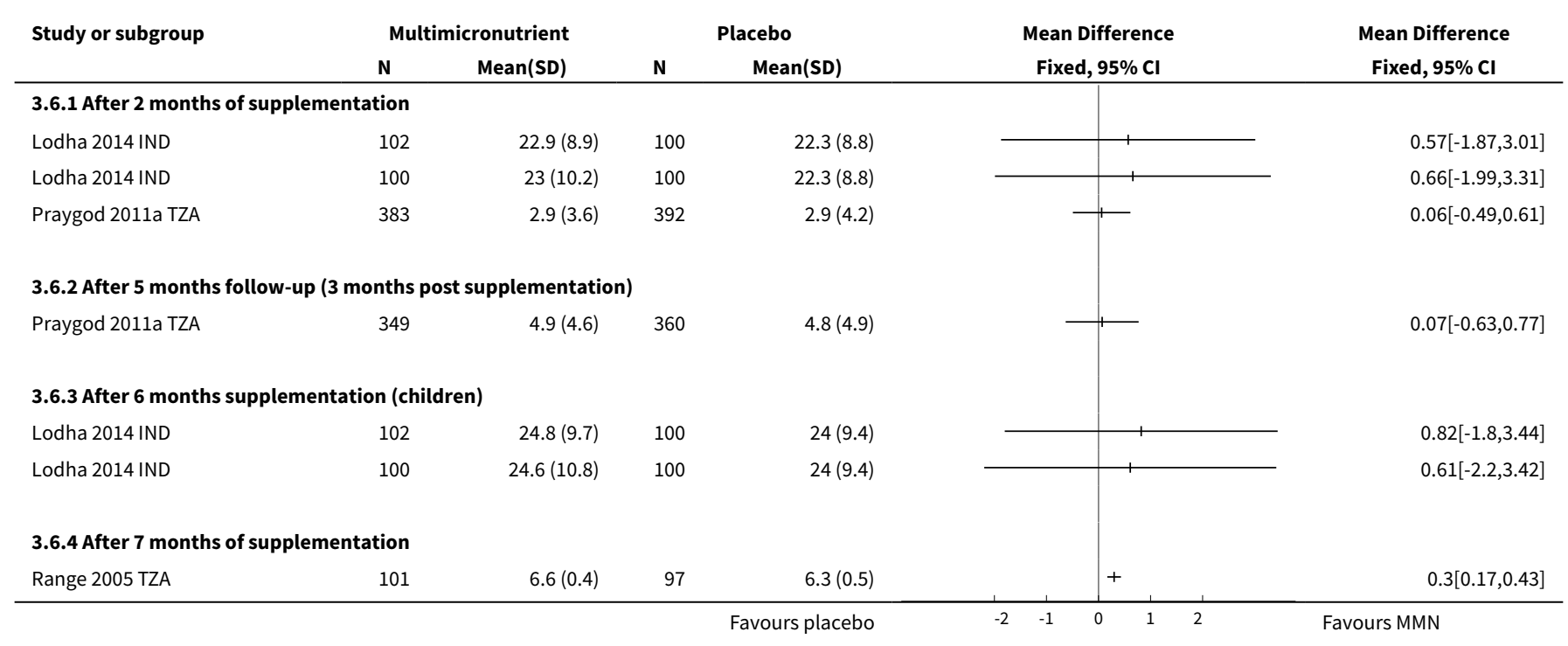




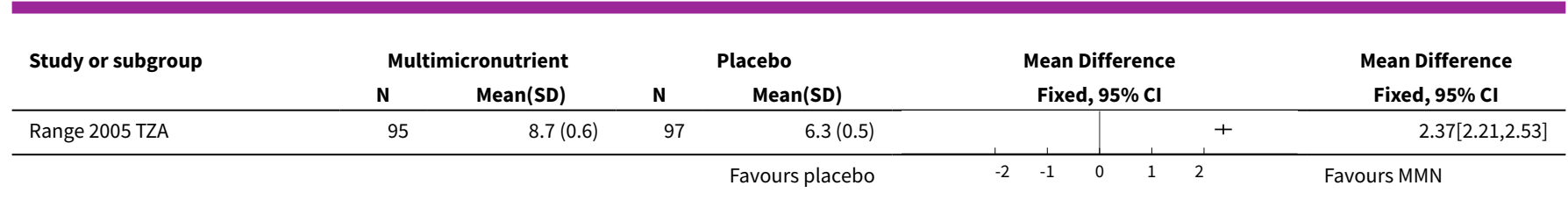

Analysis 3.7. Comparison 3 Multivitamin and trace element tablets versus placebo, Outcome 7 Anthropometrical changes at follow-up.

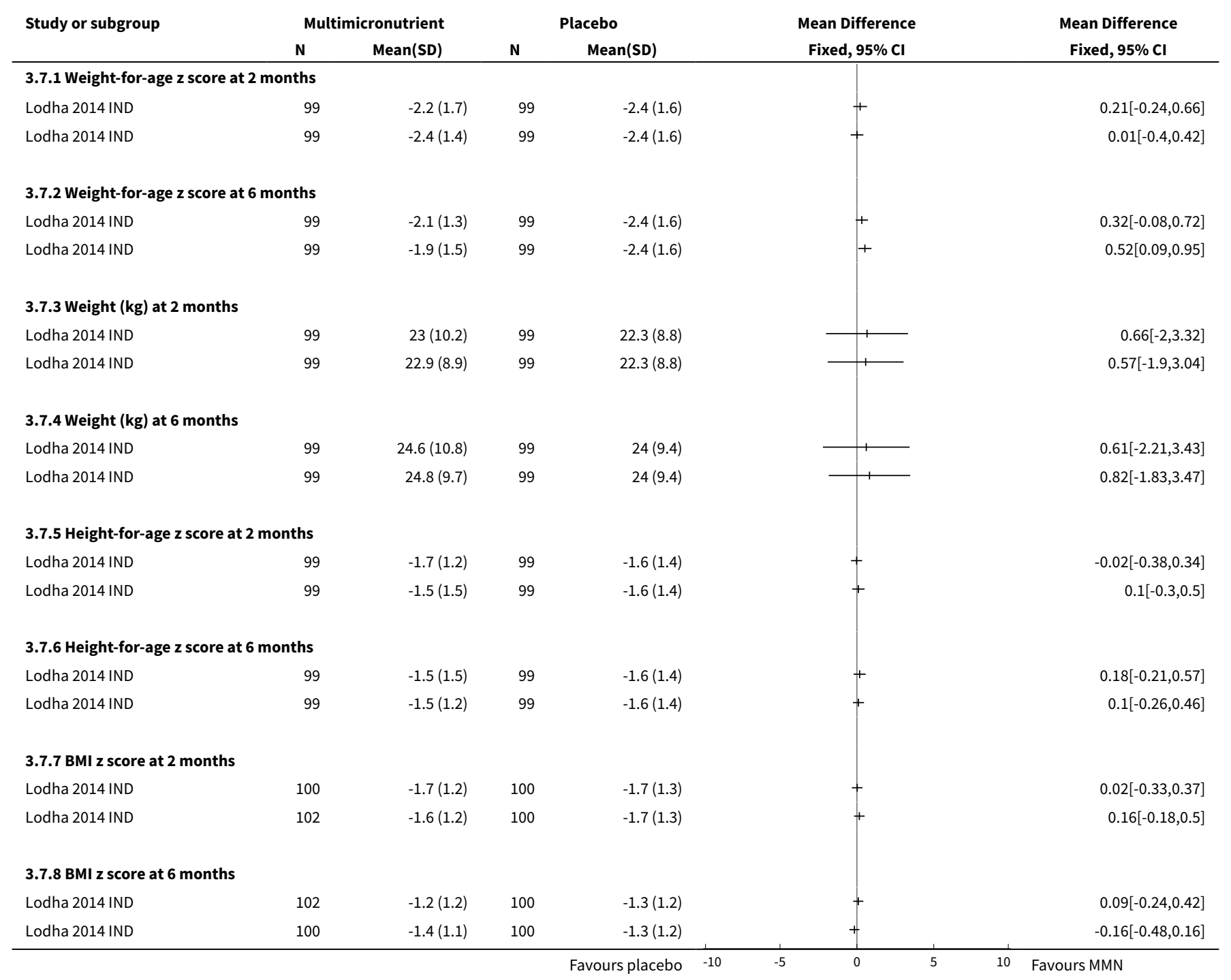

Analysis 3.8. Comparison 3 Multivitamin and trace element tablets versus placebo, Outcome 8 Mean change in handgrip strength (kg).

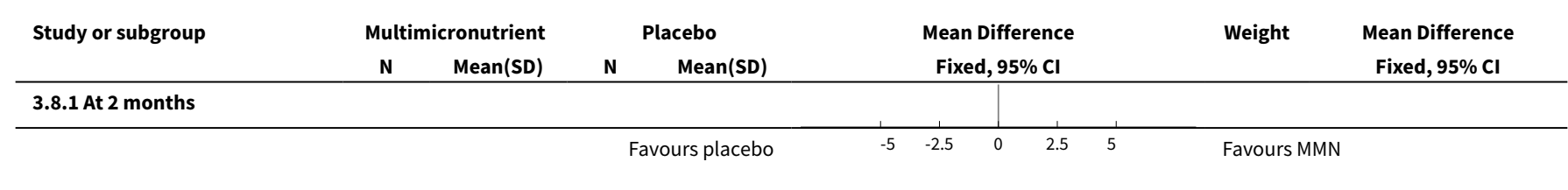

Nutritional supplements for people being treated for active tuberculosis (Review) 


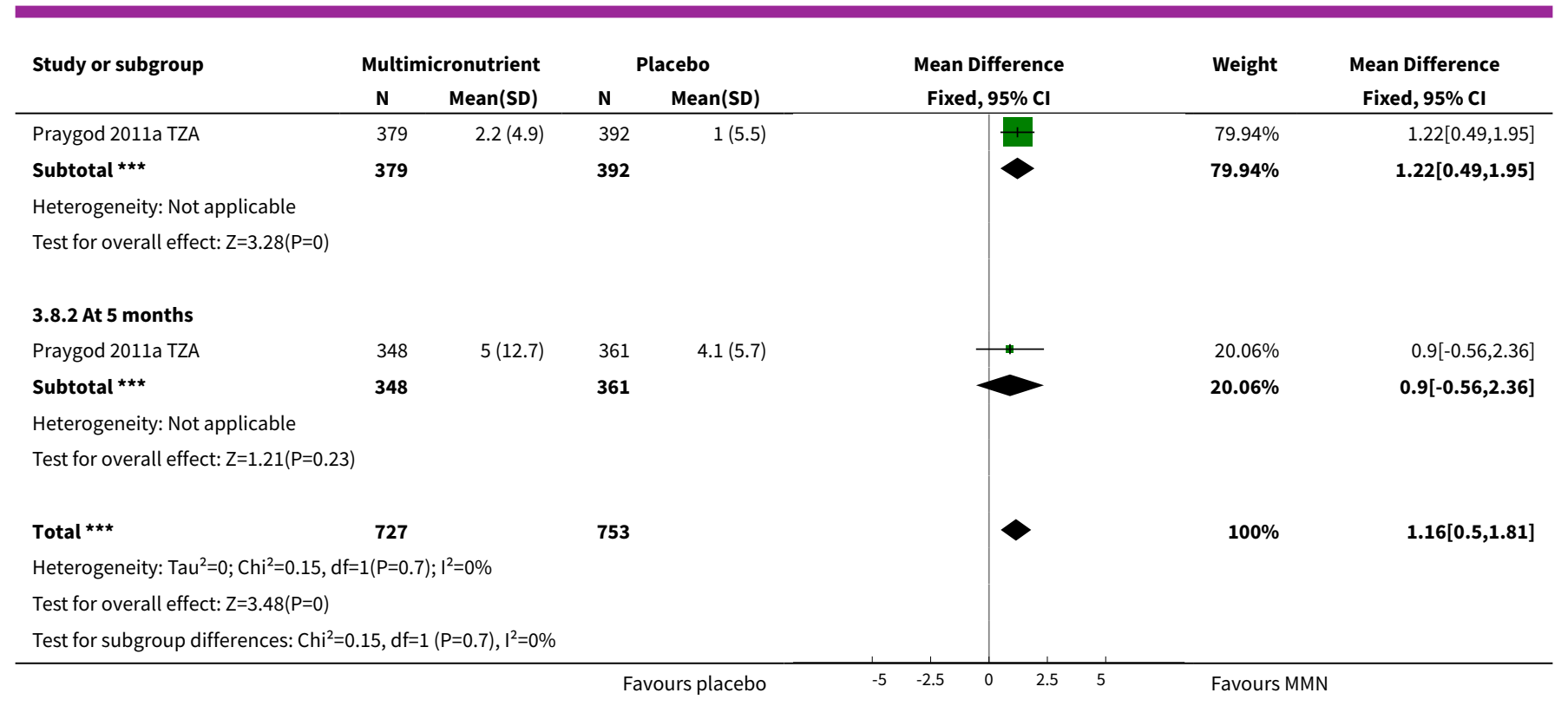

\section{Comparison 4. Vitamin A versus placebo}

\begin{tabular}{|c|c|c|c|c|}
\hline $\begin{array}{l}\text { Outcome or subgroup } \\
\text { title }\end{array}$ & No. of studies & $\begin{array}{l}\text { No. of partici- } \\
\text { pants }\end{array}$ & Statistical method & Effect size \\
\hline $\begin{array}{l}1 \text { Children: mean serum } \\
\text { retinol (normal range > } \\
20 \mu \mathrm{g} / \mathrm{L} \text { ) }\end{array}$ & 1 & & Mean Difference (IV, Fixed, 95\% CI) & Subtotals only \\
\hline 1.1 At baseline & 1 & 85 & Mean Difference (IV, Fixed, 95\% CI) & $-1.0[-5.38,3.38]$ \\
\hline 1.2 At 6 weeks & 1 & 85 & Mean Difference (IV, Fixed, 95\% Cl) & $1.30[-3.91,6.51]$ \\
\hline 1.3 At 3 months & 1 & 85 & Mean Difference (IV, Fixed, 95\% CI) & $0.70[-3.85,5.25]$ \\
\hline $\begin{array}{l}2 \text { Adults: mean serum } \\
\text { retinol (normal range > } \\
70 \mu \mathrm{mol} / \mathrm{L})\end{array}$ & 3 & & Mean Difference (IV, Fixed, 95\% CI) & Subtotals only \\
\hline 2.1 At baseline & 3 & 242 & Mean Difference (IV, Fixed, 95\% CI) & $-0.06[-0.13,0.01]$ \\
\hline 2.2 At 2 months & 3 & 242 & Mean Difference (IV, Fixed, 95\% Cl) & $0.05[-0.03,0.14]$ \\
\hline 2.3 At 6 months & 3 & 242 & Mean Difference (IV, Fixed, 95\% CI) & $0.07[-0.02,0.16]$ \\
\hline 3 Death & 8 & 3308 & Risk Ratio (M-H, Fixed, 95\% Cl) & $0.97[0.84,1.12]$ \\
\hline 3.1 Vitamin A alone & 1 & 115 & Risk Ratio (M-H, Fixed, 95\% Cl) & $1.79[0.19,16.69]$ \\
\hline 3.2 Vitamin A plus zinc & 4 & 535 & Risk Ratio (M-H, Fixed, 95\% CI) & $2.38[0.87,6.53]$ \\
\hline $\begin{array}{l}\text { 3.3 Vitamin A as part of a } \\
\text { multi-micronutrient sup- } \\
\text { plement }\end{array}$ & 4 & 2658 & Risk Ratio (M-H, Fixed, 95\% Cl) & $0.94[0.81,1.09]$ \\
\hline
\end{tabular}




\begin{tabular}{|c|c|c|c|c|}
\hline $\begin{array}{l}\text { Outcome or subgroup } \\
\text { title }\end{array}$ & No. of studies & $\begin{array}{l}\text { No. of partici- } \\
\text { pants }\end{array}$ & Statistical method & Effect size \\
\hline 4 Treatment completion & 1 & 158 & Risk Ratio (M-H, Fixed, 95\% Cl) & $0.92[0.80,1.04]$ \\
\hline $\begin{array}{l}5 \text { Symptomatic at } 6 \\
\text { weeks }\end{array}$ & 1 & & Risk Ratio (M-H, Fixed, 95\% Cl) & Totals not selected \\
\hline $\begin{array}{l}6 \text { Sputum-smear and } \\
\text { sputum-culture positive } \\
\text { during follow-up }\end{array}$ & 2 & & Risk Ratio (M-H, Fixed, 95\% Cl) & Subtotals only \\
\hline 6.1 Baseline & 1 & 158 & Risk Ratio (M-H, Fixed, 95\% Cl) & $1.0[0.98,1.03]$ \\
\hline 6.22 weeks & 1 & 158 & Risk Ratio (M-H, Fixed, 95\% Cl) & $0.80[0.50,1.28]$ \\
\hline 6.31 month & 1 & 148 & Risk Ratio (M-H, Fixed, 95\% Cl) & $0.70[0.33,1.48]$ \\
\hline 6.42 months & 2 & 199 & Risk Ratio (M-H, Fixed, 95\% Cl) & $1.03[0.23,4.73]$ \\
\hline $7 \mathrm{BMI}\left(\mathrm{kg} / \mathrm{m}^{2}\right)$ & 1 & & Mean Difference (IV, Fixed, 95\% CI) & Subtotals only \\
\hline 7.1 Baseline & 1 & 158 & Mean Difference (IV, Fixed, 95\% CI) & $0.10[-0.63,0.83]$ \\
\hline 7.22 months & 1 & 148 & Mean Difference (IV, Fixed, 95\% CI) & $0.30[-0.44,1.04]$ \\
\hline 7.36 months & 1 & 136 & Mean Difference (IV, Fixed, 95\% CI) & $-0.30[-1.15,0.55]$ \\
\hline 8 Body fat (\%) & 1 & & Mean Difference (IV, Fixed, 95\% CI) & Subtotals only \\
\hline 8.1 Baseline & 1 & 158 & Mean Difference (IV, Fixed, 95\% CI) & $-0.90[-2.80,1.00]$ \\
\hline 8.22 months & 1 & 148 & Mean Difference (IV, Fixed, 95\% CI) & $-0.90[-2.84,1.04]$ \\
\hline 8.36 months & 1 & 136 & Mean Difference (IV, Fixed, 95\% CI) & $-1.80[-3.96,0.36]$ \\
\hline
\end{tabular}

\section{Analysis 4.1. Comparison 4 Vitamin A versus placebo, Outcome} 1 Children: mean serum retinol (normal range $>20 \mu \mathrm{g} / \mathrm{L}$ ).

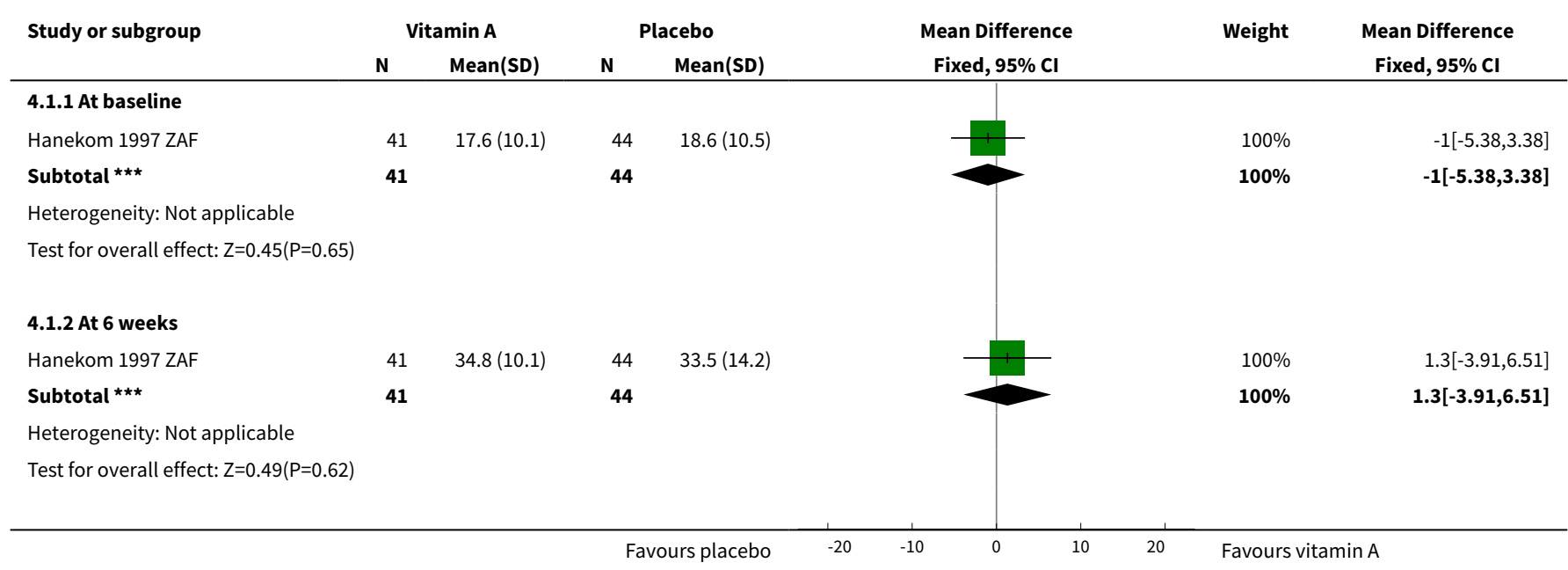




\begin{tabular}{|c|c|c|c|c|c|c|c|c|}
\hline \multirow[t]{2}{*}{ Study or subgroup } & \multicolumn{2}{|c|}{ Vitamin A } & \multicolumn{2}{|c|}{ Placebo } & \multirow{2}{*}{\multicolumn{2}{|c|}{$\begin{array}{c}\text { Mean Difference } \\
\text { Fixed, } 95 \% \mathrm{Cl}\end{array}$}} & \multirow[t]{2}{*}{ Weight } & \multirow{2}{*}{$\begin{array}{c}\text { Mean Difference } \\
\text { Fixed, } 95 \% \mathrm{Cl}\end{array}$} \\
\hline & $\mathbf{N}$ & Mean(SD) & $\mathbf{N}$ & Mean(SD) & & & & \\
\hline \multicolumn{9}{|l|}{ 4.1.3 At 3 months } \\
\hline Hanekom 1997 ZAF & 41 & $34.4(10)$ & 44 & $33.7(11.4)$ & & & $100 \%$ & $0.7[-3.85,5.25]$ \\
\hline Subtotal $\star \star \star$ & 41 & & 44 & & & & $100 \%$ & $0.7[-3.85,5.25]$ \\
\hline \multicolumn{9}{|c|}{ Heterogeneity: Not applicable } \\
\hline \multicolumn{9}{|c|}{ Test for overall effect: $Z=0.3(P=0.76)$} \\
\hline \multicolumn{9}{|c|}{ Test for subgroup differences: $\mathrm{Chi}^{2}=0.51, \mathrm{df}=1(\mathrm{P}=0.78), \mathrm{I}^{2}=0 \%$} \\
\hline
\end{tabular}

\section{Analysis 4.2. Comparison 4 Vitamin A versus placebo, Outcome 2 Adults: mean serum retinol (normal range $>70 \mu \mathrm{mol} / \mathrm{L}$ ).}

\begin{tabular}{lrrrr} 
Study or subgroup & \multicolumn{2}{c}{ Vitamin A } & \multicolumn{2}{c}{ Placebo } \\
& N & Mean(SD) & N & Mean(SD) \\
\hline 4.2.1 At baseline & & & & \\
Armijos 2010 MEX & 17 & $1(0.5)$ & 16 & $1(0.5)$ \\
Karyadi 2002 IDN & 40 & $0.8(0.3)$ & 40 & $0.9(0.3)$ \\
Ginawi 2013 IND & 41 & $0.8(0.2)$ & 20 & $0.8(0.3)$ \\
Ginawi 2013 IND & 47 & $0.8(0.2)$ & 21 & $0.8(0.3)$ \\
Subtotal $\star \star \star$ & $\mathbf{1 4 5}$ & & $\mathbf{9 7}$ &
\end{tabular}

Heterogeneity: $\mathrm{Tau}^{2}=0 ; \mathrm{Chi}^{2}=0.31, \mathrm{df}=3(\mathrm{P}=0.96) ; \mathrm{I}^{2}=0 \%$

Test for overall effect: $Z=1.59(P=0.11)$

\subsubsection{At 2 months}

Armijos 2010 MEX

Karyadi 2002 IDN

Ginawi 2013 IND

Ginawi 2013 IND

Subtotal ***

$\begin{array}{rlll}17 & 1.4(0.5) & 16 & 1.3(0.4) \\ 40 & 1.1(0.3) & 40 & 1.1(0.3) \\ 41 & 1.1(0.3) & 20 & 1.1(0.3) \\ 47 & 1.2(0.3) & 21 & 1.1(0.3) \\ 145 & & 97 & \end{array}$

Heterogeneity: $\mathrm{Tau}^{2}=0 ; \mathrm{Chi}^{2}=0.46, \mathrm{df}=3(\mathrm{P}=0.93) ; \mathrm{I}^{2}=0 \%$

Test for overall effect: $Z=1.31(P=0.19)$

\subsubsection{At 6 months}

Ginawi 2013 IND

\section{Armijos 2010 MEX}

Karyadi 2002 IDN

Ginawi 2013 IND

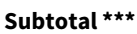

$\begin{array}{rlll}17 & 1.6(0.5) & 16 & 1.6(0.4) \\ 40 & 1.4(0.4) & 40 & 1.3(0.3) \\ 41 & 1.6(0.2) & 20 & 1.6(0.3) \\ 47 & 1.7(0.3) & 21 & 1.6(0.3) \\ 145 & & 97 & \end{array}$

Heterogeneity: $\mathrm{Tau}^{2}=0 ; \mathrm{Chi}^{2}=0.83, \mathrm{df}=3(\mathrm{P}=0.84) ; \mathrm{I}^{2}=0 \%$

Test for overall effect: $Z=1.6(P=0.11)$

Test for subgroup differences: $\mathrm{Chi}^{2}=6.5, \mathrm{df}=1(\mathrm{P}=0.04), \mathrm{I}^{2}=69.23 \%$

\begin{tabular}{crr}
$\begin{array}{c}\text { Mean Difference } \\
\text { Fixed, 95\% Cl }\end{array}$ & Weight & \multicolumn{1}{c}{$\begin{array}{c}\text { Mean Difference } \\
\text { Fixed, 95\% Cl }\end{array}$} \\
\hline & $5.02 \%$ & $-0.01[-0.33,0.31]$ \\
\hline & $43.15 \%$ & $-0.08[-0.19,0.03]$ \\
\hline & $24.54 \%$ & $-0.04[-0.19,0.11]$ \\
& $27.28 \%$ & $-0.05[-0.19,0.09]$ \\
& $\mathbf{1 0 0 \%}$ & $-\mathbf{0 . 0 6 [ - 0 . 1 3 , 0 . 0 1}]$
\end{tabular}

$8.5 \%$

$0.11[-0.17,0.39]$

$0.06[-0.07,0.19]$

$0.01[-0.16,0.18]$

$0.07[-0.09,0.23]$

$0.05[-0.03,0.14]$

Analysis 4.3. Comparison 4 Vitamin A versus placebo, Outcome 3 Death.

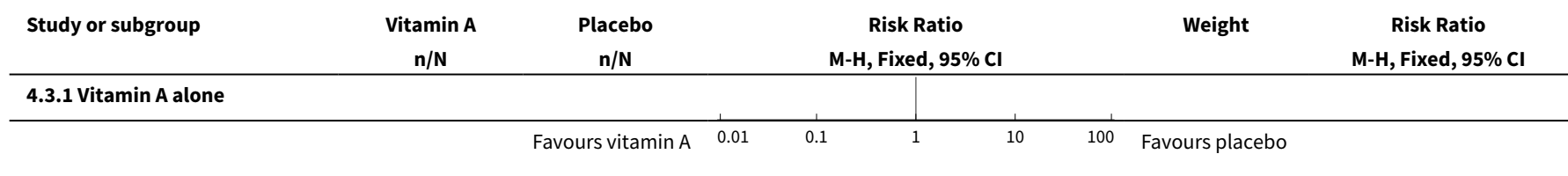

Nutritional supplements for people being treated for active tuberculosis (Review) 


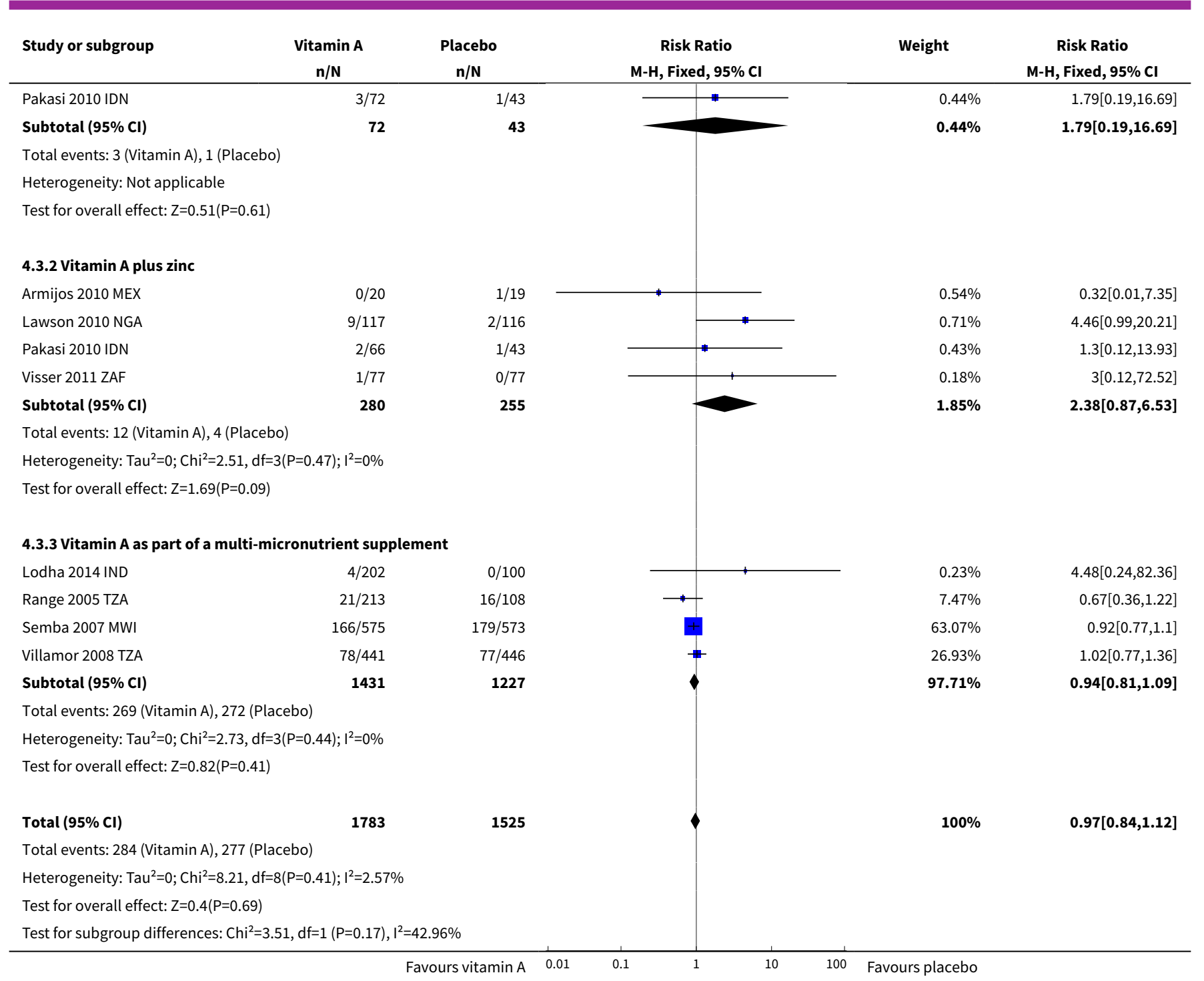

Analysis 4.4. Comparison 4 Vitamin A versus placebo, Outcome 4 Treatment completion.

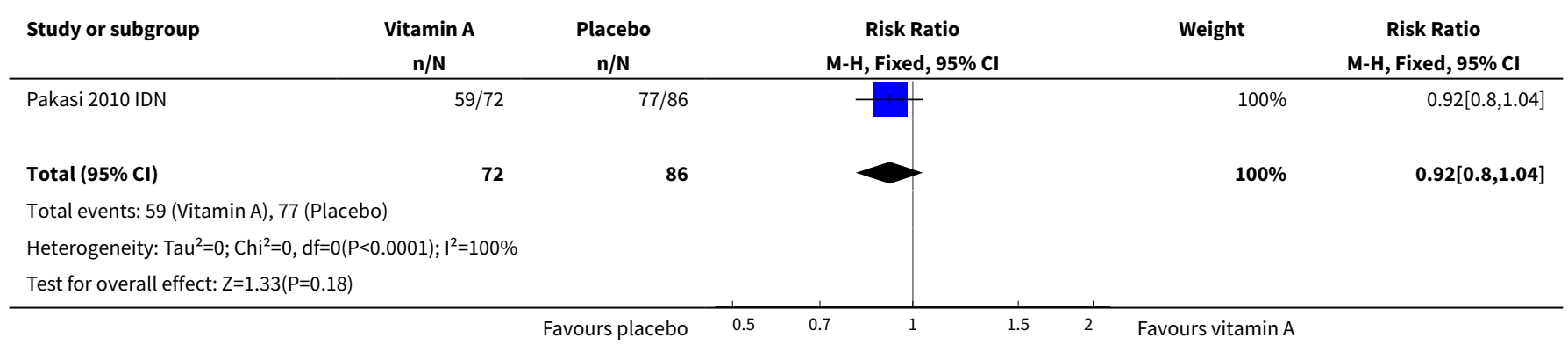


Analysis 4.5. Comparison 4 Vitamin A versus placebo, Outcome 5 Symptomatic at 6 weeks.

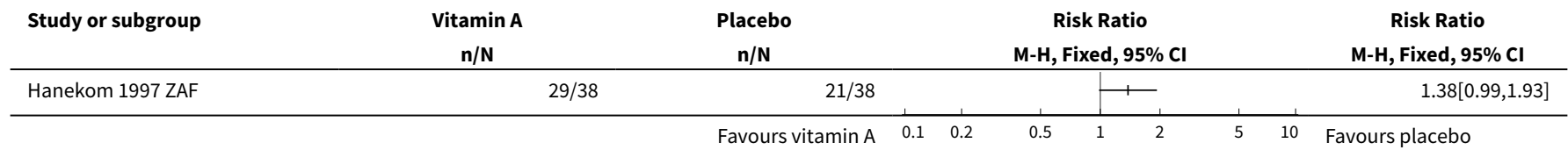

Analysis 4.6. Comparison 4 Vitamin A versus placebo, Outcome

\section{Sputum-smear and sputum-culture positive during follow-up.}

\begin{tabular}{|c|c|c|c|c|c|}
\hline \multirow{2}{*}{$\begin{array}{l}\text { Study or subgroup } \\
\text { 4.6.1 Baseline }\end{array}$} & \multirow[t]{2}{*}{$\begin{array}{c}\text { Vitamin A } \\
\mathrm{n} / \mathrm{N}\end{array}$} & \multirow[t]{2}{*}{$\begin{array}{c}\text { Placebo } \\
\mathbf{n} / \mathbf{N}\end{array}$} & \multirow[t]{2}{*}{$\begin{array}{c}\text { Risk Ratio } \\
\text { M-H, Fixed, 95\% Cl }\end{array}$} & \multirow[t]{2}{*}{ Weight } & \multirow[t]{2}{*}{$\begin{array}{c}\text { Risk Ratio } \\
\text { M-H, Fixed, 95\% Cl }\end{array}$} \\
\hline & & & & & \\
\hline Pakasi 2010 IDN & $72 / 72$ & $86 / 86$ & & $100 \%$ & $1[0.98,1.03]$ \\
\hline Subtotal $(95 \% \mathrm{Cl})$ & 72 & 86 & & $100 \%$ & $1[0.98,1.03]$ \\
\hline \multicolumn{6}{|c|}{ Total events: 72 (Vitamin A), 86 (Placebo) } \\
\hline \multicolumn{6}{|c|}{ Heterogeneity: Not applicable } \\
\hline \multicolumn{6}{|l|}{ 4.6.2 2 weeks } \\
\hline Pakasi 2010 IDN & $20 / 72$ & $30 / 86$ & & $100 \%$ & $0.8[0.5,1.28]$ \\
\hline Subtotal $(95 \% \mathrm{Cl})$ & 72 & 86 & & $100 \%$ & $0.8[0.5,1.28]$ \\
\hline \multicolumn{6}{|c|}{ Total events: 20 (Vitamin A), 30 (Placebo) } \\
\hline \multicolumn{6}{|c|}{ Heterogeneity: Not applicable } \\
\hline \multicolumn{6}{|l|}{ 4.6.3 1 month } \\
\hline Pakasi 2010 IDN & $9 / 66$ & $16 / 82$ & & $100 \%$ & $0.7[0.33,1.48]$ \\
\hline Subtotal $(95 \% \mathrm{Cl})$ & 66 & 82 & & $100 \%$ & $0.7[0.33,1.48]$ \\
\hline \multicolumn{6}{|c|}{ Total events: 9 (Vitamin A), 16 (Placebo) } \\
\hline \multicolumn{6}{|c|}{ Heterogeneity: $\operatorname{Tau}^{2}=0 ; \mathrm{Chi}^{2}=0, \mathrm{df}=0(\mathrm{P}<0.0001) ; \mathrm{I}^{2}=100 \%$} \\
\hline \multicolumn{6}{|c|}{ Test for overall effect: $Z=0.94(P=0.35)$} \\
\hline \multicolumn{6}{|l|}{ 4.6.4 2 months } \\
\hline Ginawi 2013 IND & $3 / 31$ & $3 / 32$ & & $100 \%$ & $1.03[0.23,4.73]$ \\
\hline Pakasi 2010 IDN & $0 / 59$ & $0 / 77$ & & & Not estimable \\
\hline Subtotal $(95 \% \mathrm{CI})$ & 90 & 109 & & $100 \%$ & $1.03[0.23,4.73]$ \\
\hline \multicolumn{6}{|c|}{ Total events: 3 (Vitamin A), 3 (Placebo) } \\
\hline \multicolumn{6}{|c|}{ Test for overall effect: $\mathrm{Z}=0.04(\mathrm{P}=0.97)$} \\
\hline \multicolumn{6}{|c|}{ Test for subgroup differences: $\mathrm{Chi}^{2}=1.77, \mathrm{df}=1(\mathrm{P}=0.62), \mathrm{I}^{2}=0 \%$} \\
\hline
\end{tabular}

Analysis 4.7. Comparison 4 Vitamin A versus placebo, Outcome $7 \mathrm{BMI}\left(\mathrm{kg} / \mathrm{m}^{2}\right)$.

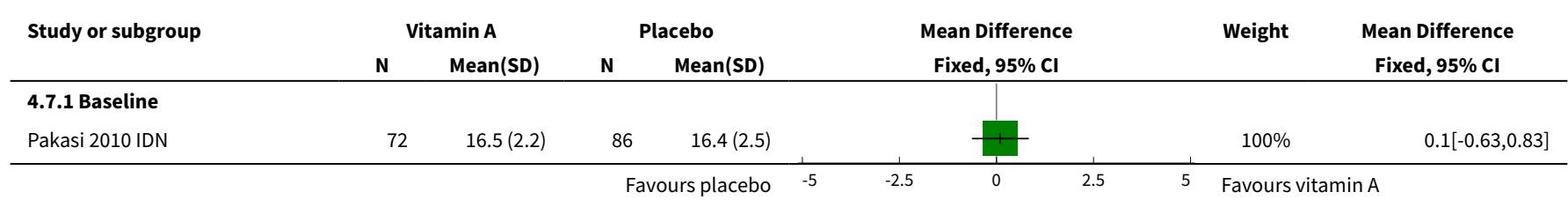




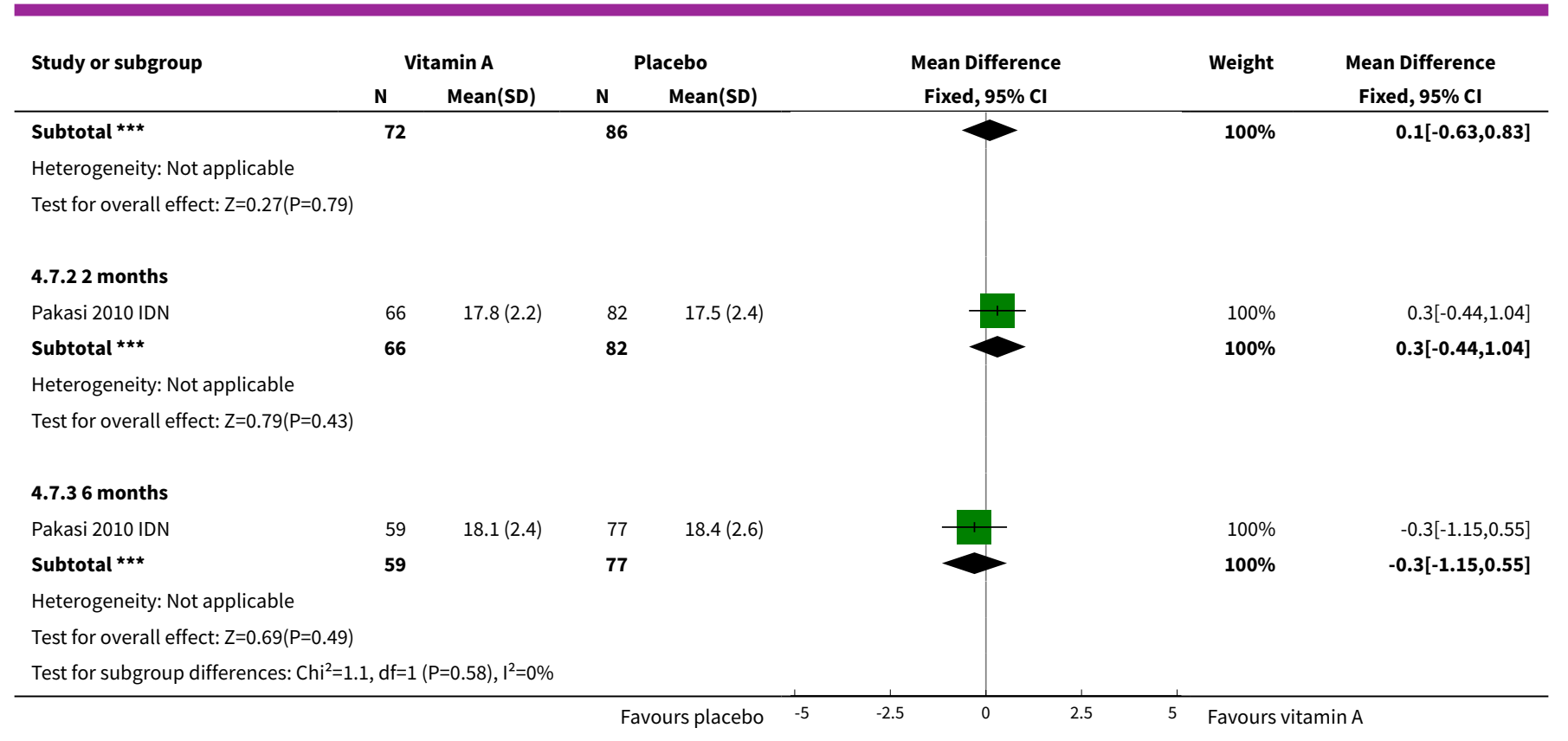

Analysis 4.8. Comparison 4 Vitamin A versus placebo, Outcome 8 Body fat (\%).

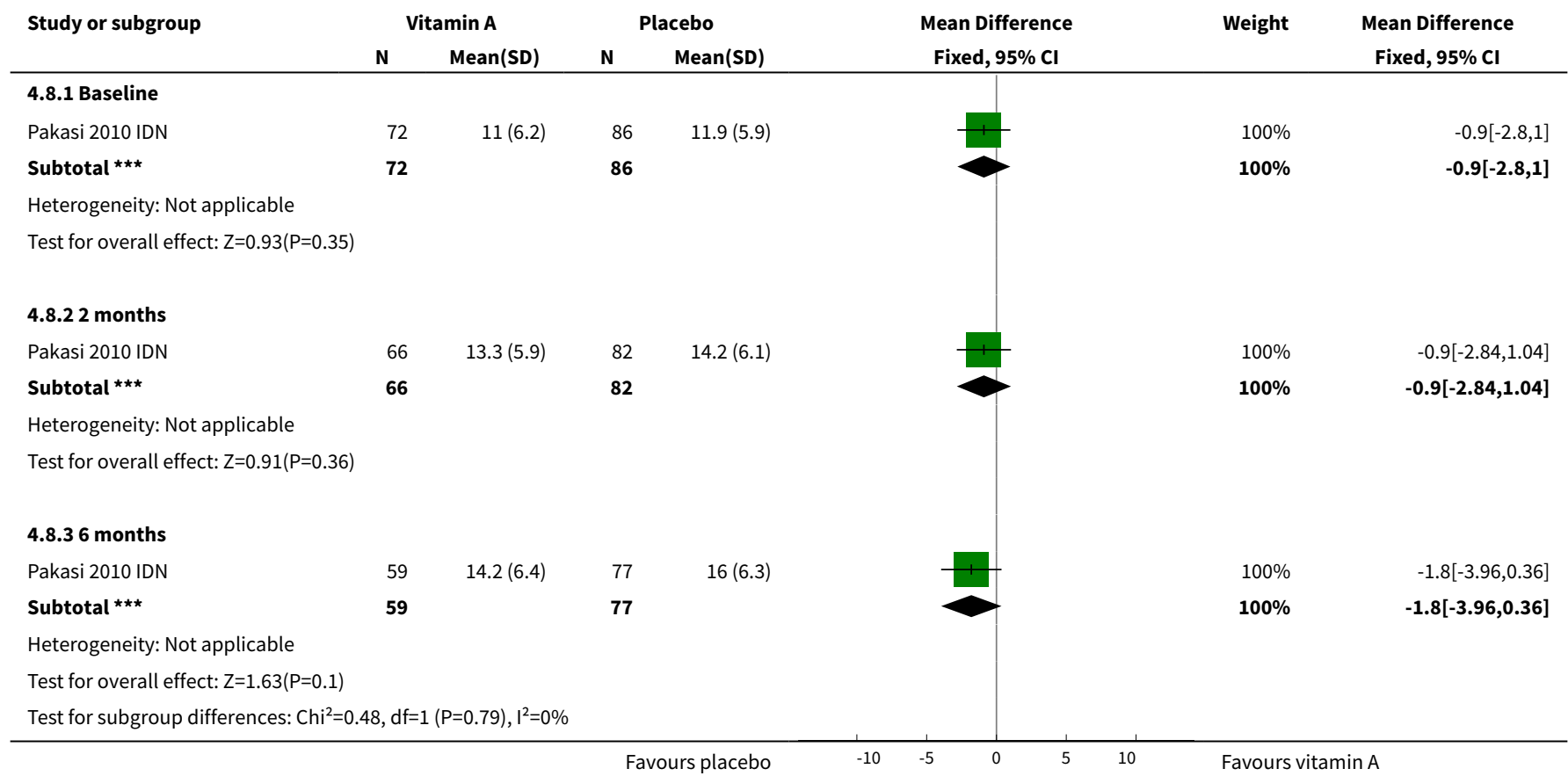


Comparison 5. Zinc versus placebo

\begin{tabular}{|c|c|c|c|c|}
\hline Outcome or subgroup title & No. of studies & $\begin{array}{l}\text { No. of partici- } \\
\text { pants }\end{array}$ & Statistical method & Effect size \\
\hline $\begin{array}{l}1 \text { Serum zinc level (normal } \\
\text { range }>10.7 \mu \mathrm{mol} / \mathrm{L} \text { ) }\end{array}$ & 4 & & Mean Difference (IV, Fixed, 95\% CI) & Subtotals only \\
\hline 1.1 At baseline & 4 & 472 & Mean Difference (IV, Fixed, 95\% CI) & $-0.03[-0.36,0.30]$ \\
\hline 1.2 At 2 months & 4 & 452 & Mean Difference (IV, Fixed, 95\% CI) & $0.59[0.24,0.93]$ \\
\hline 1.3 At 6 months & 4 & 440 & Mean Difference (IV, Fixed, 95\% CI) & $0.60[0.31,0.88]$ \\
\hline 2 Death by 6 to 8 months & 7 & 2862 & Risk Ratio (M-H, Fixed, 95\% Cl) & $0.96[0.82,1.13]$ \\
\hline 2.1 Zinc alone & 4 & 714 & Risk Ratio (M-H, Fixed, 95\% Cl) & $1.25[0.70,2.22]$ \\
\hline 2.2 Zinc plus vitamin A & 4 & 477 & Risk Ratio (M-H, Fixed, 95\% Cl) & $2.08[0.65,6.64]$ \\
\hline $\begin{array}{l}2.3 \text { Zinc as part of a multi-mi- } \\
\text { cronutrient supplement }\end{array}$ & 3 & 1671 & Risk Ratio (M-H, Fixed, 95\% Cl) & $0.91[0.77,1.07]$ \\
\hline $\begin{array}{l}3 \text { Death by } 6 \text { to } 8 \text { months } \\
\text { (subgrouped by HIV status) }\end{array}$ & 4 & 815 & Risk Ratio (M-H, Fixed, 95\% Cl) & $1.25[0.75,2.09]$ \\
\hline 3.1 HIV-negative individuals & 3 & 442 & Risk Ratio (M-H, Fixed, 95\% Cl) & $1.92[0.53,6.98]$ \\
\hline 3.2 HIV-positive individuals & 2 & 211 & Risk Ratio (M-H, Fixed, 95\% Cl) & $1.06[0.59,1.91]$ \\
\hline 3.3 HIV status unknown & 1 & 162 & Risk Ratio (M-H, Fixed, 95\% Cl) & $1.70[0.29,9.89]$ \\
\hline $\begin{array}{l}4 \text { Treatment completion at } 6 \\
\text { months }\end{array}$ & 2 & 353 & Risk Ratio (M-H, Fixed, 95\% Cl) & $0.98[0.92,1.04]$ \\
\hline $\begin{array}{l}5 \text { Sputum-smear or spu- } \\
\text { tum-culture positive during } \\
\text { follow-up }\end{array}$ & 5 & & Risk Ratio (M-H, Fixed, 95\% Cl) & Subtotals only \\
\hline 5.1 At baseline & 3 & 596 & Risk Ratio (M-H, Fixed, 95\% Cl) & $0.97[0.92,1.03]$ \\
\hline 5.2 At 2 weeks & 3 & 806 & Risk Ratio (M-H, Fixed, 95\% Cl) & $1.09[1.02,1.17]$ \\
\hline 5.3 At 4 weeks & 3 & 783 & Risk Ratio (M-H, Fixed, 95\% Cl) & $1.05[0.93,1.20]$ \\
\hline 5.4 At 8 weeks & 5 & 1076 & Risk Ratio (M-H, Fixed, 95\% Cl) & $0.96[0.72,1.28]$ \\
\hline $\begin{array}{l}6 \text { Clearance of chest X-ray at } \\
6 \text { months }\end{array}$ & 1 & & Risk Ratio (M-H, Fixed, 95\% Cl) & Subtotals only \\
\hline 7 Weight at follow-up & 2 & & Mean Difference (IV, Fixed, 95\% CI) & Totals not selected \\
\hline 7.1 Baseline: weight (kg) & 2 & & Mean Difference (IV, Fixed, 95\% CI) & $0.0[0.0,0.0]$ \\
\hline 7.22 months: weight $(\mathrm{kg})$ & 1 & & Mean Difference (IV, Fixed, 95\% CI) & $0.0[0.0,0.0]$ \\
\hline 7.36 months: weight (kg) & 1 & & Mean Difference (IV, Fixed, 95\% CI) & $0.0[0.0,0.0]$ \\
\hline
\end{tabular}




\begin{tabular}{|c|c|c|c|c|}
\hline Outcome or subgroup title & No. of studies & $\begin{array}{l}\text { No. of partici- } \\
\text { pants }\end{array}$ & Statistical method & Effect size \\
\hline 7.47 months: weight (kg) & 1 & & Mean Difference (IV, Fixed, 95\% CI) & $0.0[0.0,0.0]$ \\
\hline $8 \mathrm{BMI}\left(\mathrm{kg} / \mathrm{m}^{2}\right)$ & 1 & & Mean Difference (IV, Fixed, 95\% CI) & Subtotals only \\
\hline 8.1 Baseline & 1 & 162 & Mean Difference (IV, Fixed, 95\% CI) & $0.10[-0.62,0.82]$ \\
\hline 8.22 months & 1 & 151 & Mean Difference (IV, Fixed, 95\% CI) & $0.20[-0.55,0.95]$ \\
\hline 8.36 months & 1 & 140 & Mean Difference (IV, Fixed, 95\% CI) & $0.10[-0.70,0.90]$ \\
\hline 9 Body fat (\%) & 1 & & Mean Difference (IV, Fixed, 95\% CI) & Subtotals only \\
\hline 9.1 Baseline & 1 & 162 & Mean Difference (IV, Fixed, 95\% CI) & $-0.90[-2.51,0.71]$ \\
\hline 9.22 months & 1 & 151 & Mean Difference (IV, Fixed, 95\% CI) & $-1.30[-3.07,0.47]$ \\
\hline 9.36 months & 1 & 140 & Mean Difference (IV, Fixed, 95\% CI) & $-1.5[-3.51,0.51]$ \\
\hline 10 Weight-for-age z score & 1 & & Mean Difference (IV, Fixed, 95\% CI) & Totals not selected \\
\hline $\begin{array}{l}\text { 10.1 Baseline: weight-for-age } \\
\text { z score }\end{array}$ & 1 & & Mean Difference (IV, Fixed, 95\% CI) & $0.0[0.0,0.0]$ \\
\hline $\begin{array}{l}10.22 \text { months: weight-for- } \\
\text { age } z \text { score }\end{array}$ & 1 & & Mean Difference (IV, Fixed, 95\% CI) & $0.0[0.0,0.0]$ \\
\hline $\begin{array}{l}10.36 \text { months: weight-for- } \\
\text { age z score }\end{array}$ & 1 & & Mean Difference (IV, Fixed, 95\% CI) & $0.0[0.0,0.0]$ \\
\hline 11 BMI-for-age z score & 1 & & Mean Difference (IV, Fixed, 95\% CI) & Totals not selected \\
\hline $\begin{array}{l}\text { 11.1 Baseline: BMI-for-age z } \\
\text { score }\end{array}$ & 1 & & Mean Difference (IV, Fixed, 95\% CI) & $0.0[0.0,0.0]$ \\
\hline $\begin{array}{l}11.22 \text { months: BMI-for-age } z \\
\text { score }\end{array}$ & 1 & & Mean Difference (IV, Fixed, 95\% CI) & $0.0[0.0,0.0]$ \\
\hline $\begin{array}{l}11.36 \text { months: BMI-for-age } z \\
\text { score }\end{array}$ & 1 & & Mean Difference (IV, Fixed, 95\% CI) & $0.0[0.0,0.0]$ \\
\hline $\begin{array}{l}12 \text { Height-for-age } z \text { score at } \\
\text { follow-up }\end{array}$ & 1 & & Mean Difference (IV, Fixed, 95\% CI) & Totals not selected \\
\hline $\begin{array}{l}12.1 \text { Baseline: height-for-age } \\
\text { z score }\end{array}$ & 1 & & Mean Difference (IV, Fixed, 95\% CI) & $0.0[0.0,0.0]$ \\
\hline $\begin{array}{l}12.22 \text { months: height-for-age } \\
\text { z score }\end{array}$ & 1 & & Mean Difference (IV, Fixed, 95\% CI) & $0.0[0.0,0.0]$ \\
\hline $\begin{array}{l}12.36 \text { months: height-for-age } \\
\text { z score }\end{array}$ & 1 & & Mean Difference (IV, Fixed, 95\% CI) & $0.0[0.0,0.0]$ \\
\hline
\end{tabular}


Analysis 5.1. Comparison 5 Zinc versus placebo, Outcome 1 Serum zinc level (normal range $>10.7 \mu \mathrm{mol} / \mathrm{L}$ ).

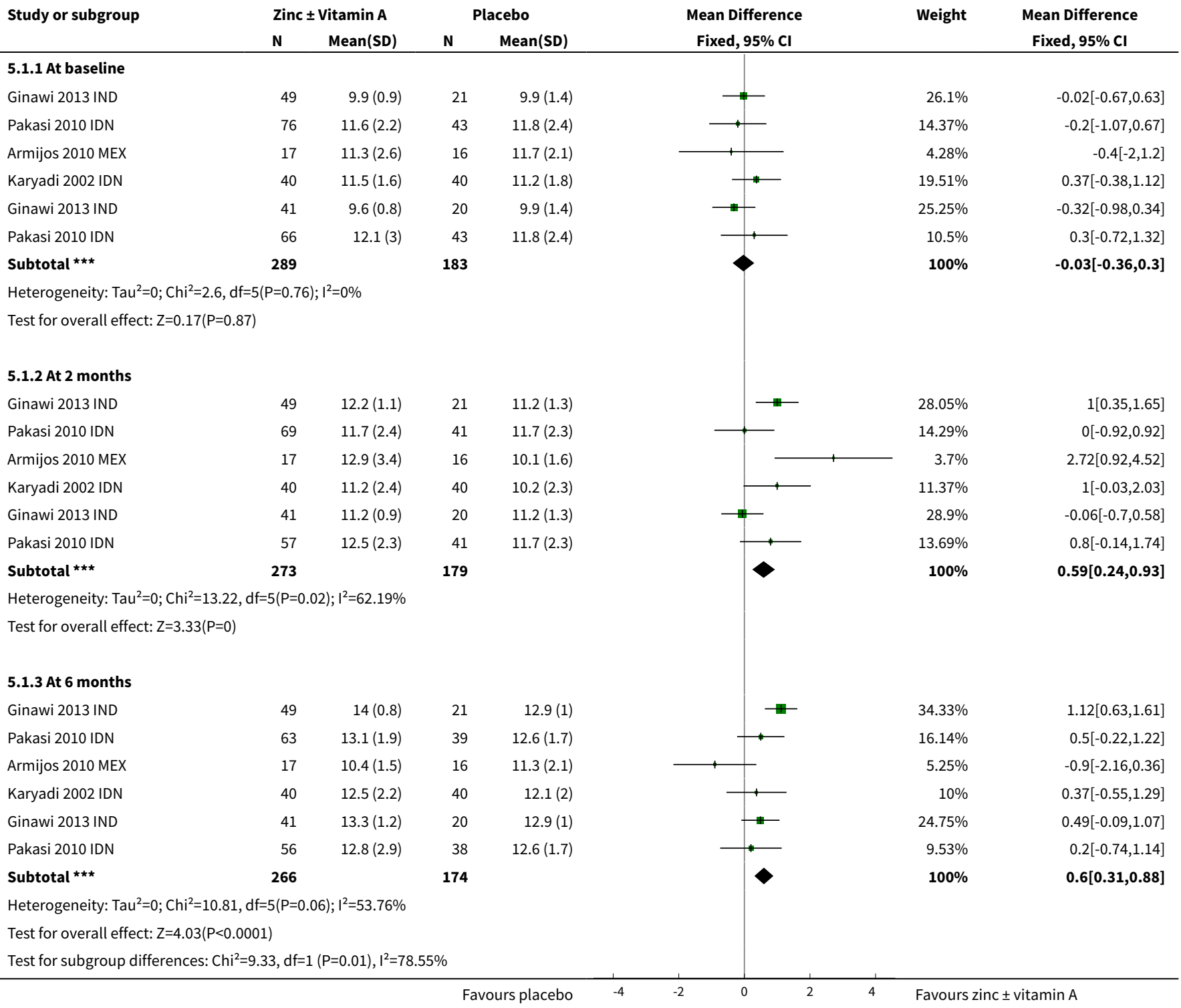

Analysis 5.2. Comparison 5 Zinc versus placebo, Outcome 2 Death by 6 to 8 months.

\begin{tabular}{|c|c|c|c|c|c|}
\hline Study or subgroup & $\begin{array}{c}\text { Zinc } \pm \text { vitamin A } \\
\mathrm{n} / \mathrm{N}\end{array}$ & $\begin{array}{c}\text { Placebo } \\
\mathbf{n} / \mathbf{N}\end{array}$ & $\begin{array}{c}\text { Risk Ratio } \\
\text { M-H, Fixed, 95\% Cl }\end{array}$ & Weight & $\begin{array}{c}\text { Risk Ratio } \\
\text { M-H, Fixed, 95\% CI }\end{array}$ \\
\hline \multicolumn{6}{|l|}{ 5.2.1 Zinc alone } \\
\hline Lawson 2010 NGA & $9 / 117$ & $1 / 58$ & - & $0.59 \%$ & $4.46[0.58,34.38]$ \\
\hline Lodha 2014 IND & $1 / 101$ & $0 / 100$ & 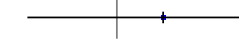 & $0.22 \%$ & $2.97[0.12,72.06]$ \\
\hline Pakasi 2010 IDN & $3 / 76$ & $1 / 43$ & $\rightarrow$ & $0.57 \%$ & $1.7[0.18,15.82]$ \\
\hline Range 2005 TZA & $15 / 112$ & $16 / 107$ & $\longrightarrow$ & $7.27 \%$ & $0.9[0.47,1.72]$ \\
\hline Subtotal $(95 \% \mathrm{Cl})$ & 406 & 308 & & $8.65 \%$ & $1.25[0.7,2.22]$ \\
\hline \multicolumn{6}{|c|}{ Total events: 28 (Zinc \pm vitamin A), 18 (Placebo) } \\
\hline \multicolumn{6}{|c|}{ Heterogeneity: $\operatorname{Tau}^{2}=0 ; \mathrm{Chi}^{2}=2.84, \mathrm{df}=3(\mathrm{P}=0.42) ; \mathrm{I}^{2}=0 \%$} \\
\hline \multicolumn{6}{|c|}{ Test for overall effect: $Z=0.75(P=0.45)$} \\
\hline
\end{tabular}

Nutritional supplements for people being treated for active tuberculosis (Review) 


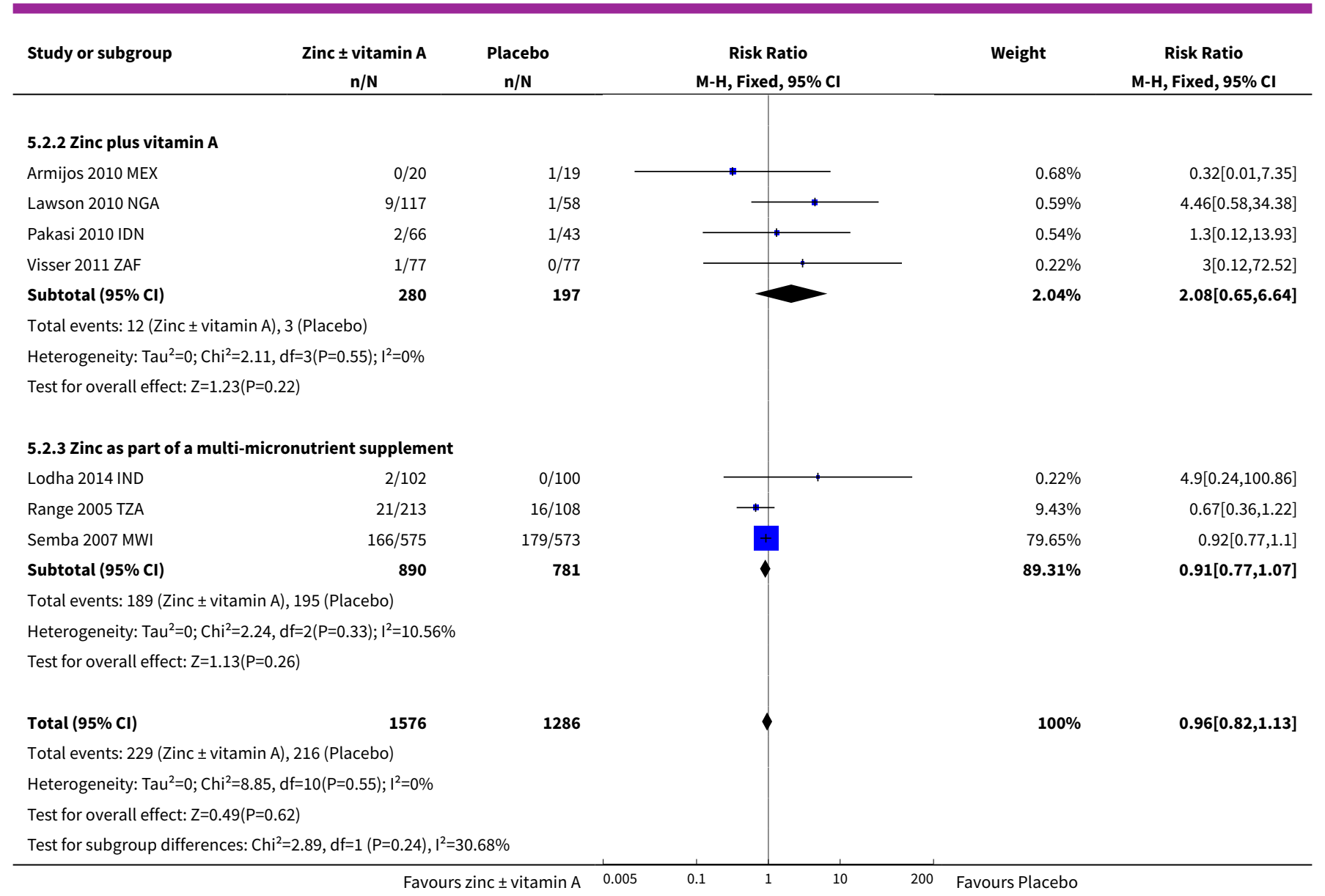

\section{Analysis 5.3. Comparison 5 Zinc versus placebo, Outcome 3 Death by 6 to 8 months (subgrouped by HIV status).}

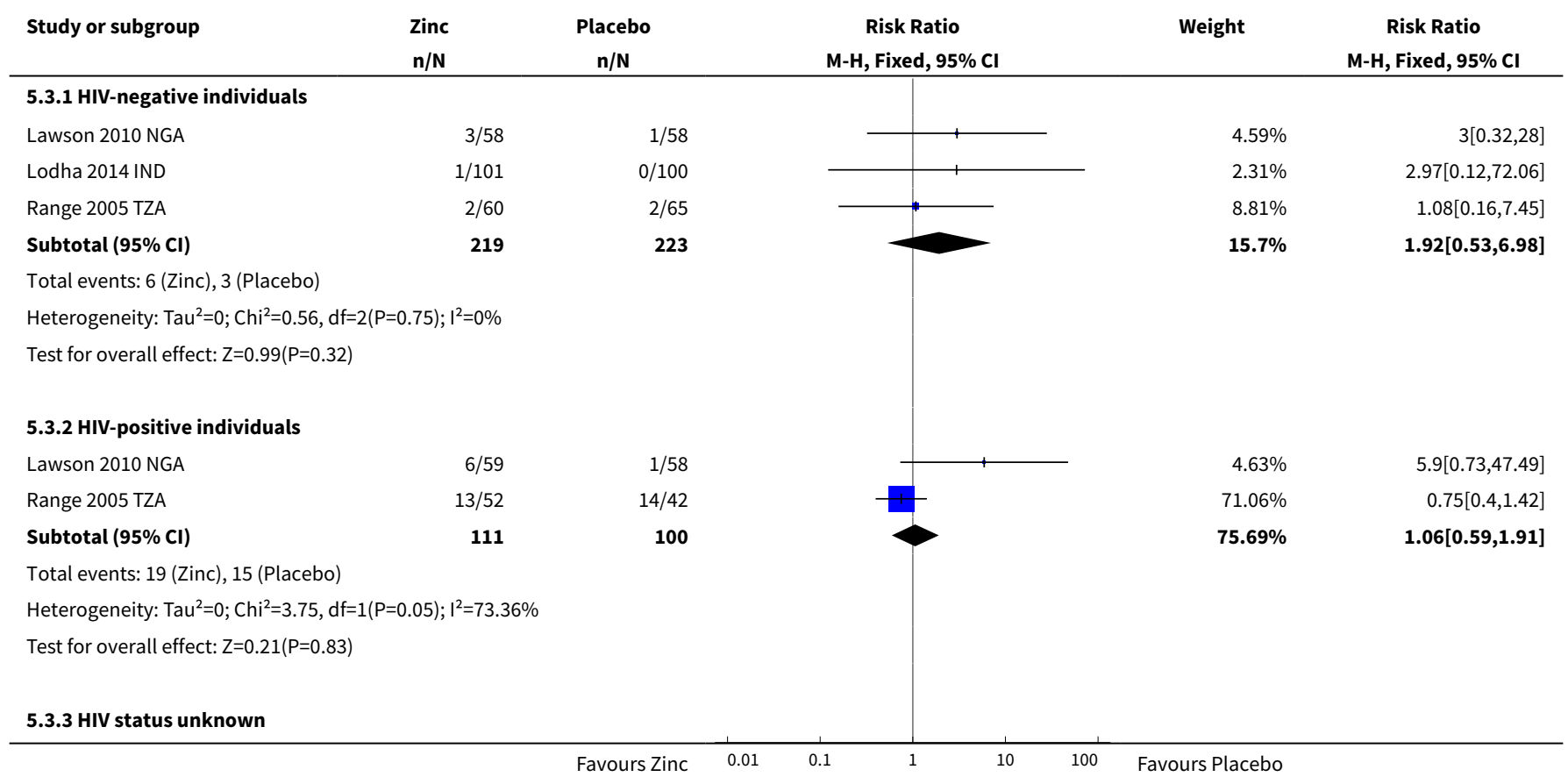

Nutritional supplements for people being treated for active tuberculosis (Review) 


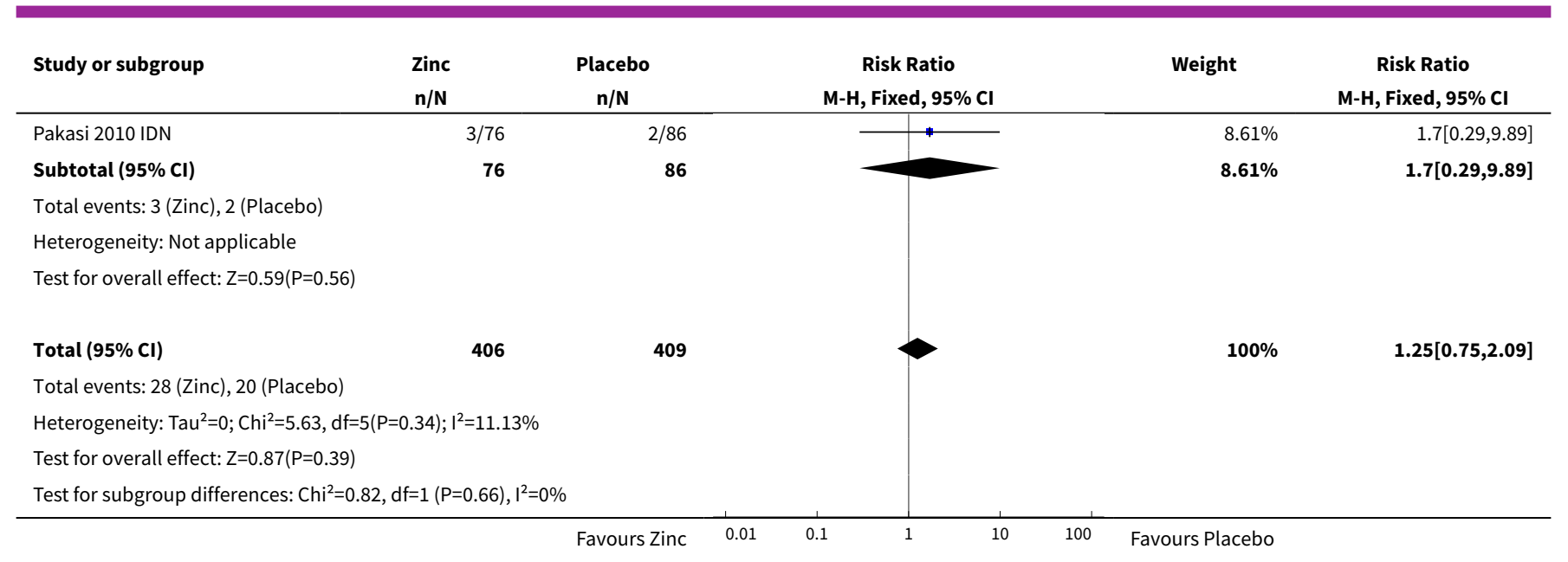

Analysis 5.4. Comparison 5 Zinc versus placebo, Outcome 4 Treatment completion at 6 months.

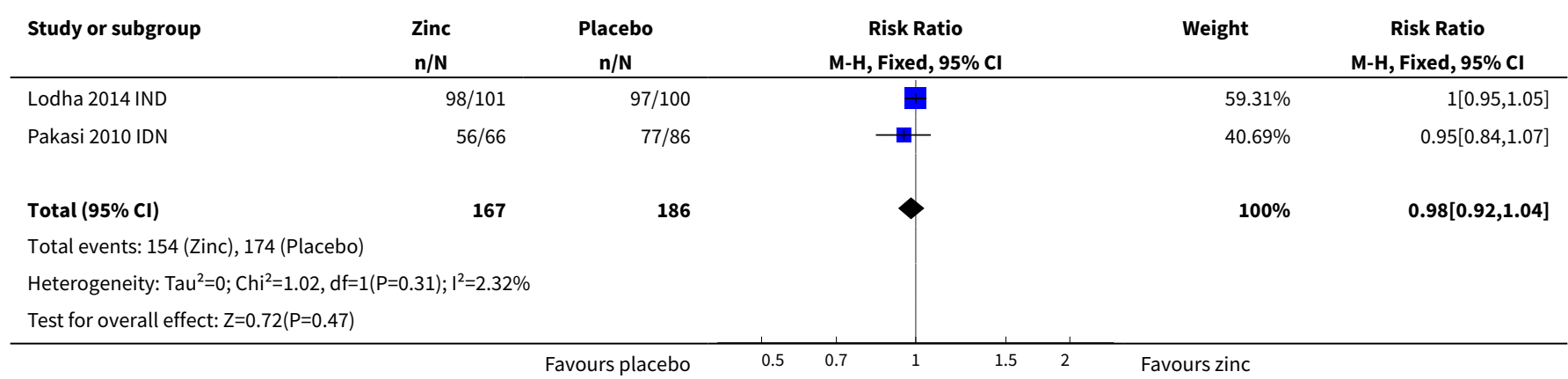

Analysis 5.5. Comparison 5 Zinc versus placebo, Outcome 5

Sputum-smear or sputum-culture positive during follow-up.

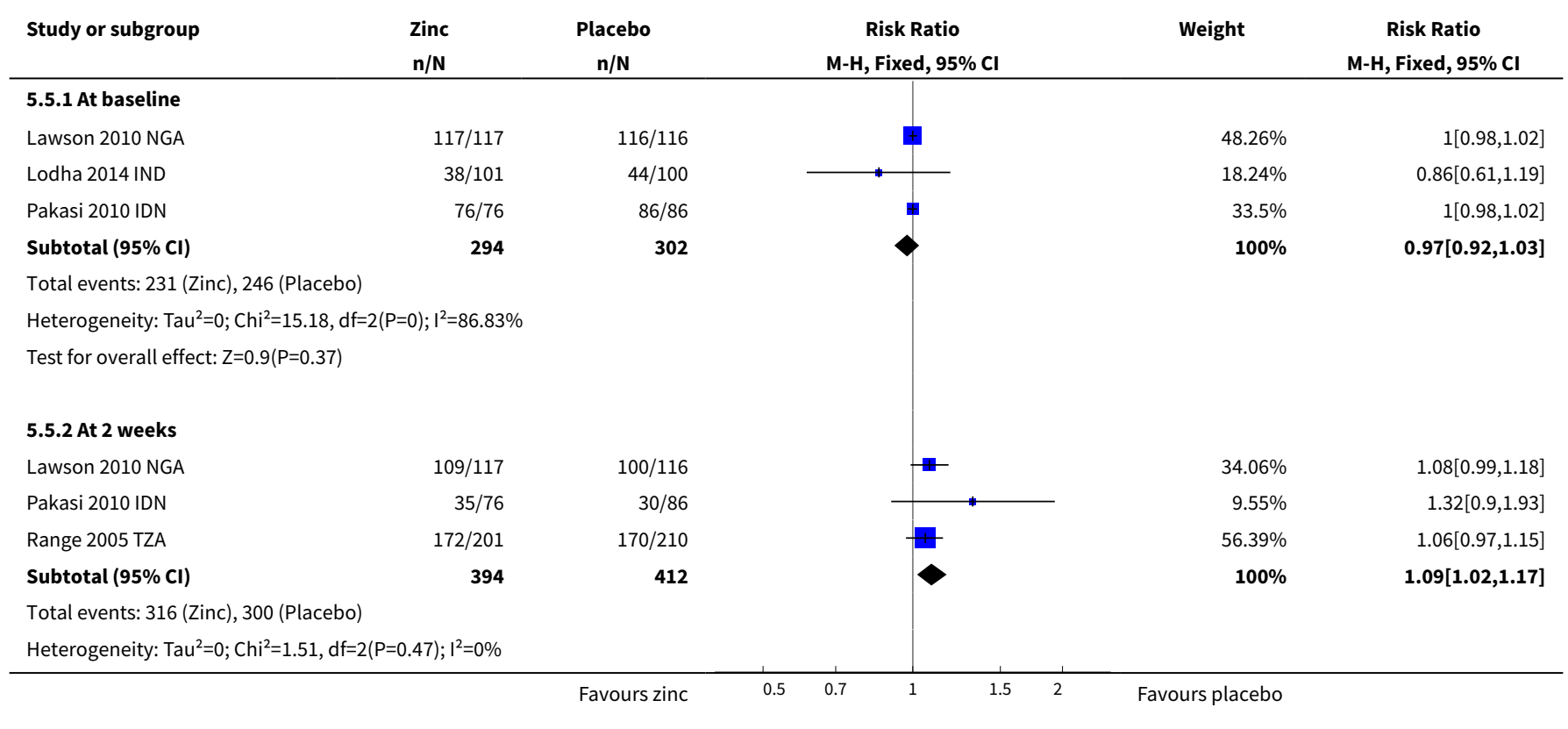

Nutritional supplements for people being treated for active tuberculosis (Review) 


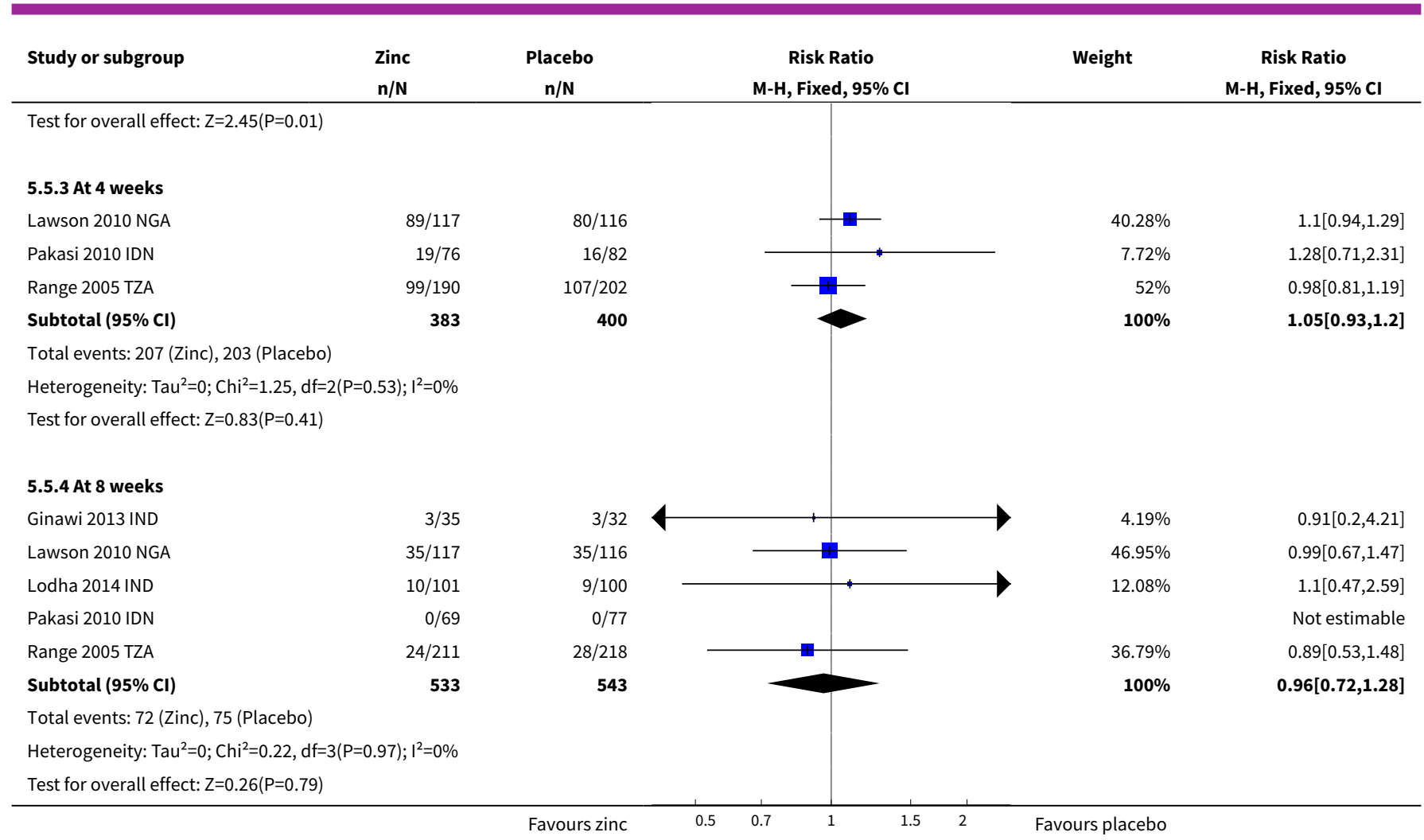

Analysis 5.6. Comparison 5 Zinc versus placebo, Outcome 6 Clearance of chest X-ray at 6 months.

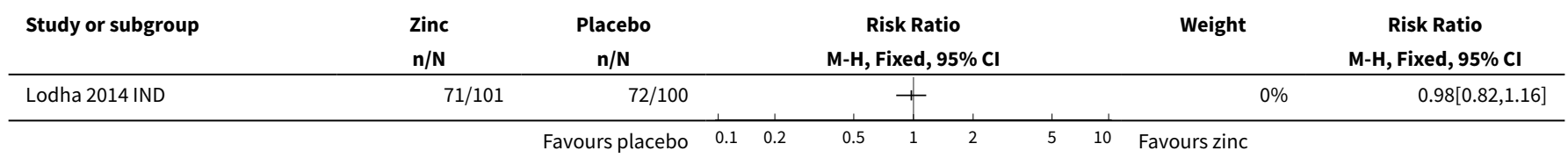

Analysis 5.7. Comparison 5 Zinc versus placebo, Outcome 7 Weight at follow-up.

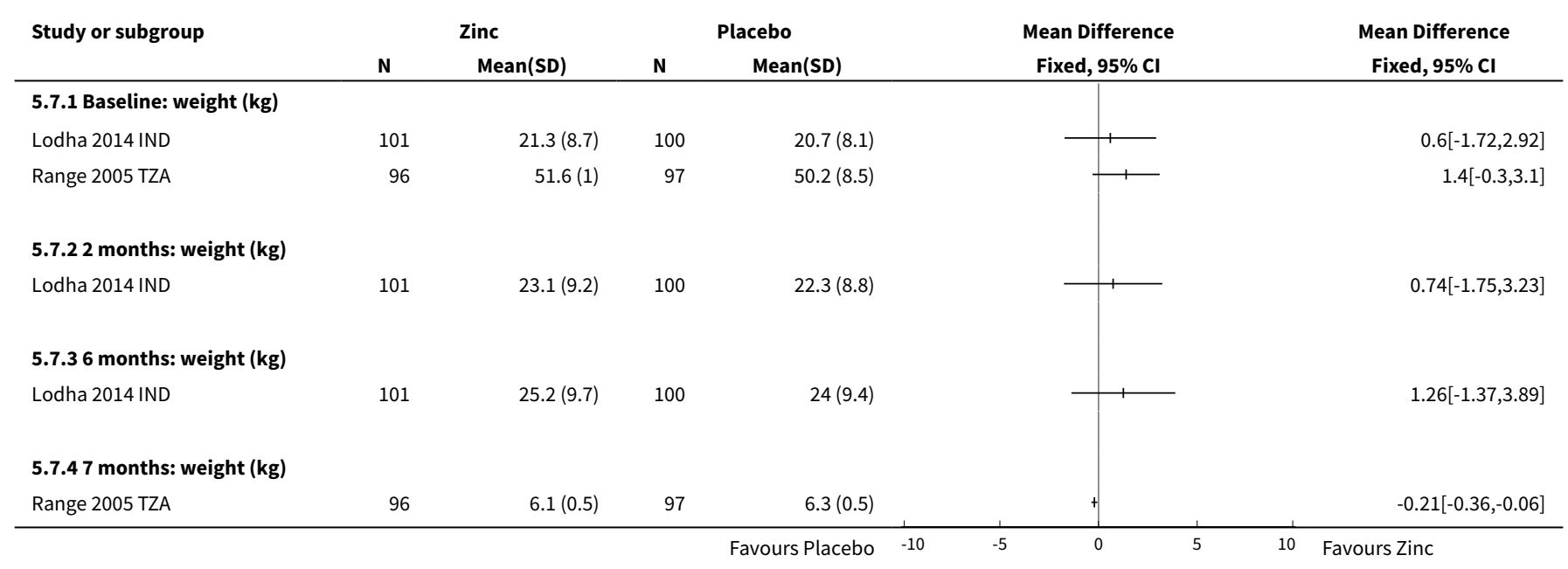


Analysis 5.8. Comparison 5 Zinc versus placebo, Outcome $8 \mathrm{BMI}\left(\mathrm{kg} / \mathrm{m}^{2}\right)$.

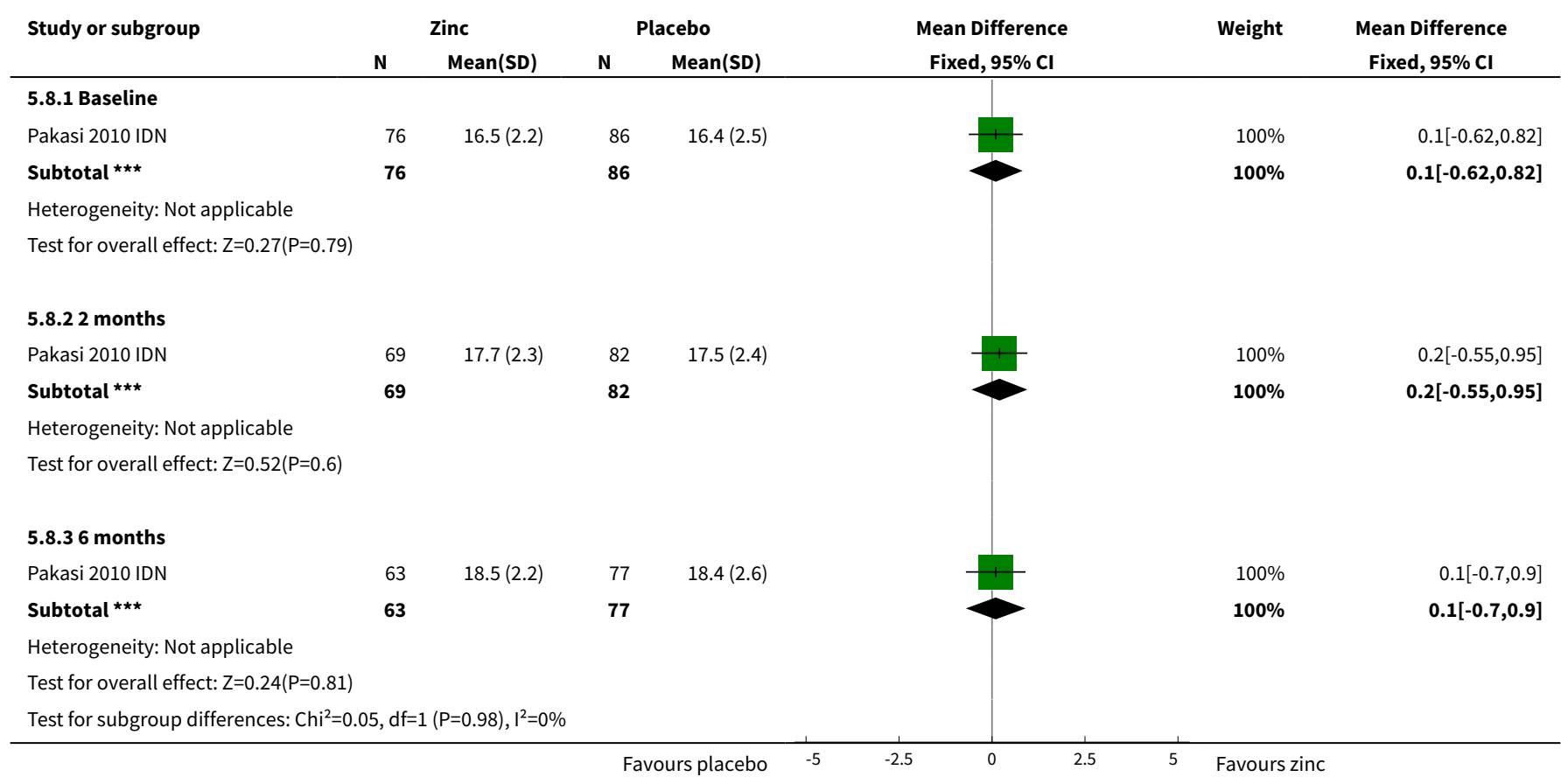

Analysis 5.9. Comparison 5 Zinc versus placebo, Outcome 9 Body fat (\%).

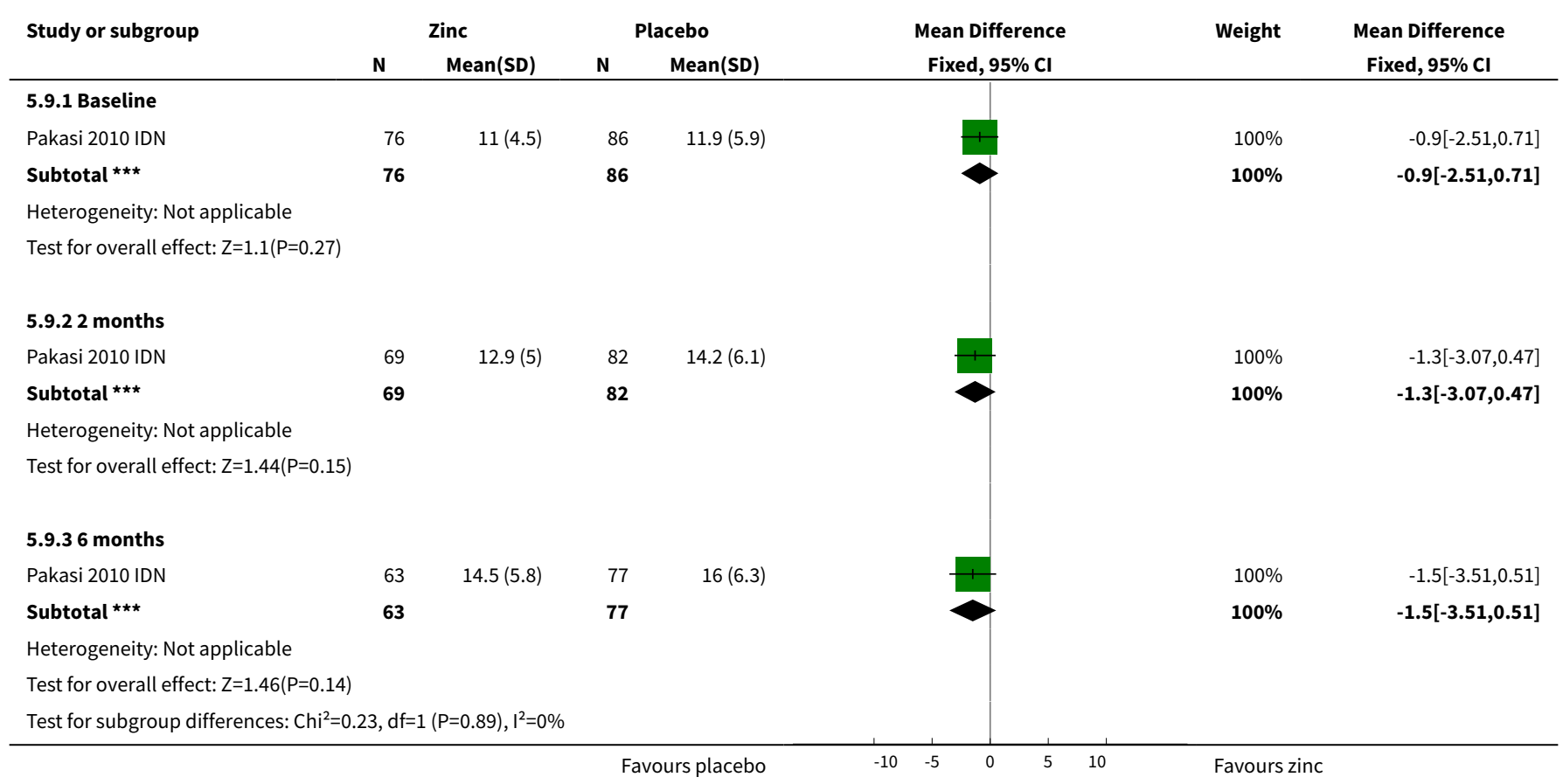


Analysis 5.10. Comparison 5 Zinc versus placebo, Outcome 10 Weight-for-age z score.

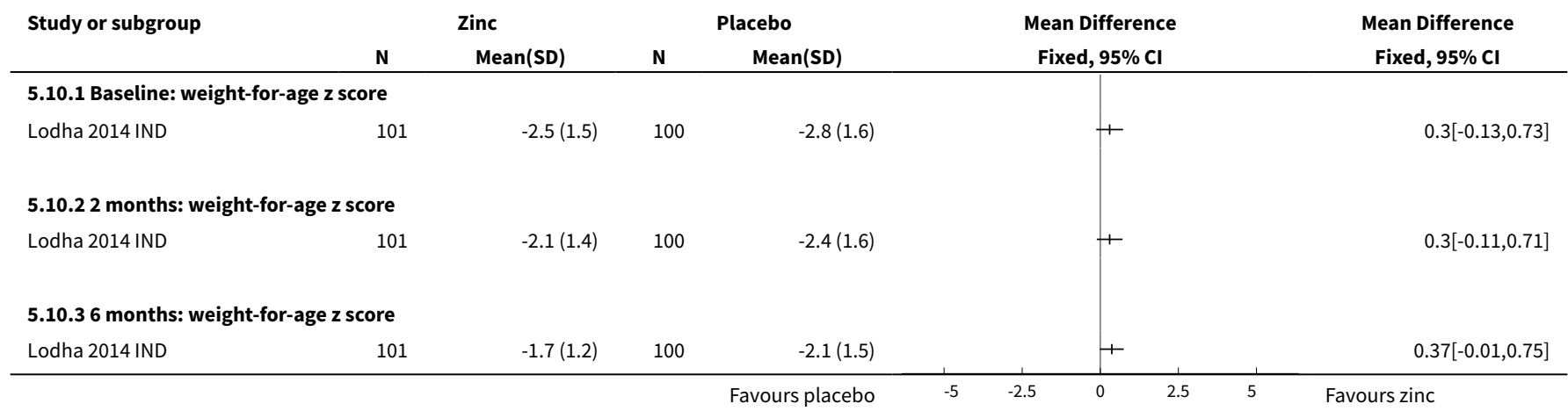

Analysis 5.11. Comparison 5 Zinc versus placebo, Outcome 11 BMI-for-age z score.

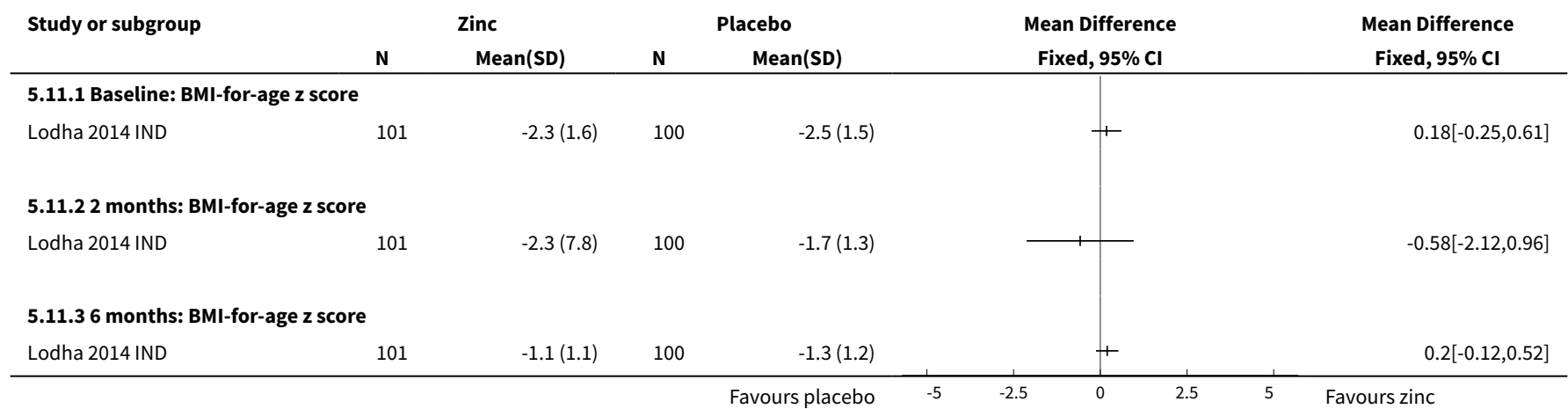

Analysis 5.12. Comparison 5 Zinc versus placebo, Outcome 12 Height-for-age z score at follow-up.

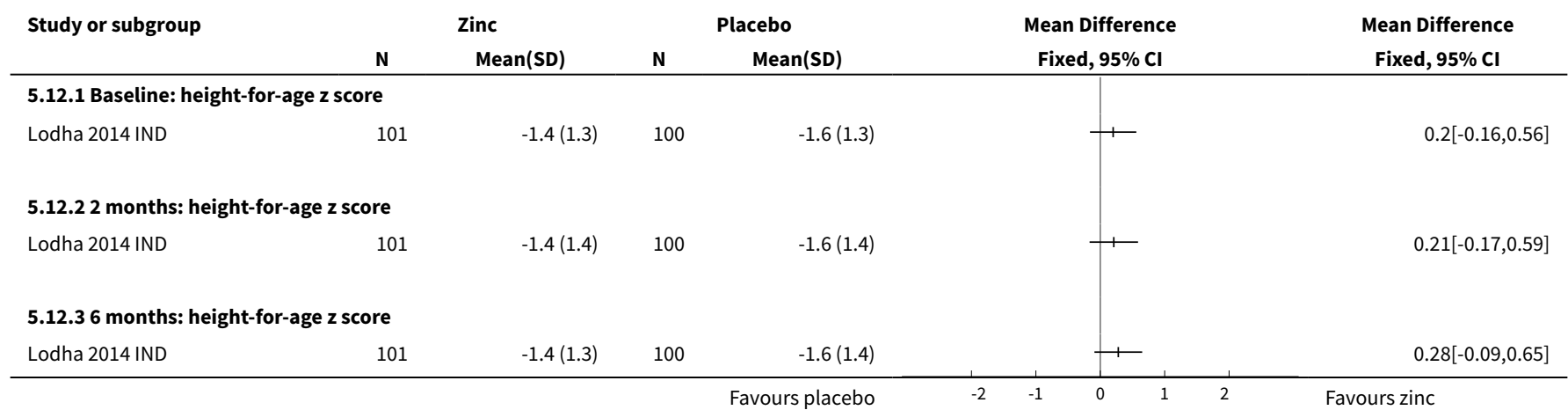

\section{Comparison 6. Zinc plus vitamin A versus placebo}

\begin{tabular}{lllll}
\hline $\begin{array}{l}\text { Outcome or subgroup } \\
\text { title }\end{array}$ & No. of studies & $\begin{array}{l}\text { No. of partici- } \\
\text { pants }\end{array}$ & Statistical method & Effect size \\
\hline 1 Death by 6 months & 4 & 578 & Risk Ratio (M-H, Fixed, 95\% Cl) & $2.33[0.90,6.07]$ \\
\hline \hline
\end{tabular}

Nutritional supplements for people being treated for active tuberculosis (Review)

Copyright (c) 2016 The Authors. Cochrane Database of Systematic Reviews published by John Wiley \& Sons, Ltd. on behalf of The Cochrane

Collaboration. 


\begin{tabular}{|c|c|c|c|c|}
\hline $\begin{array}{l}\text { Outcome or subgroup } \\
\text { title }\end{array}$ & No. of studies & $\begin{array}{l}\text { No. of partici- } \\
\text { pants }\end{array}$ & Statistical method & Effect size \\
\hline $\begin{array}{l}1.1 \text { HIV-negative indi- } \\
\text { viduals }\end{array}$ & 4 & 430 & Risk Ratio (M-H, Fixed, 95\% Cl) & $1.11[0.31,3.99]$ \\
\hline $\begin{array}{l}1.2 \text { HIV-positive individ- } \\
\text { uals }\end{array}$ & 2 & 136 & Risk Ratio (M-H, Fixed, 95\% Cl) & $5.94[1.07,32.96]$ \\
\hline 1.3 Unknown HIV status & 1 & 12 & Risk Ratio (M-H, Fixed, 95\% Cl) & $0.0[0.0,0.0]$ \\
\hline $\begin{array}{l}2 \text { Treatment comple- } \\
\text { tion at } 6 \text { months }\end{array}$ & 1 & 152 & Risk Ratio (M-H, Fixed, 95\% Cl) & $0.95[0.84,1.07]$ \\
\hline $\begin{array}{l}3 \text { Sputum-smear and } \\
\text { sputum-culture positive } \\
\text { during follow-up }\end{array}$ & 7 & & Risk Ratio (M-H, Fixed, 95\% Cl) & Subtotals only \\
\hline 3.1 At baseline & 5 & 652 & Risk Ratio (M-H, Fixed, 95\% Cl) & $1.0[0.99,1.01]$ \\
\hline 3.21 month & 4 & 485 & Risk Ratio (M-H, Fixed, 95\% Cl) & $1.01[0.86,1.17]$ \\
\hline 3.32 months & 7 & 726 & Risk Ratio (M-H, Fixed, 95\% Cl) & $0.90[0.71,1.15]$ \\
\hline 3.43 months & 2 & 266 & Risk Ratio (M-H, Fixed, 95\% Cl) & $0.95[0.61,1.49]$ \\
\hline 3.54 months & 2 & 266 & Risk Ratio (M-H, Fixed, 95\% Cl) & $1.51[0.86,2.65]$ \\
\hline 3.65 months & 1 & 33 & Risk Ratio (M-H, Fixed, 95\% Cl) & $0.0[0.0,0.0]$ \\
\hline 3.76 months & 2 & 113 & Risk Ratio (M-H, Fixed, 95\% Cl) & $0.2[0.01,4.04]$ \\
\hline 4 Body weight (kg) & 1 & & Mean Difference (IV, Fixed, 95\% CI) & Totals not selected \\
\hline 4.1 Baseline & 1 & & Mean Difference (IV, Fixed, 95\% CI) & $0.0[0.0,0.0]$ \\
\hline 4.22 months & 1 & & Mean Difference (IV, Fixed, 95\% CI) & $0.0[0.0,0.0]$ \\
\hline 4.36 months & 1 & & Mean Difference (IV, Fixed, 95\% CI) & $0.0[0.0,0.0]$ \\
\hline $5 \mathrm{BMI}\left(\mathrm{kg} / \mathrm{m}^{2}\right)$ & 2 & 664 & Mean Difference (IV, Fixed, 95\% CI) & $-0.09[-0.45,0.28]$ \\
\hline 5.1 Baseline & 2 & 232 & Mean Difference (IV, Fixed, 95\% CI) & $-0.00[-0.62,0.61]$ \\
\hline 5.22 months & 2 & 219 & Mean Difference (IV, Fixed, 95\% CI) & $-0.03[-0.65,0.58]$ \\
\hline 5.36 months & 2 & 213 & Mean Difference (IV, Fixed, 95\% CI) & $-0.24[-0.91,0.43]$ \\
\hline $\begin{array}{l}6 \text { Mid upper arm cir- } \\
\text { cumference }(\mathrm{cm})\end{array}$ & 1 & & Mean Difference (IV, Fixed, 95\% CI) & Totals not selected \\
\hline 6.1 Baseline & 1 & & Mean Difference (IV, Fixed, 95\% CI) & $0.0[0.0,0.0]$ \\
\hline 6.22 months & 1 & & Mean Difference (IV, Fixed, 95\% CI) & $0.0[0.0,0.0]$ \\
\hline 6.36 months & 1 & & Mean Difference (IV, Fixed, 95\% CI) & $0.0[0.0,0.0]$ \\
\hline
\end{tabular}




\begin{tabular}{|c|c|c|c|c|}
\hline $\begin{array}{l}\text { Outcome or subgroup } \\
\text { title }\end{array}$ & No. of studies & $\begin{array}{l}\text { No. of partici- } \\
\text { pants }\end{array}$ & Statistical method & Effect size \\
\hline $\begin{array}{l}7 \text { Biceps skinfold thick- } \\
\text { ness (mm) }\end{array}$ & 1 & & Mean Difference (IV, Fixed, 95\% CI) & Totals not selected \\
\hline 7.1 Baseline & 1 & & Mean Difference (IV, Fixed, 95\% CI) & $0.0[0.0,0.0]$ \\
\hline 7.22 months & 1 & & Mean Difference (IV, Fixed, 95\% CI) & $0.0[0.0,0.0]$ \\
\hline 7.36 months & 1 & & Mean Difference (IV, Fixed, 95\% CI) & $0.0[0.0,0.0]$ \\
\hline $\begin{array}{l}8 \text { Triceps skinfold thick- } \\
\text { ness }(\mathrm{mm})\end{array}$ & 1 & & Mean Difference (IV, Fixed, 95\% CI) & Totals not selected \\
\hline 8.1 Baseline & 1 & & Mean Difference (IV, Fixed, 95\% CI) & $0.0[0.0,0.0]$ \\
\hline 8.22 months & 1 & & Mean Difference (IV, Fixed, 95\% CI) & $0.0[0.0,0.0]$ \\
\hline 8.36 months & 1 & & Mean Difference (IV, Fixed, 95\% CI) & $0.0[0.0,0.0]$ \\
\hline $\begin{array}{l}9 \text { Subscapular skinfold } \\
\text { thickness }(\mathrm{mm})\end{array}$ & 1 & & Mean Difference (IV, Fixed, 95\% CI) & Totals not selected \\
\hline 9.1 Baseline & 1 & & Mean Difference (IV, Fixed, 95\% CI) & $0.0[0.0,0.0]$ \\
\hline 9.22 months & 1 & & Mean Difference (IV, Fixed, 95\% CI) & $0.0[0.0,0.0]$ \\
\hline 9.36 months & 1 & & Mean Difference (IV, Fixed, 95\% CI) & $0.0[0.0,0.0]$ \\
\hline $\begin{array}{l}10 \text { Suprailiac skinfold } \\
\text { thickness (mm) }\end{array}$ & 1 & & Mean Difference (IV, Fixed, 95\% CI) & Totals not selected \\
\hline 10.1 Baseline & 1 & & Mean Difference (IV, Fixed, 95\% CI) & $0.0[0.0,0.0]$ \\
\hline 10.22 months & 1 & & Mean Difference (IV, Fixed, 95\% CI) & $0.0[0.0,0.0]$ \\
\hline 10.36 months & 1 & & Mean Difference (IV, Fixed, 95\% CI) & $0.0[0.0,0.0]$ \\
\hline 11 Body fat (\%) & 2 & & Mean Difference (IV, Fixed, 95\% CI) & Totals not selected \\
\hline 11.1 Baseline & 2 & & Mean Difference (IV, Fixed, 95\% CI) & $0.0[0.0,0.0]$ \\
\hline 11.22 months & 2 & & Mean Difference (IV, Fixed, 95\% CI) & $0.0[0.0,0.0]$ \\
\hline 11.36 months & 2 & & Mean Difference (IV, Fixed, 95\% CI) & $0.0[0.0,0.0]$ \\
\hline 12 Fat mass (kg) & 1 & & Mean Difference (IV, Fixed, 95\% CI) & Totals not selected \\
\hline 12.1 Baseline & 1 & & Mean Difference (IV, Fixed, 95\% CI) & $0.0[0.0,0.0]$ \\
\hline 12.22 months & 1 & & Mean Difference (IV, Fixed, 95\% CI) & $0.0[0.0,0.0]$ \\
\hline 12.36 months & 1 & & Mean Difference (IV, Fixed, 95\% CI) & $0.0[0.0,0.0]$ \\
\hline 13 Karnofsky score & 1 & & Mean Difference (IV, Fixed, 95\% CI) & Totals not selected \\
\hline
\end{tabular}




\begin{tabular}{lllll}
\hline $\begin{array}{l}\text { Outcome or subgroup } \\
\text { title }\end{array}$ & No. of studies & $\begin{array}{l}\text { No. of partici- } \\
\text { pants }\end{array}$ & Statistical method & Effect size \\
\hline 13.1 Baseline & 1 & Mean Difference (IV, Fixed, 95\% Cl) & $0.0[0.0,0.0]$ \\
\hline 13.22 months & 1 & Mean Difference (IV, Fixed, 95\% Cl) & $0.0[0.0,0.0]$ \\
\hline 13.36 months & 1 & Mean Difference (IV, Fixed, 95\% Cl) & $0.0[0.0,0.0]$ \\
\hline
\end{tabular}

\section{Analysis 6.1. Comparison 6 Zinc plus vitamin A versus placebo, Outcome 1 Death by 6 months.}

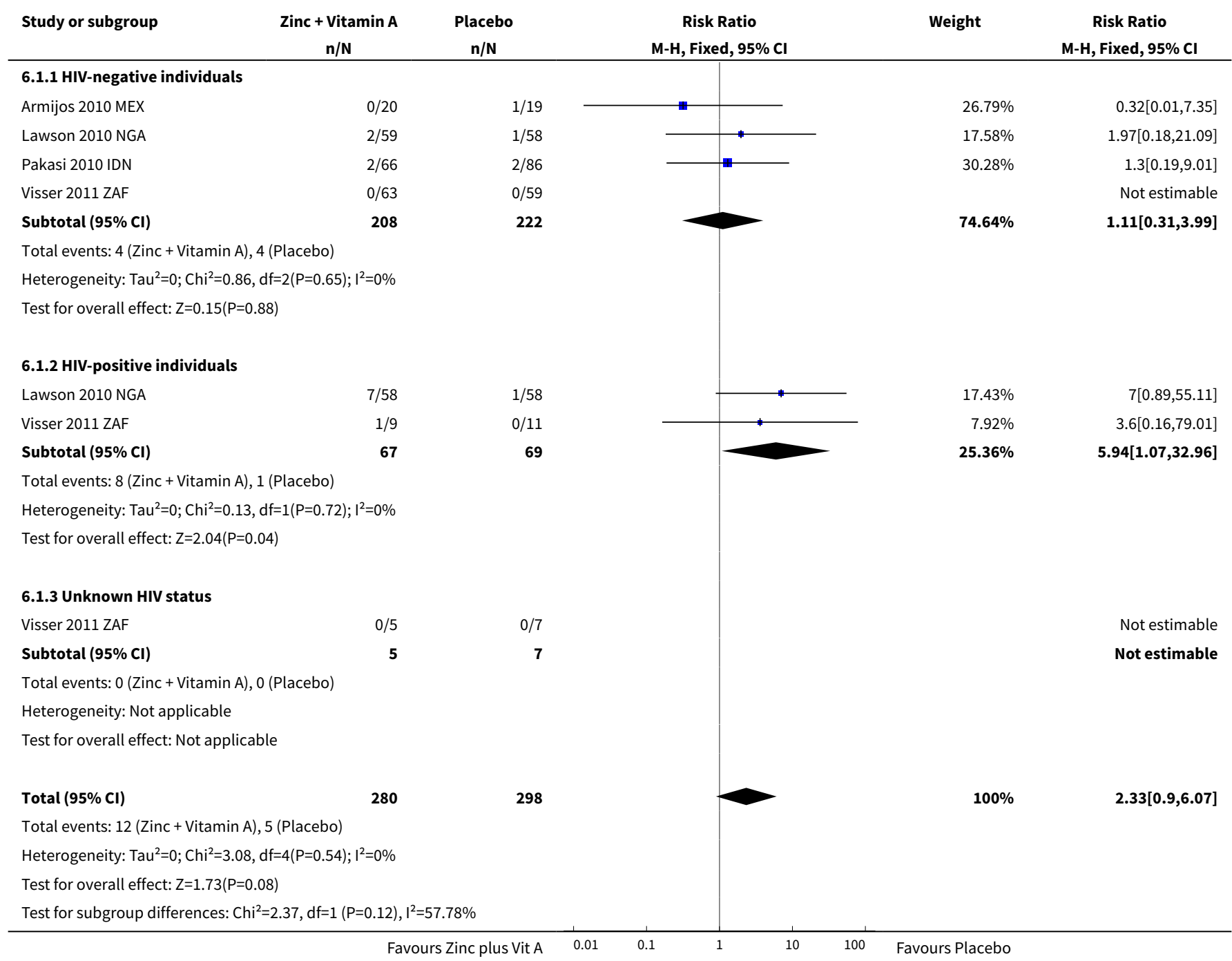


Analysis 6.2. Comparison 6 Zinc plus vitamin A versus placebo, Outcome 2 Treatment completion at 6 months.

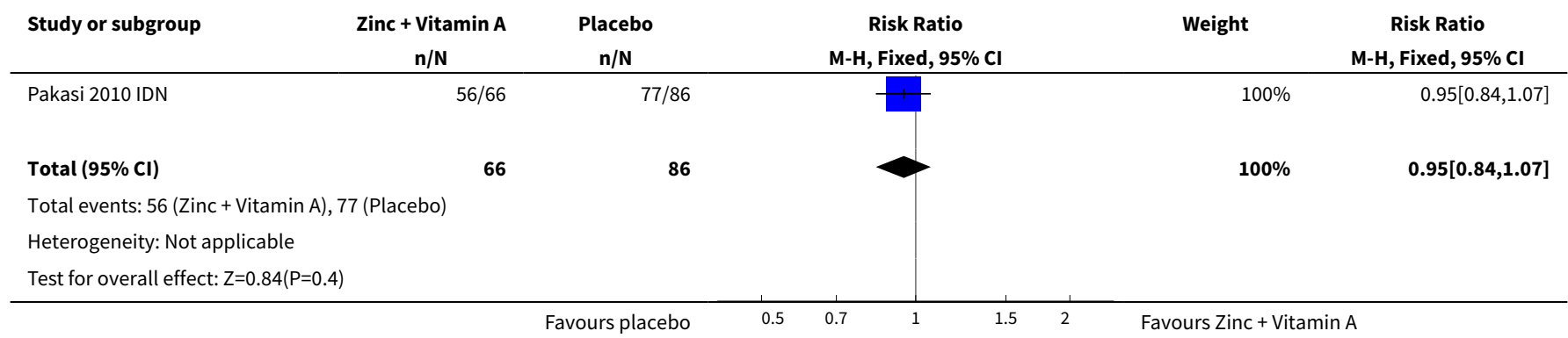

Analysis 6.3. Comparison 6 Zinc plus vitamin A versus placebo, Outcome 3 Sputum-smear and sputum-culture positive during follow-up.

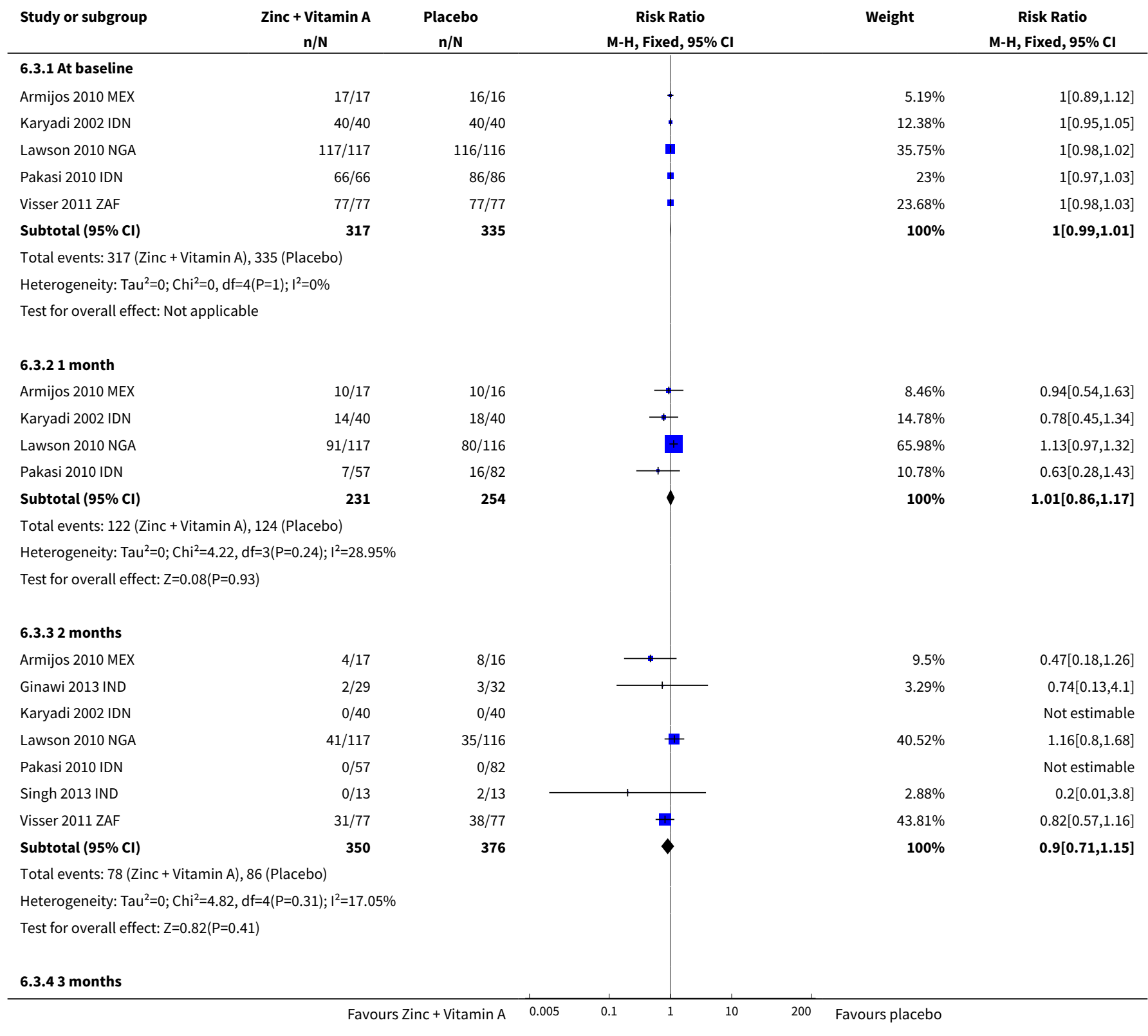

Nutritional supplements for people being treated for active tuberculosis (Review) 


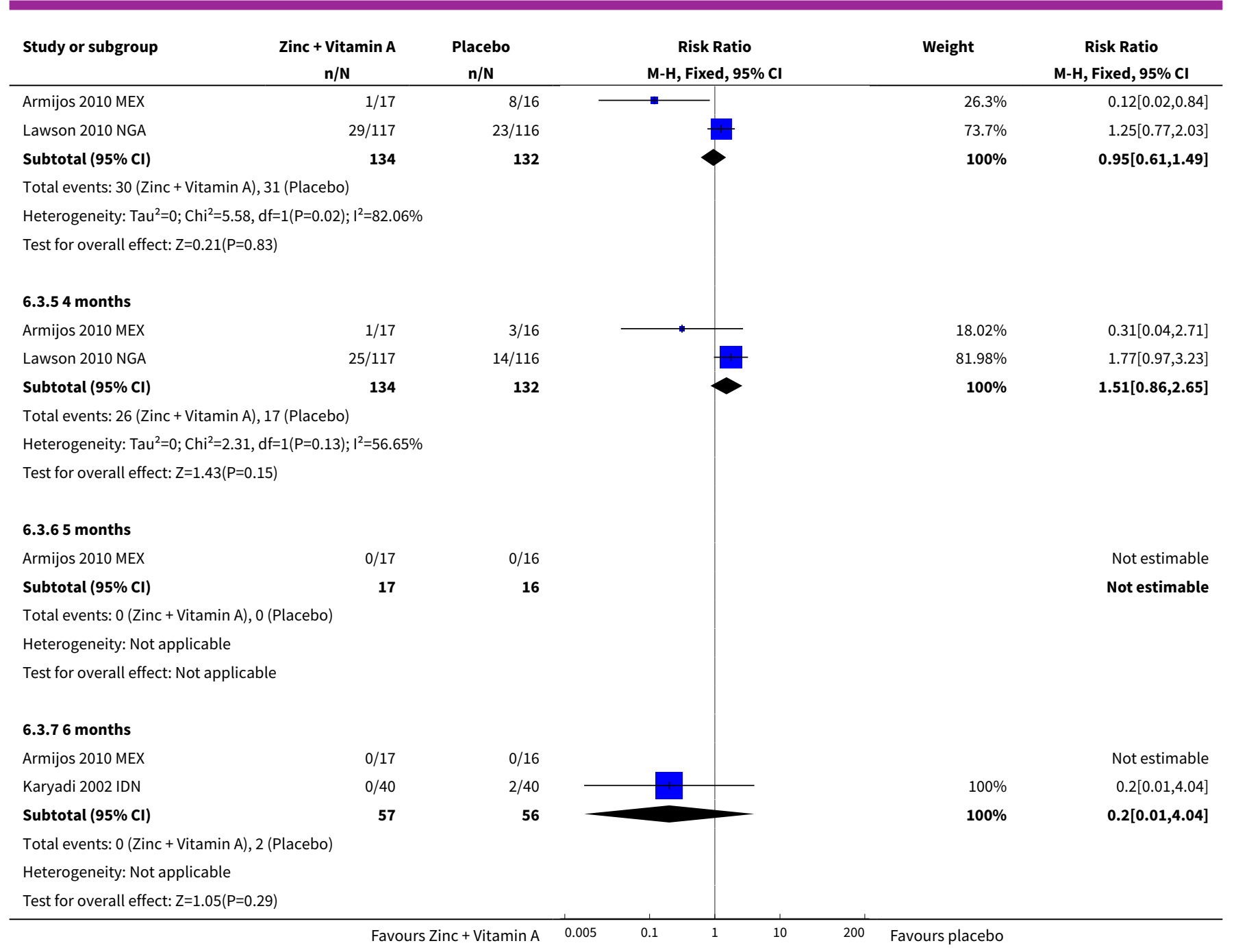

Analysis 6.4. Comparison 6 Zinc plus vitamin A versus placebo, Outcome 4 Body weight (kg).

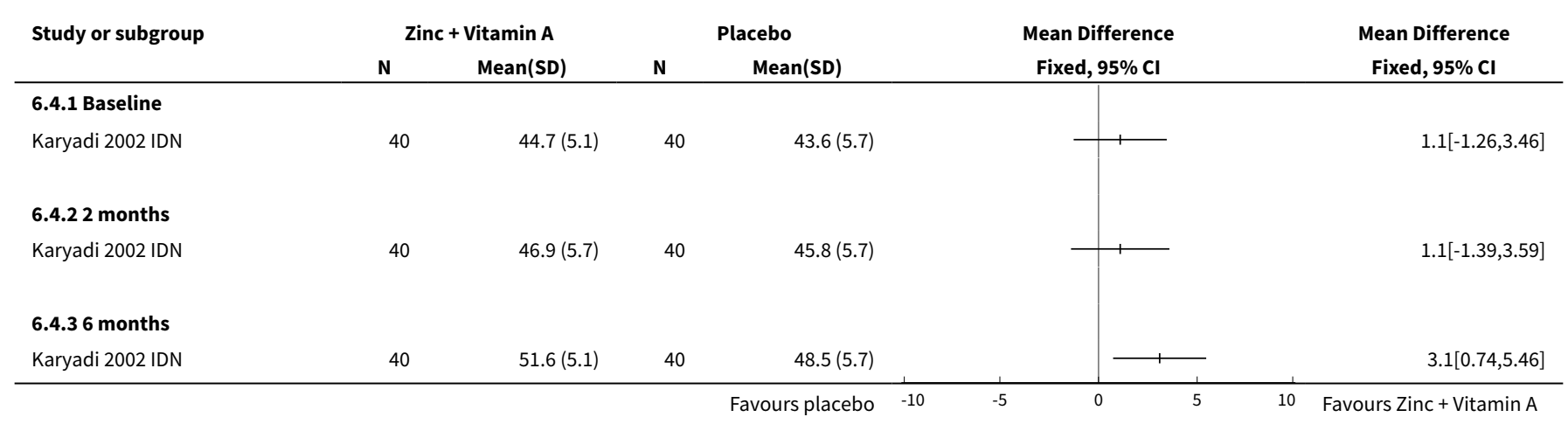


Analysis 6.5. Comparison 6 Zinc plus vitamin A versus placebo, Outcome $5 \mathrm{BMI}\left(\mathrm{kg} / \mathrm{m}^{2}\right)$.

\begin{tabular}{|c|c|c|c|c|c|c|c|}
\hline \multirow{3}{*}{$\begin{array}{l}\text { Study or subgroup } \\
\text { 6.5.1 Baseline }\end{array}$} & \multicolumn{2}{|c|}{ Zinc + Vitamin A } & \multicolumn{2}{|c|}{ Placebo } & \multirow{2}{*}{$\begin{array}{c}\text { Mean Difference } \\
\text { Fixed, } 95 \% \mathrm{Cl}\end{array}$} & \multirow[t]{2}{*}{ Weight } & \multirow{2}{*}{$\begin{array}{c}\text { Mean Difference } \\
\text { Fixed, } 95 \% \mathrm{Cl}\end{array}$} \\
\hline & \multirow[t]{2}{*}{$\mathbf{N}$} & \multirow[t]{2}{*}{ Mean(SD) } & \multirow[t]{2}{*}{$\mathbf{N}$} & \multirow[t]{2}{*}{ Mean(SD) } & & & \\
\hline & & & & & & & \\
\hline Karyadi 2002 IDN & 40 & $17.6(1.9)$ & 40 & $18.1(3.2)$ & & $10.22 \%$ & $-0.5[-1.64,0.64]$ \\
\hline Pakasi 2010 IDN & 66 & $16.6(2.1)$ & 86 & $16.4(2.5)$ & & $24.9 \%$ & $0.2[-0.53,0.93]$ \\
\hline Subtotal $\star \star \star$ & 106 & & 126 & & & $35.12 \%$ & $-0[-0.62,0.61]$ \\
\hline \multicolumn{8}{|c|}{ Heterogeneity: Tau $^{2}=0 ; \mathrm{Chi}^{2}=1.02, \mathrm{df}=1(\mathrm{P}=0.31) ; \mathrm{I}^{2}=2.17 \%$} \\
\hline \multicolumn{8}{|l|}{ 6.5.2 2 months } \\
\hline Karyadi 2002 IDN & 40 & $18.4(1.9)$ & 40 & $19(3.2)$ & & $10.22 \%$ & $-0.6[-1.74,0.54]$ \\
\hline Pakasi 2010 IDN & 57 & $17.7(2)$ & 82 & $17.5(2.4)$ & & $24.74 \%$ & $0.2[-0.53,0.93]$ \\
\hline Subtotal $\star \star \star$ & 97 & & 122 & & & $34.96 \%$ & $-0.03[-0.65,0.58]$ \\
\hline \multicolumn{8}{|c|}{ Heterogeneity: $\operatorname{Tau}^{2}=0 ; \mathrm{Chi}^{2}=1.33, \mathrm{df}=1(\mathrm{P}=0.25) ; \mathrm{I}^{2}=24.95 \%$} \\
\hline \multicolumn{8}{|l|}{ 6.5.3 6 months } \\
\hline Karyadi 2002 IDN & 40 & $19.4(2.5)$ & 40 & $20(3.2)$ & & $8.48 \%$ & $-0.6[-1.85,0.65]$ \\
\hline Pakasi 2010 IDN & 56 & $18.3(2)$ & 77 & $18.4(2.6)$ & & $21.44 \%$ & $-0.1[-0.89,0.69]$ \\
\hline Subtotal $\star \star \star ~$ & 96 & & 117 & & & $29.92 \%$ & $-0.24[-0.91,0.43]$ \\
\hline \multicolumn{8}{|c|}{ Heterogeneity: $\operatorname{Tau}^{2}=0 ; \mathrm{Chi}^{2}=0.44, \mathrm{df}=1(\mathrm{P}=0.51) ; \mathrm{I}^{2}=0 \%$} \\
\hline \multicolumn{8}{|c|}{ Test for overall effect: $Z=0.71(P=0.48)$} \\
\hline Total *** & 299 & & 365 & & & $100 \%$ & $-0.09[-0.45,0.28]$ \\
\hline \multicolumn{8}{|c|}{ Heterogeneity: $\mathrm{Tau}^{2}=0 ; \mathrm{Chi}^{2}=3.1, \mathrm{df}=5(\mathrm{P}=0.69) ; \mathrm{I}^{2}=0 \%$} \\
\hline \multicolumn{8}{|c|}{ Test for overall effect: $Z=0.46(P=0.65)$} \\
\hline Test for subgroup dif & $3, \mathrm{df}=1$ & $=0.86), I^{2}=0 \%$ & & & & & \\
\hline
\end{tabular}

Analysis 6.6. Comparison 6 Zinc plus vitamin A versus placebo, Outcome 6 Mid upper arm circumference (cm).

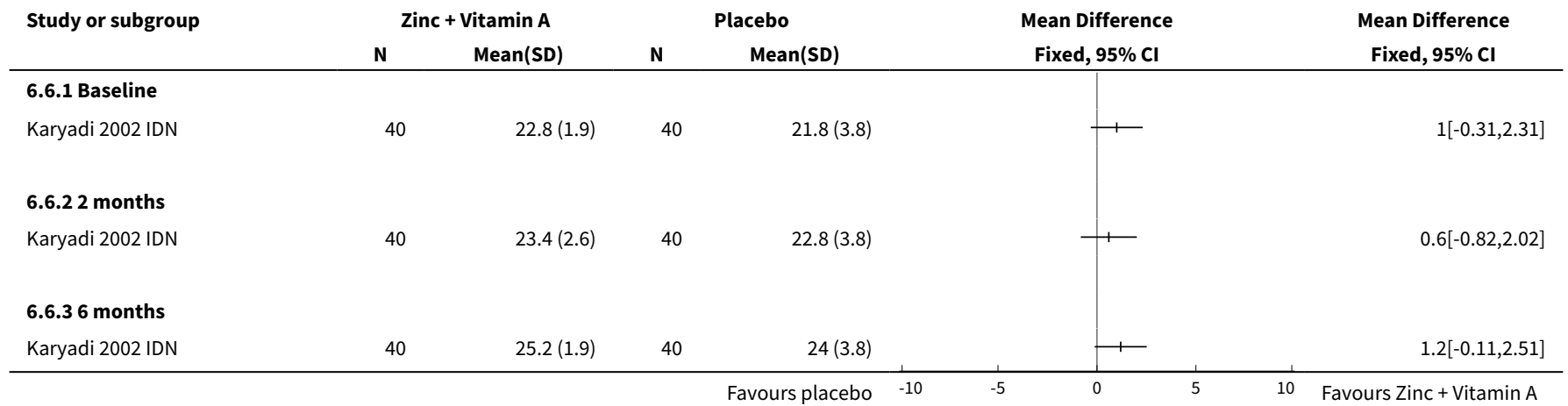


Analysis 6.7. Comparison 6 Zinc plus vitamin A versus placebo, Outcome 7 Biceps skinfold thickness (mm).

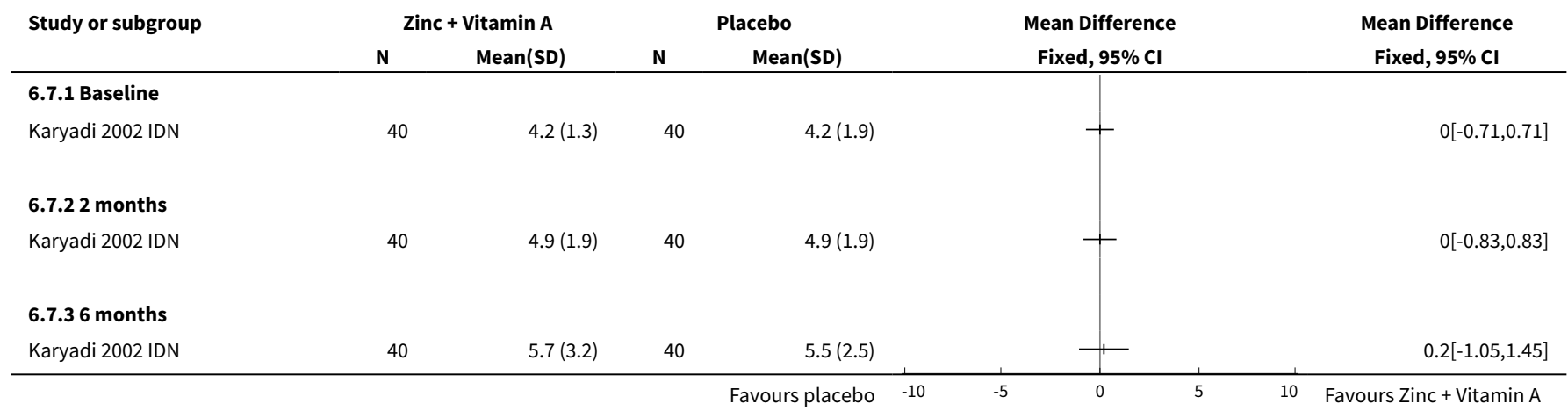

Analysis 6.8. Comparison 6 Zinc plus vitamin A versus placebo, Outcome 8 Triceps skinfold thickness (mm).

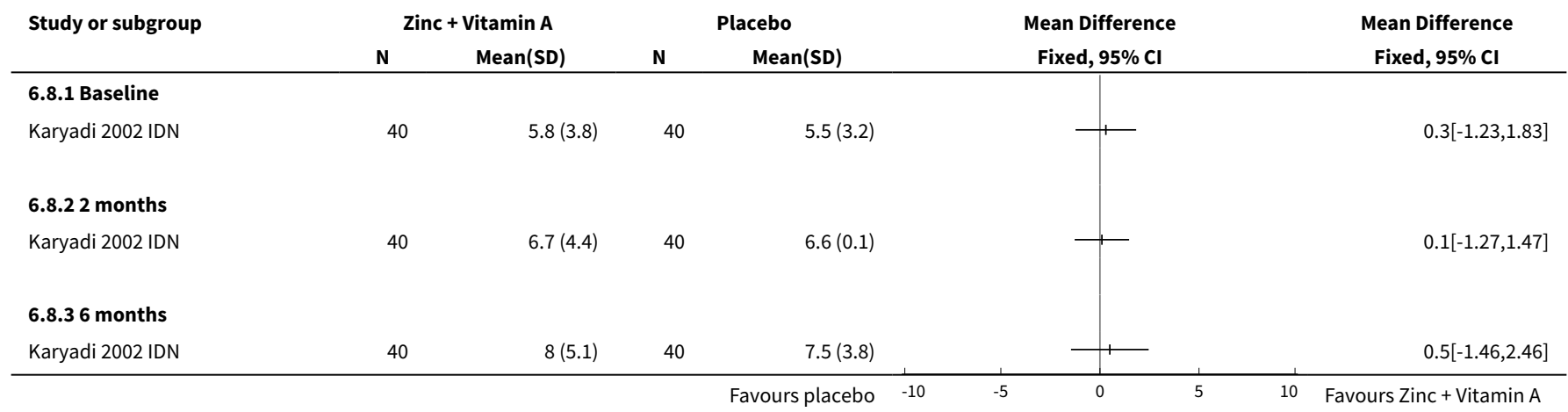

Analysis 6.9. Comparison 6 Zinc plus vitamin A versus placebo, Outcome 9 Subscapular skinfold thickness (mm).

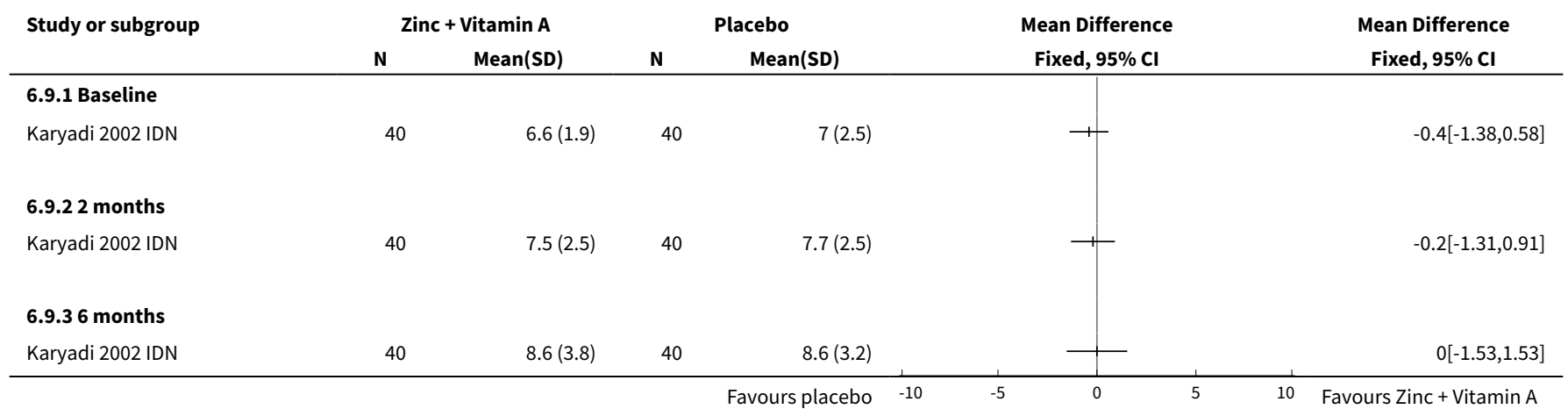

Analysis 6.10. Comparison 6 Zinc plus vitamin A versus placebo, Outcome 10 Suprailiac skinfold thickness (mm).

\begin{tabular}{|c|c|c|c|c|c|c|c|}
\hline \multirow[t]{2}{*}{ Study or subgroup } & Zinc + Vitamin A & \multicolumn{2}{|c|}{ Placebo } & \multirow{2}{*}{\multicolumn{2}{|c|}{$\begin{array}{c}\text { Mean Difference } \\
\text { Fixed, } 95 \% \mathrm{Cl}\end{array}$}} & & \multirow{2}{*}{$\begin{array}{c}\text { Mean Difference } \\
\text { Fixed, } 95 \% \mathrm{Cl}\end{array}$} \\
\hline & Mean(SD) & $\mathbf{N}$ & Mean(SD) & & & & \\
\hline \multicolumn{8}{|l|}{ 6.10.1 Baseline } \\
\hline
\end{tabular}




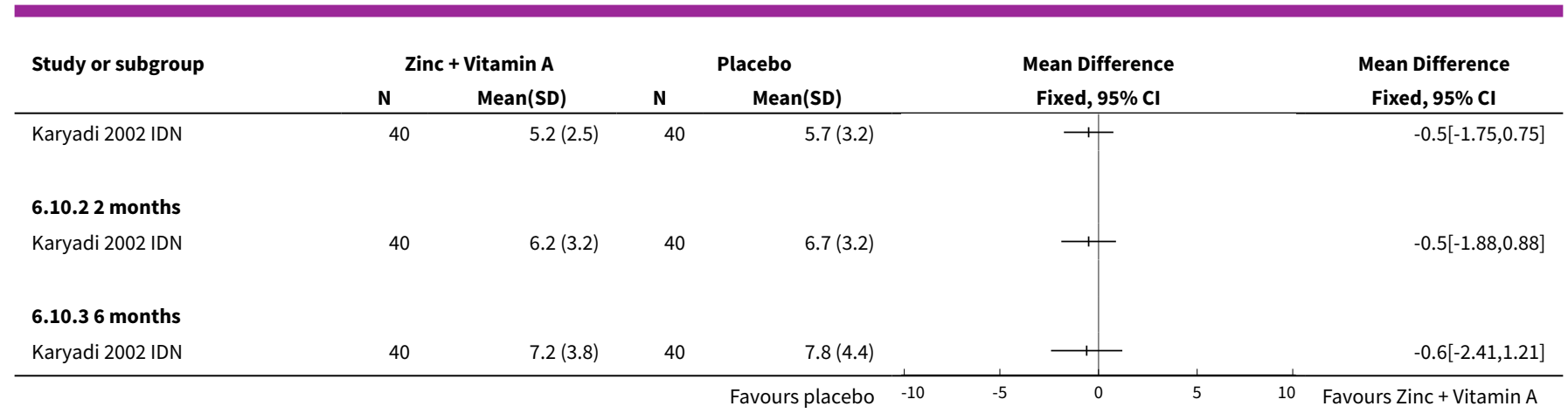

Analysis 6.11. Comparison 6 Zinc plus vitamin A versus placebo, Outcome 11 Body fat (\%).

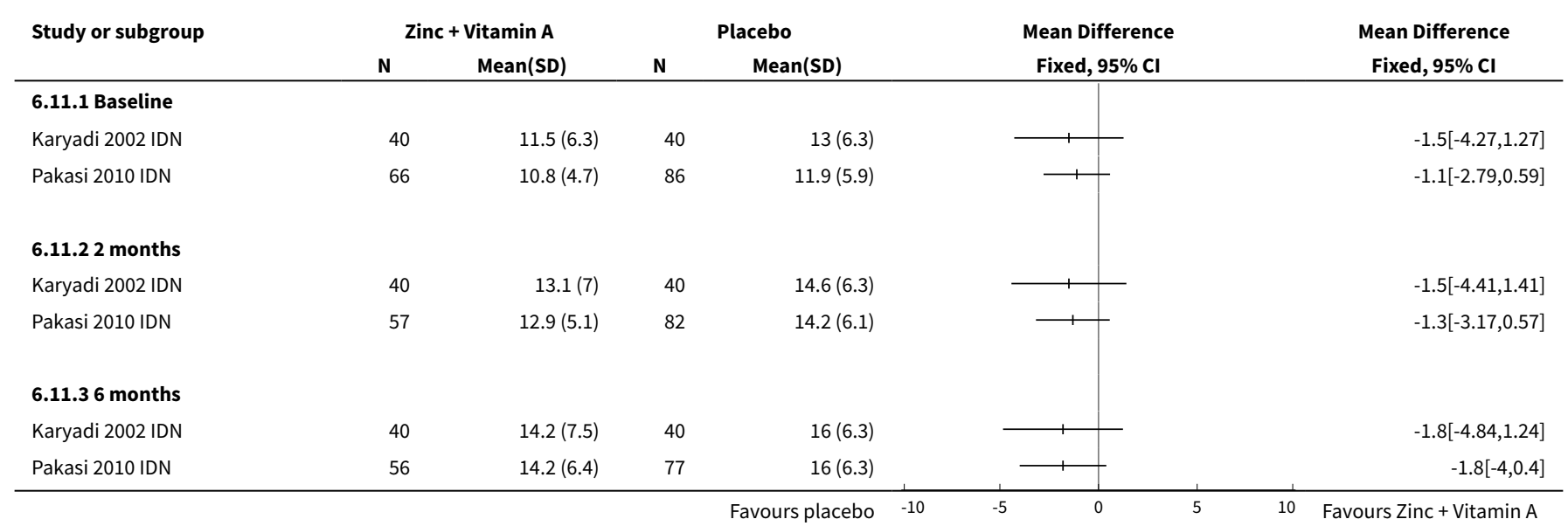

Analysis 6.12. Comparison 6 Zinc plus vitamin A versus placebo, Outcome 12 Fat mass (kg).

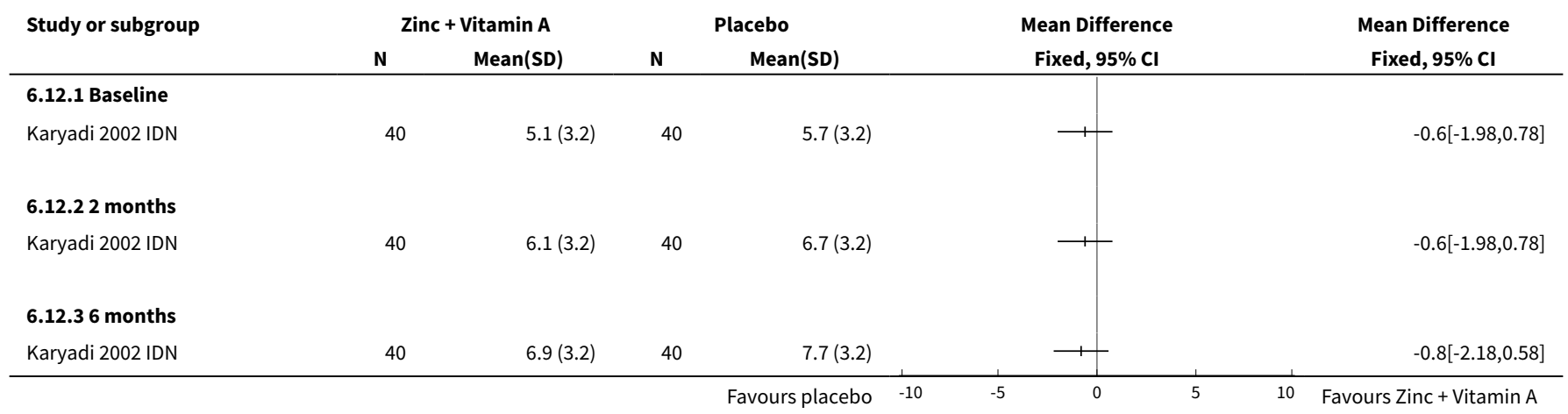


Analysis 6.13. Comparison 6 Zinc plus vitamin A versus placebo, Outcome 13 Karnofsky score.

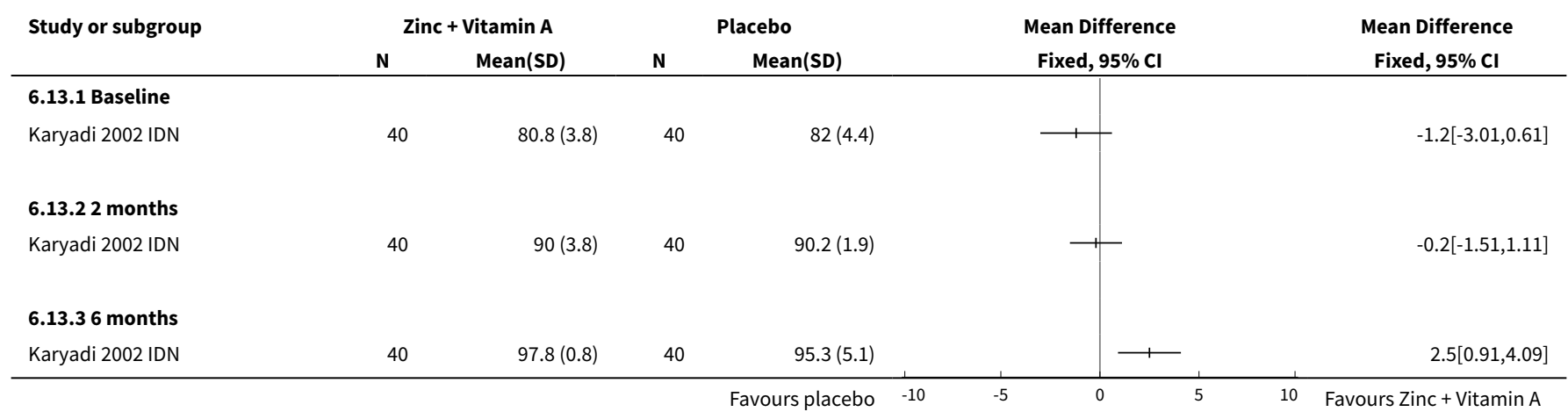

\section{Comparison 7. Vitamin D versus placebo or no supplement}

\begin{tabular}{|c|c|c|c|c|}
\hline $\begin{array}{l}\text { Outcome or subgroup } \\
\text { title }\end{array}$ & No. of studies & $\begin{array}{l}\text { No. of partici- } \\
\text { pants }\end{array}$ & Statistical method & Effect size \\
\hline $\begin{array}{l}1 \text { Serum vitamin D levels } \\
(\mathrm{nmol} / \mathrm{L})\end{array}$ & 5 & & Mean Difference (IV, Random, 95\% CI) & Subtotals only \\
\hline 1.1 At baseline & 5 & 894 & Mean Difference (IV, Random, 95\% CI) & $-0.10[-3.01,2.82]$ \\
\hline 1.2 At 8 weeks & 3 & 460 & Mean Difference (IV, Random, 95\% CI) & $33.68[3.99,63.37]$ \\
\hline 1.3 At 6 to 8 months & 2 & 376 & Mean Difference (IV, Random, 95\% CI) & $7.90[0.52,15.28]$ \\
\hline $\begin{array}{l}2 \text { Death during follow-up } \\
\text { ( } 2 \text { to } 12 \text { months) }\end{array}$ & 7 & 2649 & Risk Ratio (M-H, Fixed, 95\% Cl) & $0.96[0.81,1.12]$ \\
\hline 2.1 Vitamin D alone & 4 & 814 & Risk Ratio (M-H, Fixed, 95\% Cl) & $1.26[0.79,2.02]$ \\
\hline $\begin{array}{l}2.2 \text { Vitamin D plus argi- } \\
\text { nine }\end{array}$ & 1 & 75 & Risk Ratio (M-H, Fixed, 95\% Cl) & $1.53[0.06,36.25]$ \\
\hline $\begin{array}{l}2.3 \text { Vitamin } D \text { as part of a } \\
\text { multi-micronutrient sup- } \\
\text { plement }\end{array}$ & 3 & 1760 & Risk Ratio (M-H, Fixed, 95\% Cl) & $0.91[0.77,1.08]$ \\
\hline $\begin{array}{l}3 \text { Death during follow-up } \\
\text { ( } 2 \text { to } 12 \text { months) }\end{array}$ & 7 & 2649 & Risk Ratio (M-H, Fixed, 95\% Cl) & $0.97[0.83,1.13]$ \\
\hline $\begin{array}{l}3.1 \text { HIV-positive individu- } \\
\text { als }\end{array}$ & 3 & 1089 & Risk Ratio (M-H, Fixed, 95\% Cl) & $0.93[0.80,1.09]$ \\
\hline $\begin{array}{l}3.2 \text { HIV-negative individ- } \\
\text { uals }\end{array}$ & 6 & 1403 & Risk Ratio (M-H, Fixed, 95\% Cl) & $1.26[0.72,2.21]$ \\
\hline $\begin{array}{l}\text { 3.3 HIV status mixed or } \\
\text { unknown }\end{array}$ & 2 & 157 & Risk Ratio (M-H, Fixed, 95\% Cl) & $1.5[0.30,7.38]$ \\
\hline 4 Cure at 6 months & 1 & 151 & Risk Ratio (M-H, Fixed, 95\% Cl) & $0.99[0.75,1.31]$ \\
\hline 5 Tuberculosis score & 1 & 1142 & Mean Difference (IV, Fixed, 95\% CI) & $-0.13[-0.32,0.06]$ \\
\hline
\end{tabular}

Nutritional supplements for people being treated for active tuberculosis (Review) 


\begin{tabular}{|c|c|c|c|c|}
\hline $\begin{array}{l}\text { Outcome or subgroup } \\
\text { title }\end{array}$ & No. of studies & $\begin{array}{l}\text { No. of partici- } \\
\text { pants }\end{array}$ & Statistical method & Effect size \\
\hline 5.1 At baseline & 1 & 348 & Mean Difference (IV, Fixed, 95\% CI) & $-0.10[-0.52,0.31]$ \\
\hline 5.22 months & 1 & 297 & Mean Difference (IV, Fixed, 95\% CI) & $-0.02[-0.47,0.42]$ \\
\hline 5.35 months & 1 & 271 & Mean Difference (IV, Fixed, 95\% CI) & $-0.16[-0.51,0.19]$ \\
\hline 5.48 months & 1 & 226 & Mean Difference (IV, Fixed, 95\% CI) & $-0.19[-0.52,0.14]$ \\
\hline $\begin{array}{l}6 \text { Sputum-smear or spu- } \\
\text { tum-culture positive }\end{array}$ & 7 & & Risk Ratio (M-H, Fixed, 95\% Cl) & Subtotals only \\
\hline 6.1 At baseline & 5 & 1022 & Risk Ratio (M-H, Fixed, 95\% Cl) & $0.97[0.92,1.03]$ \\
\hline 6.24 weeks & 5 & 929 & Risk Ratio (M-H, Fixed, 95\% Cl) & $0.87[0.74,1.03]$ \\
\hline 6.36 weeks & 4 & 656 & Risk Ratio (M-H, Fixed, 95\% Cl) & $0.76[0.55,1.03]$ \\
\hline 6.48 weeks & 6 & 856 & Risk Ratio (M-H, Fixed, 95\% Cl) & $0.81[0.54,1.20]$ \\
\hline 6.55 months & 1 & 148 & Risk Ratio (M-H, Fixed, 95\% Cl) & $3.0[0.32,28.18]$ \\
\hline 6.66 months & 1 & 247 & Risk Ratio (M-H, Fixed, 95\% Cl) & $0.74[0.37,1.47]$ \\
\hline 6.78 months & 1 & 147 & Risk Ratio (M-H, Fixed, 95\% Cl) & $0.0[0.0,0.0]$ \\
\hline 7 Body mass index & 4 & & Mean Difference (IV, Fixed, 95\% CI) & Subtotals only \\
\hline 7.1 At baseline & 4 & 464 & Mean Difference (IV, Fixed, 95\% CI) & $-0.20[-0.71,0.30]$ \\
\hline 7.2 At 6 to 8 weeks & 4 & 430 & Mean Difference (IV, Fixed, 95\% CI) & $-0.19[-0.70,0.32]$ \\
\hline 8 Body weight (kg) & 2 & & Mean Difference (IV, Fixed, 95\% CI) & Subtotals only \\
\hline 8.1 Before treatment & 2 & 150 & Mean Difference (IV, Fixed, 95\% CI) & $0.20[-2.43,2.83]$ \\
\hline 8.2 At 8 weeks & 2 & 150 & Mean Difference (IV, Fixed, 95\% CI) & $1.08[-1.61,3.77]$ \\
\hline $\begin{array}{l}9 \text { Karnofsky score at } 8 \\
\text { weeks }\end{array}$ & 1 & & Mean Difference (IV, Fixed, 95\% CI) & Subtotals only \\
\hline 9.1 At baseline & 1 & 247 & Mean Difference (IV, Fixed, 95\% CI) & $-1.47[-3.42,0.48]$ \\
\hline 9.2 At 8 weeks & 1 & 212 & Mean Difference (IV, Fixed, 95\% CI) & $0.85[-1.33,3.03]$ \\
\hline
\end{tabular}

Analysis 7.1. Comparison 7 Vitamin D versus placebo or no supplement, Outcome 1 Serum vitamin D levels (nmol/L).

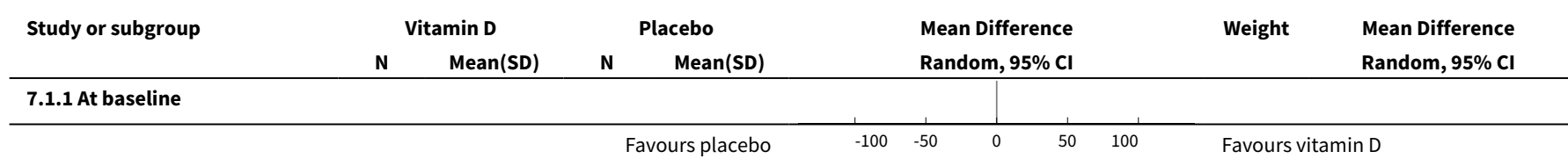




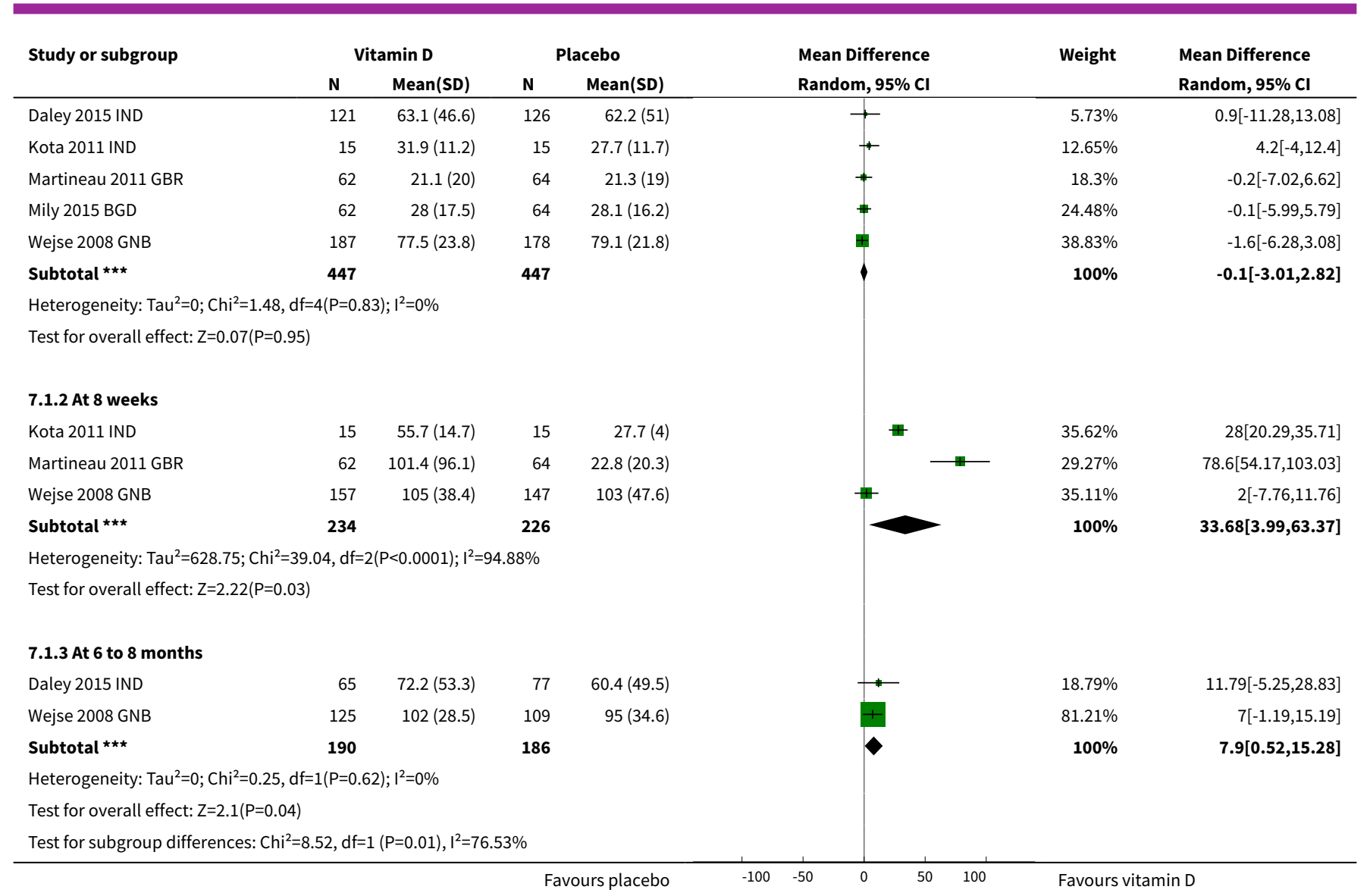

Analysis 7.2. Comparison 7 Vitamin D versus placebo or no supplement, Outcome 2 Death during follow-up (2 to 12 months).

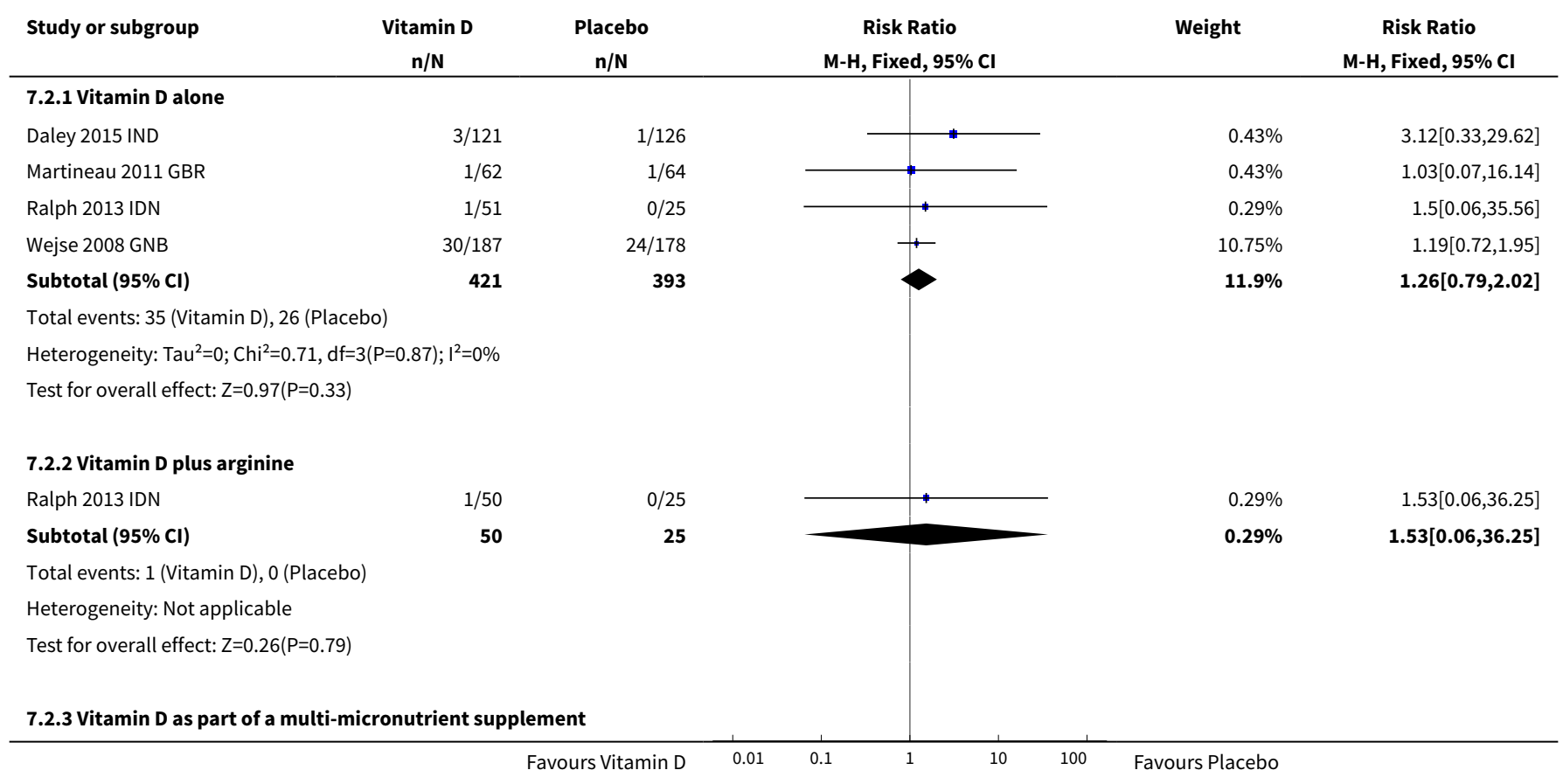

Nutritional supplements for people being treated for active tuberculosis (Review) 


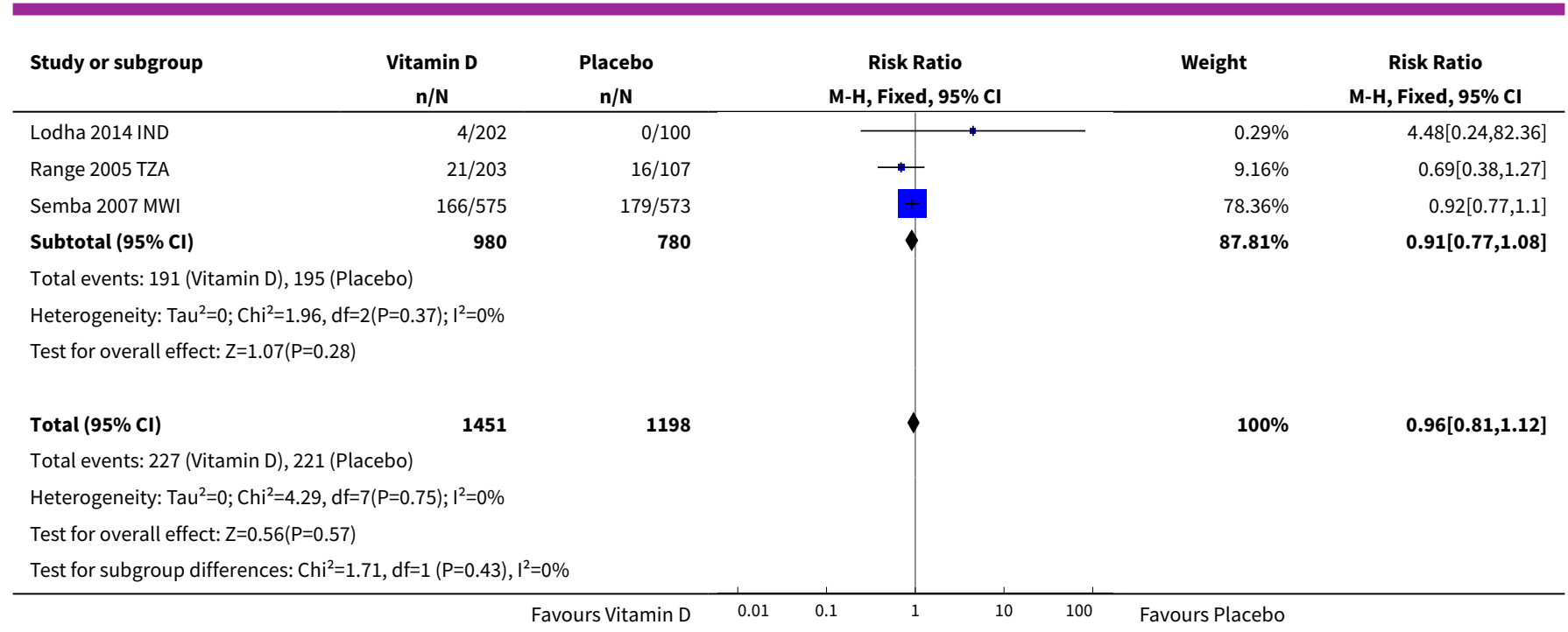

Analysis 7.3. Comparison 7 Vitamin $D$ versus placebo or no supplement, Outcome 3 Death during follow-up (2 to 12 months).

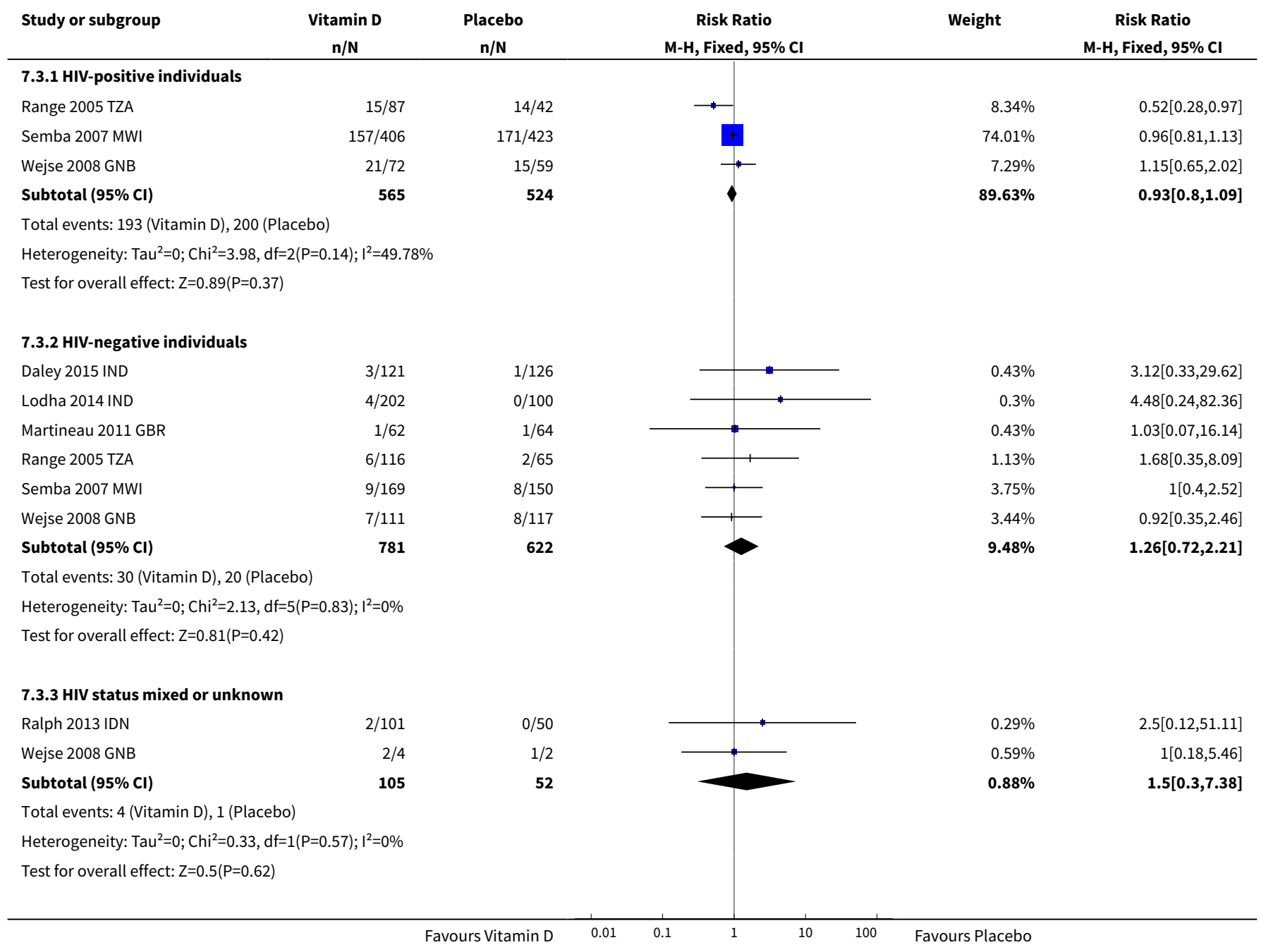

Nutritional supplements for people being treated for active tuberculosis (Review) 


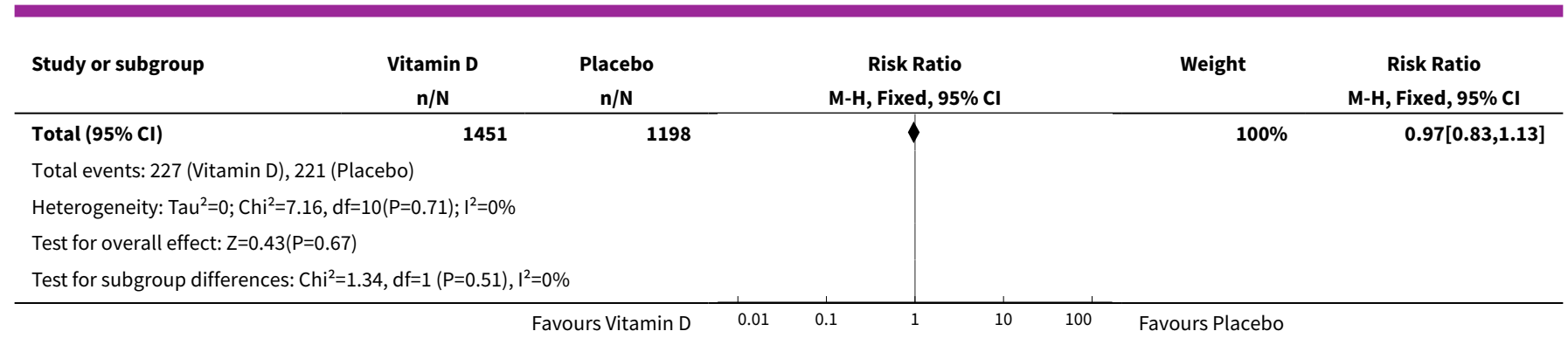

Analysis 7.4. Comparison 7 Vitamin D versus placebo or no supplement, Outcome 4 Cure at 6 months.

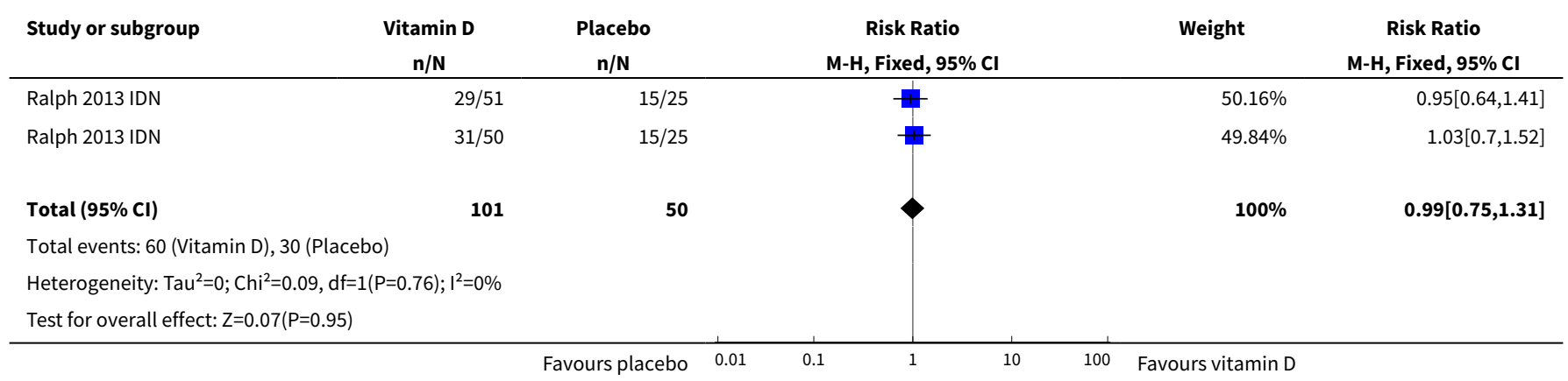

\section{Analysis 7.5. Comparison 7 Vitamin D versus placebo or no supplement, Outcome 5 Tuberculosis score.}

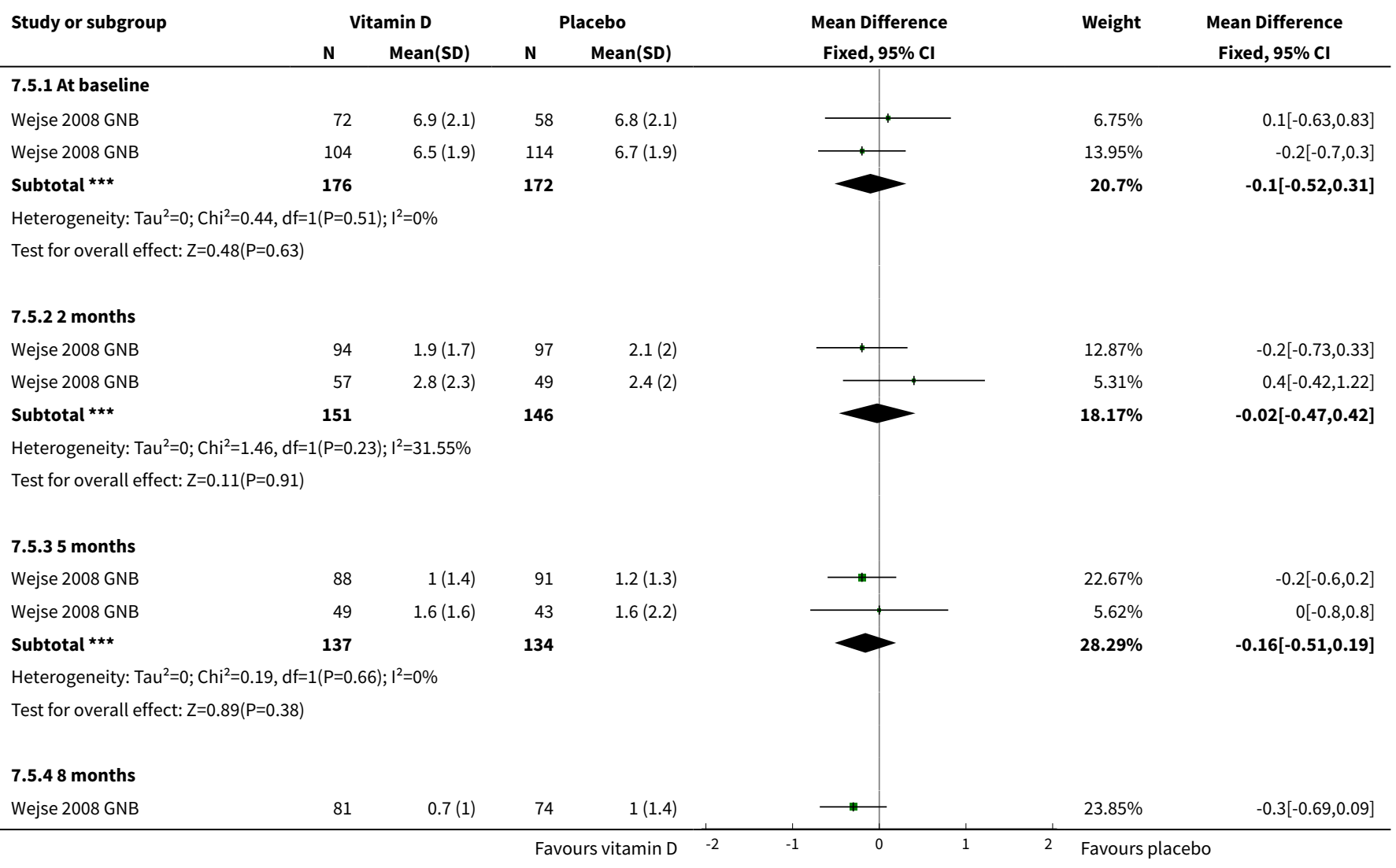




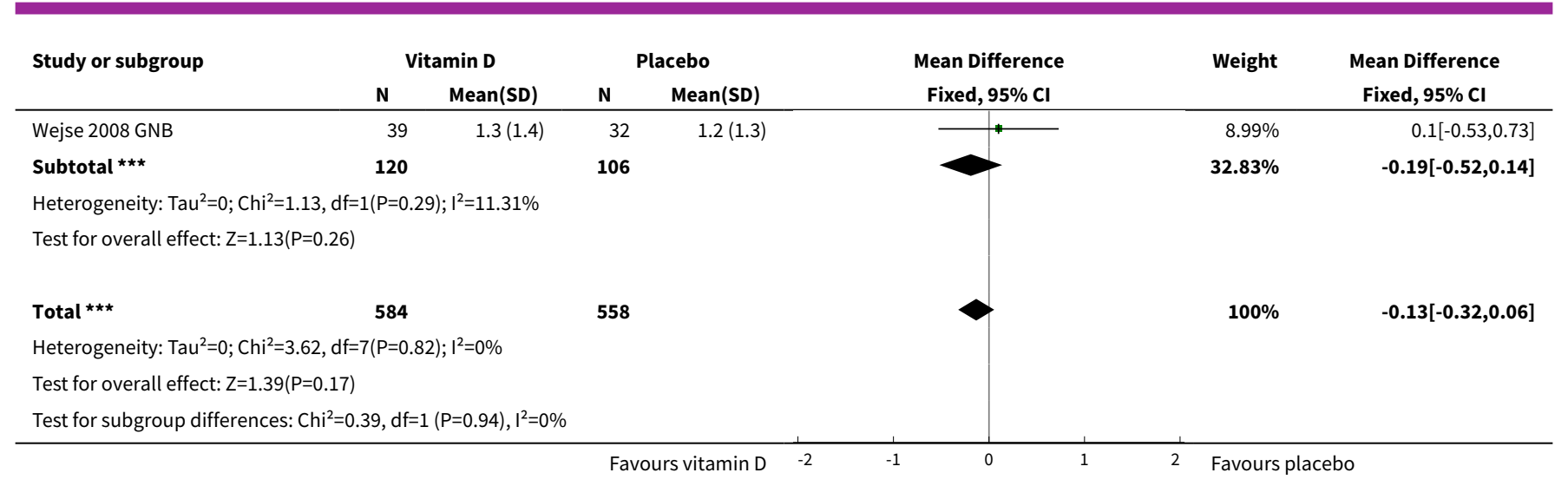

Analysis 7.6. Comparison 7 Vitamin $D$ versus placebo or no supplement, Outcome 6 Sputum-smear or sputum-culture positive.

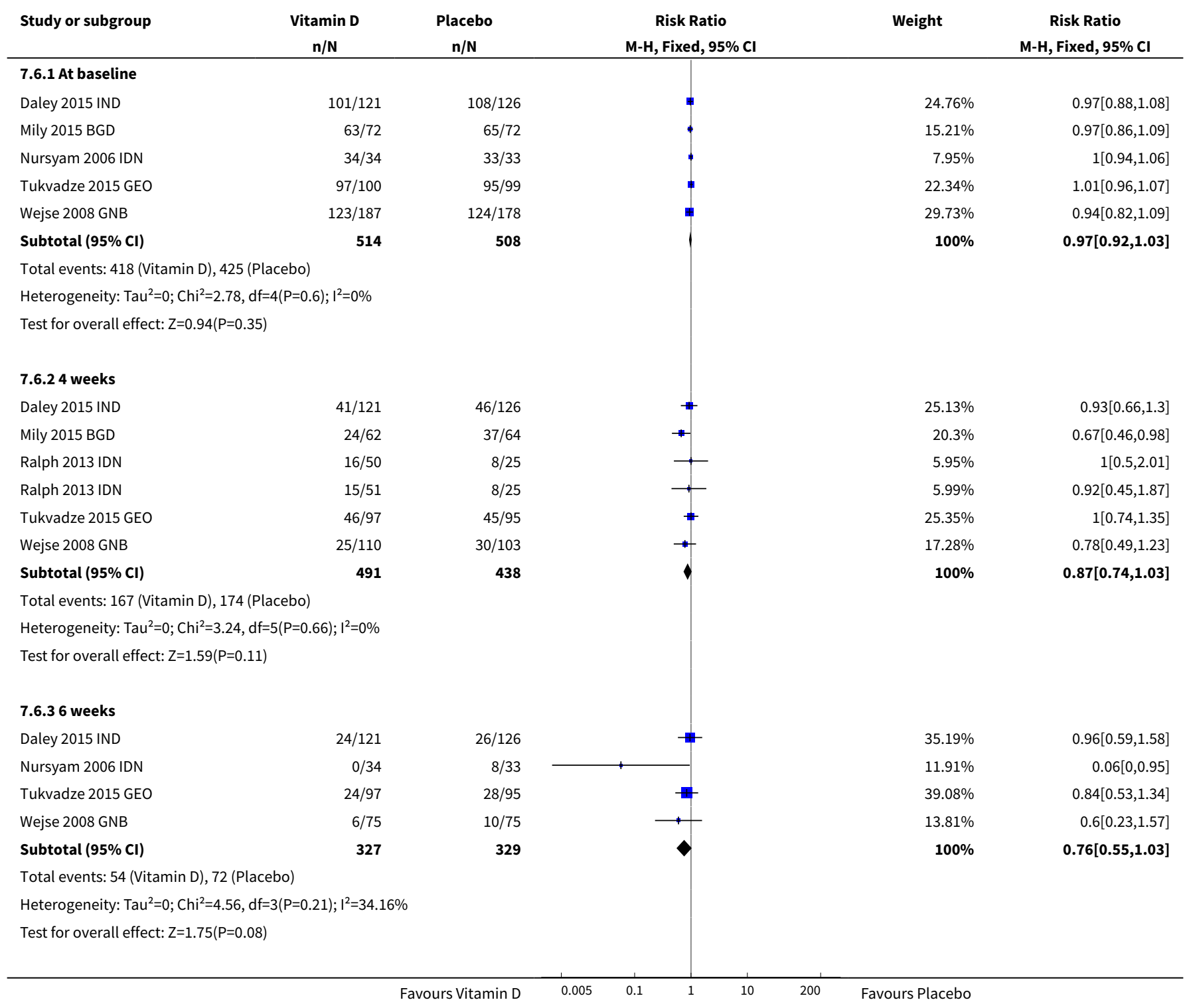

Nutritional supplements for people being treated for active tuberculosis (Review) 


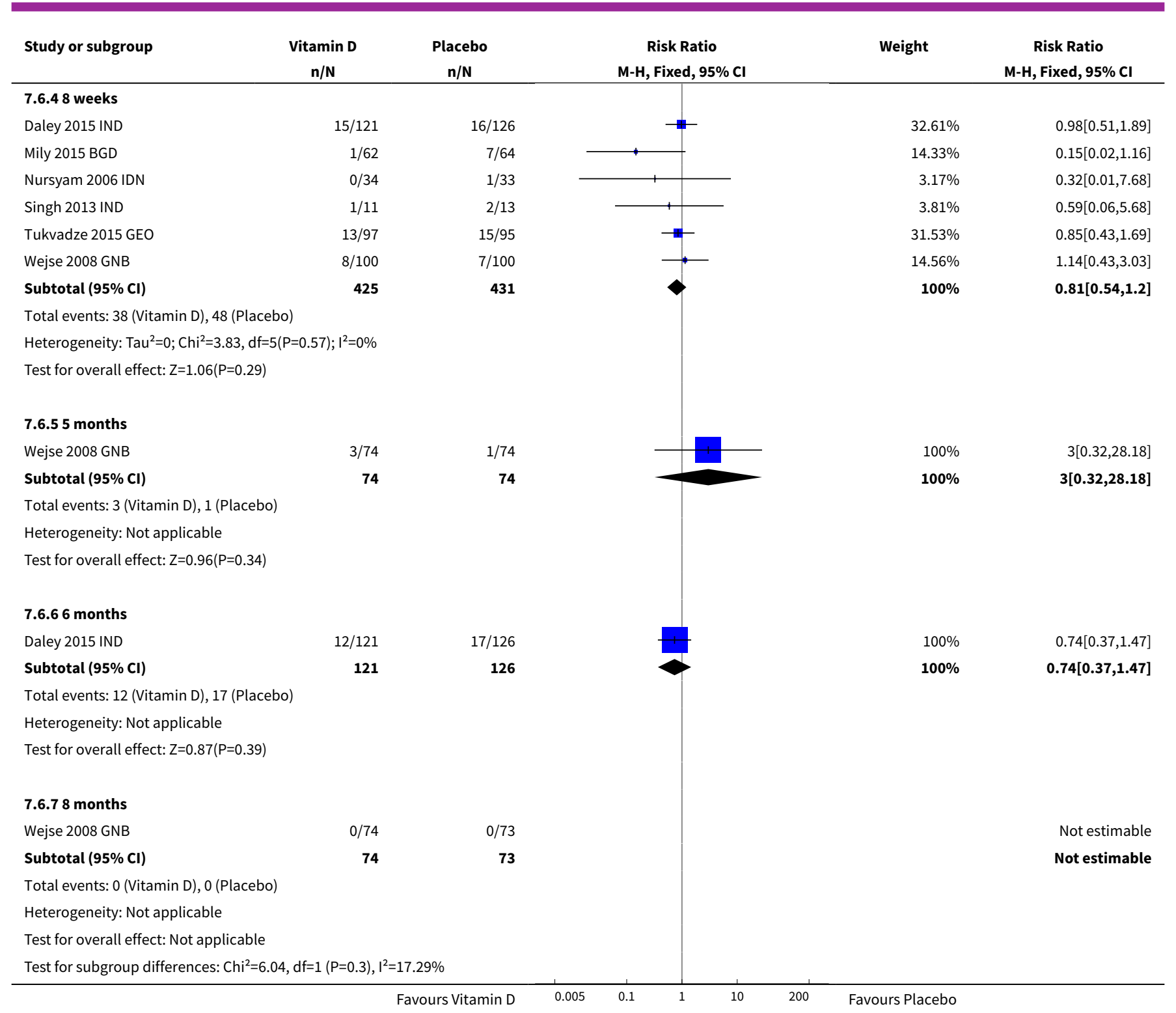

Analysis 7.7. Comparison 7 Vitamin $D$ versus placebo or no supplement, Outcome 7 Body mass index.

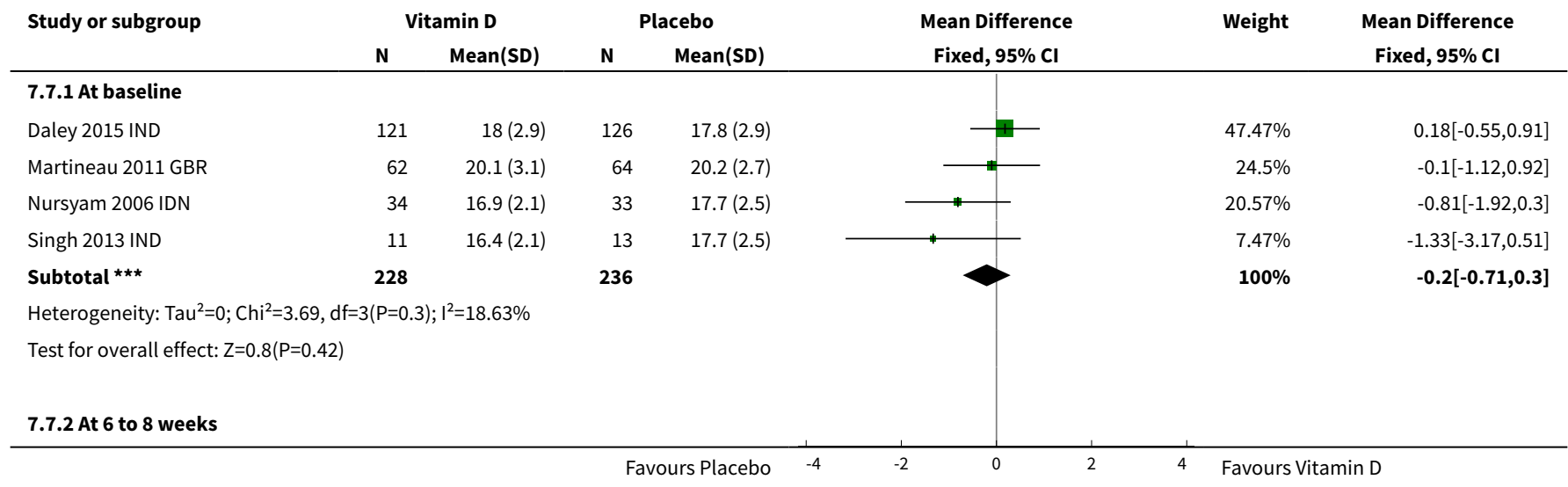

Nutritional supplements for people being treated for active tuberculosis (Review) 


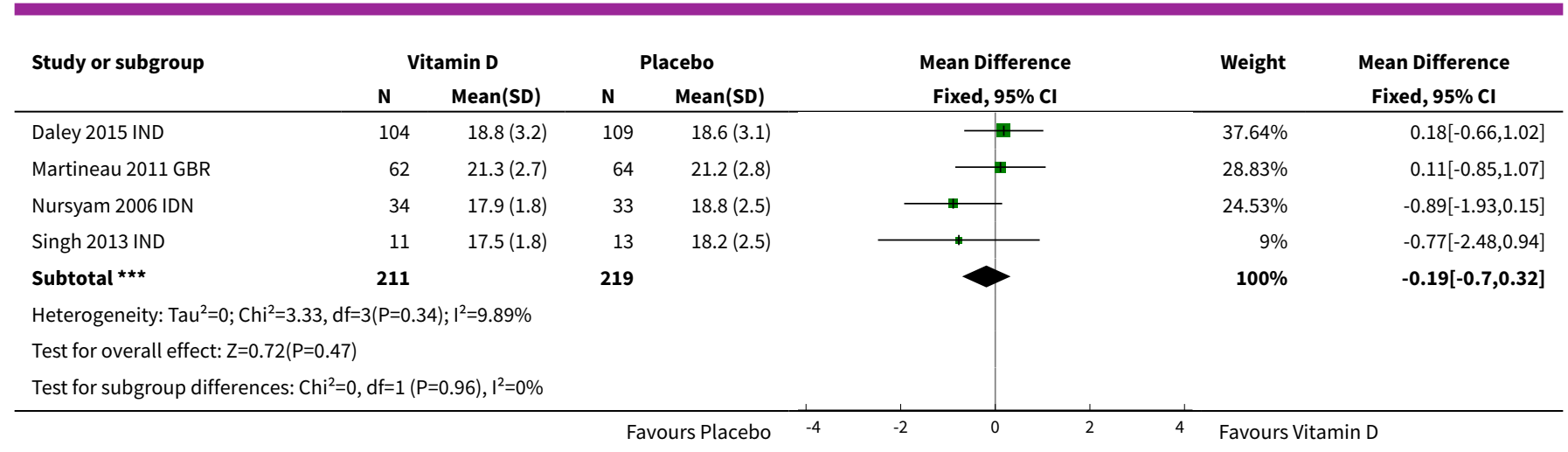

Analysis 7.8. Comparison 7 Vitamin D versus placebo or no supplement, Outcome 8 Body weight (kg).

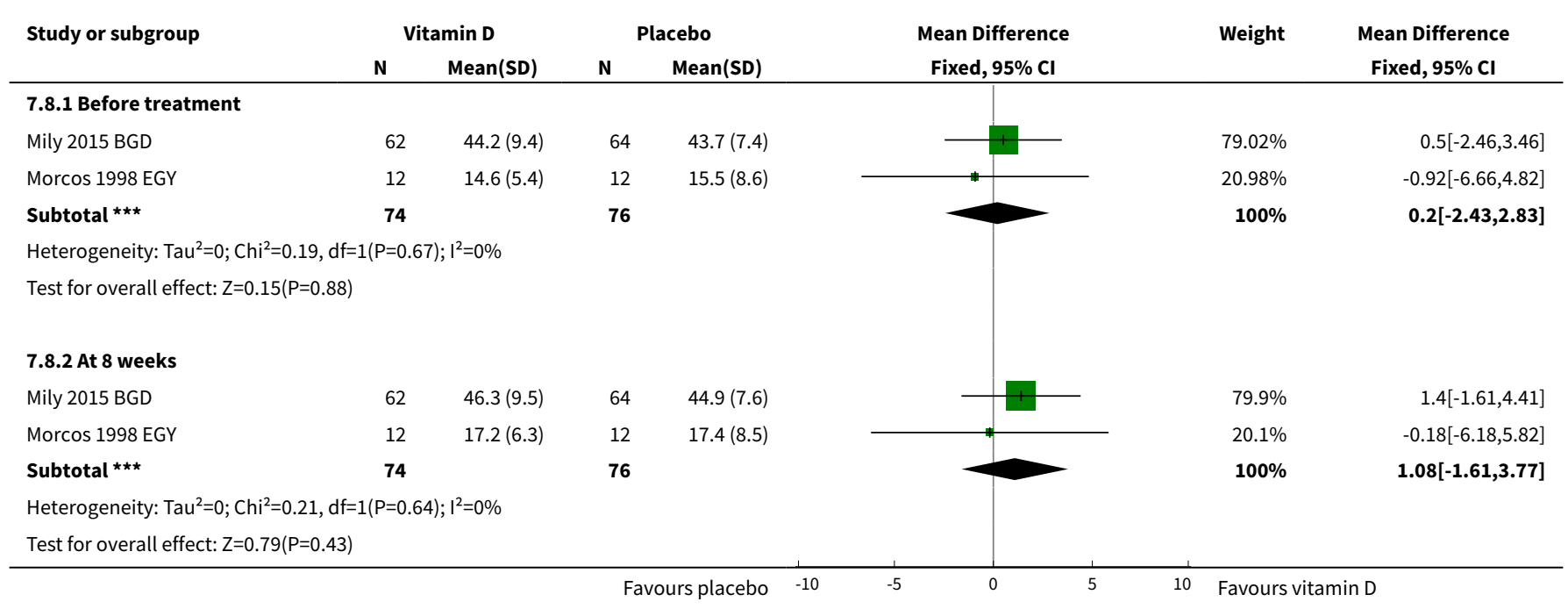

Analysis 7.9. Comparison 7 Vitamin D versus placebo or no supplement, Outcome 9 Karnofsky score at 8 weeks.

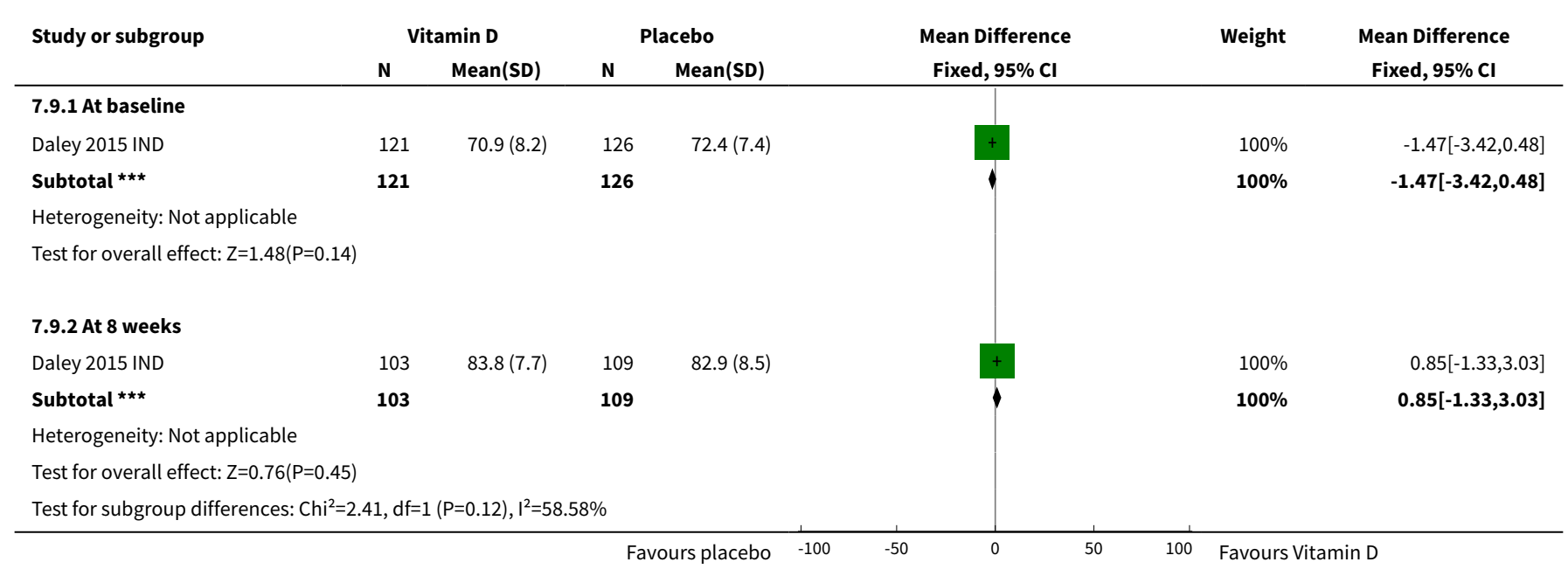




\section{Comparison 8. Arginine versus placebo}

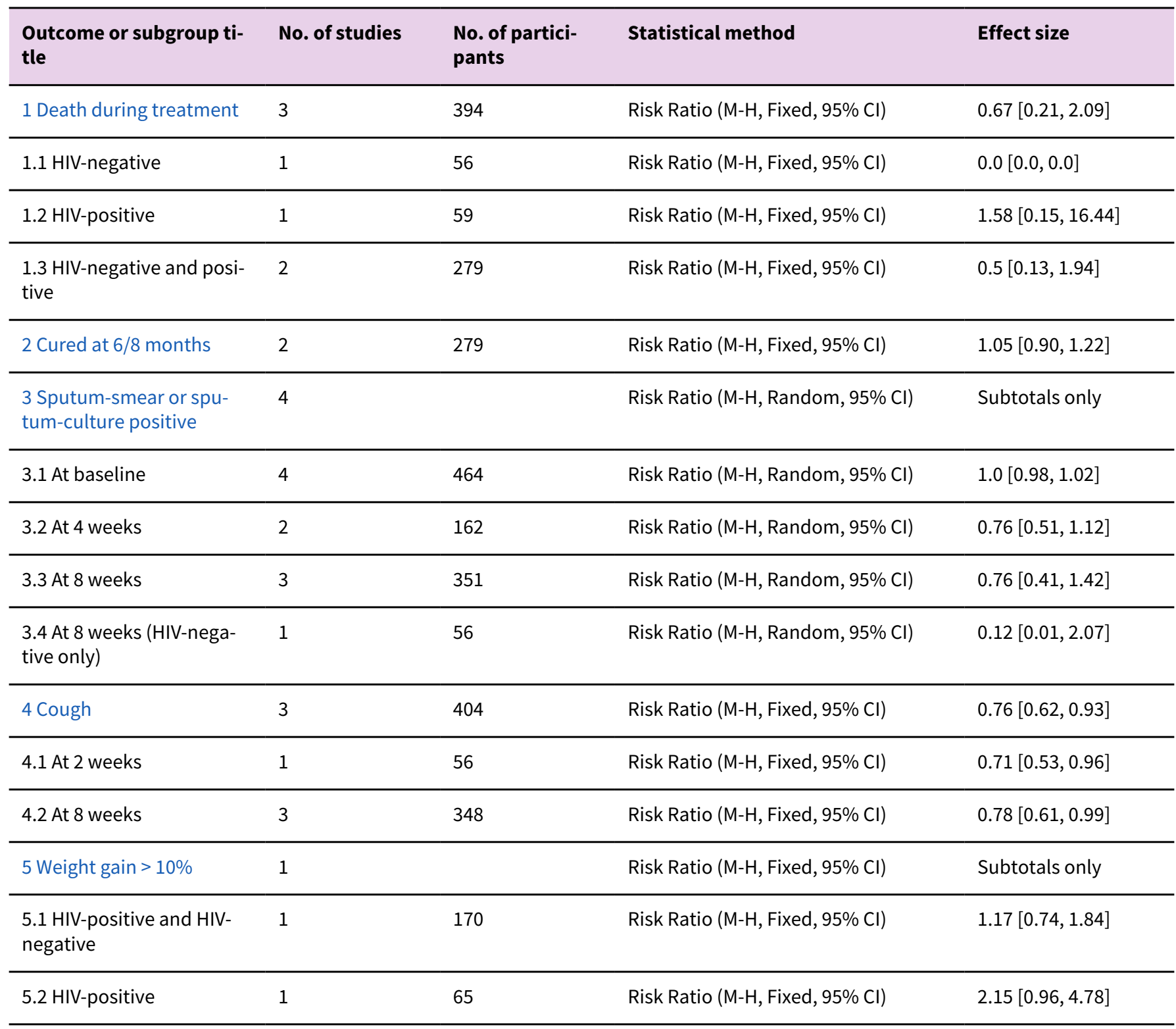

Analysis 8.1. Comparison 8 Arginine versus placebo, Outcome 1 Death during treatment.

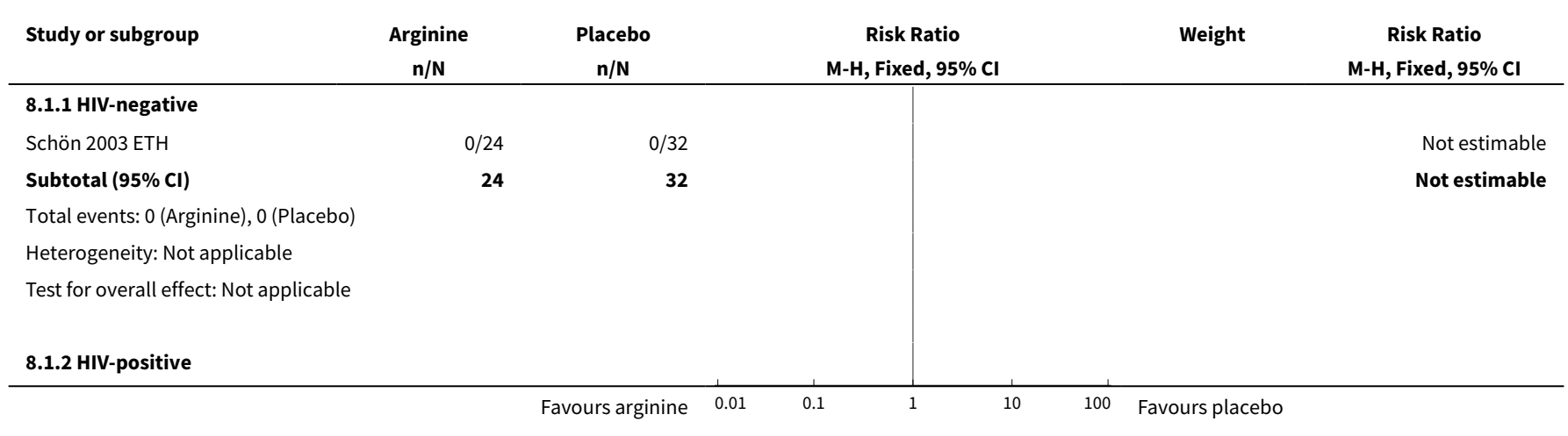




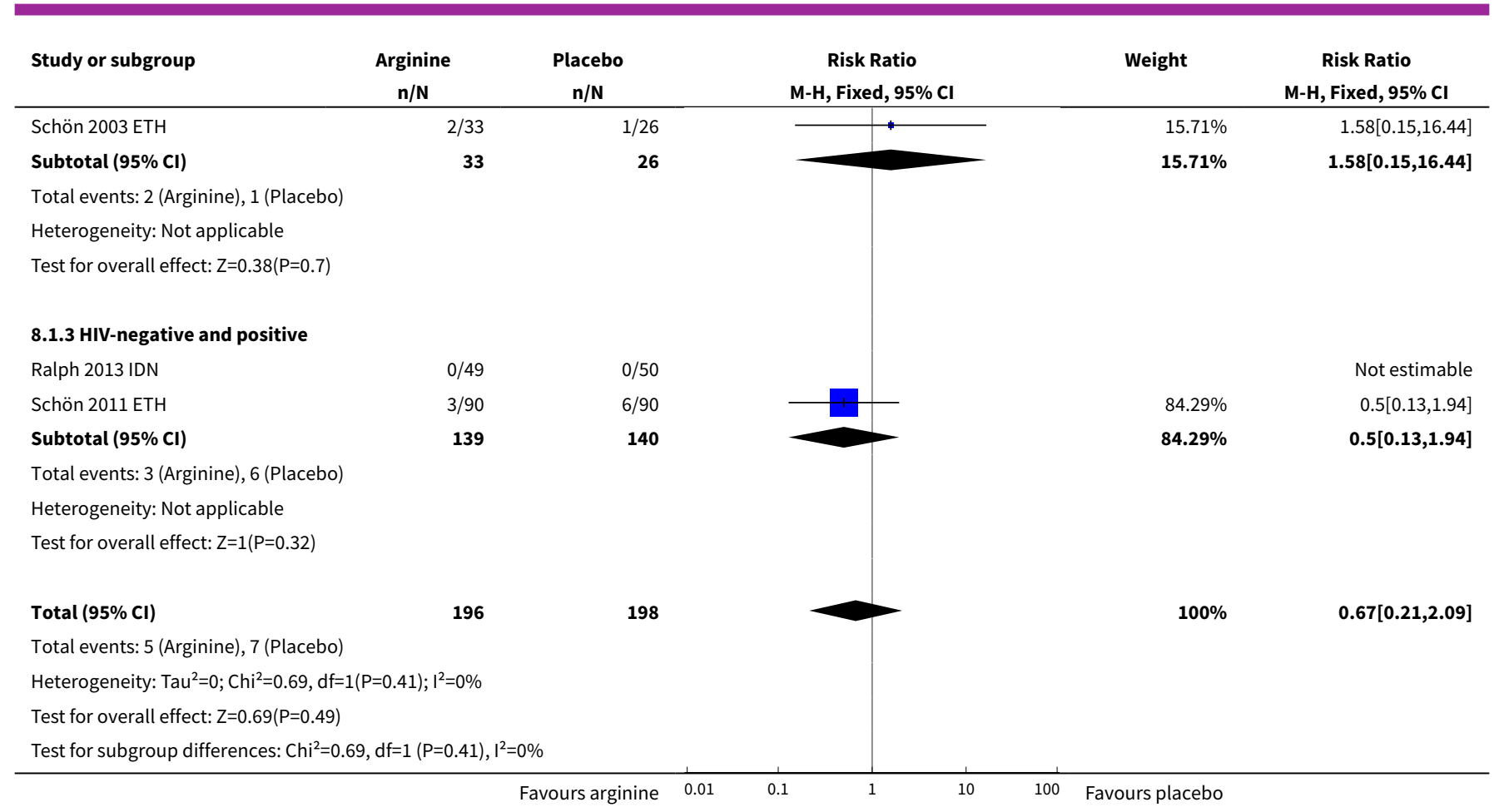

Analysis 8.2. Comparison 8 Arginine versus placebo, Outcome 2 Cured at $6 / 8$ months.

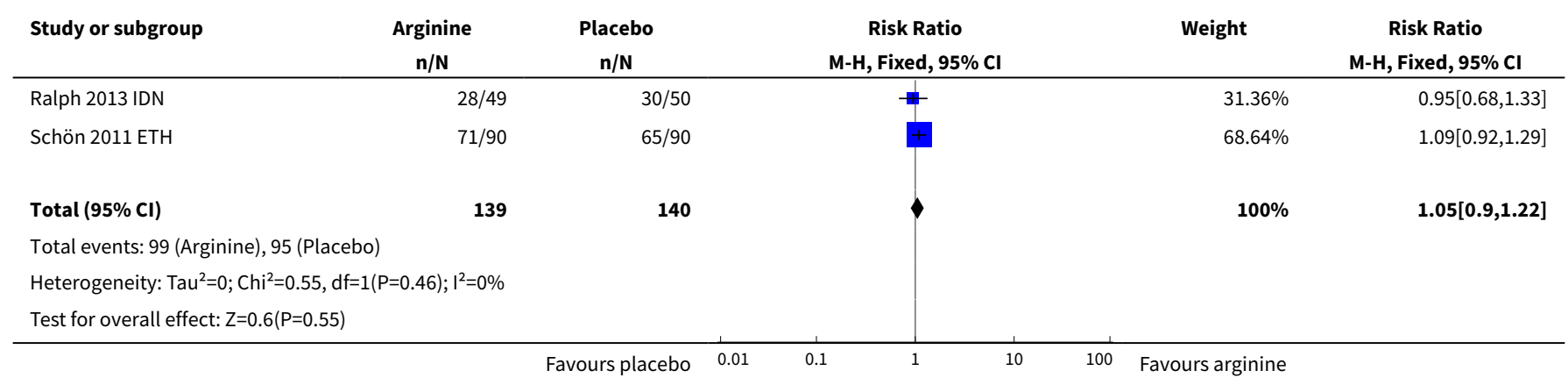

\section{Analysis 8.3. Comparison 8 Arginine versus placebo, Outcome 3 Sputum-smear or sputum-culture positive.}

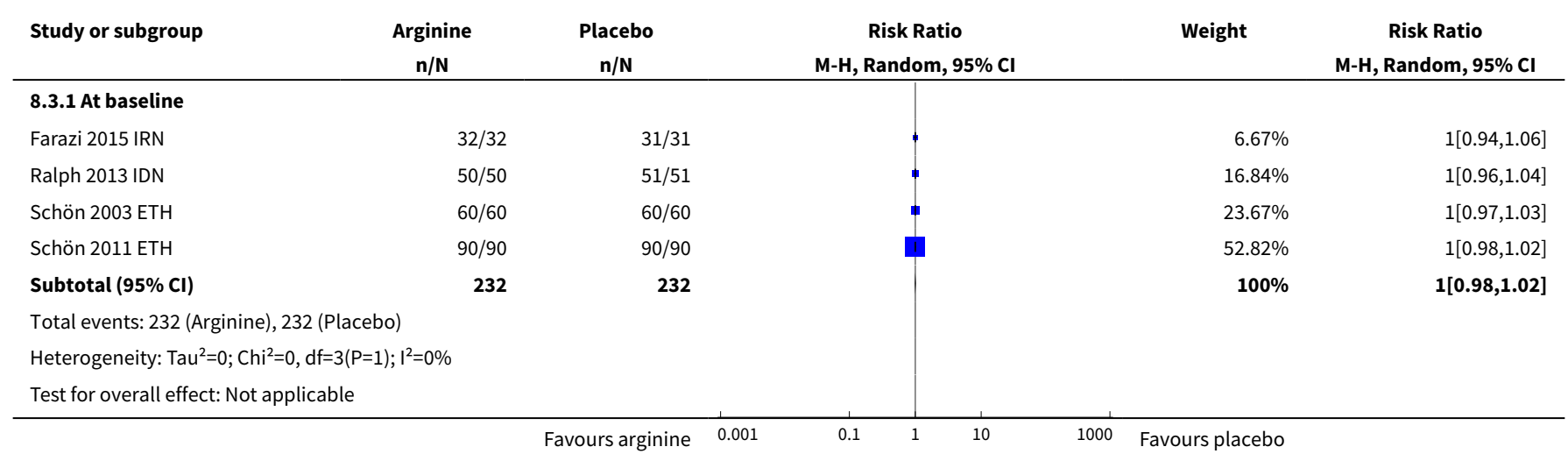




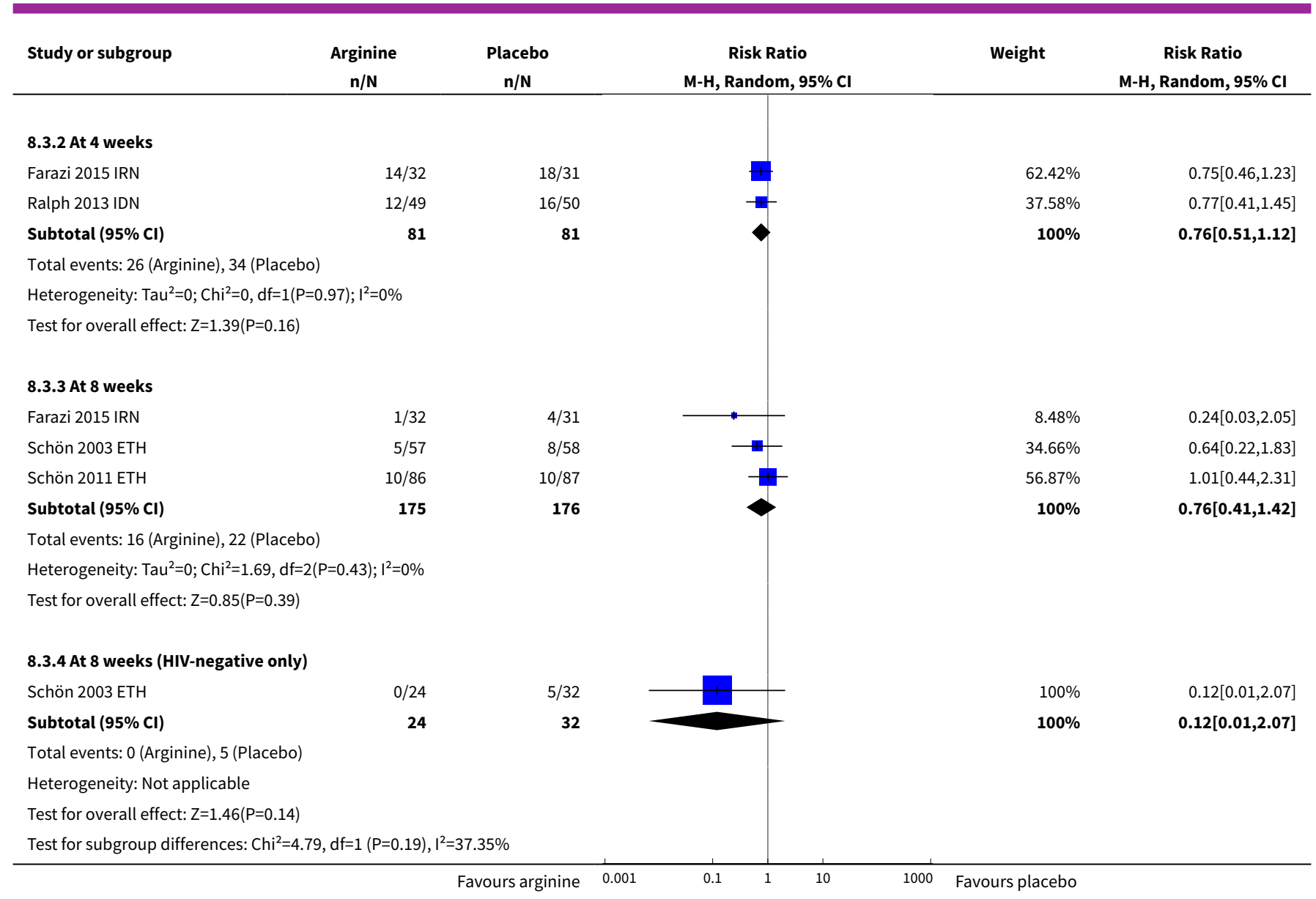

Analysis 8.4. Comparison 8 Arginine versus placebo, Outcome 4 Cough.

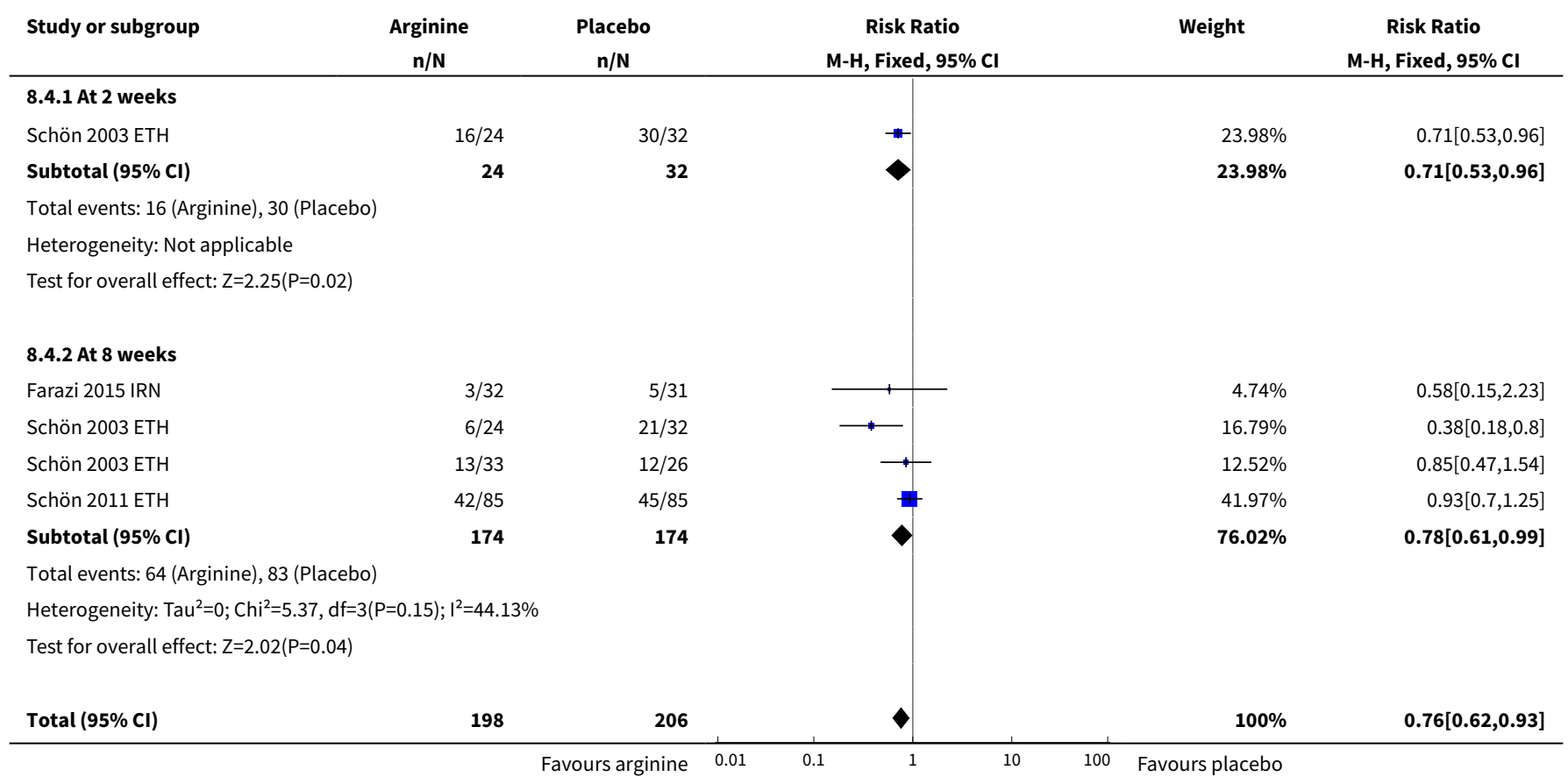

Nutritional supplements for people being treated for active tuberculosis (Review) 


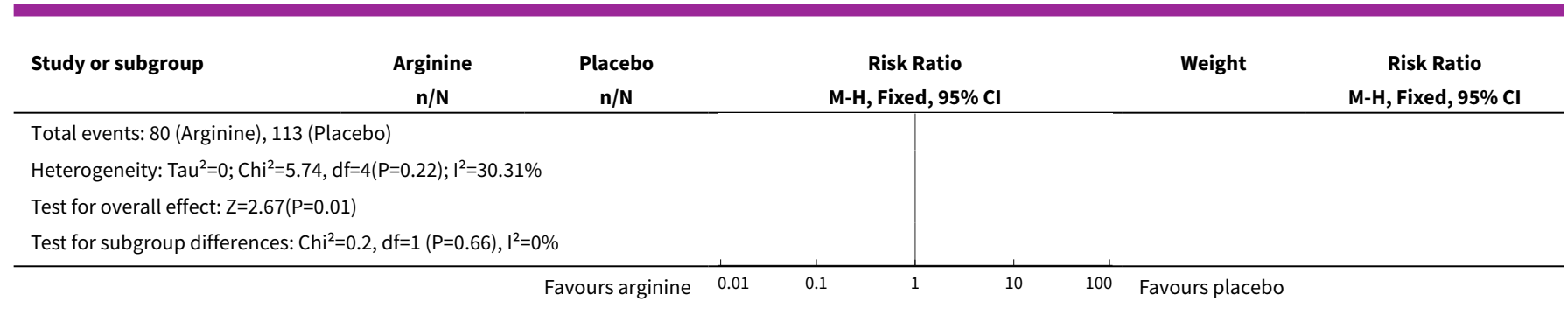

Analysis 8.5. Comparison 8 Arginine versus placebo, Outcome 5 Weight gain $>10 \%$.

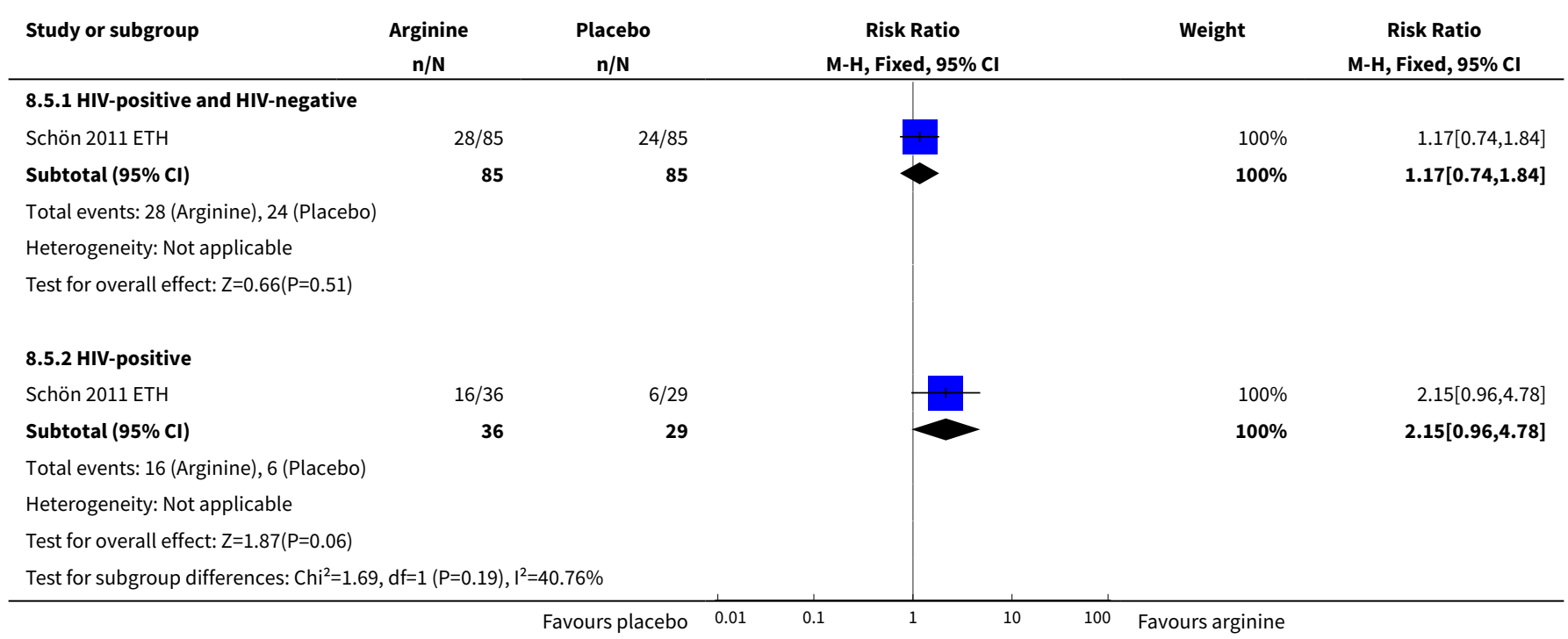

\section{Comparison 9. Vitamin E plus selenium versus placebo}

\begin{tabular}{lllll}
\hline $\begin{array}{l}\text { Outcome or subgroup } \\
\text { title }\end{array}$ & No. of studies & $\begin{array}{l}\text { No. of partici- } \\
\text { pants }\end{array}$ & Statistical method & Effect size \\
\hline $\begin{array}{l}1 \text { Sputum-smear positive } \\
\text { at follow-up }\end{array}$ & 1 & Risk Ratio (M-H, Fixed, $95 \% \mathrm{Cl})$ & Totals not selected \\
\hline 1.115 days & 1 & Risk Ratio (M-H, Fixed, $95 \% \mathrm{Cl})$ & $0.0[0.0,0.0]$ \\
\hline 1.230 days & 1 & Risk Ratio (M-H, Fixed, $95 \% \mathrm{Cl})$ & $0.0[0.0,0.0]$ \\
\hline 1.345 days & 1 & Risk Ratio $(\mathrm{M}-\mathrm{H}$, Fixed, $95 \% \mathrm{Cl})$ & $0.0[0.0,0.0]$ \\
\hline 1.460 days & 1 & Risk Ratio $(\mathrm{M}-\mathrm{H}$, Fixed, $95 \% \mathrm{Cl})$ & $0.0[0.0,0.0]$
\end{tabular}


Analysis 9.1. Comparison 9 Vitamin E plus selenium versus placebo, Outcome 1 Sputum-smear positive at follow-up.

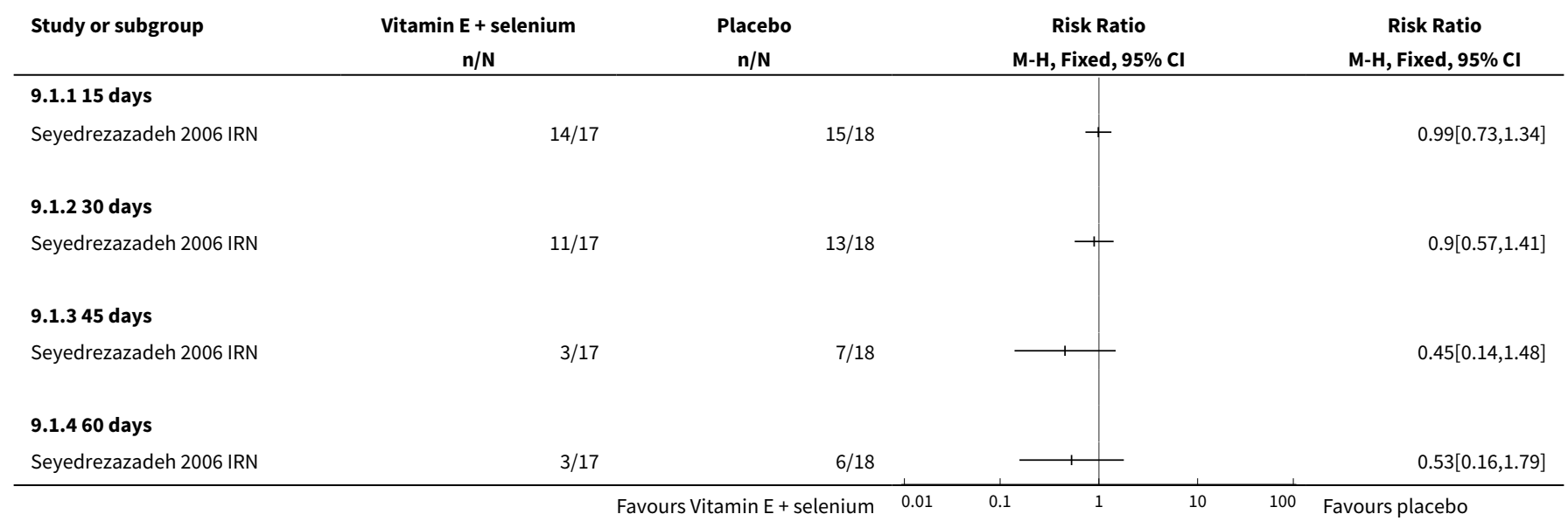

\section{ADDITIONAL TABLES}

Table 1. Effect of multi-micronutrient supplementation on nutritional recovery

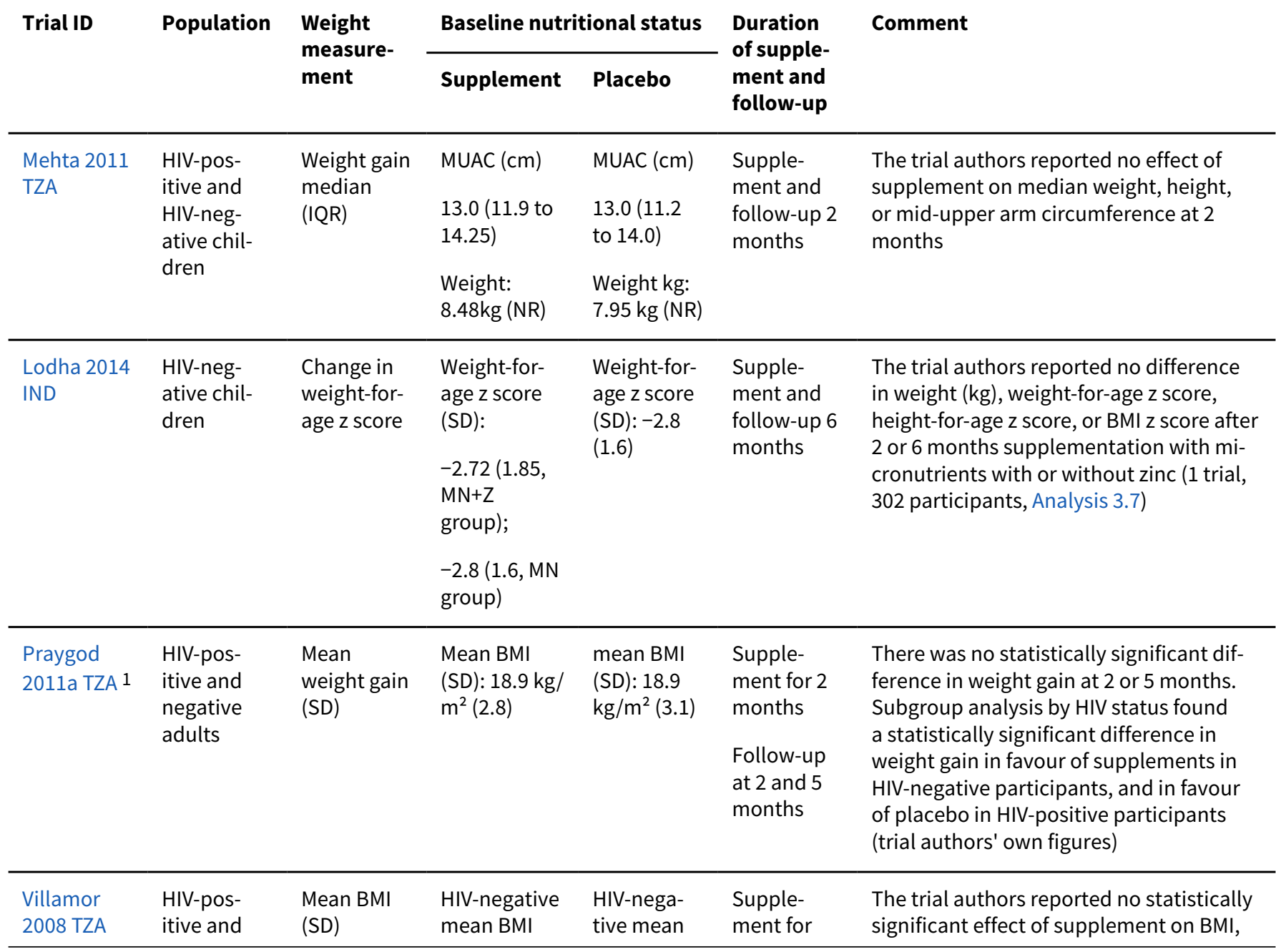

Nutritional supplements for people being treated for active tuberculosis (Review) 
Table 1. Effect of multi-micronutrient supplementation on nutritional recovery (Continued)

negative

adults

$\begin{array}{ll}(\mathrm{SD}): 18.9 \mathrm{~kg} / & \text { BMI (SD): } \\ \mathrm{m}^{2}(2.5) & 18.9 \mathrm{~kg} / \mathrm{m}^{2} \\ & (2.5)\end{array}$

HIV-positive

mean BMI

(SD): $19.3 \mathrm{~kg} /$

$\mathrm{m}^{2}(2.8)$

HIV-posi-

tive mean

BMI (SD):
24 months

and fol-

low-up at

8 and 24

$19.6 \mathrm{~kg} / \mathrm{m}^{2}$

(2.9)

\begin{tabular}{|c|c|c|c|c|c|c|}
\hline $\begin{array}{l}\text { Range } 2005 \\
\text { TZA 2 }\end{array}$ & $\begin{array}{l}\text { HIV-pos- } \\
\text { itive and } \\
\text { negative } \\
\text { adults }\end{array}$ & $\begin{array}{l}\text { Mean } \\
\text { weight gain } \\
\text { (SD) }\end{array}$ & $\begin{array}{l}\text { Mean BMI } \\
(\mathrm{SD}): 18.3 \mathrm{~kg} / \\
\mathrm{m}^{2}(2.5) \text { zinc } \\
+ \text { MMN group }\end{array}$ & $\begin{array}{l}\text { Mean BMI } \\
(\mathrm{SD}): 18.7 \\
\mathrm{~kg} / \mathrm{m}^{2}(2.7)\end{array}$ & $\begin{array}{l}\text { Supple- } \\
\text { ment for } \\
8 \text { months } \\
\text { and fol- } \\
\text { low-up } 8 \\
\text { weeks and } \\
7 \text { months }\end{array}$ & $\begin{array}{l}\text { There was a statistically significantly } \\
\text { greater weight gain in supplemented } \\
\text { group at } 7 \text { months. While the difference in } \\
\text { weight was appreciable in both treatment } \\
\text { (zinc + MMN and MMN groups) arms com- } \\
\text { pared to placebo, the weight gain in the } \\
\text { zinc + MMN arm appeared to be clinically } \\
\text { important }\end{array}$ \\
\hline
\end{tabular}

mid-upper arm circumference, fat mass, or fat free mass at 8 or 24 months, regardless of HIV status (no figures reported)

Abbreviations: $\mathrm{SD}$ = standard deviation; $\mathrm{BMI}=$ body mass index; $\mathrm{MMN}=$ multi-micronutrient; HIV = human immunodeficiency virus; IQR = interquartile range; $M U A C=$ mid-upper arm circumference; $N R$ = not reported;

1The supplement administered by Praygod 2011a TZA included a similar dose of zinc to that used by Range 2005 TZA.

$22 \times 2$ factorial design; Group 1: zinc plus placebo; Group 2: multivitamin and mineral tablet plus placebo; Group 3: zinc plus multivitamin and mineral tablet; Group 4: placebo plus placebo. 


\begin{tabular}{|c|c|c|c|c|c|c|c|c|}
\hline \multirow[t]{2}{*}{ Trial ID } & \multirow[t]{2}{*}{ Supplement dose } & \multirow[t]{2}{*}{ Measure } & \multicolumn{2}{|l|}{ Baseline } & \multicolumn{2}{|l|}{ Follow-up } & \multirow[t]{2}{*}{ Follow-up } & \multirow[t]{2}{*}{ Comment } \\
\hline & & & $\begin{array}{l}\text { Supple- } \\
\text { ment }\end{array}$ & Control & $\begin{array}{l}\text { Supple- } \\
\text { ment }\end{array}$ & Control & & \\
\hline $\begin{array}{l}\text { Hanekom } \\
1997 \mathrm{ZAF}\end{array}$ & $\begin{array}{l}200000 \text { IU vitamin A } 2 \\
\text { doses at baseline }\end{array}$ & $\begin{array}{l}\text { Mean } \mu \mathrm{g} / \mathrm{L} \\
(\mathrm{SD})\end{array}$ & $\begin{array}{l}17.6 \\
(10.1)\end{array}$ & $\begin{array}{l}18.6 \\
(10.5)\end{array}$ & $\begin{array}{l}34.8 \\
(10.1)\end{array}$ & $\begin{array}{l}33.5 \\
(14.2)\end{array}$ & 6 weeks & $\begin{array}{l}\text { No statistically significant differ- } \\
\text { ence in serum vitamin A levels at } 6 \\
\text { weeks or } 2 \text { months }\end{array}$ \\
\hline $\begin{array}{l}\text { Ginawi } 2013 \\
\text { IND }\end{array}$ & 5000 IU vitamin A daily & $\begin{array}{l}\text { Mean } \mu \mathrm{mol} / \\
\mathrm{L} \\
\text { (SD) }\end{array}$ & $\begin{array}{l}0.77 \\
(0.21)\end{array}$ & $\begin{array}{l}0.82 \\
(0.29)\end{array}$ & $\begin{array}{l}1.2 \\
(0.27)\end{array}$ & $\begin{array}{l}1.13 \\
(0.34)\end{array}$ & 2 months & $\begin{array}{l}\text { No statistically significant differ- } \\
\text { ence in serum vitamin A levels at } 2 \\
\text { or } 6 \text { months }\end{array}$ \\
\hline $\begin{array}{l}\text { Pakasi } 2010 \\
\text { IDN }\end{array}$ & $\begin{array}{l}5000 \text { IU vitamin A daily } \\
\text { for } 6 \text { months }\end{array}$ & $\begin{array}{l}\text { Median } \\
\mu \mathrm{mol} / \mathrm{L} \\
(\mathrm{IQR})\end{array}$ & $\begin{array}{l}0.7 \\
\text { (0.5 to } 1.5)\end{array}$ & $\begin{array}{l}0.7 \\
(0.5 \text { to } 1.0)\end{array}$ & $\begin{array}{l}1.5 \\
\text { (1.0 to } 2.0)\end{array}$ & $\begin{array}{l}1.2 \\
\text { (0.9 to } 1.6)\end{array}$ & 2 months & $\begin{array}{l}\text { No statistically significant differ- } \\
\text { ence at } 2 \text { or } 6 \text { months }\end{array}$ \\
\hline $\begin{array}{l}\text { Armijos } \\
2010 \text { MEX }\end{array}$ & $\begin{array}{l}5000 \text { IU vitamin A plus } \\
50 \text { mg zinc daily for } 4 \\
\text { months }\end{array}$ & $\begin{array}{l}\text { Mean } \mu \mathrm{mol} / \\
\mathrm{L} \\
\text { (SD) }\end{array}$ & $\begin{array}{l}1.03 \\
(0.46)\end{array}$ & $\begin{array}{l}1.04 \\
(0.48)\end{array}$ & $\begin{array}{l}1.4 \\
(0.47)\end{array}$ & $\begin{array}{l}1.29 \\
(0.35)\end{array}$ & 2 months & $\begin{array}{l}\text { No statistically significant differ- } \\
\text { ence in serum vitamin A levels at } 2 \\
\text { or } 6 \text { months }\end{array}$ \\
\hline $\begin{array}{l}\text { Karyadi } \\
2002 \text { IDN }\end{array}$ & $\begin{array}{l}5000 \text { IU vitamin A plus } \\
15 \text { mg zinc daily for } 6 \\
\text { months }\end{array}$ & $\begin{array}{l}\text { Mean } \mu \mathrm{mol} / \\
\mathrm{L} \\
\text { (SD) }\end{array}$ & $\begin{array}{l}0.82 \\
(0.25)\end{array}$ & $\begin{array}{l}0.9 \\
(0.25)\end{array}$ & $\begin{array}{l}1.14 \\
(0.32)\end{array}$ & $\begin{array}{l}1.08 \\
(0.25)\end{array}$ & 2 months & $\begin{array}{l}\text { No statistically significant differ- } \\
\text { ence in serum vitamin A levels at } 2 \\
\text { or } 6 \text { months }\end{array}$ \\
\hline $\begin{array}{l}\text { Ginawi } 2013 \\
\text { IND }\end{array}$ & $\begin{array}{l}5000 \text { IU vitamin A plus } \\
15 \mathrm{mg} \text { zinc sulphate } \\
\text { daily }\end{array}$ & $\begin{array}{l}\text { Mean } \mu \mathrm{mol} / \\
\mathrm{L} \\
\text { (SD) }\end{array}$ & $\begin{array}{l}0.78 \\
(0.23)\end{array}$ & $\begin{array}{l}0.82 \\
(0.29)\end{array}$ & $\begin{array}{l}1.14 \\
(0.25)\end{array}$ & $\begin{array}{l}1.13 \\
(0.34)\end{array}$ & 2 months & $\begin{array}{l}\text { No statistically significant differ- } \\
\text { ence in serum vitamin A levels at } 2 \\
\text { or } 6 \text { months }\end{array}$ \\
\hline $\begin{array}{l}\text { Pakasi } 2010 \\
\text { IDN }\end{array}$ & $\begin{array}{l}5000 \text { IU vitamin A plus } \\
15 \text { mg zinc sulphate } \\
\text { daily for } 6 \text { months }\end{array}$ & $\begin{array}{l}\text { Median } \\
\mu \mathrm{mol} / \mathrm{L} \\
\text { (IQR) }\end{array}$ & $\begin{array}{l}0.7 \\
\text { (0.4 to } 1.1 \text { ) }\end{array}$ & $\begin{array}{l}0.7 \\
(0.5 \text { to } 1.0)\end{array}$ & $\begin{array}{l}1.3 \\
\text { (1.0 to } 1.9 \text { ) }\end{array}$ & $\begin{array}{l}1.2 \\
\text { (0.9 to } 1.6 \text { ) }\end{array}$ & 2 months & $\begin{array}{l}\text { No statistically significant differ- } \\
\text { ence in serum vitamin A levels at } 2 \\
\text { or } 6 \text { months }\end{array}$ \\
\hline $\begin{array}{l}\text { Visser } 2011 \\
\text { ZAF }\end{array}$ & $\begin{array}{l}200,000 \text { IU vitamin A } \\
\text { once plus } 15 \mathrm{mg} \text { zinc } \\
\text { sulphate } 5 \text { days per } \\
\text { week for } 8 \text { weeks }\end{array}$ & $\begin{array}{l}\text { Median } \mu \mathrm{d} / \\
\mathrm{dL} \\
(\mathrm{IQR})\end{array}$ & $\begin{array}{l}21.1(15.1 \text { to } \\
27.8)\end{array}$ & $\begin{array}{l}21.2(15.7 \text { to } \\
28.9)\end{array}$ & $\begin{array}{l}40.3(28.7 \text { to } \\
48.5)\end{array}$ & $\begin{array}{l}35.8(27.7 \text { to } \\
43.2)\end{array}$ & 2 months & $\begin{array}{l}\text { No statistically significant differ- } \\
\text { ence in serum vitamin A levels at } 2 \\
\text { or } 8 \text { weeks }\end{array}$ \\
\hline
\end{tabular}


Table 2. Effects of vitamin A supplementation on serum vitamin A levels (Continued)

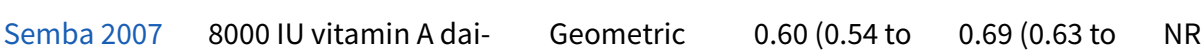

$\begin{array}{llllll}\text { Semba } 2007 & 8000 \mathrm{IU} \text { vitamin A dai- } & \text { Geometric } & 0.60(0.54 \text { to } & 0.69(0.63 \text { to } & \text { NR } \\ \text { MWI } & \begin{array}{l}\text { ly as part of a multi-mi- } \\ \text { cronutrient supple- } \\ \text { ment }\end{array} & \begin{array}{lll}\text { mean } \mu \mathrm{mol} / \\ \mathrm{L}(95 \% \mathrm{Cl})\end{array} & 0.66)^{1} & 0.75)^{1} & \\ & & & \end{array}$

ment

Abbreviations: IU = international units; $\mathrm{IQR}=$ interquartile range; $\mathrm{Cl}$ = confidence interval; $\mathrm{SD}=$ standard deviation.

${ }^{1}$ Serum vitamin A levels for HIV-negative participants.

Table 3. Effects of zinc supplementation on serum zinc levels

\begin{tabular}{|c|c|c|c|c|c|c|c|c|}
\hline \multirow[t]{2}{*}{ Trial ID } & \multirow[t]{2}{*}{ Supplement dose } & \multirow[t]{2}{*}{ Measure } & \multicolumn{2}{|l|}{ Baseline } & \multicolumn{2}{|c|}{ Follow-up } & \multirow[t]{2}{*}{ Follow-up } & \multirow[t]{2}{*}{ Comment } \\
\hline & & & $\begin{array}{l}\text { Supple- } \\
\text { ment }\end{array}$ & Control & $\begin{array}{l}\text { Supple- } \\
\text { ment }\end{array}$ & Control & & \\
\hline $\begin{array}{l}\text { Ginawi } 2013 \\
\text { IND }\end{array}$ & $\begin{array}{l}15 \mathrm{mg} \text { zinc sulphate } \\
\text { daily }\end{array}$ & $\begin{array}{l}\text { Mean } \mu \mathrm{mol} / \\
\mathrm{L} \\
\text { (SD) }\end{array}$ & $\begin{array}{l}9.86 \\
(0.87)\end{array}$ & $\begin{array}{l}9.88 \\
(1.44)\end{array}$ & $\begin{array}{l}12.23 \\
(1.12)\end{array}$ & $\begin{array}{l}11.23 \\
(1.34)\end{array}$ & 2 months & $\begin{array}{l}\text { Statistically significant increase in } \\
\text { serum zinc levels in the zinc group at } \\
2 \text { and } 6 \text { months }\end{array}$ \\
\hline $\begin{array}{l}\text { Pakasi } 2010 \\
\text { IDN }\end{array}$ & $\begin{array}{l}15 \mathrm{mg} \text { zinc sulphate } \\
\text { daily for } 6 \text { months }\end{array}$ & $\begin{array}{l}\text { Mean } \mu \mathrm{mol} / \\
\mathrm{L} \\
\text { (SD) }\end{array}$ & $\begin{array}{l}11.6 \\
(2.2)\end{array}$ & $\begin{array}{l}11.8 \\
(2.4)\end{array}$ & $\begin{array}{l}11.7 \\
(2.43)\end{array}$ & $\begin{array}{l}11.7 \\
(2.33)\end{array}$ & 2 months & $\begin{array}{l}\text { No statistically significant difference } \\
\text { in serum zinc levels at } 2 \text { months }\end{array}$ \\
\hline $\begin{array}{l}\text { Armijos } \\
2010 \text { MEX }\end{array}$ & $\begin{array}{l}50 \mathrm{mg} \text { zinc plus } 5000 \\
\text { IU vitamin A daily for } \\
4 \text { months }\end{array}$ & $\begin{array}{l}\text { Mean } \mu \mathrm{mol} / \\
\mathrm{L} \\
\text { (SD) }\end{array}$ & $\begin{array}{l}11.29 \\
(2.57)\end{array}$ & $\begin{array}{l}11.69 \\
(2.1)\end{array}$ & $\begin{array}{l}12.85 \\
(3.4)\end{array}$ & $\begin{array}{l}10.13 \\
(1.61)\end{array}$ & 2 months & $\begin{array}{l}\text { Statistically significant increase in } \\
\text { serum zinc levels in zinc plus vitamin } \\
\text { A group at } 2 \text { months. Increase not } \\
\text { sustained post supplementation. }\end{array}$ \\
\hline $\begin{array}{l}\text { Ginawi } 2013 \\
\text { IND }\end{array}$ & $\begin{array}{l}15 \text { mg zinc sulphate } \\
\text { plus } 5000 \text { IU vitamin } \\
\text { A daily }\end{array}$ & $\begin{array}{l}\text { Mean } \mu \mathrm{mol} / \\
\mathrm{L} \\
\text { (SD) }\end{array}$ & $\begin{array}{l}9.56 \\
(0.77)\end{array}$ & $\begin{array}{l}9.88 \\
(1.4)\end{array}$ & $\begin{array}{l}11.17 \\
(0.86)\end{array}$ & $\begin{array}{l}11.23 \\
(1.34)\end{array}$ & 2 months & $\begin{array}{l}\text { No statistically significant difference } \\
\text { in serum zinc levels at } 2 \text { months }\end{array}$ \\
\hline $\begin{array}{l}\text { Pakasi } 2010 \\
\text { IDN }\end{array}$ & $\begin{array}{l}15 \text { mg zinc sulphate } \\
\text { plus } 5000 \text { IU vitamin } \\
\text { A daily for } 6 \text { months }\end{array}$ & $\begin{array}{l}\text { Mean } \mu \mathrm{mol} / \\
\mathrm{L}\end{array}$ & $\begin{array}{l}12.1 \\
(3.0)\end{array}$ & $\begin{array}{l}11.8 \\
(2.4)\end{array}$ & $\begin{array}{l}12.5 \\
(2.33)\end{array}$ & $\begin{array}{l}11.7 \\
(2.33)\end{array}$ & 2 months & $\begin{array}{l}\text { No statistically significant difference } \\
\text { in serum zinc levels at } 2 \text { months }\end{array}$ \\
\hline
\end{tabular}




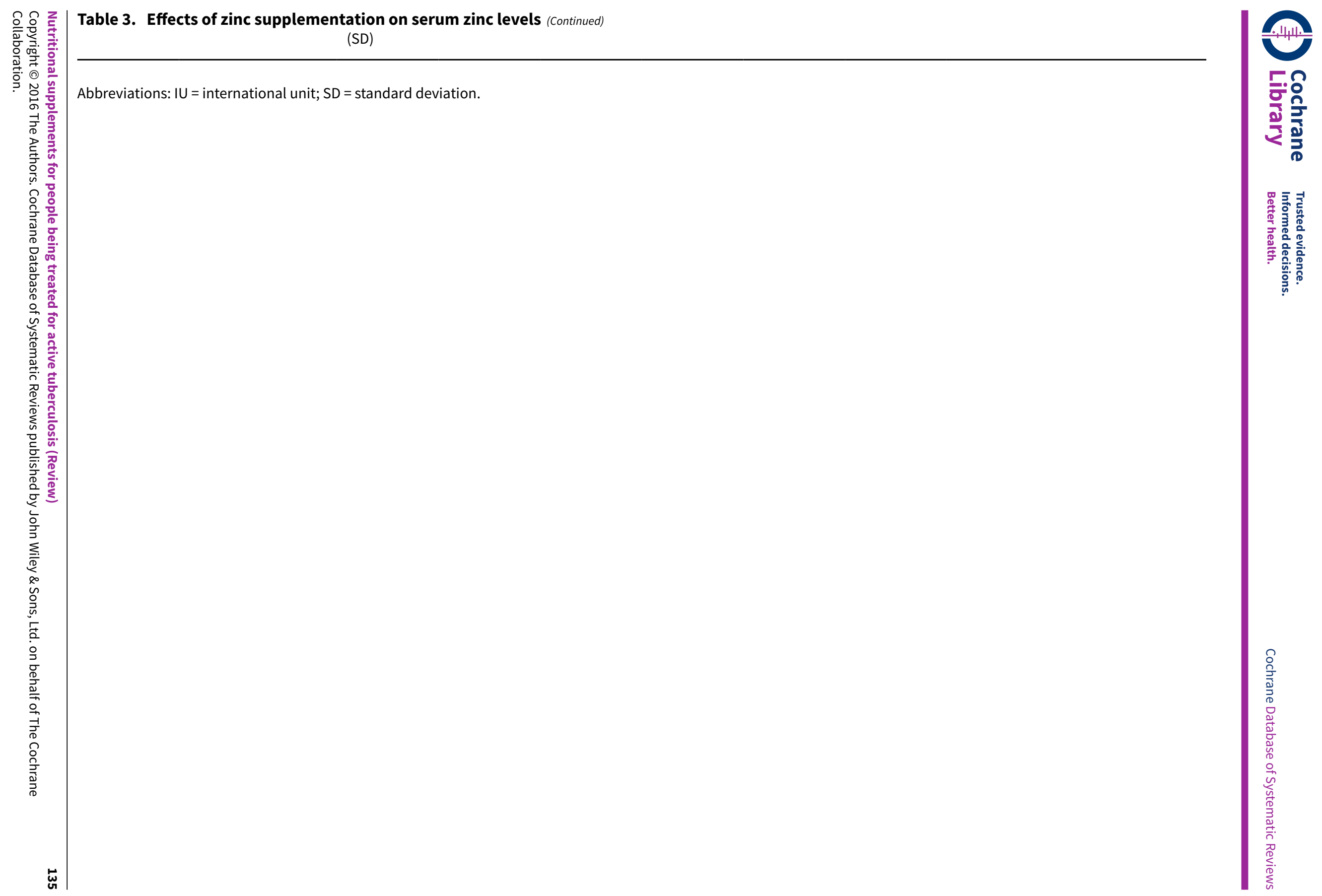


Table 4. Effect of vitamin A plus zinc supplementation on nutritional recovery

\begin{tabular}{|c|c|c|c|c|c|c|}
\hline \multirow[t]{2}{*}{ Trial ID } & \multirow[t]{2}{*}{ Population } & \multicolumn{2}{|c|}{$\begin{array}{l}\text { Baseline nutritional sta- } \\
\text { tus } \\
\text { Mean BMI (SD) kg/m² }\end{array}$} & \multicolumn{2}{|c|}{$\begin{array}{l}\text { Endpoint nutritional sta- } \\
\text { tus }\end{array}$} & \multirow[t]{2}{*}{ Comments } \\
\hline & & $\begin{array}{l}\text { Vitamin A } \\
\text { plus zinc }\end{array}$ & Placebo & $\begin{array}{l}\text { Vitamin A } \\
\text { plus zinc }\end{array}$ & Placebo & \\
\hline $\begin{array}{l}\text { Karyadi } \\
2002 \text { IDN }\end{array}$ & $\begin{array}{l}\text { Adults HIV } \\
\text { status un- } \\
\text { known }\end{array}$ & $17.6(1.9)$ & $18.1(3.2)$ & $\begin{array}{l}\text { Mean BMI } \\
\text { (SD) } 6 \\
\text { months: } \\
19.4(2.5)\end{array}$ & $\begin{array}{l}\text { Mean BMI } \\
\text { (SD) } 6 \\
\text { months: } \\
20.0(3.2)\end{array}$ & $\begin{array}{l}\text { Statistically significantly greater body } \\
\text { weight }(\mathrm{kg}) \text { in supplemented group at } 6 \\
\text { months ( } 3.10 \mathrm{~kg}, 95 \% \mathrm{Cl} 0.74 \text { to } 5.46) \text {. No } \\
\text { statistically significant differences in BMI, } \\
\text { mid-upper arm circumference, biceps skin- } \\
\text { fold thickness, triceps skinfold thickness, } \\
\text { subscapular skinfold thickness, supra-ili- } \\
\text { ac skinfold thickness, body fat (\%), or fat } \\
\text { mass (kg) between groups at } 2 \text { or } 6 \text { months }\end{array}$ \\
\hline $\begin{array}{l}\text { Lawson } \\
2010 \text { NGA }\end{array}$ & $\begin{array}{l}\text { Adults HIV- } \\
\text { positive } \\
\text { and HIV- } \\
\text { negative }\end{array}$ & $19.6(3.5)$ & $19.8(3.3)$ & \multicolumn{2}{|c|}{$\begin{array}{l}\text { BMI data reported graphi- } \\
\text { cally }\end{array}$} & $\begin{array}{l}\text { BMI appears to increase along a similar tra- } \\
\text { jectory for both supplemented and place- } \\
\text { bo groups at } 2 \text { and } 6 \text { months }\end{array}$ \\
\hline $\begin{array}{l}\text { Pakasi } 2010 \\
\text { IDN }\end{array}$ & $\begin{array}{l}\text { Adults HIV } \\
\text { status un- } \\
\text { known }\end{array}$ & $16.6(2.1)$ & $16.4(2.5)$ & $\begin{array}{l}\text { Mean BMI } \\
\text { (SD) } 6 \\
\text { months: } \\
18.3(2.0)\end{array}$ & $\begin{array}{l}\text { Mean BMI } \\
\text { (SD) } 6 \\
\text { months: } \\
18.4(2.6)\end{array}$ & $\begin{array}{l}\text { No statistically significant differences in } \\
\text { BMI between the supplement and placebo } \\
\text { group at } 2 \text { or } 6 \text { months }\end{array}$ \\
\hline $\begin{array}{l}\text { Visser } 2011 \\
\text { ZAF }\end{array}$ & $\begin{array}{l}\text { Adults HIV- } \\
\text { positive } \\
\text { and HIV- } \\
\text { negative }\end{array}$ & $\begin{array}{l}\text { Male: } 18.9 \\
(2.7) \\
\text { Female: } \\
23.0(4.3)\end{array}$ & $\begin{array}{l}\text { Male: } 19.0 \\
(2) \\
\text { Female: } \\
21.6(4.8)\end{array}$ & $\begin{array}{l}\text { Mean } \\
\text { weight gain } \\
2.3 \mathrm{~kg}\end{array}$ & $\begin{array}{l}\text { Mean } \\
\text { weight gain } \\
2.2 \mathrm{~kg}\end{array}$ & $\begin{array}{l}\text { No statistically significant difference in } \\
\text { weight gain during the first } 2 \text { months of } \\
\text { treatment ( } P=0.68 \text {, trial authors' own fig- } \\
\text { ures) }\end{array}$ \\
\hline
\end{tabular}

Abbreviations: $\mathrm{HIV}=$ human immunodeficiency virus; $\mathrm{BMI}=$ body mass index; $\mathrm{SD}$ = standard deviation. 


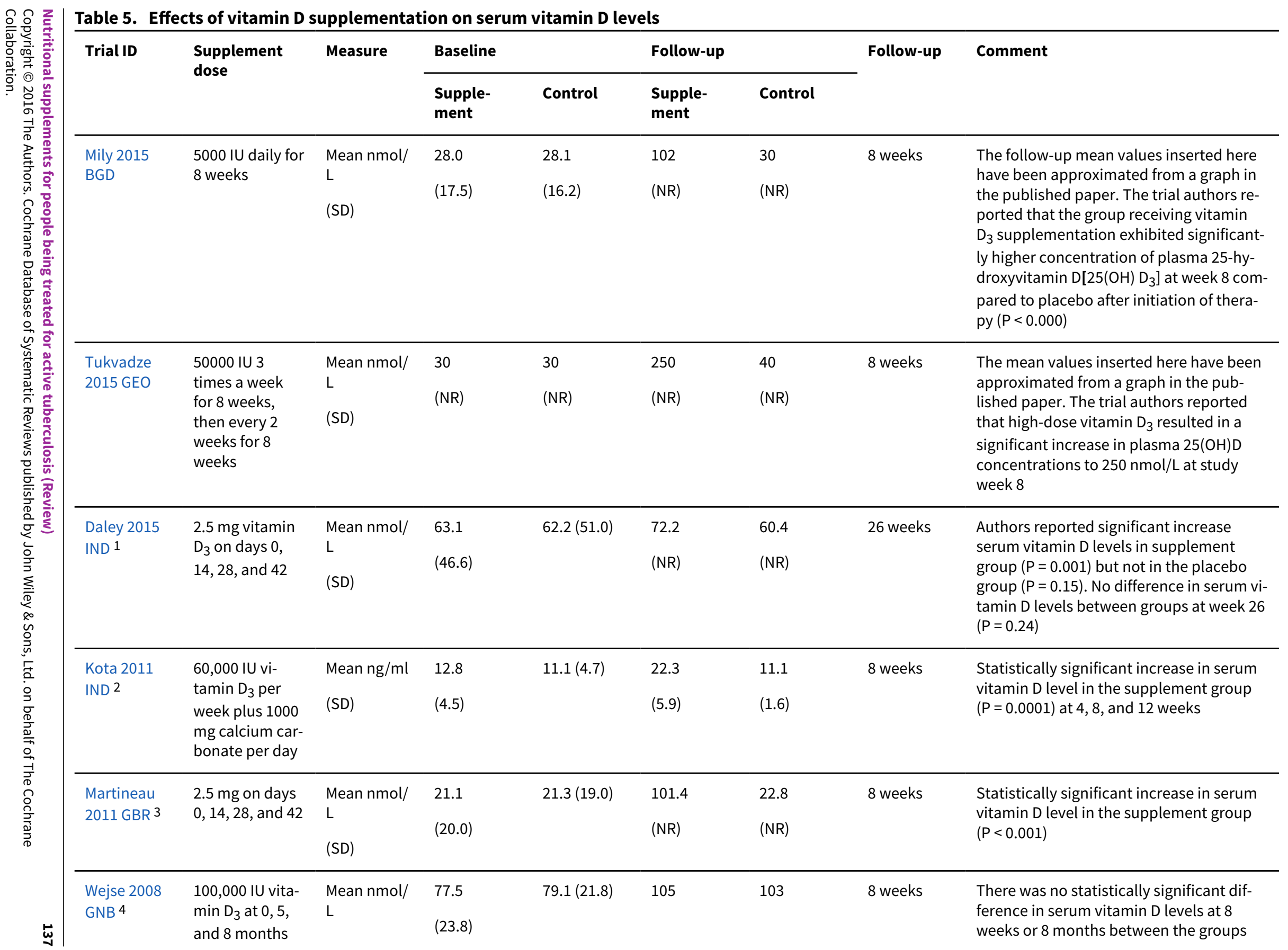




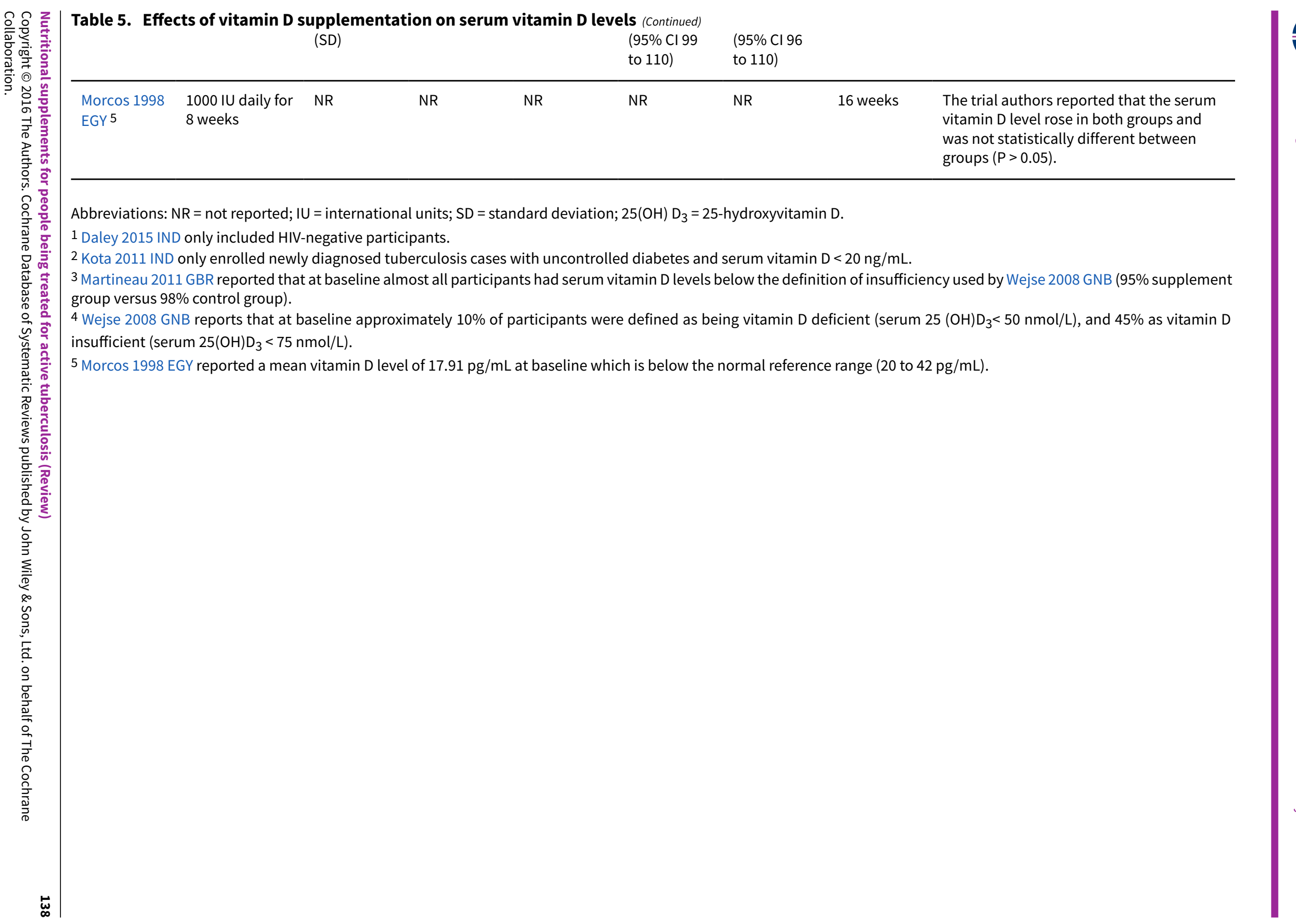


Table 6. Adverse effects of vitamin D

\begin{tabular}{|c|c|c|c|c|}
\hline Trial ID & Dose & $\begin{array}{l}\text { Severe adverse } \\
\text { events }\end{array}$ & Effects on calcium & Other \\
\hline $\begin{array}{l}\text { Tukvadze } 2015 \\
\text { GEO }\end{array}$ & $\begin{array}{l}50,000 \text { IU } 3 \text { times a } \\
\text { week for } 8 \text { weeks, } \\
\text { then every } 2 \text { weeks } \\
\text { for } 8 \text { weeks }\end{array}$ & $\begin{array}{l}\text { 5/100 vitamin } \\
\text { D versus } 15 / 99 \\
\text { placebo }\end{array}$ & $\begin{array}{l}\text { Hypercalcemia: } 3 / 100 \text { vitamin D } \\
\text { versus } 7 / 99 \text { placebo }\end{array}$ & $\begin{array}{l}\text { No differences between } \\
\text { study arms }\end{array}$ \\
\hline Daley 2015 IND & $\begin{array}{l}2.5 \mathrm{mg} \text { vitamin } \mathrm{D}_{3} \text { on } \\
\text { days } 0,14,28 \text {, and } 42\end{array}$ & $\begin{array}{l}\text { None in the vita- } \\
\text { min D group }\end{array}$ & Hypercalcaemia: none & $\begin{array}{l}\text { 4/121 vitamin D versus 3/126 } \\
\text { placebo } \\
\text { (none required a change in } \\
\text { medical therapy) }\end{array}$ \\
\hline $\begin{array}{l}\text { Martineau } 2011 \\
\text { GBR }\end{array}$ & $\begin{array}{l}2.5 \mathrm{mg} \text { on days } 0,14, \\
28, \text { and } 42\end{array}$ & $\begin{array}{l}\text { 7/71 vitamin } \\
\text { D versus } 2 / 70 \\
\text { placebo }\end{array}$ & $\begin{array}{l}\text { Hypercalcemia: } 2 / 71 \text { vitamin D ver- } \\
\text { sus } 0 / 70 \text { placebo } \\
\text { Hypocalcaemia: } 5 / 71 \text { vitamin D } \\
\text { versus } 2 / 70 \text { placebo }\end{array}$ & $\begin{array}{l}\text { No differences between } \\
\text { study arms }\end{array}$ \\
\hline Wejse 2008 GNB & $\begin{array}{l}100,000 \text { IU vitamin } \\
\mathrm{D}_{3} \text { at } 0,5 \text {, and } 8 \\
\text { months }\end{array}$ & No comment & $\begin{array}{l}\text { Hypercalcemia: at } 2 \text { months: } 1 / 157 \\
\text { vitamin D versus } 2 / 147 \text { placebo } \\
\text { At } 8 \text { months: none }\end{array}$ & $\begin{array}{l}\text { At } 2 \text { months: only } 24 \text { re- } \\
\text { ported any symptom, most } \\
\text { commonly excessive thirst: } \\
10 / 157 \text { vitamin } D \text { versus } \\
14 / 147 \text { placebo }(P=0.31)\end{array}$ \\
\hline
\end{tabular}

Abbreviations: IU = international units.

APPENDICES

Appendix 1. Composition of multi-micronutrient supplements: adults

\begin{tabular}{|c|c|c|c|c|c|}
\hline \multirow[t]{2}{*}{ Nutrient } & \multicolumn{5}{|l|}{ Adults } \\
\hline & $\begin{array}{l}\text { DRI for males } \\
\text { aged } 19 \text { to } 70 \text { years }\end{array}$ & $\begin{array}{l}\text { Semba } 2007 \\
\text { MWI }\end{array}$ & $\begin{array}{l}\text { Range } 2005 \\
\text { TZA }\end{array}$ & $\begin{array}{l}\text { Villamor } 2008 \\
\text { TZA }\end{array}$ & $\begin{array}{l}\text { Praygod } \\
\text { 2011a TZA }\end{array}$ \\
\hline Vitamin A & $\begin{array}{l}900 \mu \mathrm{g} \\
(3000 \mathrm{IU})\end{array}$ & $\begin{array}{l}2400 \mu \mathrm{g} \\
(8000 \mathrm{IU})\end{array}$ & $\begin{array}{l}1500 \mu \mathrm{g} \\
(5000 \mathrm{IU})\end{array}$ & $\begin{array}{l}1500 \mu \mathrm{g} \\
(5000 \mathrm{IU})\end{array}$ & $\begin{array}{l}1500 \mu \mathrm{g} \\
(5000 \mathrm{IU})\end{array}$ \\
\hline Vitamin B1 (thiamine) & $1.2 \mathrm{mg}$ & $1.5 \mathrm{mg}$ & $20 \mathrm{mg}$ & $20 \mathrm{mg}$ & $20 \mathrm{mg}$ \\
\hline Vitamin B2 (riboflavin) & $1.3 \mathrm{mg}$ & $1.7 \mathrm{mg}$ & $20 \mathrm{mg}$ & $20 \mathrm{mg}$ & $20 \mathrm{mg}$ \\
\hline Vitamin B3 (niacin) & $16 \mathrm{mg}$ & $20 \mathrm{mg}$ & $40 \mathrm{mg}$ & $100 \mathrm{mg}$ & $40 \mathrm{mg}$ \\
\hline Vitamin B6 (pyridoxine) & 1.3 to $1.7 \mathrm{mg}$ & $2 \mathrm{mg}$ & $25 \mathrm{mg}$ & $25 \mathrm{mg}$ & $25 \mathrm{mg}$ \\
\hline
\end{tabular}




\begin{tabular}{|c|c|c|c|c|c|}
\hline $\begin{array}{l}\text { Vitamin B9 } \\
\text { (folic acid) }\end{array}$ & $400 \mu \mathrm{g}$ & $400 \mu \mathrm{g}$ & $800 \mu \mathrm{g}$ & $800 \mu \mathrm{g}$ & $800 \mu \mathrm{g}$ \\
\hline Vitamin B12 & $2.4 \mu \mathrm{g}$ & $6 \mu \mathrm{g}$ & $50 \mu \mathrm{g}$ & $50 \mu \mathrm{g}$ & $50 \mu \mathrm{g}$ \\
\hline Vitamin C & $90 \mathrm{mg}$ & $500 \mathrm{mg}$ & $200 \mathrm{mg}$ & $500 \mathrm{mg}$ & $200 \mathrm{mg}$ \\
\hline Vitamin D & 5 to $15 \mu \mathrm{g}$ & $\begin{array}{l}10 \mu \mathrm{g} \\
(400 \mathrm{IU})\end{array}$ & $5 \mu \mathrm{g}$ & - & $5 \mu \mathrm{g}$ \\
\hline Vitamin E & $15 \mathrm{mg}$ & $\begin{array}{l}133 \mathrm{mg} \\
(200 \mathrm{IU})\end{array}$ & $60 \mathrm{mg}$ & $200 \mathrm{mg}$ & $60 \mathrm{mg}$ \\
\hline Selenium & $55 \mu \mathrm{g}$ & $65 \mu \mathrm{g}$ & $200 \mu g$ & $100 \mu g$ & $200 \mu \mathrm{g}$ \\
\hline Copper & $0.9 \mathrm{mg}$ & - & $5 \mathrm{mg}$ & - & $5 \mathrm{mg}$ \\
\hline Zinc & $11 \mathrm{mg}$ & $10 \mathrm{mg}$ & $\begin{array}{l} \pm 45 \text { mg (ele- } \\
\text { mentary zinc) }\end{array}$ & - & $\begin{array}{l}30 \mathrm{mg} \\
\text { (as acetate) }\end{array}$ \\
\hline lodine & $150 \mu g$ & $175 \mu \mathrm{g}$ & - & - & - \\
\hline Calcium & $1000 \mathrm{mg}$ & - & - & - & - \\
\hline Manganese & $2.3 \mathrm{mg}$ & - & - & - & - \\
\hline Magnesium & 410 to $420 \mathrm{mg}$ & - & - & - & - \\
\hline D-panthenol & - & - & - & - & - \\
\hline
\end{tabular}

Abbreviations: DRI = Dietary Reference Intake; IU = international unit.

Standards taken from the US Department of Agriculture Dietary Guidance available at http://fnic.nal.usda.gov/nal_display/index

\section{Appendix 2. Search strategies for databases}

\begin{tabular}{|c|c|c|c|c|c|}
\hline Search set & CIDG SRa & CENTRAL & MEDLINEb & EMBASEb & LILACS $\mathbf{b}$ \\
\hline 1 & tuberculosis & tuberculosis & tuberculosis & tuberculosis & tuberculosis \\
\hline 2 & $\begin{array}{l}\text { dietary sup- } \\
\text { plements }\end{array}$ & $\begin{array}{l}\text { DIETARY SUPPLE- } \\
\text { MENTS }\end{array}$ & DIETARY SUPPLEMENTS & dietary supplement\$ & $\begin{array}{l}\text { dietary sup- } \\
\text { plements }\end{array}$ \\
\hline 3 & $\begin{array}{l}\text { macronutri- } \\
\text { ents }\end{array}$ & food supplement* & food supplement* & $\begin{array}{l}\text { DIET-SUPPLEMEN- } \\
\text { TATION }\end{array}$ & $\begin{array}{l}\text { macronutri- } \\
\text { ents }\end{array}$ \\
\hline 4 & $\begin{array}{l}\text { micronutri- } \\
\text { ents }\end{array}$ & FOOD, FORTIFIED & FOOD, FORTIFIED & MACRONUTRIENT & $\begin{array}{l}\text { micronutri- } \\
\text { ents }\end{array}$ \\
\hline 5 & zinc & macronutrients & macronutrients & micronutrient\$ & zinc \\
\hline 6 & 2 or 3 or 4 or 5 & MICRONUTRIENTS & MICRONUTRIENTS & $\begin{array}{l}\text { VITAMIN-SUPPLEMEN- } \\
\text { TATION }\end{array}$ & 2 or 3 or 4 or 5 \\
\hline
\end{tabular}




\begin{tabular}{|c|c|c|c|c|c|}
\hline \multicolumn{6}{|c|}{ (Continued) } \\
\hline 7 & 1 and 6 & TRACE ELEMENTS & TRACE ELEMENTS & IRON & 1 and 6 \\
\hline 8 & - & VITAMINS & VITAMINS & ZINC & - \\
\hline 9 & - & vitamin* & vitamin* & TRACE-ELEMENT & - \\
\hline 10 & - & zinc & zinc & $2-9$ & - \\
\hline 11 & - & iron & iron & 1 and 10 & - \\
\hline 12 & - & $2-11 / O R$ & $2-11 / O R$ & Limit 11 to human & - \\
\hline 13 & - & 1 and 12 & 1 and 12 & - & - \\
\hline 14 & - & - & Limit 13 to human & - & - \\
\hline
\end{tabular}

aCochrane Infectious Diseases Group Specialized Register.

bSearch terms used in combination with the search strategy for retrieving trials developed by Cochrane (Lefebvre 2011); upper case: MeSH or EMTREE heading, lower case: free text term. 


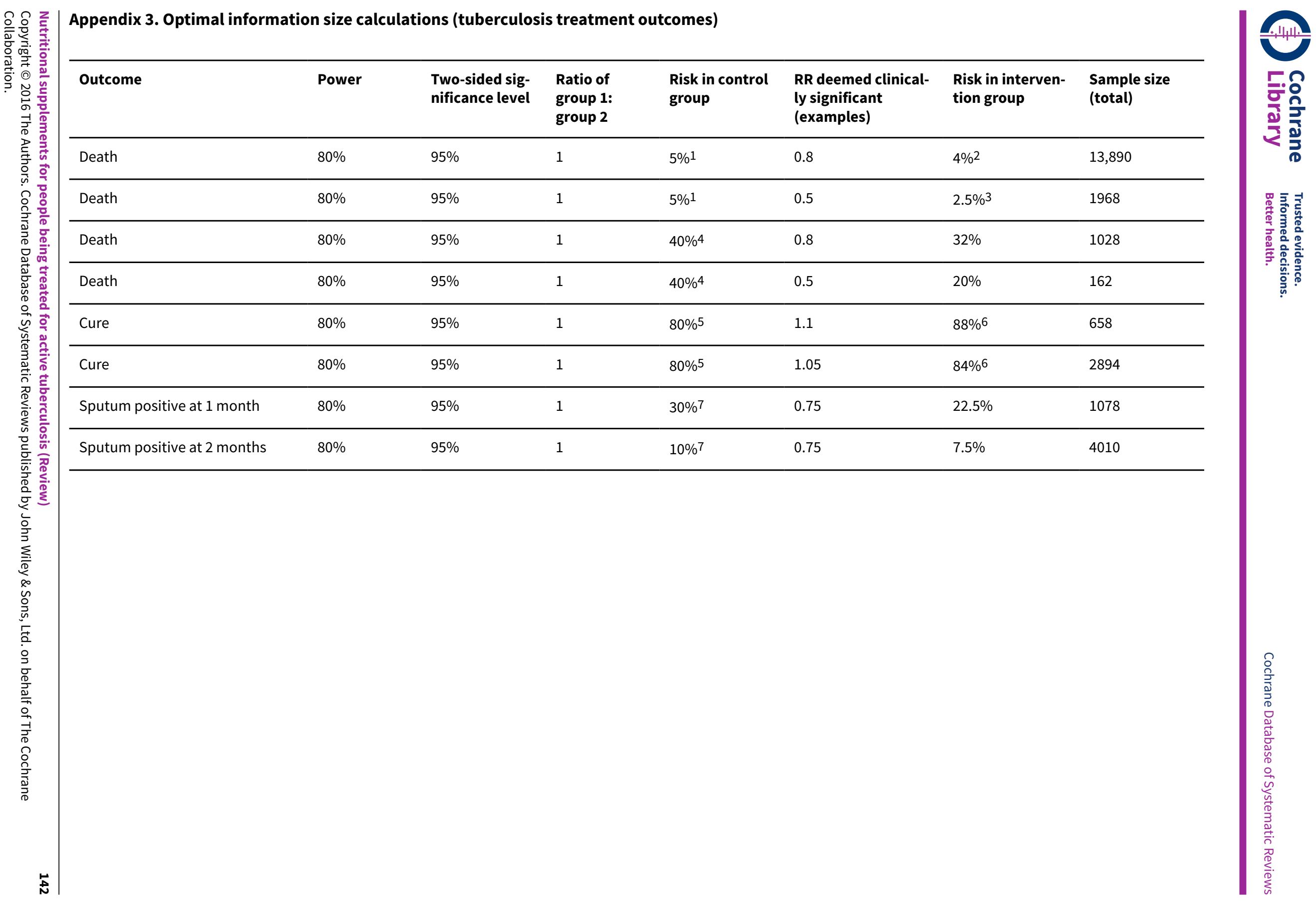


Abbreviations: $\mathrm{RR}=$ risk ratio

1 Globally the risk of death in tuberculosis patients receiving treatment for tuberculosis is around $5 \%$.

2 Vitamins are relatively cheap and safe interventions, therefore even very modest reductions in the risk of death might be considered important.

${ }^{3} \mathrm{~A}$ sample size of 2000 participants (higher than any of the included studies) would be necessary to reliably detect even a very large relative reduction in death $(50 \%)$.

${ }^{4} \mathrm{~A}$ very high risk of death was seen in HIV-positive participants in some trials due to antiretrovirals being unavailable at the study site at the time. Death rates this high should not be seen in patients taking antiretrovirals.

5 The target cure rate for directly observed treatment, short course (DOTs) programmes is $80 \%$. The current global average is $86 \%$.

${ }^{6}$ Vitamins are relatively cheap and safe interventions, therefore even very modest increases in successful cure might be considered important.

${ }^{7}$ Sputum positivity rates in these trials were very variable. These examples are for illustrative purposes only.

We performed the calculations using nMaster 1.0 (nMaster 1.0), a sample size software that incorporates sample size calculation(STATA, Epilnfo, nQuery, etc.), in terms of contents, each of use and the cost. 


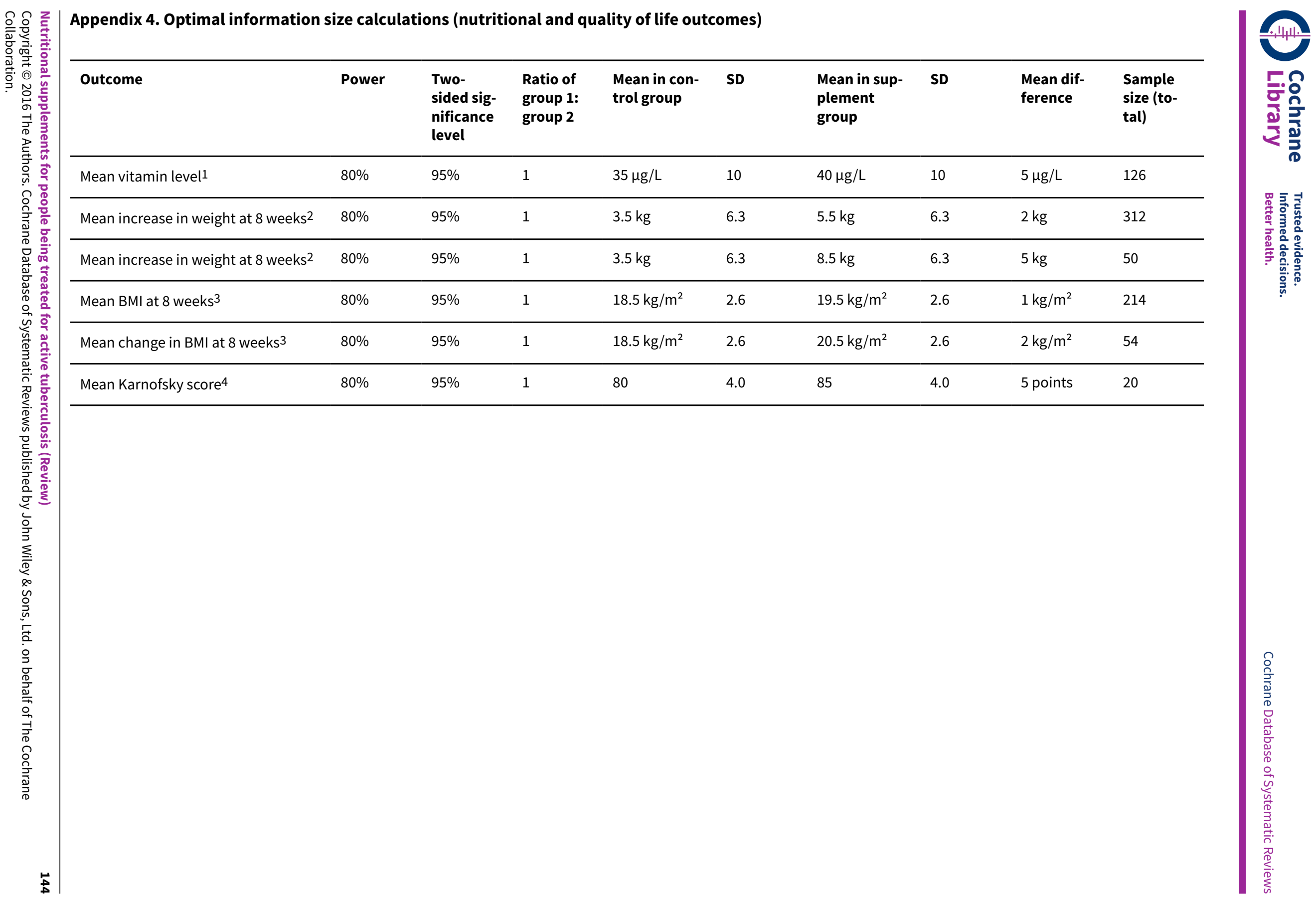


Abbreviations: $\mathrm{BMI}=$ body mass index; $\mathrm{SD}=$ standard deviation .

1We have taken this example from Hanekom 1997 ZAF

2We have taken this example from Martins 2009 TLS. This trial showed a $1.7 \mathrm{~kg}$ mean difference.

3This example uses the SD from Martins 2009 TLS but uses a $5 \mathrm{~kg}$ mean difference. This is for illustrative purposes.

4This example uses the SD taken from Karyadi 2002 IDN.

Appendix 5. Macronutrient supplements

\begin{tabular}{|c|c|c|c|c|c|c|}
\hline Study ID & $\begin{array}{l}\text { Jahnavi } \\
2010 \text { IND }\end{array}$ & $\begin{array}{l}\text { Paton } 2004 \\
\text { SGP }\end{array}$ & $\begin{array}{l}\text { Jeremiah } 2014 \\
\text { TZA }\end{array}$ & $\begin{array}{l}\text { Praygod 2011b } \\
\text { TZA }\end{array}$ & Martins 2009 TLS & Sudarsanam 2010 IND \\
\hline $\begin{array}{l}\text { Descrip- } \\
\text { tion of in- } \\
\text { tervention }\end{array}$ & $\begin{array}{l}\text { Advice on } \\
\text { target en- } \\
\text { ergy intake } \\
\text { and on how } \\
\text { to achieve } \\
\text { this with } \\
\text { normal } \\
\text { diet plus } \\
\text { food sup- } \\
\text { plements } \\
\text { (daily: } \\
\text { sweet balls } \\
\text { made from } \\
\text { wheat flour, } \\
\text { caramel, } \\
\text { ground- } \\
\text { nuts, and } \\
\text { vegetable } \\
\text { ghee as } \\
\text { well as } 100 \\
\text { g of sprout- } \\
\text { ed grams } \\
\text { and nuts } \\
\text { for vitamins } \\
\text { and miner- } \\
\text { als) }\end{array}$ & $\begin{array}{l}\text { Advice on } \\
\text { target en- } \\
\text { ergy intake } \\
\text { and on how } \\
\text { to achieve } \\
\text { this with } \\
\text { normal di- } \\
\text { et plus } 2 \text { to } \\
3 \text { high-en- } \\
\text { ergy oral } \\
\text { nutrition- } \\
\text { al supple- } \\
\text { ments }\end{array}$ & $\begin{array}{l}4 \text { high ener- } \\
\text { gy-protein bis- } \\
\text { cuits plus } 1 \text { vita- } \\
\text { min/mineral for- } \\
\text { tified biscuit }\end{array}$ & $\begin{array}{l}5 \text { high ener- } \\
\text { gy-protein bis- } \\
\text { cuits plus } 1 \text { vita- } \\
\text { min/mineral for- } \\
\text { tified biscuit }\end{array}$ & $\begin{array}{l}\text { A daily meal (in- } \\
\text { tensive phase; } \\
\text { week } 1 \text { to } 8 \text { ) fol- } \\
\text { lowed by a food } \\
\text { parcel (contin- } \\
\text { uation phase; } \\
\text { week } 9 \text { to 32). } \\
\text { The meal con- } \\
\text { sisted of a bowl } \\
\text { of meat, kidney } \\
\text { beans, and veg- } \\
\text { etable stew with } \\
\text { rice. The food } \\
\text { parcel contained } \\
\text { unprepared red } \\
\text { kidney beans, } \\
\text { rice, and oil ade- } \\
\text { quate for } 1 \text { meal } \\
\text { per day. } \\
\text { Control: nutri- } \\
\text { tional advice } \\
\text { alone. }\end{array}$ & $\begin{array}{l}\text { Macronutrient (ready-to- } \\
\text { serve powder, given as } \\
\text { monthly rations) and mi- } \\
\text { cronutrient (daily multivit- } \\
\text { amin tablet) supplementa- } \\
\text { tion } \\
\text { Control: dietary advice } \\
\text { alone }\end{array}$ \\
\hline $\begin{array}{l}\text { Duration } \\
\text { of supple- } \\
\text { mentation }\end{array}$ & 3 months & $\begin{array}{l}\text { Until they } \\
\text { reached a } \\
\text { body mass } \\
\text { index of } \\
20 \text { or usu- } \\
\text { al body } \\
\text { weight }\end{array}$ & 2 months & 60 days & 8 months & 6 months \\
\hline $\begin{array}{l}\text { Average di- } \\
\text { etary ener- } \\
\text { gy intake } \\
\text { per day }\end{array}$ & Not stated & $\begin{array}{l}1560 \mathrm{kcal} / \\
\text { day } \\
1502 \mathrm{kcal} / \\
\text { day }\end{array}$ & Not stated & Not stated & Not stated & $\begin{array}{l}2129 \mathrm{kcal} \\
2072 \mathrm{kcal}\end{array}$ \\
\hline $\begin{array}{l}\text { Total dai- } \\
\text { ly ener- } \\
\text { gy intake } \\
\text { through } \\
\text { supple- } \\
\text { mentation }\end{array}$ & $\begin{array}{l}\text { Not stated } \\
\text { (600 kcal } \\
\text { per sweet- } \\
\text { ball) }\end{array}$ & $\begin{array}{l}600 \text { to } 900 \\
\text { kcal } \\
\text { (300 kcal } \\
\text { per packet) }\end{array}$ & $\begin{array}{l}3075 \mathrm{kcal} \\
\text { (615 kcal per bis- } \\
\text { cuit) }\end{array}$ & $\begin{array}{l}3690 \text { kcal } \\
\text { ( } 615 \text { kcal per bis- } \\
\text { cuit) }\end{array}$ & $\begin{array}{l}1800 \mathrm{~kJ} \text { per daily } \\
\text { meal }\end{array}$ & $930 \mathrm{kcal}$ \\
\hline
\end{tabular}

Nutritional supplements for people being treated for active tuberculosis (Review) 


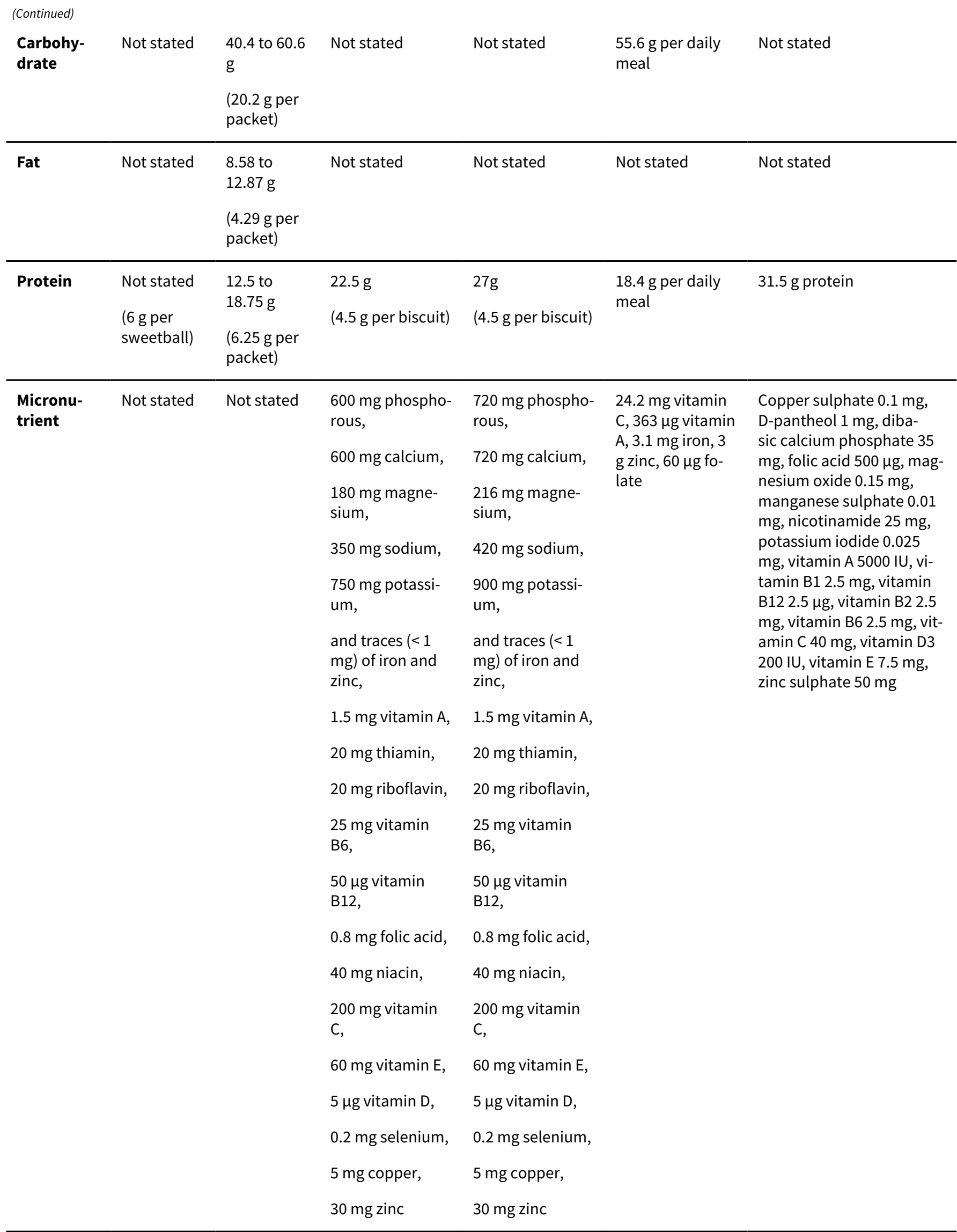




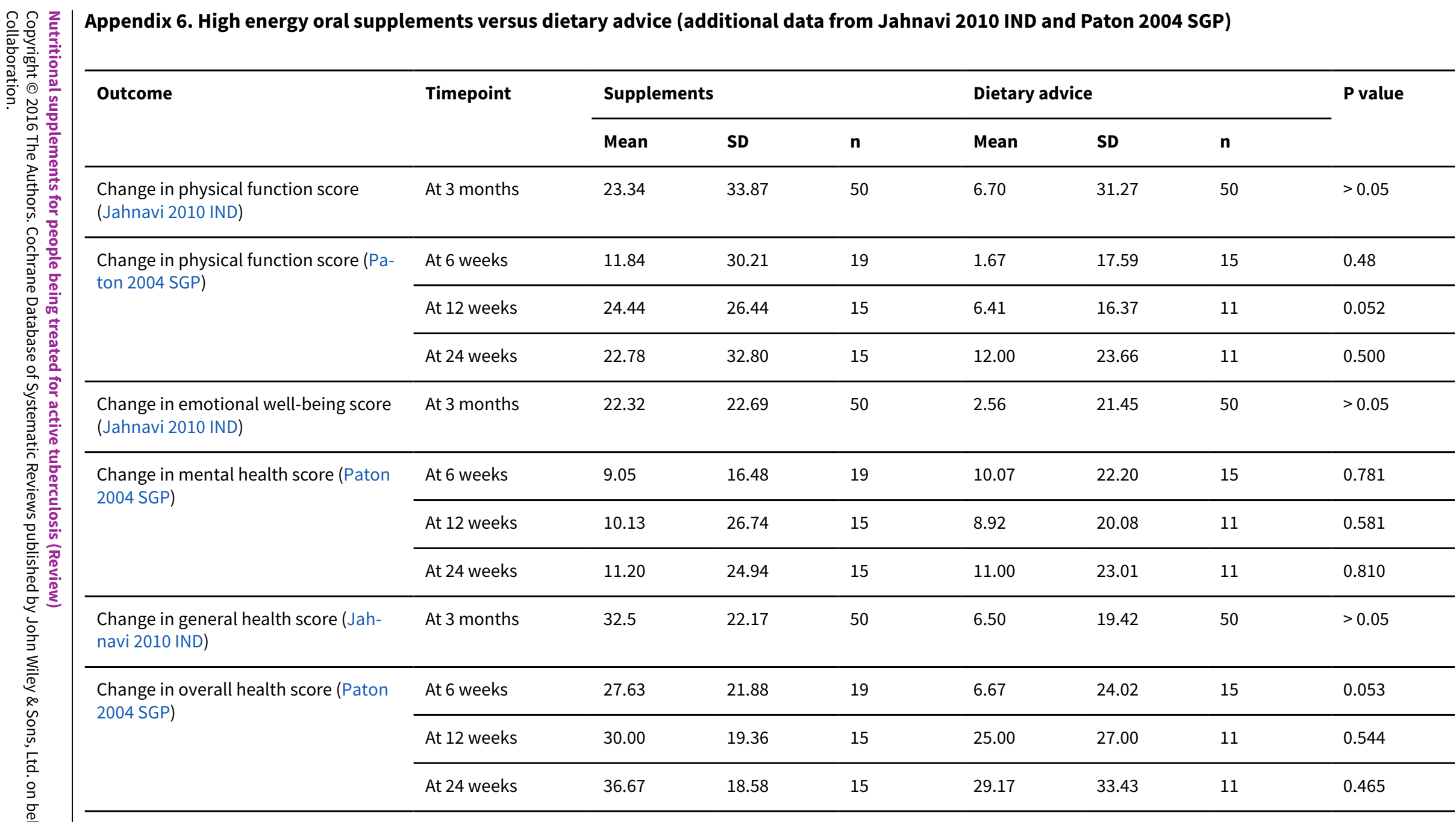


Abbreviations: SD = standard deviation

In total Jahnavi 2010 IND reported 8 and Paton 2004 SGP reported 12 quality of life/physical function scores. See the original papers for full results. 


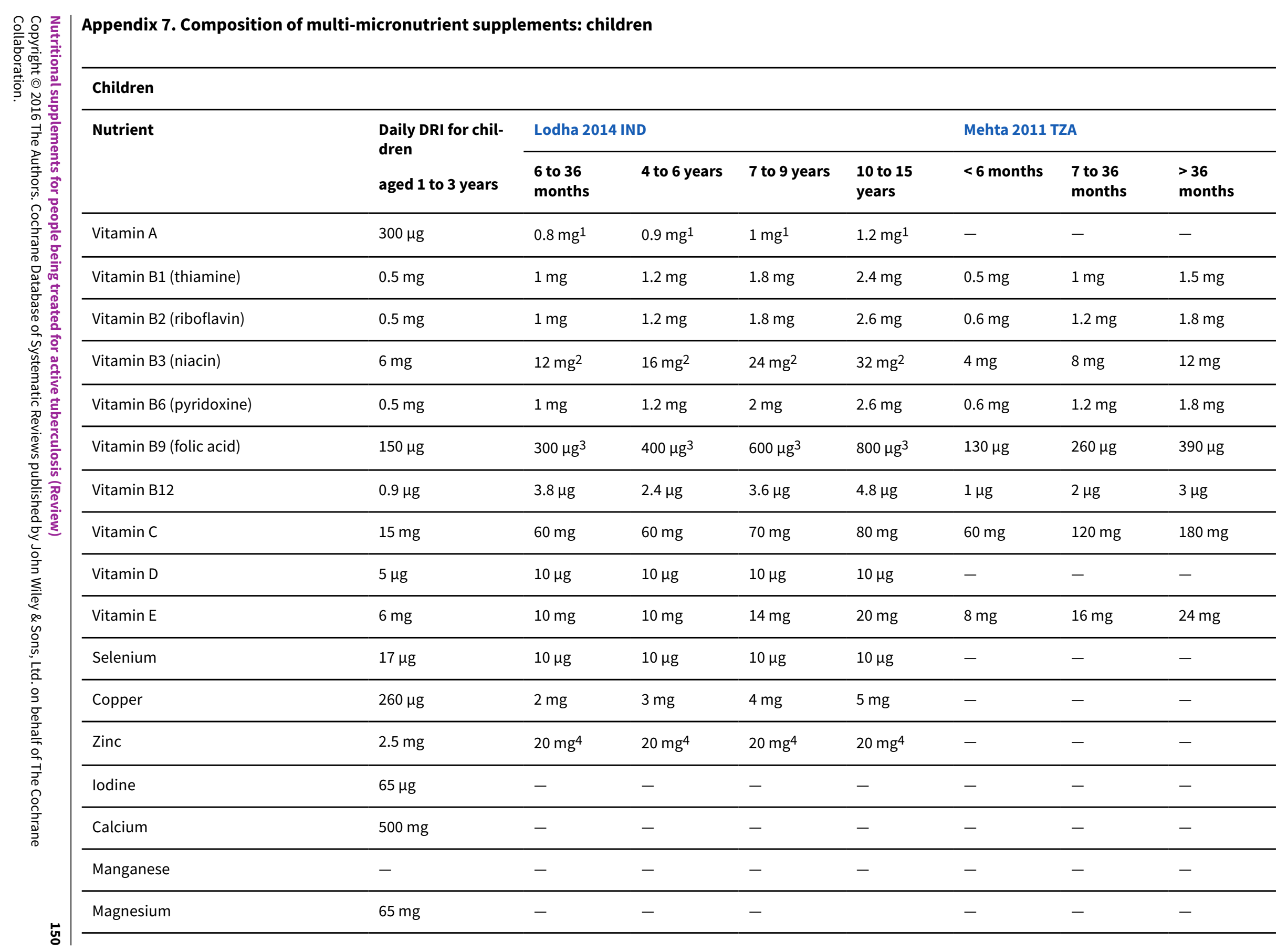




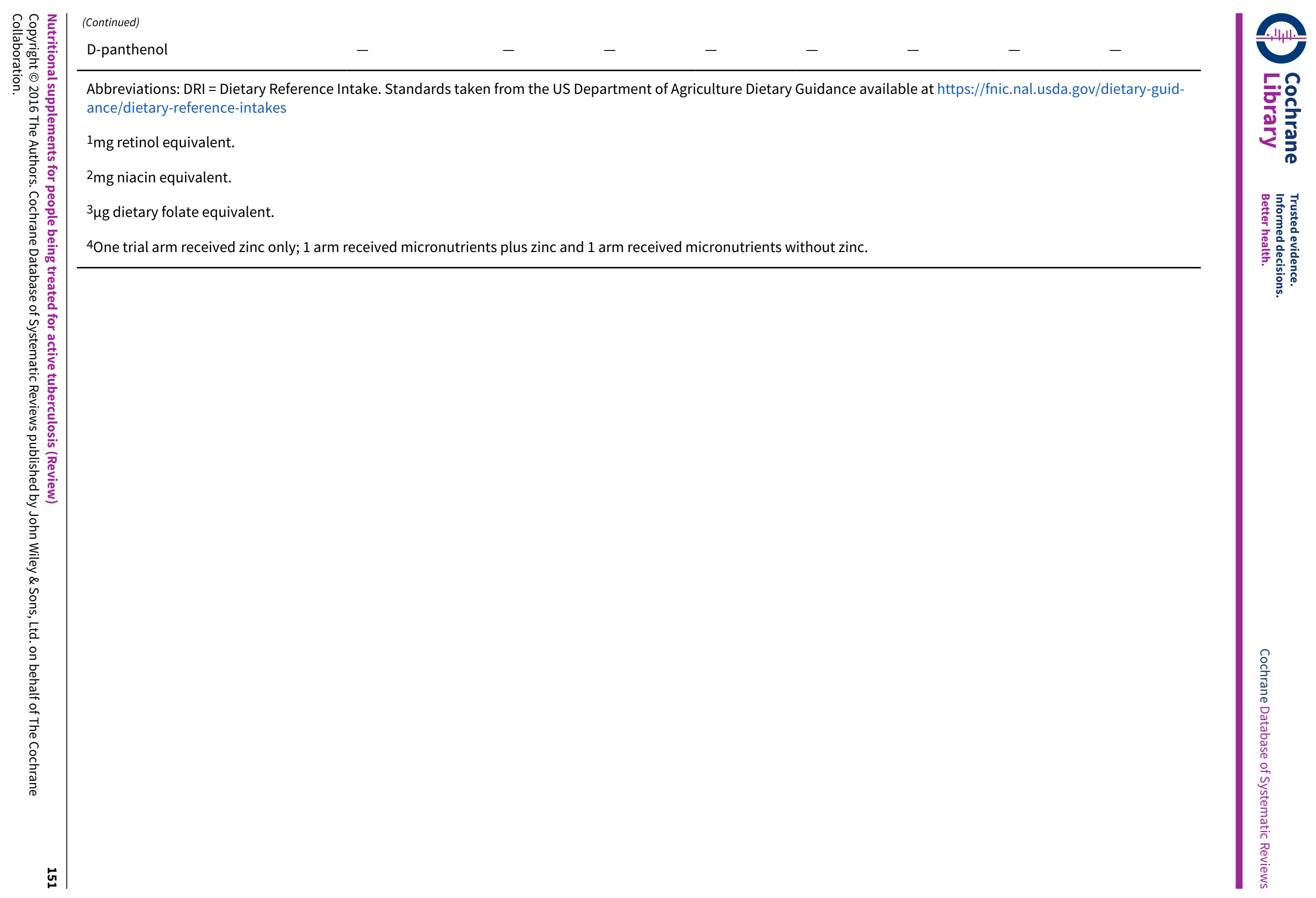




\section{Appendix 8. Vitamin E and selenium levels (Seyedrezazadeh 2006)}

\begin{tabular}{|c|c|c|c|c|}
\hline \multirow[t]{2}{*}{ Time point } & \multicolumn{2}{|c|}{$\begin{array}{l}\text { Plasma vitamin E levels }(\mu \mathrm{mol} / \mathrm{L}) \\
\text { Median value (range) }\end{array}$} & \multicolumn{2}{|c|}{$\begin{array}{l}\text { Serum selenium levels ( } \mu \mathrm{mol} / \mathrm{L} \text { ) } \\
\text { Median value (range) }\end{array}$} \\
\hline & Supplement group $(\mathrm{N}=17)$ & Placebo group $(\mathrm{N}=18)$ & $\begin{array}{l}\text { Supplement group }(\mathrm{N}= \\
\text { 17) }\end{array}$ & Placebo group $(\mathrm{N}=18)$ \\
\hline At baseline & 24.7 (0 to 87$)$ & 20.2 (5.1 to 49$)$ & $1.0(0.34$ to 2.5$)$ & 0.93 (0.1 to 1.9$)$ \\
\hline At 8 weeks & $28.2(10.5$ to 86.5$)$ & 19.3 (5.1 to 48.6$)$ & Not reported & Not reported \\
\hline
\end{tabular}

Abbreviations: $\mathrm{N}=$ number of participants.

WHAT'S NEW

\begin{tabular}{lll}
\hline Date & Event & Description \\
\hline 28 June 2016 & $\begin{array}{l}\text { New citation required but conclusions } \\
\text { have not changed }\end{array}$ & $\begin{array}{l}\text { We performed a new literature search and included } 12 \text { new trials } \\
\text { (from } 15 \text { articles). The author team has been updated. }\end{array}$ \\
\hline 28 June 2016 & New search has been performed & $\begin{array}{l}\text { We amended the objective of this Cochrane Review to simpli- } \\
\text { fy the wording and to reflect the need to assess any differences } \\
\text { in response depending on HIV status. We amended some of the } \\
\text { outcomes. Also, we added total calorie intake and micronutrient } \\
\text { levels before and after supplementation as outcomes in the re- } \\
\text { view as there are important explanatory factors for any effects } \\
\text { seen. Also, we adapted the methods to reflect changes in the } \\
\text { methods of assessing and reporting risk of bias. }\end{array}$
\end{tabular}

\section{H I S T ORY}

Protocol first published: Issue 3, 2006

Review first published: Issue 4, 2008

\begin{tabular}{lll}
\hline Date & Event & Description \\
\hline 30 September 2011 & $\begin{array}{l}\text { New citation required but conclusions } \\
\text { have not changed }\end{array}$ & $\begin{array}{l}\text { We added eight new trials and have considered more carefully } \\
\text { the nutritional status at baseline (both weight and biochemical } \\
\text { status of individual micronutrients). The author team has also } \\
\text { been updated. }\end{array}$ \\
\hline 20 September 2011 & New search has been performed & $\begin{array}{l}\text { We performed a new search, and included eight new trials. We } \\
\text { constructed 'Summary of findings' tables, which summarize the } \\
\text { quality of the evidence. Also we performed a calculation of the } \\
\text { optimal information size to reliably detect clinically important } \\
\text { effects if they exist. }\end{array}$ \\
& $\begin{array}{l}\text { We updated the 'Risk of bias' assessments to the new format. } \\
\end{array}$ & \\
\hline
\end{tabular}




\begin{tabular}{lll}
\hline Date & Event & Description \\
\hline 10 November 2009 & Amended & $\begin{array}{l}\text { An observant reader noted that there was an error in referencing } \\
\text { in the 'Risk of bias' tables. This error has now been corrected. }\end{array}$ \\
\hline 10 November 2008 & Amended & $\begin{array}{l}\text { We corrected minor errors. There were no changes to the conclu- } \\
\text { sions. }\end{array}$ \\
\hline
\end{tabular}

\section{CONTRIBUTIONS OF AUTHORS}

Thambu David Sudarsanam conceived this Cochrane protocol, and designed it in collaboration with all review authors (Abba 2006). We performed the selection of trials for inclusion, 'Risk of bias' assessments, and data extraction as indicated in the Methods. Katharine Abba and David Sinclair mainly undertook the analyses of previous versions of the review, in consultation with the other review authors. In the most recent update of this Cochrane review, Liesl Grobler, Sukrti Nagpal, and Thambu David Sudarsanam screened the search results and extracted the data from the eligible studies. Liesl Grobler and David Sinclair, in consultation with the other review authors, analysed the data and wrote the review.

\section{DECLARATIONS OF INTEREST}

Liesl Grobler has no known conflicts of interest.

David Sinclair was previously a member of the World Health Organization (WHO) Technical Advisory Group on Nutrition. This work may contribute to future recommendations on nutritional care in tuberculosis.

Sukrti Nagpal has no known conflicts of interest.

Thambu D Sudarsanam has no known conflicts of interest.

\section{SOURCES OF SUPPORT}

\section{Internal sources}

- Liverpool School of Tropical Medicine, UK.

- Stellenbosch University, South Africa.

- Christian Medical College Vellore, India.

\section{External sources}

- Department for International Development (DFID), UK.

Grant: 5242

\section{DIFFERENCES BETWEEN PROTOCOL AND REVIEW}

We amended the objective of this Cochrane Review from "To assess the provision of oral nutritional supplements to promote the recovery of people being treated with anti-TB drug therapy for active TB" to the current objective to simplify the wording and reflect the need to assess any differences in response depending on HIV status.

Also we changed some of the outcomes, as follows: we expanded "change in weight or skinfold thickness" to "change in weight, skinfold thickness, or other measure of lean or total mass" because we became aware that other measures, besides skinfold thickness, are equally valid indicators of overall nutritional status; we added "any measure of growth in children" because it is a useful indicator of health and nutritional status in children, which we had overlooked at the protocol stage; and included "sputum positive at follow-up" because it was a primary outcome of many included trials, and it became apparent that it is a meaningful outcome as, depending on the period of followup, it may be used as a proxy for cure or as an indicator of the time taken to become sputum-smear negative. Early sputum conversion is a desirable outcome because on becoming smear-negative, patients become less ill and less infectious to those around them.

Between the publication of the original review (Abba 2008; Sinclair 2011), and this review update, the method of assessing and reporting risk of bias has changed slightly. We have adapted the methods to reflect this.

For this review update, we included additional details on the nutritional and micronutrient status at baseline. Where reported, we have also included plasma micronutrient levels during follow-up as an outcome. This outcome is not a patient important outcome, and is of little interest on its own, but does contribute to the understanding of the results. 


\section{N D EX TERMS}

\section{Medical Subject Headings (MeSH)}

*Dietary Supplements; Antitubercular Agents [therapeutic use]; Energy Intake; HIV Infections [complications] [mortality]; Malnutrition [complications] [ ${ }^{\star}$ diet therapy]; Micronutrients [administration \& dosage]; Randomized Controlled Trials as Topic; Tuberculosis [complications] [*diet therapy] [drug therapy] [mortality]

\section{MeSH check words}

Adult; Child; Humans 